US Army Corps

of Engineers
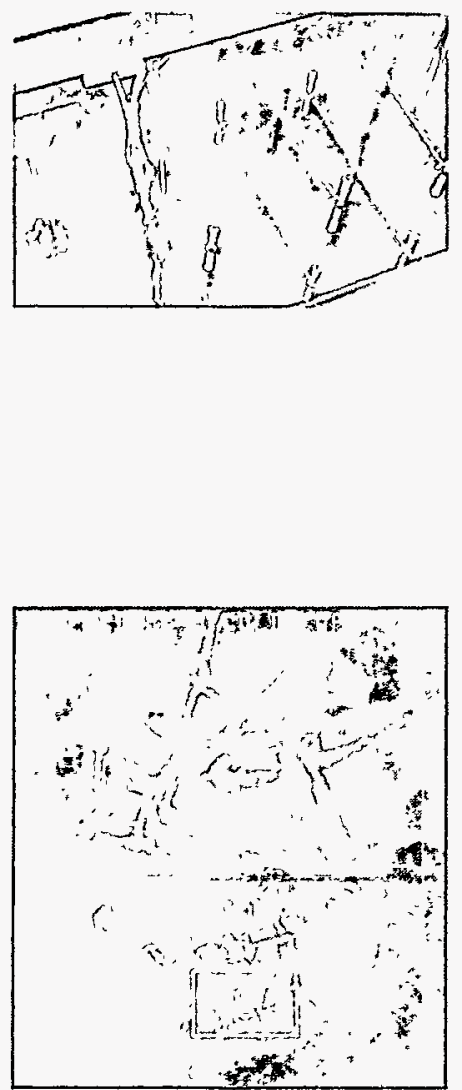

Prepared for US DEPARTMENT OF ENERGY Oak Ridge Operations, PO Box 2001 Oak Ridge, Tennessee 37831-8614

TECHNICAL REPORT SL-92-21

\section{GROUT FOR CLOSURE OF THE DEMONSTRATION VAULT AT THE US DOE HANFORD FACILITY}

\author{
by
}

Lillian D. Wakeley, James J. Ernzen

Structures Laboratory

DEPARTMENT OF THE ARMY

Waterways Experiment Station, Corps of Engineers

3909 Halls Ferry Road, Vicksburg, Mississippi 39180-6199

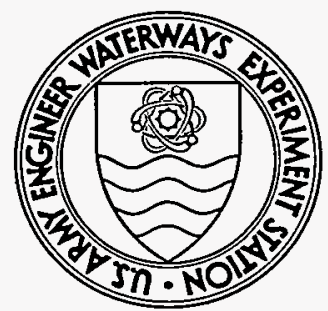

August 1992

Final Report

Approved For Public Release; Distribution Is Unlimited MASTER 
Destroy this report when no longer needad. Do not return it to the originator.

The findings in this report are not to be construed as an official Depariment of the Army position unless so designated by other authorized documents.

The contents of this report are not to be used for advertising, publication, or prornotional purposes. Cilation of trade names does not constitute an official endorsement or approval of the use of such commercial products. 


\section{DISCLAIMER}

Portions of this document may be illegible in electronic image products. Images are produced from the best available original document. 
Public reporting burden for this collection of information is estımated to average $t$ hour per response, inciuding the time for reviewing instructions, searching existing data sources, gathering and maintaining the data needed, and completing and reviewing the collection of information. Send comments regarding this burden estimate or any other aspect of this collection of information, including suggestions for reducing this burden. to Washington Headquarters Services, Directorate for information Operations and Reports, 1215 Jefferson Davis Highway, Suite 1204, Arlington, VA 22202-4302, and to the Office of Management and Budget, Paperwork Reduction Project (0704-0188), Washington, DC 20503.
1. AGENCY USE ONLY (Leave blank)
2. REPORT DATE
August 1992

\section{REPORT TYPE AND DATES COVERED}
Final report

4. TITLE AND SUBTITLE

Grout for Closure of the Demonstration Vault at the

US DOE Hanford Facility

6. AUTHOR(S)

Lillian D. Wakeley

James J. Ernzen

\section{PERFORMING ORGANIZATION NAME(S) AND ADDRESS(ES)}

U.S. Army Engineer Waterways Experiment Station

Structures Laboratory

3909 Halls Ferry Road

Vicksburg, MS 39180-6199

9. SPONSORING/MONITORING AGENCY NAME(S) AND ADDRESS(ES)

U.S. Department of Energy

Oak Ridge Operations

P.0. Box 2001

Oak Ridge, TN 37831-8614

\section{SUPPLEMENTARY NOTES}

Available from National Technical Information Service, 5285 Port Royal Road, Springfield, VA 22161

12a. DISTRIBUTION/AVAILABILITY STATEMENT

8. PERFORMING ORGANIZATION REPORT NUMBER

Technical Report SL-92-2I

10. SPONSORING / MONITORING AGENCY REPORT NUMBER

Approved for public release; distribution is unlimited.

13. ABSTRACT (Maximum 200words)

The Waterways Experiment Station (WES) developed a grout to be used as a cold- (nonradioactive) cap or void-fill grout between the solidified low-level waste and the cover blocks of a demonstration vault for disposal of phosphatesulfate waste (PSW) at the U.S. Department of Energy (DOE) Hanford Facility. The project consisted of formulation and evaluation of candidate grouts and selection of the best candidate grout, followed by a physical scale-model test to verify grout performance under project-specific conditions. Further, the project provided data to verify numerical models (accomplished elsewhere) of stresses and isotherms inside the Hanford demonstration vault. Evaluation of unhardened grout included obtaining data on segregation, bleeding, flow, and working time. For hardened grout, strength, volume stability, temperature rise, and chemical compatibility with surrogate wasteform grout were examined.

(Continued)

\section{SUBJECT TERMS}

Grout

Hanford
Waste disposal

\begin{tabular}{|l|c|}
\hline $\begin{array}{l}\text { 17. SECURITY CLASSIFICATION } \\
\text { OF REPORT }\end{array}$ & $\begin{array}{c}\text { 18. SECURITY CLASSIFICATION } \\
\text { OF THIS PAGE } \\
\text { UNCLASSIFIED }\end{array}$ \\
\hline UNCLASSIFIED & UNCLS
\end{tabular}

19. SECURITY CLASSIFICATION OF ABSTRACT 


\section{ABSTRACT (Continued).}

The grout was formulated to accommodate unique environmental boundary conditions (vault temperature $=45^{\circ} \mathrm{C}$ ) and exacting regulatory requirements (mandating less than 0.1 percent shrinkage with no expansion and no bleeding); and to remain pumpable for a minimum of $2 \mathrm{hr}$. A grout consisting of API Class $\mathrm{H}$ oil-well cement, an ASTM C 618 Class F fly ash, sodium bentonite clay, and a natural sand from the Hanford area met performance requirements in laboratory studies. It is recommended for use in the DOE Hanford demonstration PSW vault. 
The work described in this report is part of an ongoing research effort accomplished in the Concrete Technology Division (CTD), Structures Laboratory (SL), U.S. Army Engineer Waterways Experiment Station (WES), under an Interagency Agreement with the U.S. Department of Energy, Oak Ridge Office via Oak Ridge National Laboratory (ORNL), Oak Ridge, TN, for support to the DOE Hanford, WA, Facility. Mr. Earl W. McDaniel, ORNL, was the technical monitor for this research.

Drs. Lillian D. Wakeley and James J. Ernzen directed the laboratory studies in CTD and prepared this report under the general supervision of Mr. Bryant Mather, Director, SL, and Mr. Kenneth L. Saucier, Chief, CTD. The authors acknowledge Messrs. Billy Neeley, L. W. Mason, Charles White, Dennis Bean, Mike Hammons, Anthony Bombich, Dan Wilson, Cliff Gill, Brent Lamb, Michel Alexander, Mike Lloyd, and Percy Collins and Mses. Linda Mayfield and Judy Tom for their assistance during this investigation. The authors also acknowledge the support of Drs. Toy Poole and Charles Weiss, Jr., and Messrs. J. Pete Burkes, John Boa, Jr., Hugh Wilson, Ken Loyd, Don Walley, Melvin Sykes, and John Cook and Ms. Estelle Stegall.

Westinghouse Hanford Corporation (WHC) is responsible for the Hanford Grout Vault Program. Messrs. Jeff Voogd and Kenneth Bledsoe, WHC, reviewed and commented on this document during its preparation.

At the time of publication of this report, Director of WES was Dr. Robert W. Whalin. Commander and Deputy Director was COL Leonard G. Hassell, EN.

\section{DISCLAIMER}

This report was prepared as an account of work sponsored by an agency of the United States Government. Neither the United States Government nor any agency thereof, nor any of their employees, makes any warranty, express or implied, or assumes any legal liability or responsibility for the accuracy, completeness, or usefulness of any information, apparatus, product, or process disclosed, or represents that its use would not infringe privately owned rights. Reference herein to any specific commercial product, process, or service by trade name, trademark, manufacturer, or otherwise does not necessarily constitute or imply its endorsement, recommendation, or favoring by the United States Government or any agency thereof. The views and opinions of authors expressed herein do not necessarily state or reflect those of the United States Government or any agency thereof. 
PART I: INTRODUCTION . . . . . . . . . . . . . . . . . . . . . . . . 4

Executive Summary . . . . . . . . . . . . . . . . . . . . . . . . . . . . . 4

The Grout Vault Program . . . . . . . . . . . . . . . . . . . . 8

Performance Requirements for Cold-Cap Grout . . . . . . . . . . 8

PART II: MATERIALS SELECTION AND CHARACTERIZATION . • . . . . . . . . 10

Criteria . . . . . . . . . . . . . . . . . . . . . . . . . 10

Cement and Fly Ash . . . . . . . . . . . . . . . . . . . 10

Aggregates . . . . . . . . . . . . . . . . . . . . . . . . . 10

Other Components . . . . . . . . . . . . . . . . . . . . . . . 11

PART III: EXPERIMENTAL PROCEDURES . . . . . . . . . . . . . . . . . . 12

Mixture Proportioning and Unhardened Properties Testing . . . . 12

Hardened Properties Testing . . . . . . . . . . . . . . . . . . 13

Interface with Wasteform Grout . . . . . . . . . . . . . . . . 15

Analyses of Small Interface Samples . . • . . . . . . . . . . . 15

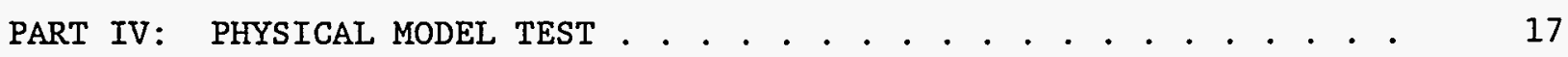

Mixing and Placement . . . . . . . . . . . . . . . . . . . . 17

Strain and Temperature Measurements . . . . . . . . . . . . . . 18

Volume Stability Measurements . . . . . . . . . . . . . . . . . 21

Analyses of the Interface in the Physical Model . . . . . . . . 21

Implications for Chemical Interaction . . . . . . . . . . . . . 21

PART V: SUMMARY . . . . . . . . . . . . . . . . . . . . . . . . . . . . 23

Recommendations . . . . . . . . . . . . . . . . . . . . . . . . . . . . . 23

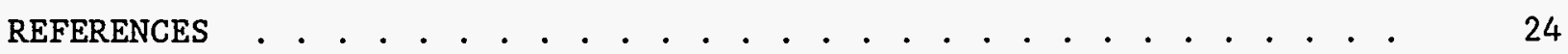

Tables $1-7$

Figures $1-55$

APPENDIX A: PROPORTIONS OF EXPERIMENTAL GROUT MIXTURES TESTED

DURING GROUT DEVELOPMENT . . . . . . . . . . . . . . . .

APPENDIX B: REPORTS FROM EXAMINATION OF CEMENT, AGGREGATES, AND INTERFACE BETWEEN COLD-CAP GROUT AND SIMULATED WASTE . . . . . . . . . . . . . . . . . . . . 


\section{CONVERSION FACTORS, NON-SI TO SI (METRIC) \\ UNITS OF MEASUREMENT}

Non-SI units of measurement used in this report can be converted to SI (metric) units as follows:

\section{Multiply}

Btu (International Table) per pound (mass)

- degree Fahrenheit

Fahrenheit degrees

feet

fluid ounces

inches

pounds (force) per square inch

pounds (mass)

pounds (mass) per cubic foot

pounds (mass) per cubic yard
By

$4,186.800$

$5 / 9$

0.3048000

29.5625

25.40000

0.006894757

0.4535924

16.01846

1.6875
To Obtain

joules per kilogram kelvin

Celsius degrees or kelvins* metres

millilitres

millimetres

megapascals

kilograms

kilograms per cubic metre

kilograms per cubic metre

* To obtain Celsius (C) temperature readings from Fahrenheit (F) readings, use the following formula: $C=(5 / 9)(F-32)$. To obtain Kelvin (K) readings, use: $K=(5 / 9)(F-32)+273.15$. 


\section{GROUT FOR CLOSURE OF THE DEMONSTRATION VAULT \\ AT THE US DOE HANFORD FACILITY}

\section{PART I: INTRODUCTION}

\section{Executive Summary}

1. The US Army Engineer Waterways Experiment Station (WES) recommends the following formulation for the cold-cap grout to serve as a void-fill material between the waste-form grout and the cover blocks in the phosphatesulfate waste (PSW) demonstration vault at Hanford, WA. This grout mixture was designated $\mathrm{CC}-20$ in our experiments.

\section{Material}

API Class H Cement

ASTM Class F Fly Ash

Natural Fine Aggregate

(all passing the $2.36-\mathrm{mm}$

[No. 8] sieve)

Sodium Bentonite Clay

Water

High-Range Water-Reducing Admixture

Set-Retarding Admixture
Lb Per Gubic Yard 300

1,112

1,314

38

564

4.5

4.56 fluid oz

2. Materials selection and experimental design focused on meeting the grout requirements provided by Westinghouse Hanford Corporation (WHC), dated October 25, 1990, which had been revised following our written comments of October 17, 1990. These requirements are summarized here. The grout was required to have a compressive strength of $400 \mathrm{psi}$ or greater at 28 days of age. Shrinkage was to be no more than 0.1 percent in the lower lifts and not more than 0.01 percent in the top lift, and the grout was to be nonexpansive. It was to be chemically stable in contact with the wasteform grout at

* A table of factors for converting non-SI units of measurement to SI (metric) units is presented on page 3. 
temperature up to $70^{\circ} \mathrm{C}$ and should not bleed. The grout must generate as little heat as possible. It must be pumpable and be capable of flowing approximately $14 \mathrm{ft}$ horizontally without segregating after a placement drop of $4 \mathrm{ft}$. Although not stated originally, subsequent conversations revealed that the grout probably would be mixed offsite by a supplier of ready-mixed concrete. This would require approximately an hour of transport time, in addition to anticipated mixing and pumping time.

3. Materials were selected and proportioned based on those requirements. API Class $\mathrm{H}$ oil-well cement was chosen because of its coarse particle size and resulting slow heat evolution. Class F fly ash was chosen over Class $C$ because of its demonstrated ability to reduce permeability over time and because mixtures containing Class F fly ash commonly generate less heat and are less subject to sulfate attack. An appropriate Class F fly ash was available near the Hanford site. Two fine aggregates with differing thermal expansion characteristics were tested: a crushed limestone sand available at WES and a natural sand from a supplier close to Hanford. The latter was selected for this grout. Sodium bentonite was chosen for its ability to hold water, aid in pumpability, and reduce bleeding. The highrange water-reducing and set-retarding admixtures were chosen because of their demonstrated performance in wES experience with mixtures containing similar materials.

4. In proportioning this mixture, we used a low cement content to minimize the heat rise and still meet the specified unhardened and hardened properties. The ratio of cement to fly ash (c/fa) was held between $1: 2$ and $1: 3$ to obtain a low cement content. The ratio of cement + fly ash to fine aggregate was initially varied between $1: 1$ and $2: 1$ to investigate how the aggregate content would affect the volume stability of the grout at the elevated temperatures in the vault. The ratio of water to cement + fly ash (w/c+fa) was held low at 0.4 by mass to obtain a high quality microstructure and still deliver pumpable grout of the required properties during the transit times expected. The dosages of high-range water reducer and set retarder were adjusted to aid in maintaining these properties until the grout was in place.

5. Over 20 different mixtures were proportioned, cast, and tested in the early phase of the research effort. Proportions for these mixtures are presented in Appendix A. These mixtures were prepared in Hobart mixers 
(described in ASTM 305) as 0.1-cu-ft batches, mixed for $2 \mathrm{hr}$, and tested for flow, segregation, bleeding, and compressive strength. Grout flow was measured according to ASTM C 939, bleeding according to ASTM C 940, and strength according to ASTM C 109. Occurrence or nonoccurrence of mixture segregation was determined by visual inspection. Four of the mixtures, after passing these requirements, were then cast in larger batches and tested additionally for time of setting (ASTM C 191), chemical interaction with simulated PSW waste grout (by phase composition using X-ray diffraction [XRD] and chemical composition by energy dispersive $\mathrm{X}$-ray analysis [EDX]), semiadiabatic heat rise (using a CIMS HayBox Calorimeter), and volume stability.

6. The volume-stability measurements involved measuring the length changes of 1 - by 1 - by 11 -in. prisms that were cured and stored at $45^{\circ} \mathrm{C}$ and 100 percent relative humidity. The temperature of $45{ }^{\circ} \mathrm{C}$ was provided to the WES from WHC Process Engineering Office as the current vault temperature as of 1991. Relative humidity of 100 percent was chosen as a reasonable approximation of probable vault conditions. Molds and comparator were as described in ASTM C 157, as was the method of calculating length change. Measurements of heat rise were obtained by measuring the thermal loss from a 6 - by 12 -in. grout cylinder, in a calibrated environment (inside the CIMS calorimeter), and then calculating the adiabatic heat rise this mixture would exhibit inside the vault (assuming the vault will remain at a temperature of $\left.45^{\circ} \mathrm{C}\right)$.

7. Test results showed that all mixtures, when prepared as described, met the specifications with regard to strength and flow, and with adjustments to the admixtures or the clay content or both, could meet the segregation and bleeding requirements. The deciding factors on choice of materials and proportions hinged upon the issues of volume stability and heat rise. The mixtures with higher sand contents clearly showed lower temperatures than identical mixtures with less sand and more fly ash in them. This factor eliminated the low-sand mixtures.

8. At 60 days, expansion prisms of the grout made with $480 \mathrm{lb}$ of cement and natural sand showed an average positive expansion of 0.003 percent. Data from tests at 120 days age show that the prisms of the grout made with natural sand have an average expansion of +0.002 percent. These values represent 
extremely small changes (they are close to the limit of measuring error) and excellent volume stability. The small positive expansions observed are not a serious concern and are probably beneficial. With time the vault will begin to cool, and some thermal contraction will result. The natural sand was selected for the final phase of testing, the proximity of its source to Hanford being an important factor.

9. A mixture with natural sand and $480 \mathrm{lb}$ of cement was chosen for full-scale adiabatic tests. For these tests, batches of $0.5 \mathrm{cu}$ yd were mixed for $2 \mathrm{hr}$ in a revolving drum mixer. The results of the initial large-scale adiabatic test showed this mixture to be much hotter (temperature rise $>57{ }^{\circ} \mathrm{C}$ in 4 days) than was estimated from the smaller CIMS calorimeter tests. It was unclear whether this mixture would overheat inside the vault environment.

10. For this reason, a new mixture containing 300 lb of cement was proportioned and tested by the previously described regimen. This mixture, CC-20, is the one recommended by WES, and meets all the specifications for the grout in the unhardened and hardened state except for shrinkage where its volume change is -0.02 percent. This value easily meets the requirement for the lower lifts but misses the specification for less than 0.01 percent shrinkage in the top lift. As we stated in letters exchanged before the research effort began at WES, we have come as close as we could to the specifications in the time and with the resources given. This is an extremely small volume change. It seems unlikely that shrinkage between 0.02 and 0.05 percent in the top lift will compromise the integrity of the cover blocks above it.

11. The final phase of the research was to cast large-scale batches, $1.5 \mathrm{cu}$ yd in size, and place them in a fully instrumented, full-depth physical model. This model is a cube, $5 \mathrm{ft}$ on each side, heated to $45^{\circ} \mathrm{C}$ to simulate the vault environment and the thickness between the PSW waste grout and the cover blocks. Materials were batched and mixed in a computer-controlled automated batch plant using a pug-mill mixer and a mixing time of $2 \mathrm{hr}$. Three 16-in. lifts were placed on top of a 6-in. layer of simulated waste grout.

12. The highest temperature attained in the WES physical model was approximately $60^{\circ} \mathrm{C}$, and no significant problems were encountered. The final lift was instrumented with six dial gages to measure the movement of the grout relative to the bottom of the cover blocks. Analyses of interfaces between 
simulated wasteform grout and WES cold-cap grout indicated virtually no bonding and minimal potential for chemical interaction.

The Grout Vault Program

13. The Hanford Grout Vault Program was developed to reduce the need for temporary storage capacity for soluble radioactive waste and provide permanent disposal of defense low-level wastes at the Department of Energy facility at Hanford, WA. These wastes include chemically toxic and radioactive salts created during more than 40 years of processing nuclear weapons materials. The wastes have been dewatered to varying extents and stored in "temporary" underground steel tanks. For permanent disposal, the waste is removed from its temporary tank, mixed with the dry-blended components of the wasteform grout, and then pumped into underground concrete vaults. Being solidified in wasteform grout makes the radioactive waste components less soluble and less likely to be leached or otherwise transported into the biosphere (Hanford Support Team, 1990). The PSW grout campaign, during which the demonstration vault was filled with its wasteform grout, is described elsewhere (Cline et al., 1990).

14. For the demonstration vault, the cold-cap grout will be placed on top of the wasteform grout in at least three layers, filling the vault to the underside of its cover blocks to form a load-bearing barrier between the covering layers and the hazardous materials contained below them. The vault measures $15.2 \mathrm{~m}$ by $38.1 \mathrm{~m}$ by $10.4 \mathrm{~m}$ and is filled to a height of $9.2 \mathrm{~m}$ with wasteform grout and later covered with $1.2 \mathrm{~m}$ of cold-cap grout (Cline et al., 1990). Figure 1 shows a section view of the first concrete vault at Hanford which is filled with wasteform grout. WES developed the cold-cap grout for this vault.

\section{Performance Requirements for Cold-Cap Grout}

15. There are three categories of performance requirements:

(1) pumping and placement properties, (2) properties of unhardened grout after placement, and (3) properties of hardened grout. 
Pumping and placement

16. The location of existing ports in the cover blocks dictates that the grout will drop $4 \mathrm{ft}$ vertically when pumped into the vault and must flow at least $14 \mathrm{ft}$ horizontally from each entry point to cover the wasteform and fill the void space. For this the grout must be self-levelling and nonsegregating. From WES grouting experience, we determined that a flow time of 15 to $18 \mathrm{sec}$ (ASTM C 939) was an appropriate measure of this property. Batching may be accomplished at a concrete plant, requiring a minimum $1 \mathrm{hr}$ travel time; the grout will need to be pumpable for $2 \mathrm{hr}$ after mixing begins. Unhardened grout

17. Avoiding evolution of free liquid, or bleeding, is the most critical property after placement and before final set. We anticipated that free liquid on the upper surface of the wasteform might have left a layer of soft and possibly soluble radioactive mineral matter. Avoiding free liquid from the cold cap will reduce the likelihood of (1) chemical interaction between the two grouts, (2) physical disturbance and remobilization of radioactive or hazardous components to contaminate the cold cap and violate the multiple-barrier system.

Hardened grout -

18. The grout was required to attain an unconfined compressive strength of $400 \mathrm{psi}(3.0 \mathrm{MPa}$ ) at 28 days. Volume stability is critical for maintaining the integrity of the cap, so shrinkage is limited to 0.1 percent in the lower lifts and 0.01 percent in the top lift, and no expansion is permitted. The grout must be geochemically stable in contact with the wasteform grout at temperatures estimated to reach $70^{\circ} \mathrm{C}$ or more and contribute as little heat as possible to the vault itself. The current demonstration vault temperature is $45^{\circ} \mathrm{C}$; a maximum temperature rise of $50^{\circ} \mathrm{C}$ was chosen as a requirement to avoid overheating. 


\section{PART II: MATERIALS SELECTION AND CHARACTERIZATION}

\section{Criteria}

19. Three groups of criteria were considered in selection of component materials for the grout. The first group was the performance demands of chemical and mechanical stability, heat generation, durability, and placability. The second group was economic, including availability of materials near the site locations, likelihood of continued availability, and shipping costs. The third group of selection criteria included WES experience with comparable materials and an acceptable performance record in comparable grout operations.

\section{Cement and Fly Ash}

20. The two main considerations in cement choice were low heat generation and resistance to sulfate attack. API Class $\mathrm{H}$ oil-well cement was chosen because of its coarse particle size and resultant reduced rate of heat evolution, expected to reduce cracking due to thermal strains. The low alumina content of the cement was also expected to provide excellent resistance to sulfates (Mindess and Young, 1981) which are known to be present in the liquid waste. The chemical and physical properties of the cement selected are shown in Table 1.

21. A low-calcium ASTM Class F fly ash was chosen over a Class $C$ ash because of the demonstrated ability of the former to provide added resistance to sulfate attack and lower early-age heat generation (Barrow et al., 1988, 1989). This fly ash also had a positive effect on workability and was expected to contribute to the cementitious microstructure with time to enhance chemical stability and leach resistance. The chemical and physical characteristics of the fly ash are shown in Table 2.

\section{Aggregates}

22. Two different fine aggregates were tested during the project. The first was a natural, well-rounded sand from a source near the Hanford site, 
and the second was a crushed limestone sand available at WES. The two aggregates were chosen specifically for their different physical and mineralogical makeup and differing linear coefficients of thermal expansion (CTE). Since aggregate makes up a significant proportion of the grout volume, the volume stability of the grout at elevated temperature is heavily dependent upon the coefficient of thermal expansion of the aggregate which is counteracting drying shrinkage of the paste. For this reason, the limestone aggregate with a CTE of 3.3 microstrains $/{ }^{\circ} \mathrm{F}$ was compared with the silica-rich Hanford sand which has a CTE of 4.4 microstrains $/{ }^{\circ} \mathrm{F}$. This allowed us to measure the effect of the CTE of the aggregate on the volume stability of the grout. The characterization tests performed on the fine aggregates included grading, bulk specific gravity, absorption, and mineralogical analysis by XRD. Data from the natural aggregate used in $\mathrm{CC}-20$ are presented in Appendix A. The grading was determined according to ASTM C 136, while the specific gravity and absorption were determined in accordance with ASTM C 127 and ASTM C 128, respectively. These results are shown in Table 3 . The fractions larger than the $2.36-\mathrm{mm}$ (No. 8) sieve size were sieved out to reduce segregation in the mixture and improve flow properties of the grout.

\section{Other Components}

23. Approximately $22.5 \mathrm{~kg}$ of sodium bentonite were used per cubic yard of grout to aid in pumpability, reduce segregation, and eliminate bleeding. A commercial brand of clay familiar to WES researchers and used extensively in the grouting industry was chosen and tested for mineralogical composition by $X R D$ and for pozzolanic activity according to ASTM $C 618$. The results are shown in Table 4.

24. To produce as durable a product as possible, the ratio of water to cementitious materials was held at 0.40 by mass. This necessitated the use of a high-range water-reducing admixture (HRWRA) and a set retarder to obtain the required flow properties for the 2 -hr time period needed between mixing and pumping. The HRWRA used was DAXAD19@, a naphthalene-based product marketed by W. R. Grace. The set-retarding admixture was a salt of hydroxylated carboxylic acid marketed by Sika Corporation as Plastiment ${ }^{\circledR}$. 
PART III: EXPERIMENTAL PROCEDURES

25. The experimental testing program was accomplished in three phases: (a) mixture proportioning and unhardened properties testing, (b) hardened properties testing, and (c) full-depth physical model.

\section{Mixture Proportioning and Unhardened Properties Testing}

26. The cold-cap grout will be pumped into an opening that is the upper $1.2-\mathrm{m}$ depth of the entire vault, above the wasteform grout. WHC has monitored the temperature of the demonstration vault since placement of the wasteform grout. The working temperature they provided to WES for our testing and physical modelling was $45^{\circ} \mathrm{C}$. It was desirable to proportion the mixture with a minimum cement content and still meet the unhardened and hardened grout properties specified. For this reason, fly ash amounts of 67 to 80 percent of the cementitious medium were used. The ratio of cementitious materials to sand $(\mathrm{C}+\mathrm{FA} / \mathrm{S})$ was varied between $1: 1$ and $2: 1$ initially, when we had not yet determined how the aggregate content would affect the volume stability of the grout at the elevated vault temperature. Initial mixtures were proportioned in $0.003-\mathrm{m}^{3}$ batches in a laboratory bench-top mixer meeting the requirements of ASTM C 305 and were tested for flow, segregation, bleeding, shrinkage, and compressive strength. Quantities of all component materials were measured on mass balances certified as accurate within 0.1 percent. Balance verification records are on file at the WES.

27. Grout flow was tested using the flow cone procedure in ASTM C 939 at intervals of $15,30,60,90$, and 120 minutes after starting mixing. From WES experience with grouting operations, we judged that a grout with a flow time of 15 to $18 \mathrm{sec}$ would meet the flow requirements. Bleeding and shrinkage were estimated by measuring the space left at the top of the cylinder after final set. Compressive strength was measured using 3 - by 6 -in. (76- by $152-\mathrm{mm}$ ) cylinders at 7 days, according to ASTM C 39. Mixture segregation was checked by physical inspection prior to each flow test. A total of 20 mixtures was proportioned from the materials listed and tested in the laboratory during this phase of the research. At the completion of Phase I, the four best candidate mixtures (CC-10, CC-11, CC-13, CC-16) were selected to 
continue to Phase II. Table 5 shows the mixture proportions for these mixtures which were chosen to proceed with hardened properties testing. Table 5 also shows proportions for mixture CC-20, the recommended candidate mixture, which was developed as a result of Phase II testing.

\section{Hardened Properties Testing}

28. The five mixtures shown in Table 5 were proportioned in $0.008-\mathrm{m}^{3}$ batches and tested for flow, segregation, bleeding, and time of setting. Also from these batches, specimens were cast for measurements of volume stability, chemical interaction with simulated wasteform grout, compressive strength, and semiadiabatic temperature rise. Duplicate batches were cast of each of these mixtures to attain statistically credible values and to minimize possible proportioning errors. Bleeding was measured, after $2 \mathrm{hr}$ of mixing time, at appropriate intervals for $3 \mathrm{hr}$ after casting in a 500-mL graduated cylinder, as described in ASTM C 940. The time of setting was measured using a Vicat apparatus according to ASTM C 953. Compressive strength was obtained by testing 2-in. (50.8 -mm) cubes according to ASTM C 109 at 7, 14, and 28 days. Strength after aging at elevated temperature also was measured on companion cubes cast in each batch and cured at $38^{\circ} \mathrm{C}$ and 40 percent $\mathrm{RH}$. The results of the strength tests are summarized in Table 6.

29. The volume stability measurements were made on 1 - by 1 - by 11-1/4-in. (25.4- by 25.4- by $287-\mathrm{mm}$ ) prisms which were cured and stored in environmental conditions of $45^{\circ} \mathrm{C}$ and 100 percent relative humidity to simulate conditions inside the vault. Since the exact relative humidity inside the vault was not known, companion prisms from each mixture were cast and stored at $38^{\circ} \mathrm{C}$ and 40 percent relative humidity to bracket plausible conditions. All batches were mixed at $23{ }^{\circ} \mathrm{C}$ for $2 \mathrm{hr}$, after which the molds were filled and immediately placed in the elevated temperature chamber. The specimens were removed at $24 \mathrm{hr}$, demolded, and returned to the chamber. Measurements were taken daily through 7 days, weekly through 28 days, then monthly to 150 days. Figures 2 through 6 plot the volume stability versus time for the five mixtures at each temperature and relative humidity through 150 days of age. 
30. As we anticipated, the specimens stored in the higher humidity environment exhibited much better volume stability than their companion prisms in the lower humidity. Table 7 summarizes prism expansion measured at 150 days. In each case involving both aggregates the mixture with moist curing exhibited shrinkage of 0.03 percent or less, while those mixtures subjected to lower humidity showed shrinkage values consistently near 0.1 percent with one as high as 0.23 percent. It is clear from these data that, at constant cement levels, varying the fine aggregate type or content did not have a large effect on the volume stability of the grout. It is also clear that lowering the cement content of the mixture caused a slight increase in the amount of shrinkage measured. Since the fine aggregate type had minimal effect on volume stability, mixtures made with limestone fine aggregate were deleted from the test matrix, and the remainder of the investigation centered on mixtures containing the natural sand fine aggregate local to the Hanford area.

31. At this point in the investigation, we decided to continue thermal investigative work with mixtures $\mathrm{CC}-10, \mathrm{CC}-16$, and $\mathrm{CC}-20$. Initial thermal screening of each candidate mixture was performed using CIMS, which measures the heat signature from a 152 - by $305-\mathrm{mm}$ cylinder specimen in a calibrated calorimeter. The CIMS coupled this heat signature with heat capacity information entered for the individual materials and calculated an adiabatic temperature rise for the mixture. This test assumed the vault would respond like an adiabatic environment at $45^{\circ} \mathrm{C}$. This test was used to screen the three remaining candidate mixtures to select the best mixture for full-scale adiabatic testing. Figure 7 shows the adiabatic temperature rise calculated by the CIMS system for these three mixtures.

32. Since the grout would be placed into an environment at $45^{\circ} \mathrm{C}$, an adiabatic temperature rise limit of $50{ }^{\circ} \mathrm{C}$ was placed on the cold-cap mixture to ensure it did not overheat in the vault. The data shown in Figure 7 indicate that mixtures $\mathrm{CC}-10$ and $\mathrm{CC}-16$ exhibited peak temperature rise values greater than $50{ }^{\circ} \mathrm{C}$ with mixture $\mathrm{CC}-16$ with its higher sand content being slightly cooler. Mixture CC-20, with its lower cement content, recorded a calculated adiabatic heat rise of $41^{\circ} \mathrm{C}$. For this reason, mixtures $\mathrm{CC}-16$ and CC-20 were chosen to perform full adiabatic temperature rise tests. 
33. Adiabatic temperature rise of candidate grout was determined by the method given in CRD-C 38 (Corps of Engineers, 1949). For this test, a $0.40-\mathrm{m}^{3}$ sample was mixed in a rotary drum mixer for $2 \mathrm{hr}$ and placed in an environmentally controlled room where the temperature of the room was matched to the heat generation of the sample. Figure 8 shows the adiabatic temperature rise measured on mixtures CC-16 and CC-20. Mixture CC-16 exceeded the $50{ }^{\circ} \mathrm{C}$ limit almost immediately, and the test was terminated after 2 days. The temperature of mixture CC-20 rose more slowly and stayed below the $50{ }^{\circ} \mathrm{C}$ limit. Based upon these data and data generated from the volume stability measurements of prisms, we decided to use mixture CC-20 in the full-depth physical model phase of the test program. The mixture proportions for CC-20 are shown in Table 5.

\section{Interface With Wasteform Grout}

34. As part of the laboratory experiments that led to mixture selection, we prepared 2 - by 2 -in. (50.8- by $50.8-\mathrm{mm}$ ) cylinders of simulated wasteform grout (based on different cement and fly ash, and two clays; formulation given in Lokken et al., 1988) in plastic molds 4 in. high. We then cast candidate cold-cap grouts (CC-9 through CC-16, Table 5) in the upper half of each mold when the simulated wasteform in the bottom half was 2 to 3 weeks old. The interfaces were studied at ages between 4 and 9 weeks, by visual and petrographic observations, XRD, and chemical composition by EDX in appropriate profiles. Observations included aggregate distribution, evidence of fluid movement, and description of interface surface textures. A typical petrographic report from these studies is included in Appendix B. As anticipated, there was virtually no bonding between candidate cold-cap grouts and simulated waste grout. The lower surface of each cold-cap grout appeared frothy, covered by a 1-mm-thick layer of uniformly sized thin-walled voids, while the upper surface of the simulated waste grout was smooth.

\section{Analyses of Small Interface Samples}

35. Phases identified by XRD are consistent with partial hydration of cementitious components both in the cold cap and in the simulated wasteform 
grout (calcium hydroxide, calcium silicate hydrate, dicalcium silicate, and mineral constituents of the aggregate). Calcite is most abundant in the froth, and ettringite is present only in the froth and not within the grouts. EDX elemental analysis revealed $\mathrm{Na}, \mathrm{Al}, \mathrm{Ti}$, and $\mathrm{S}$ more abundant in froth than grouts, and $\mathrm{Ca}$ more abundant in grouts than in froth. Results of XRD and EDX analysis are summarized in Appendix B. 
36. In the final phase of this research, we constructed an insulated and heated cube proportioned to represent the full depth of one corner of the cold-cap grout layer of the Hanford demonstration vault and cast a large-scale physical model of the cold cap. This endeavor incorporated measuring all of the grout properties tested separately in the previous phases and included extensive instrumentation and data acquisition. The concept was to simulate on an engineering scale the environmental conditions in the vault and the mixing and placement operations as they might occur at the site. Figure 9 is a photograph of the interior of the cube immediately after placement of first grout lift. This physical model was maintained at $45^{\circ} \mathrm{C}$ to simulate the vault environment and was instrumented for strain, temperature, and volume change. Model dimensions were chosen to reflect the actual depth being placed in the vault, to eliminate the size effects inherent in small specimens, and to give realistic temperature and strain profiles and volume changes. Long-term data from this model were intended to validate the measurements made on previously cast laboratory specimens and provide more complete data for thermal modelling efforts to follow.

\section{Mixing and Placement}

37. At the base of the cube, we placed a $150-\mathrm{mm}$ lift of surrogate PSW wasteform grout, using the formula provided by Lokken et al. (1988). When the simulated wasteform grout layer had been in place and at temperature in the model for several weeks, we then placed the first of three 410-mm lifts of cold-cap grout. Two more lifts followed after one week and four weeks, respectively. The cap was cast in separate lifts since the vault will be filled in this manner to decrease the likelihood of continuous crack propagation. One quarter of the cube was instrumented with 18 Carlson strain meters and 19 separate thermocouples, to measure changes in both strain and temperature from the block centerline to the outside wall as each lift was added to the cube. Figure 10 shows a 3-D view of the cube with the location of the 18 strain meters. Six meters were placed in each lift with one at the cube centerline and the remaining meters placed in a rectangular pattern to measure changes in the material as the grout approaches the corner of the 
model. Figures 11 through 13 show the meter trees and the numbered meters showing their location in the cube. Each cold-cap lift also was instrumented at the cube centerline with four thermocouples, plus one in the wasteform grout, to record a continuous profile of temperature data. This thermocouple tree is shown in Figure 14, with the centerline marked "CL."

38. Each lift of cap grout was batched in a fully automated, computercontrolled batch plant and mixed for $2 \mathrm{hr}$ in a pug mill prior to being placed in the cube by concrete bucket. Figure 15 shows the pug mill mixing the grout for the first lift. Flow and segregation were measured at 30 -min intervals during the 2-hr mixing period, and nine 152- by $305-\mathrm{mm}$ cylinders were cast and tested for compressive strength in groups of three at 7,14 , and 28 days. Figure 16 depicts the strength gain with time for two of the three lifts placed in the physical model compared to the strength figures obtained from the 2-in. cubes cast for the same mixture in the earlier phase of the project. The average 28-day compressive strength of the grout placed in the physical model was approximately $10.7 \mathrm{MPa}$. None of the lifts exhibited any bleed water.

\section{$\underline{\text { Strain and Temperature Measurements }}$}

39. Each grout lift was batched at approximately $27^{\circ} \mathrm{C}$ and placed immediately into the physical model which was kept at $45^{\circ} \mathrm{C}$. The highest temperature attained by any of the three lifts was $61{ }^{\circ} \mathrm{C}$ which equated to a $41{ }^{\circ} \mathrm{C}$ rise in the grout itself. Figure 17 plots the grout strain versus time at the centerline of each lift at the center of the cube. The maximum strain recorded at the block centerline in the first lift was over 2000 microstrains, which is well above the strain limit expected for cementitious grout. Visual inspection of the surface revealed several cracks, but it was not obvious whether they were due to thermal effects or to drying shrinkage, since they propagated from the instrumentation tree. Figure 18 is a photograph of the cracks propagating from around the instrumentation supports. While crack elimination was not a performance requirement, WES did try to prevent cracking and to determine its cause when it was observed.

40. The second lift of cold-cap grout was placed six days after the first. In an attempt to remedy the cracking problem, this lift was moist 
cured by ponding a thin layer of water on the surface each day. Most of this water was lost each day by a combination of absorption and evaporation, but it served to keep the surface from drying out and no cracking was observed during the 30-day period in between lifts 2 and 3 . Measurements made on specimens placed on the grout surface and ponded with the same thickness of water each day showed that 70 percent of the ponded water was evaporated by the heat from the model, and we assume that the remaining 30 percent was absorbed or otherwise incorporated into the grout.

41. The maximum strain measured at the cube centerline in the second lift was 1550 microstrains. This is also many times the strain limit typically associated with hardened grout yet this lift showed no visible signs of cracking. We postulate that the cracking observed in the first lift was due to drying shrinkage coupled with the restraint imposed by the instrumentation. The model was not actually a sealed system, but it is possible that enough water was evaporated from the surface of the grout to saturate the air above the surface on which cracking was observed. This situation may have been exacerbated by the failure to seal the plywood ceiling of the block. This ceiling undoubtedly absorbed water from the air above the grout surface, which would then continue to draw water from the grout. The daily wet curing of the second lift surface by ponding apparently prevented the heat from evaporating enough water away from the surface to cause it to crack. It is also possible that the elastic modulus of the grout may be low enough at early ages that the material can accommodate these large strains without macroscopic damage.

42. The third lift was placed 30 days after the second (during which we awaited arrival of additional materials). The cube was filled to within $150 \mathrm{~mm}$ of the underside of the roof to allow room for surface measurements and was not cured by ponding with water. The maximum strain in lift three was attained by the centerline meter and totaled 1300 microstrains. Several lifting shackles were inserted into the top lift which served as starting points for cracks as the grout stiffened. A complete listing of the strain vs time and temperature vs time plots for each meter is presented along with a reference table identifying each data file and plot in Appendix C.

43. As shown in Figure 14, each lift of cold-cap grout was instrumented with five thermocouples at the block centerline to record continuous 
temperature data during the filling operation. Lift 2 also was instrumented with six additional thermocouples to record temperature variations within the lift from the cube centerline to the outside wall. Figures 19 through 21 show temperature profile versus time recorded at the block centerline in each lift. Figures 22 and 23 show the temperature variation in lift 2 at positions $48 \mathrm{~cm}$ and $15 \mathrm{~cm}$ from the model face. As each new lift was added to the model, the lowest thermocouple in the new lift, which was also the thermocouple nearest the grout surface, experienced the widest range of temperature variation. These lift additions are represented by temperature spikes in Figures 20 through 23. The widest variation within a lift occurred in the third lift and measured $39{ }^{\circ} \mathrm{C}$.

44. The Carlson strain meters placed throughout the model also measured temperature on a continuous basis, and this also provided information on the temperature gradient from the model centerline to the outside edges. Elevated temperature does not cause cracking in grout and concrete but temperature gradients do. For this reason the model dimensions were specifically chosen so that the block represented a corner of the vault which is the worst-case scenario in terms of temperature gradients to the outside walls and the top of the vault. Figures 24 through 53 illustrate the changes in grout temperature and thermal strain with time and space as the model was filled.

45. When adjacent Carlson meters in the same lift were compared, there was very little difference in temperature, with the centermost meter being only slightly hotter. However, there is a large difference in the measured strains among meters within a lift, with the innermost meter always recording substantially higher strains. This trend was true when measuring from the centerline out to the cube face and also when measuring along the cube face from the center of the face to a corner. This result is attributed to the restraint imposed upon the grout layer by the increased proximity of the side wall of the model. The meters nearest the cube faces and top also showed a measure of strain relief after the last lift had been placed as evidenced by the positive (compressive) strains noted with increasing time in Figures 29 , 31 , and 35. These strains continued to rise for approximately 20 days before leveling off despite a relatively flat temperature profile during this period. The temperatures recorded at the edges and top of the cube were in most cases only a few degrees lower than those measured at the cube centerline. 


\section{Volume Stability Measurements}

46. After the final lift was placed the top of the cube, six dial gages were attached to a fixed support simulating the vault cover blocks above the grout surface. The locations of these gages are shown in Figure 54 . The actual volume stability of the grout surface was measured to validate the data obtained from the laboratory prism specimens. Figure 55 shows the deflection of the surface with respect to the cover blocks as measured by five of the gages through 90 days age. The sixth gage malfunctioned soon after installation. The average deflection is 0.021 in $(0.52 \mathrm{~mm})$. When divided by the 54-in. (137 cm) depth of the cold-cap grout, the shrinkage of the cold cap is calculated to be 0.039 percent. This value meets the shrinkage requirement of 0.1 percent for the lower lifts but misses the 0.01 percent limit for the top lift.

\section{Analyses of the Interface in the Physical Model}

47. The interface between the layer of simulated wasteform grout and the first lift of cold-cap grout in the physical model was sampled by horizontal coring after these layers had been in contact for 4 months at the vault temperature. This interface was studied by the same techniques as were the smaller samples. Again, there was minimal bonding between these layers, which is desirable for materials with different moduli and coefficients of thermal expansion. The froth was absent. However, where the two grouts had separated, the lower surface of the cold cap showed what appeared to be small channels, $<1 \mathrm{~mm}$ in diameter and several millimetres long, suggesting fluid movement. The chemical composition of grouts and interfacial region were similar to those of the smaller samples, although the phase assemblage differed in that three forms of calcium carbonate were identified on the wasteform surface, and no ettringite was detected at the interface.

\section{Implications for Chemical Interaction}

48. The presence of froth at the interface of samples from small plastic molds suggests that it was preserved where fluid movement was 
restricted. Microchannels on the interface from the larger physical model are consistent with this interpretation. We did not isolate or verify the cause of these interfacial features. However, the formation of ettringite at the interface of the small samples may indicate increased availability of sulfate from PSW. Extensive carbonation of the surface of the wasteform grout in the Hanford demonstration vault is likely because of the probable use of forcedflow air filtration system during and soon after placement of wasteform grout. 
49. A nonradioactive sanded cold-cap grout was developed to serve as a void filler between the waste grout and the underside of the cover blocks in the first Hanford Grout Vault. Using a small amount of Class $\mathrm{H}$ oil-well cement, a large amount of ASTM Class F fly ash, a natural sand, and bentonite clay, a grout was developed which met a demanding set of physical and geochemical properties.

50. Based upon this study, the following observations and conclusions are offered:

a. The required fresh-concrete properties of 2-hr workability with $15-\sec$ flow time combined with no bleeding and no segregation can be met with the right combination of materials.

b. Adiabatic temperature-rise tests indicated that the mixture may be too hot; however, the full-depth model test placed under vault-like conditions showed a peak temperature rise of only $41{ }^{\circ} \mathrm{C}$ and a maximum temperature of $61{ }^{\circ} \mathrm{C}$, which is well within the project requirements.

c. Although the vault is basically a closed system following placement of the cold-cap grout, the physical model experienced drying of the surface of the grout layers. This induced drying shrinkage cracking especially at penetration points where the grout was restrained by gage supports or other hardware. Strain measurements exceeded the nominal strain capacity expected for conventional cement-based grouts. However, the second layer did not crack when wet cured by ponding.

\section{Recommendations}

51. We recommend research to establish the early-age modulus of the grout material. Minimizing time between successive lifts and ponding water on the surface of the grout between lifts may alleviate the potential for cracking, but the demonstration vault may be sealed well enough during and following closure that it does not experience this apparent water loss by evaporation. If lower thermal strain and closer volume tolerance are required, we recommend additional work to develop grout with a lower cement content. 


\section{REFERENCES}

American Society for Testing and Materials. 1991. 1991 Annual Book of ASTM Standards, Philadelphia, PA.

a. Designation C 39-86. "Standard Test Method for Compressive Strength of Cylindrical Concrete Specimens."

b. Designation C 109-90. "Standard Test Method for Compressive Strength of Hydraulic Cement Mortars (Using 2-in. or 50-mm Cube Specimens)."

c. Designation C 127-88. "Standard Test Method for Specific Gravity and Absorption of Coarse Aggregate."

d. Designation C 128-88. "Standard Test Method for Specific Gravity and Absorption of Fine Aggregate."

e. Designation C 136-84a. "Standard Method for Sieve Analysis in Fine and Coarse Aggregates."

f. Designation C 150-89. "Standard Specification for Portland Cement."

g. Designation C 157-89. "Standard Test Method for Length Change of Hardened Hydraulic-Cement Mortar and Concrete."

h. Designation C 191-82. "Standard Test Method for Time of Setting of Hydraulic Cement by Vicat Needle."

i. Designation C 305-82. "Standard Practice for Mechanical Mixing of Hydraulic Cement Pastes and Mortars of Plastic Consistency."

j. Designation C 618-91. "Standard Specification for Fly Ash and Raw or Calcined Natural Pozzolan for Use as a Mineral Admixture in Portland Cement Concrete."

k. Designation C 939-87. "Standard Test Method for Flow of Grout for Preplaced-Aggregate Concrete (Flow Cone Method)."

1. Designation C 940-89. "Standard Test Method for Expansion and Bleeding of Freshly Mixed Grouts for Preplaced-Aggregate Concrete in Laboratory."

m. Designation C 953-87. "Standard Test Method for Time of Setting of Grouts for Preplaced-Aggregate Concrete in the Laboratory."

Barrow, S., and R. L. Carrasquillo. 1988. "The Effect of Fly Ash on the Temperature Rise in Concrete, "Research Report 481-2, Center for Transportation Research, University of Texas at Austin.

Barrow, R. S., P. M. Hadchiti, and R. L. Carrasquillo. 1989. "Temperature Rise and Durability of Concrete Containing Fly Ash," Proceedings of the Third International Conference on the Use of Fly Ash, Silica Fume, Slag, and Natural Pozzolans in Concrete, American Concrete Institute, SP 114, pp 331-338.

Cline, M. W., A. R. Tedeschi, and A. K. Yoakum. 1990. "Phosphate/Sulfate Waste Grout Campaign Report," WHC-SA-0829-FP, prepared for the U.S. Department of Energy Assistant Secretary for Defense Programs by Westinghouse Hanford Company, P.O. Box 1970, Richland, WA. 
Hanford Support Team. 1990. "Hanford Site Environmental Restoration Cost And Review," prepared for U.S. Department of Energy Office of Environmental Restoration and Waste Management by U.S. Army Corps of Engineers Division, North Pacific (CENPD), P.O. Box 2870, Portland, OR.

Lokken, R. O., Reimus, M. A., Martin, P. F. C., and Geldart, S. E. 1988. "Characterization of Simulated Low-Level Waste Grout Produced in a Pilot-Scale Test," PNL-6396, Pacific Northwest Laboratory.

Mindess, S. and J. F. Young. 1981. Concrete, 671 pp, Prentice-Hall, Englewood Cliffs, $\mathrm{NJ}$.

Tikalsky, P. J., and R. L. Carrasquillo, 1988. "Effect of Fly Ash on the Sulfate Resistance of Concrete Containing Fly Ash," Research Report 481-1, Center for Transportation Research, University of Texas at Austin.

U.S. Army Corps of Engineers. 1949. Handbook for Concrete and Cement, U.S. Army Engineer Waterways Experiment Station, Vicksburg, MS (with quarterly supplements). 
Table 1

Ghemical and Physical Properties of Portland Cement

(API Type H) Used in Cold-Cap Grout

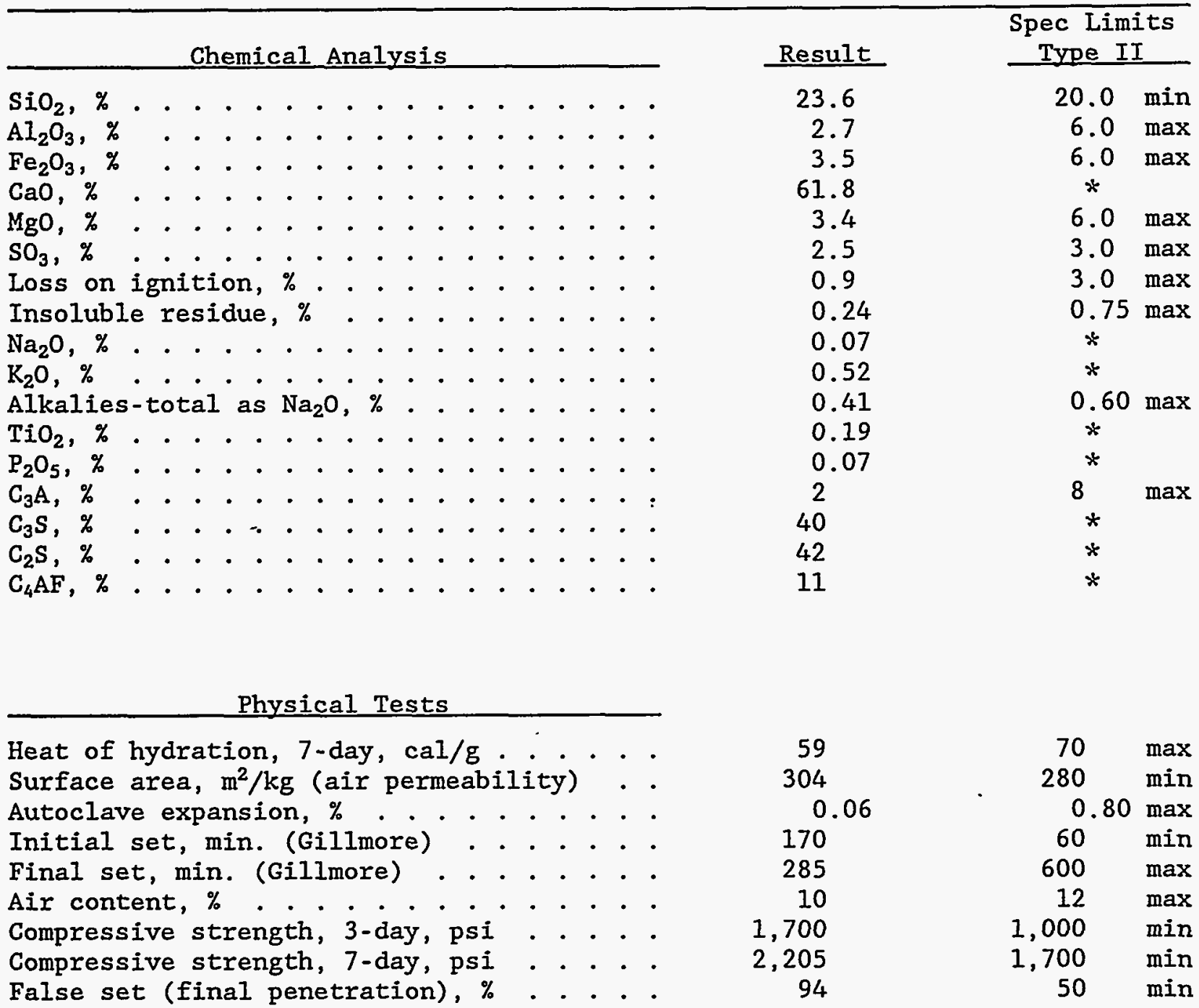

* ASTM C 150 contains no specification requirements for these chemical analysis results. 
Table 2

Chemical and Physical Properties of Fly Ash

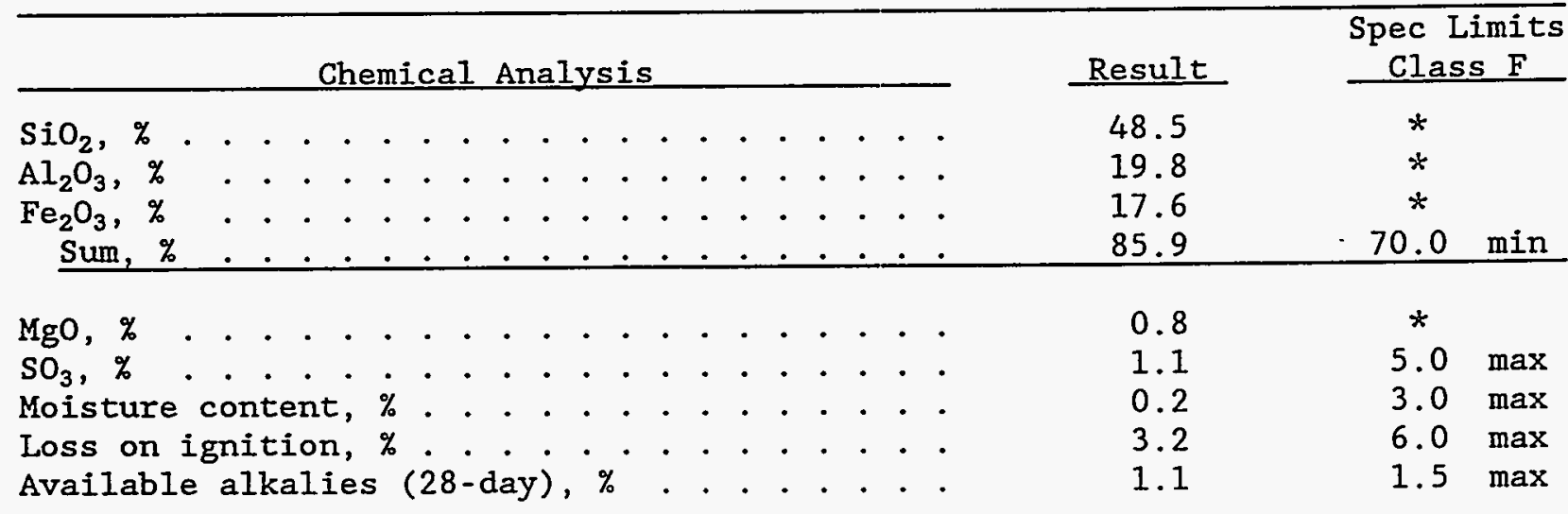

Physical Tests

Fineness $(45-\mu \mathrm{m}$ (No. 375$)$ sieve), \% retained.

Water requirement, $\%$. . . . . . . . .

Density, $\mathrm{Mg} / \mathrm{m}^{3}$. . . . . . . . . . . . . .

Autoclave expansion, \% . . . . . . . . . . .

Pozzolanic activity w/lime, psi... . . . . .

Pozzolanic activity w/cement (28-day), $\%$. .

24
103
2.38
0.02
1,020
119

$34 \max$

$105 \max$

.38

0.02

119

$0.80 \max$

900 min

$75 \min$

Laboratory cement used: Lone Star Industries, Cape Girardeau, MO Laboratory lime used: Chemstone * ASTM C 618 contains no specification requirements for results of these
determinations. 
Table 3

Fine Aggregate Data

Material: Hanford natural basaltic sand, HAN-1 S-2

Source: Acme Concrete Co. Richland, WA

\section{Sieve Size}

4.75-mm (No. 4)

2.36-mm (No. 8)

1.18-mm (No. 16)

$600-\mu \mathrm{m}$ (No. 30)

$300-\mu \mathrm{m}$ (No. 50)

$150-\mu \mathrm{m}$ (No. 100)

Finer than $150-\mu \mathrm{m}$ (No. 100)
Bulk Specific Gravity $=2.695$

Absorption $=1.6 \%$

Fineness Modulus $=\underline{2.57}$

(No. 4 - No. 100)

Material: Laboratory stock crushed

Bulk Specific Gravity $=2.69$

limestone sand, WESSC-9

\begin{tabular}{|c|c|}
\hline Ret. & Pass. \\
\hline 0.8 & 99.2 \\
\hline 18.4 & 81.6 \\
\hline 27.9 & 72.1 \\
\hline 46.4 & 53.6 \\
\hline 73.0 & 27.0 \\
\hline 90.1 & 9.9 \\
\hline$(100.0)$ & 0 \\
\hline
\end{tabular}

Source: Vulcan Materials Co.

Absorption $=0.9 \%$

Calera, AL

\section{Gumulative Percent}

Sieve Size

4.75-mm (No. 4)

$2.36-\mathrm{mm}$ (No. 8)

$1.18-\mathrm{mm}$ (No. 16)

$600-\mu \mathrm{m}$ (No. 30)

$300-\mu \mathrm{m}$ (No. 50)

$150-\mu \mathrm{m}$ (No. 100)

Finer than $150-\mu \mathrm{m}$ (No. 100)

\begin{tabular}{ccc} 
Ret. & & Pass. \\
\cline { 1 - 1 } 1 & & 99 \\
5 & & 85 \\
50 & & 50 \\
71 & & 29 \\
85 & & 15 \\
94 & & 6 \\
\hline 100.0$)$ & & 0
\end{tabular}

Fineness Modulus $=\underline{3.06}$

(No. 4 - No. 100) 
Table 4

Chemical Analysis of Bentonite

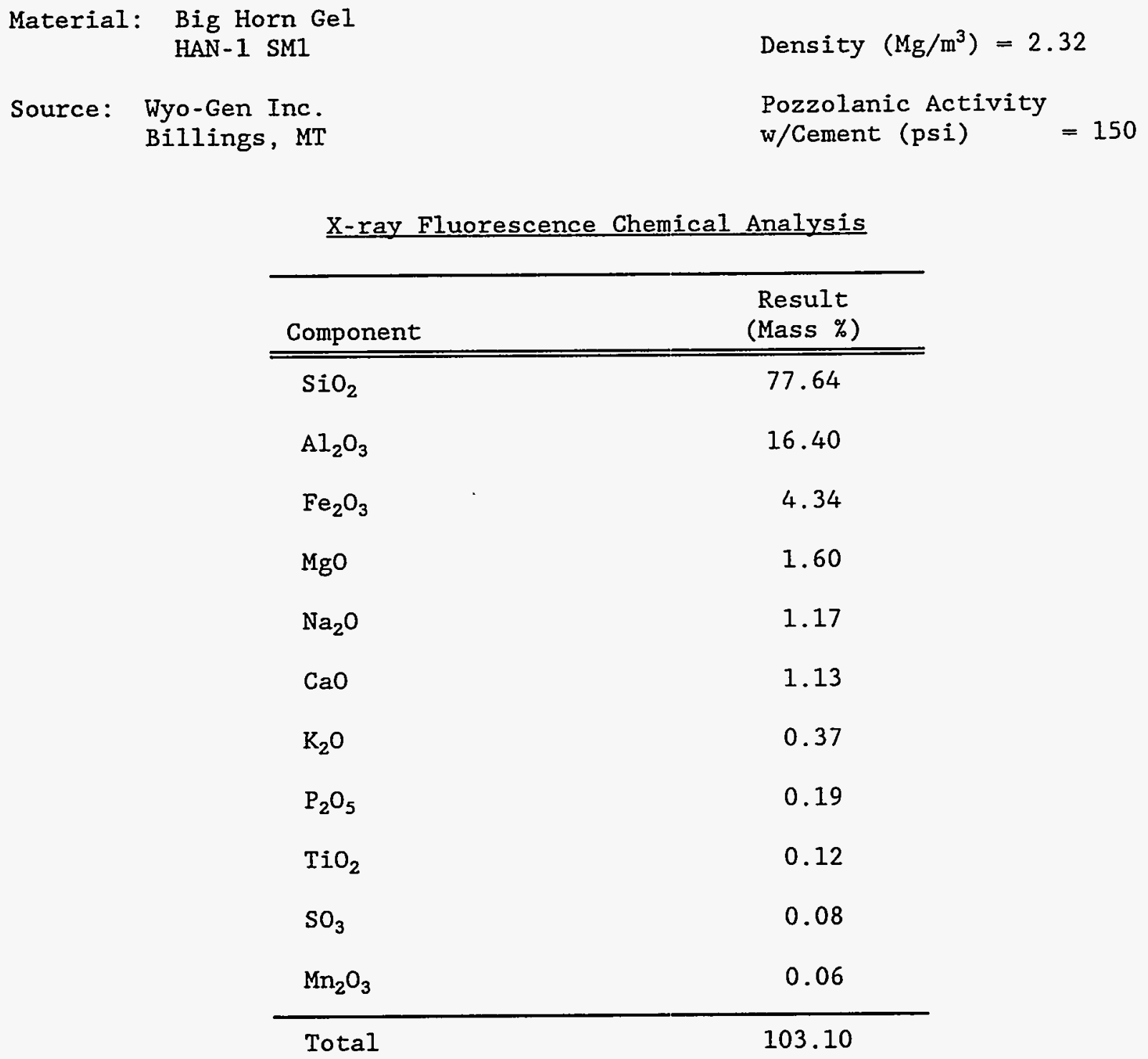


Table 5

Mixture Proportion for Grouts selected for Testing in Phase II

\begin{tabular}{|c|c|c|c|c|c|c|c|c|c|}
\hline $\begin{array}{c}\text { Mixture } \\
\text { Designation }\end{array}$ & $\begin{array}{l}\text { Class H } \\
\text { Cement } \\
\text { (1b/cy) }\end{array}$ & $\begin{array}{c}\text { F1y } \\
\text { Ash } \\
(1 \mathrm{~b} / \mathrm{cy})\end{array}$ & $\begin{array}{c}\text { ABgregate Type } \\
\text { (sand: cement + fly ash) }\end{array}$ & $\begin{array}{l}\text { Aggregate } \\
\text { Weight } \\
\text { (1b/cy) }\end{array}$ & $\begin{array}{c}\text { Clay } \\
(1 b / c y)\end{array}$ & $\begin{array}{l}\text { Water } \\
\text { (lb/cy) }\end{array}$ & $\begin{array}{l}\text { High-Range } \\
\text { Water Reducer } \\
\text { (1b/cy) }\end{array}$ & $\begin{array}{c}\text { Set } \\
\text { Retarder } \\
\text { (oz/cy) }\end{array}$ & $\begin{array}{l}\text { W/C } \\
\text { Ratio* }\end{array}$ \\
\hline CC $9 / 10$ & 481 & 1182 & $\begin{array}{l}\text { Hanford } \\
(1 / 2: 1)\end{array}$ & 800 & 38 & 670 & 2.9 & 5 & 0.40 \\
\hline $\mathrm{CC} 11 / 12$ & 481 & 1182 & $\begin{array}{l}\text { Limestone } \\
(1 / 2: 1)\end{array}$ & 844 & 38 & 670 & 2.9 & 5 & 0.40 \\
\hline CC $13 / 14$ & 481 & 988 & $\begin{array}{l}\text { Limestone } \\
\quad(1: 1)\end{array}$ & 1340 & 38 & 580 & 4.72 & 8.2 & 0.40 \\
\hline CC $15 / 16$ & 481 & 983 & $\begin{array}{l}\text { Hanford } \\
(1: 1)\end{array}$ & 1260 & 38 & 572 & 4.72 & 8.2 & 0.39 \\
\hline CC 20 & 300 & 1112 & $\begin{array}{l}\text { Hanford } \\
(1: 1)\end{array}$ & 1314 & 38 & 564 & 4.16 & 4.5 & 0.40 \\
\hline
\end{tabular}

* Ratio of water (w) to cement + fly ash (c). 
Table 6

\section{Compressive Strength Data for}

Five Phase II Mixtures

\begin{tabular}{|c|c|c|c|c|c|c|}
\hline \multirow{2}{*}{$\begin{array}{c}\text { Mixture } \\
\text { Designation }\end{array}$} & \multicolumn{3}{|c|}{$\begin{array}{c}\text { Compressive Strength a } \\
23{ }^{\circ} \mathrm{C} \text { (psi) }\end{array}$} & \multicolumn{3}{|c|}{$\begin{array}{c}\text { Compressive Strength @ } \\
38^{\circ} \mathrm{C} \text { (psi) } \\
\end{array}$} \\
\hline & 7 days & 14 days & 28 days & 7 days & 14 days & 28 days \\
\hline $\begin{array}{l}\text { CC } 9 / 10 \\
\text { Hanford } 1 / 2: 1\end{array}$ & 1060 & 1440 & 1780 & 2610 & 3400 & 3800 \\
\hline $\begin{array}{l}\text { CC } 11 / 12 \\
\text { Limestone } 1 / 2: 1\end{array}$ & 1240 & 1900 & 2400 & 3000 & 3560 & 4160 \\
\hline $\begin{array}{l}\text { CC } 13 / 14 \\
\text { Limestone } 1: 1\end{array}$ & 1520 & 1440 & 2600 & 3500 & 3400 & 4300 \\
\hline $\begin{array}{l}\text { C } 15 / 16 \\
\text { Hanford } 1: 1\end{array}$ & 1160 & 1920 & 1920 & 2980 & 3560 & 3730 \\
\hline $\begin{array}{l}\text { CC } 20 \\
\text { Hanford 1:1 }\end{array}$ & 610 & 1040 & 1330 & * & $*$ & * \\
\hline
\end{tabular}

* No specimens were tested at elevated temperature because all measured values for strength exceeded the performance requirement. 
Table 7

Overview of Expansion Bar Data

\begin{tabular}{l|l|l}
\hline & \multicolumn{2}{|c}{ Length Change (\%) } \\
\cline { 2 - 3 } $\begin{array}{c}\text { Fine Aggregate:Cement Ratio } \\
\text { and Curing Condition }\end{array}$ & Hanford & Limestone \\
\hline @1 $/ 2: 1 \& 45{ }^{\circ} \mathrm{C} / 100 \% \mathrm{RH} *$ & +0.007 & -0.002 \\
@1/2:1 \& $38{ }^{\circ} \mathrm{C} / 40 \% \mathrm{RH} *$ & -0.08 & -0.082 \\
@1:1 \& $45{ }^{\circ} \mathrm{C} / 100 \% \mathrm{RH} *$ & +0.002 & -0.004 \\
@1:1 \& $38{ }^{\circ} \mathrm{C} / 40 \% \mathrm{RH} *$ & -0.10 & -0.078 \\
Q1:1 \& $45{ }^{\circ} \mathrm{C} / 100 \% \mathrm{RH} * *$ & -0.03 & \\
@1:1 \& $38{ }^{\circ} \mathrm{C} / 40 \% \mathrm{RH} * *$ & -0.23 & \\
\hline \hline
\end{tabular}

* Mixtures containing $481 \mathrm{lb} / \mathrm{cy}$ of cement @ 150 days.

** Mixtures containing $300 \mathrm{1b} / \mathrm{cy}$ of cement (c) 90 days. 


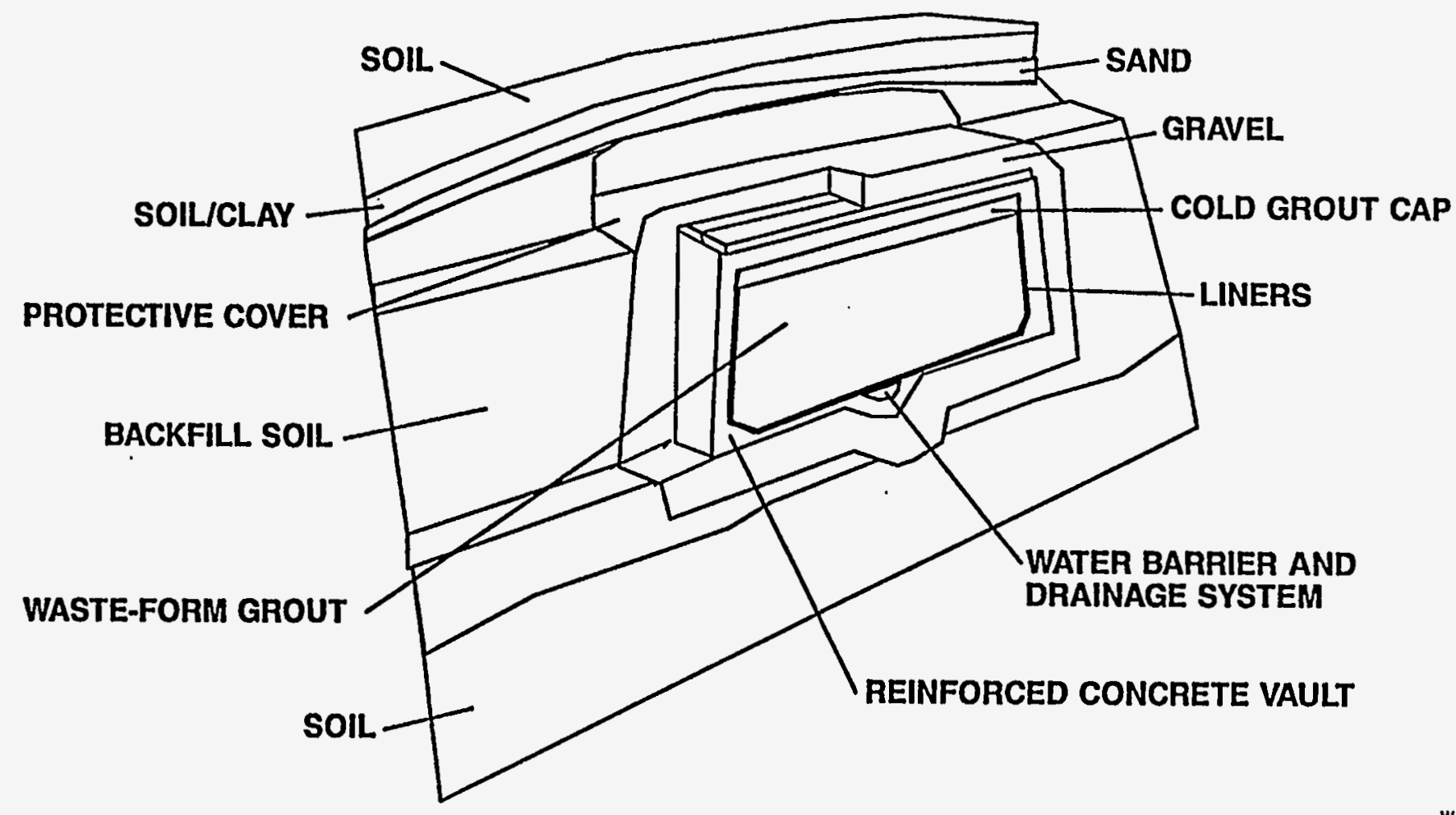

WAKELOTO

Figure 1. Grouted waste-disposal vault 


\section{HANFORD PSW COLD CAP VOLUME STABILITY VS TIME}

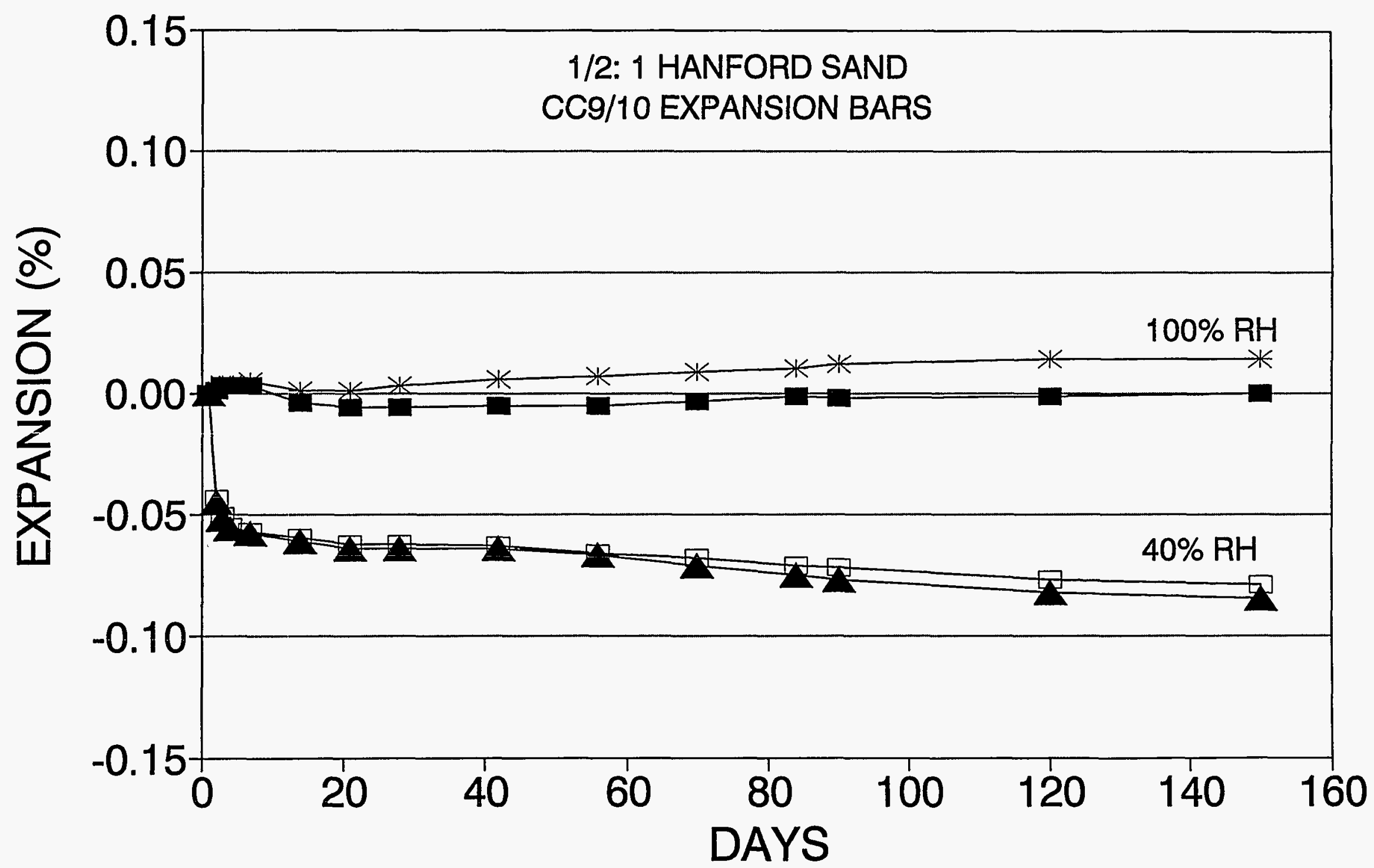

Figure 2. Plot of volume stability vs time for phase II expansion bars 


\section{HANFORD PSW COLD CAP VOLUME STABILITY VS TIME}

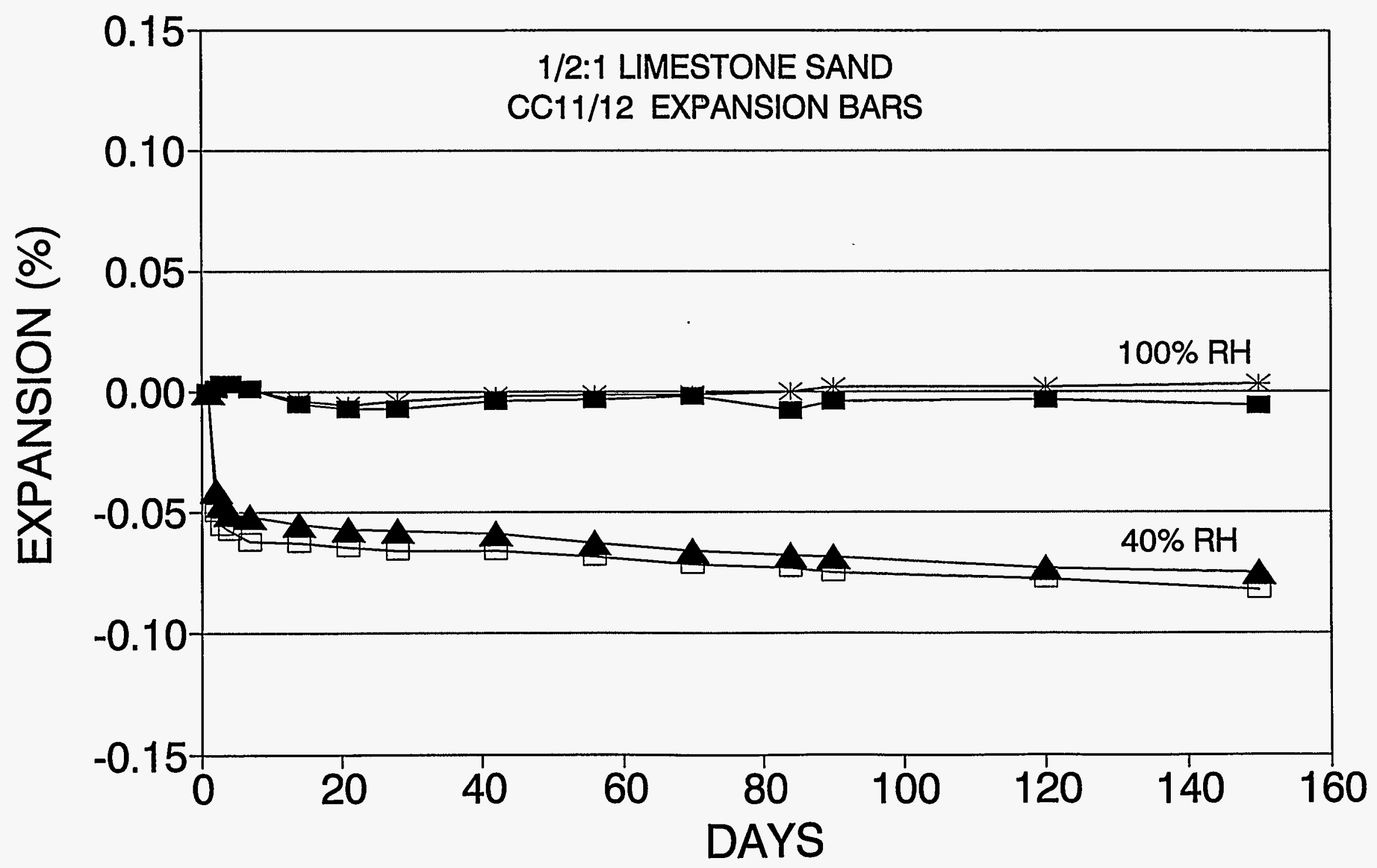

Figure 3. Plot of volume stability vs time for phase II expansion bars 


\section{HANFORD PSW COLD CAP VOLUME STABILITY VS TIME}

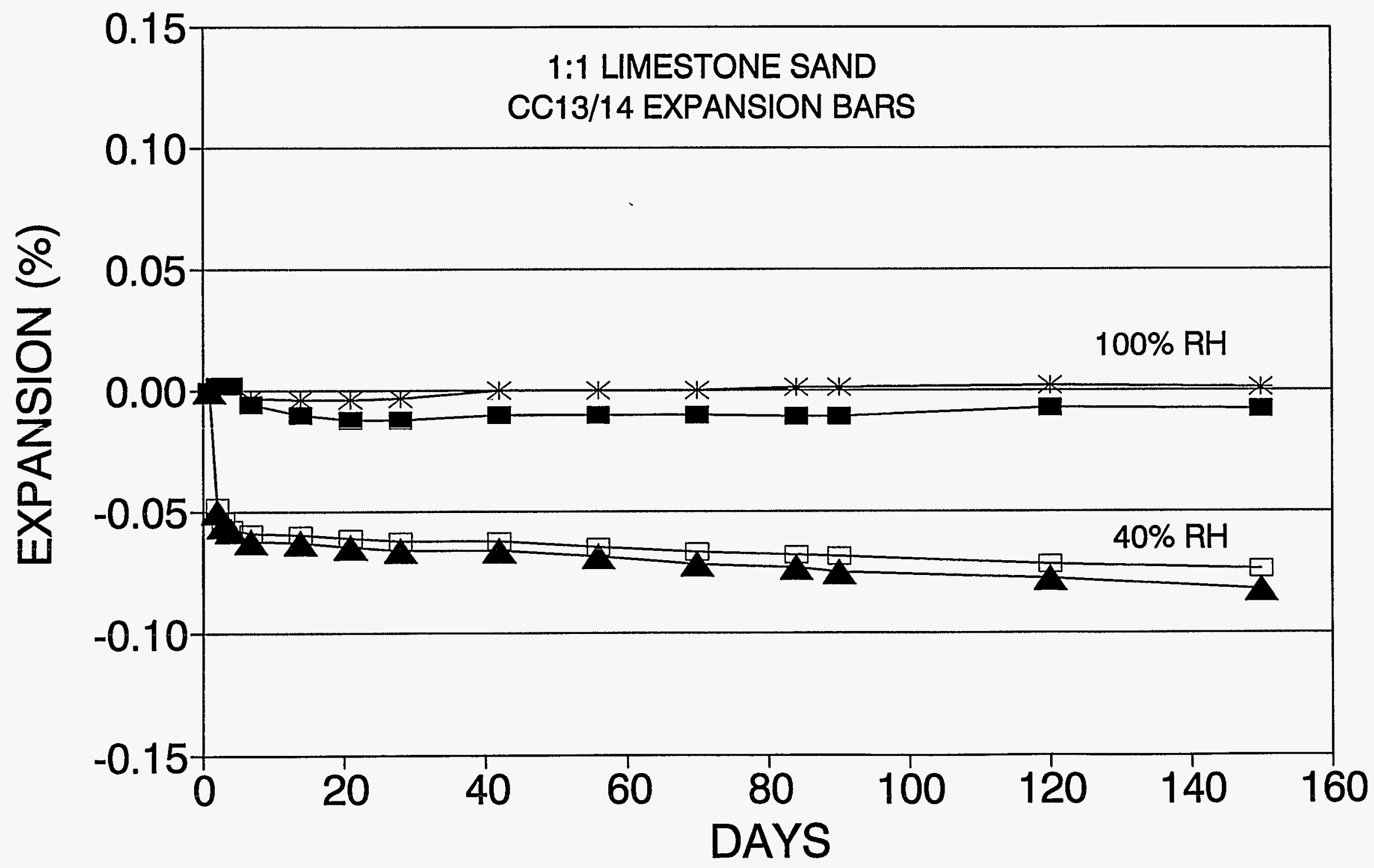

Figure 4. Plot of volume stability vs time for phase II expansion bars 


\section{HANFORD PSW COLD CAP VOLUME STABILITY VS TIME}

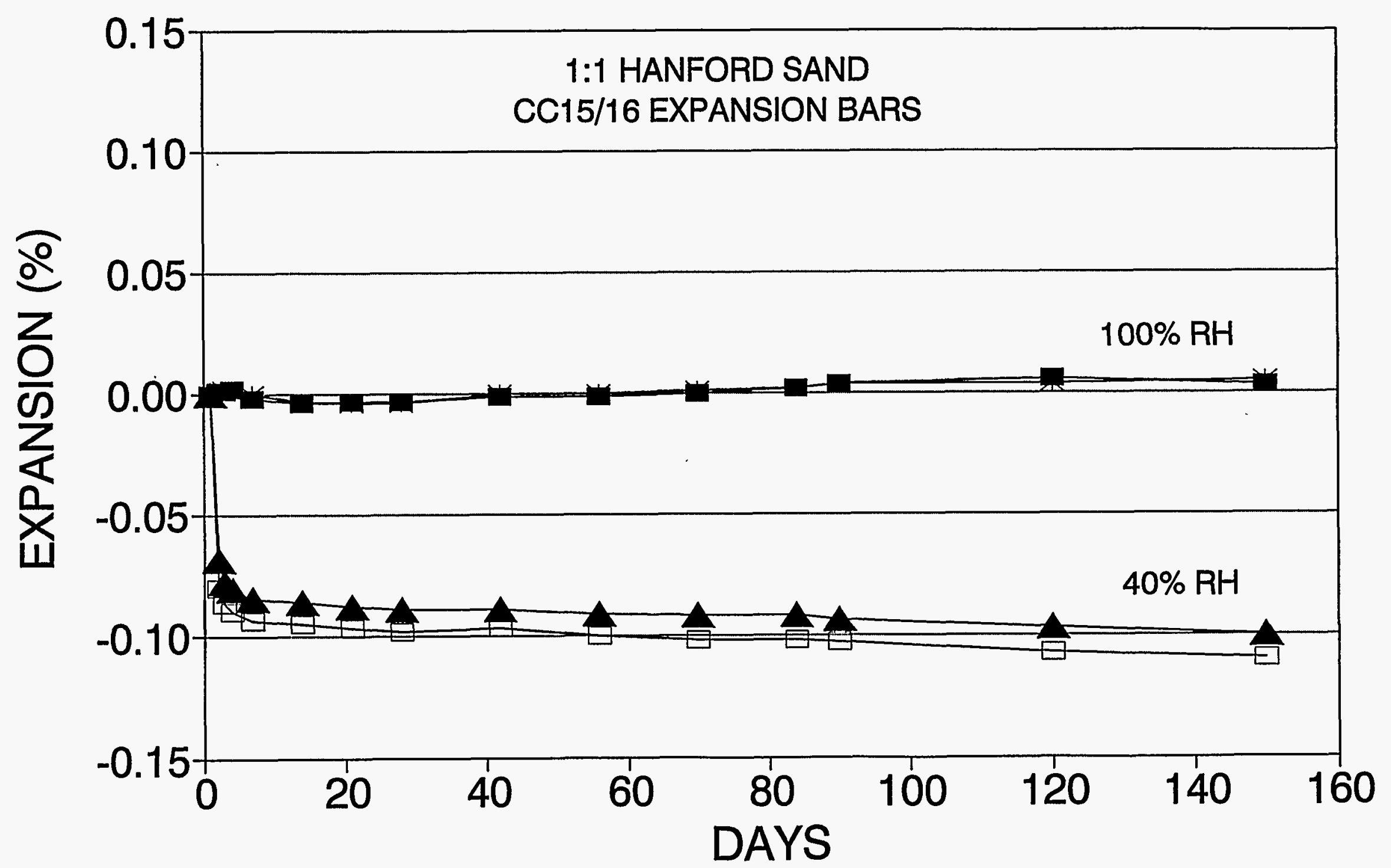

Figure 5. Plot of volume stability vs time for phase II expansion bars 


\section{HANFORD PSW COLD CAP VOLUME STABILITY VS TIME}

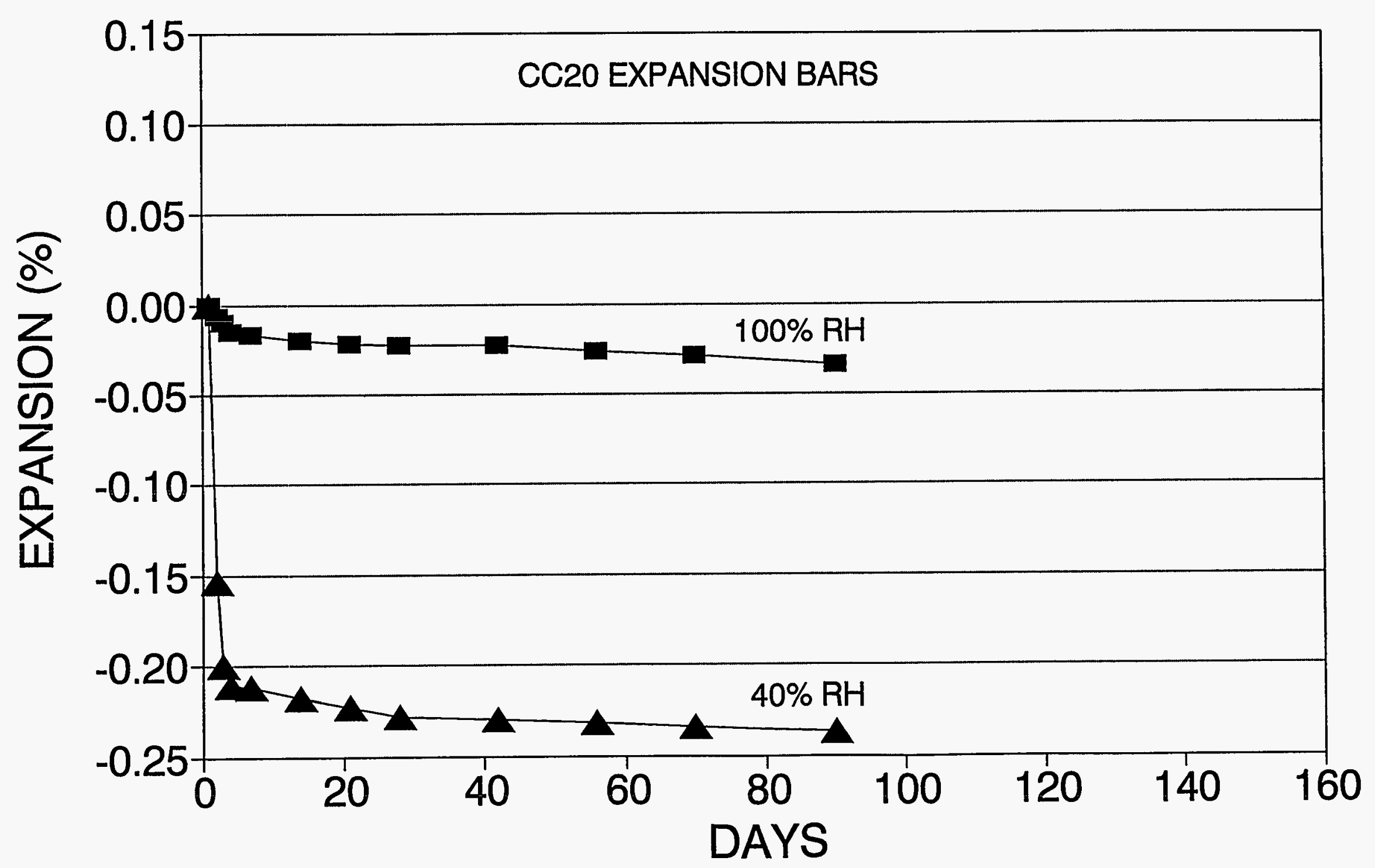

Figure 6. Plot of volume stability vs time for phase II expansion bars 
Hanford Cold Cap

Calculated Adiabatic Temperature Rise

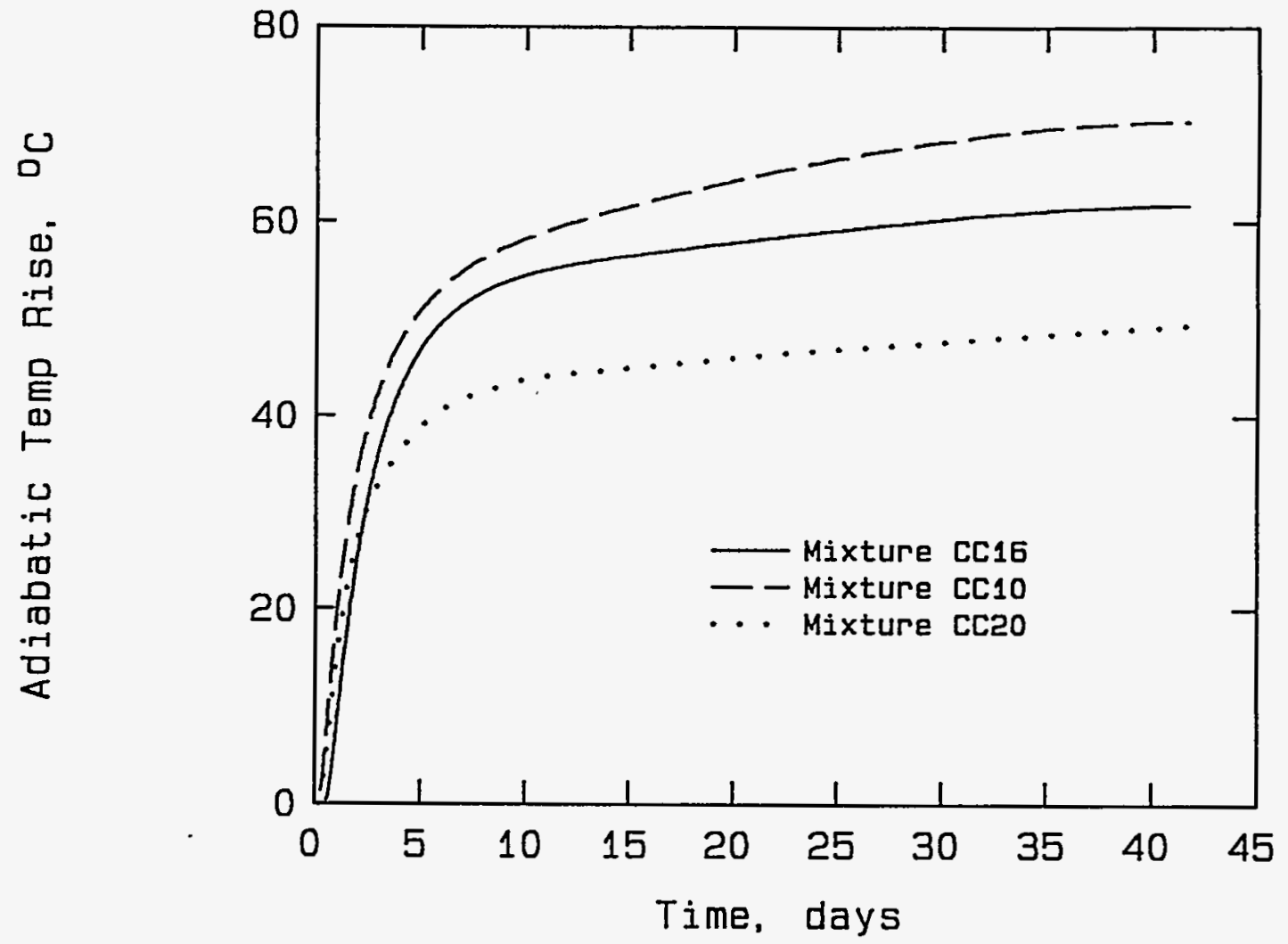

Figure 7. Calculated adiabatic temperature rise for mixtures $\mathrm{CC10}$, CC16, and CC2O as predicted by the semiadiabatic test 


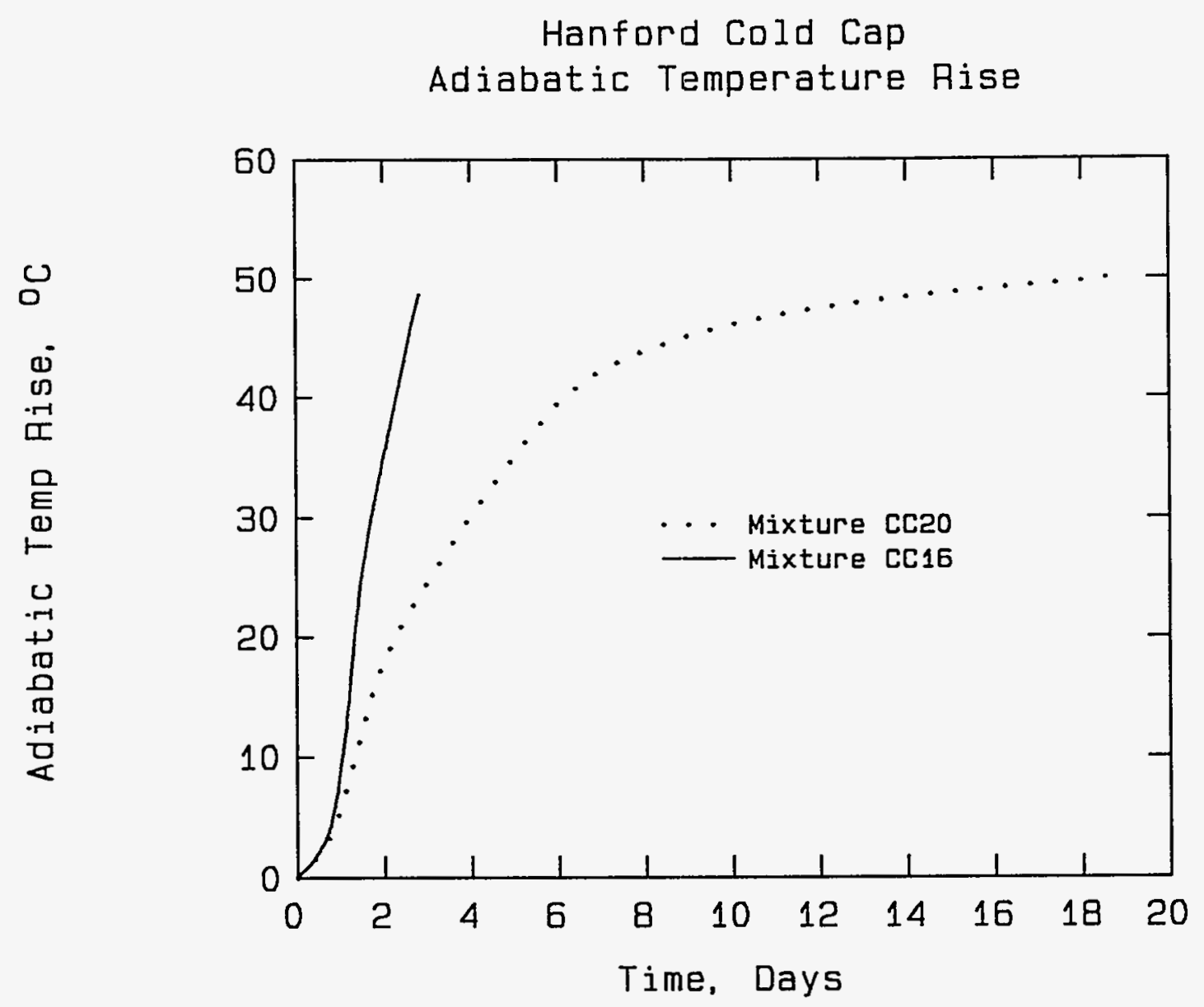

Figure 8. Adiabatic temperature rise for mixtures $\mathrm{CC} 16$ and $\mathrm{CC2} 2$ 


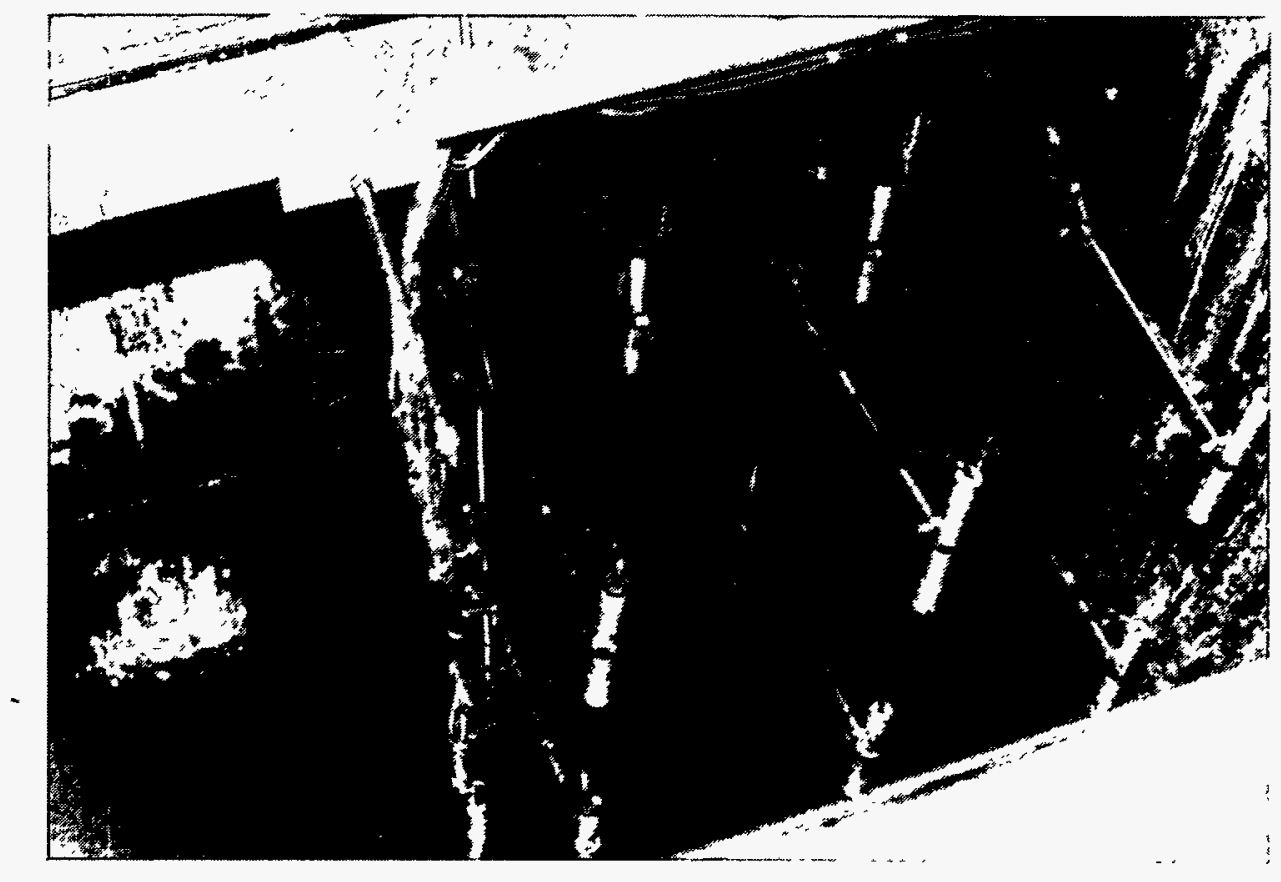

Figure 9. Photograph of inside of physical model immediately after placement of the first grout lift 


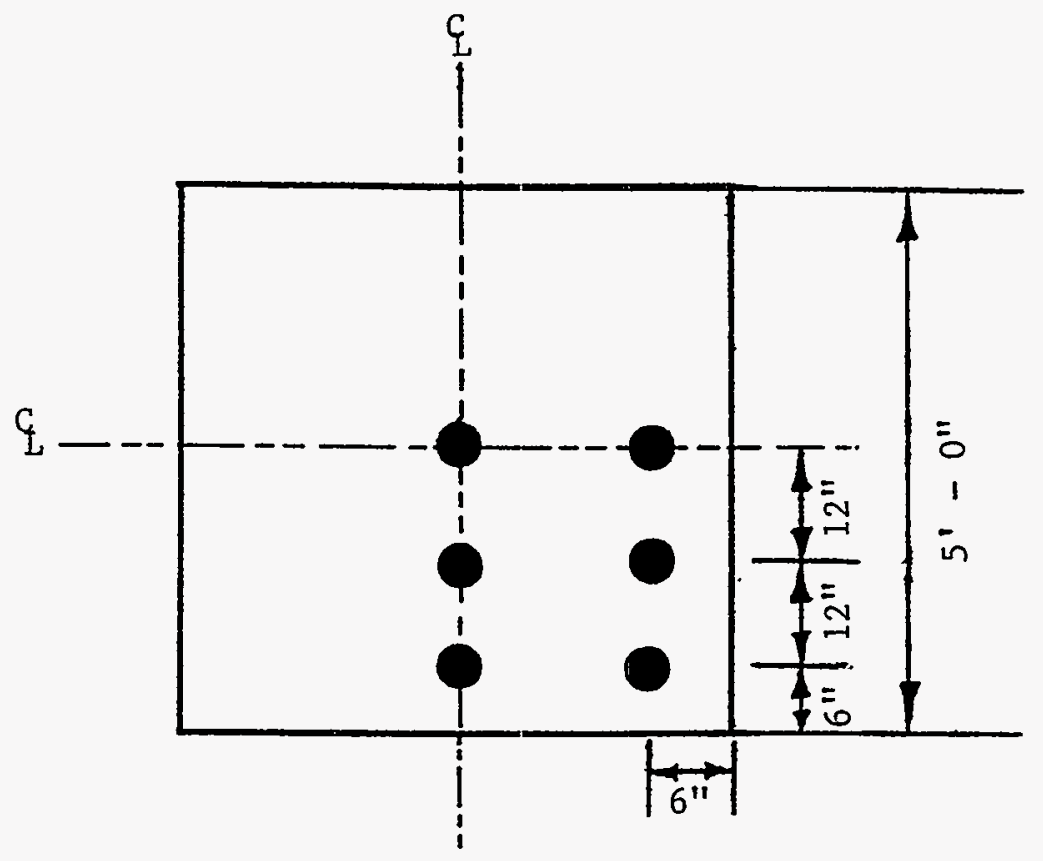

(a) Plan view

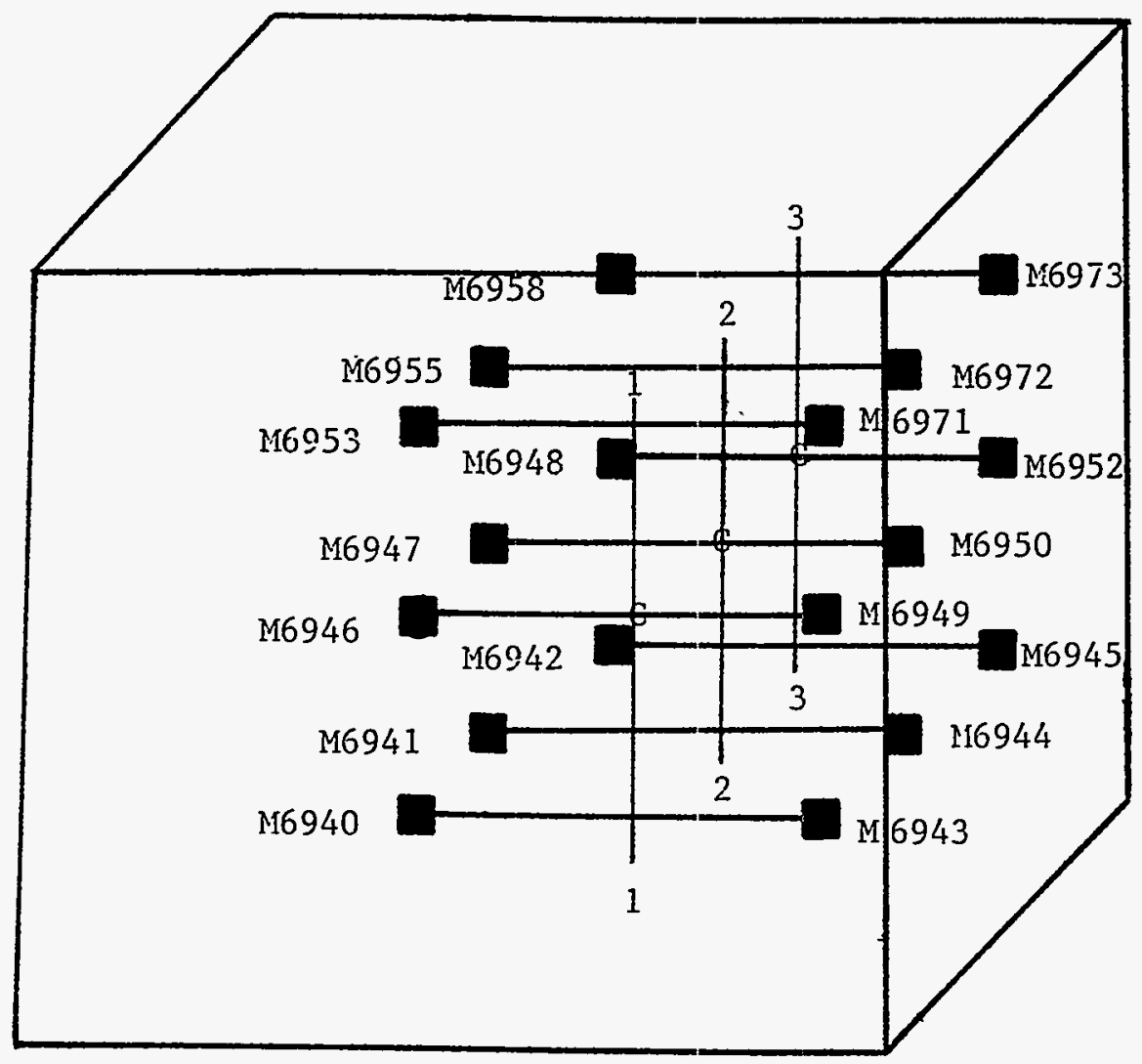

(b) Three dimensionàl

Figure 10. Drawing of physical model showing location of strain meters 
Carlson gage "TREE" assembly No. 1, Carlson gage layout
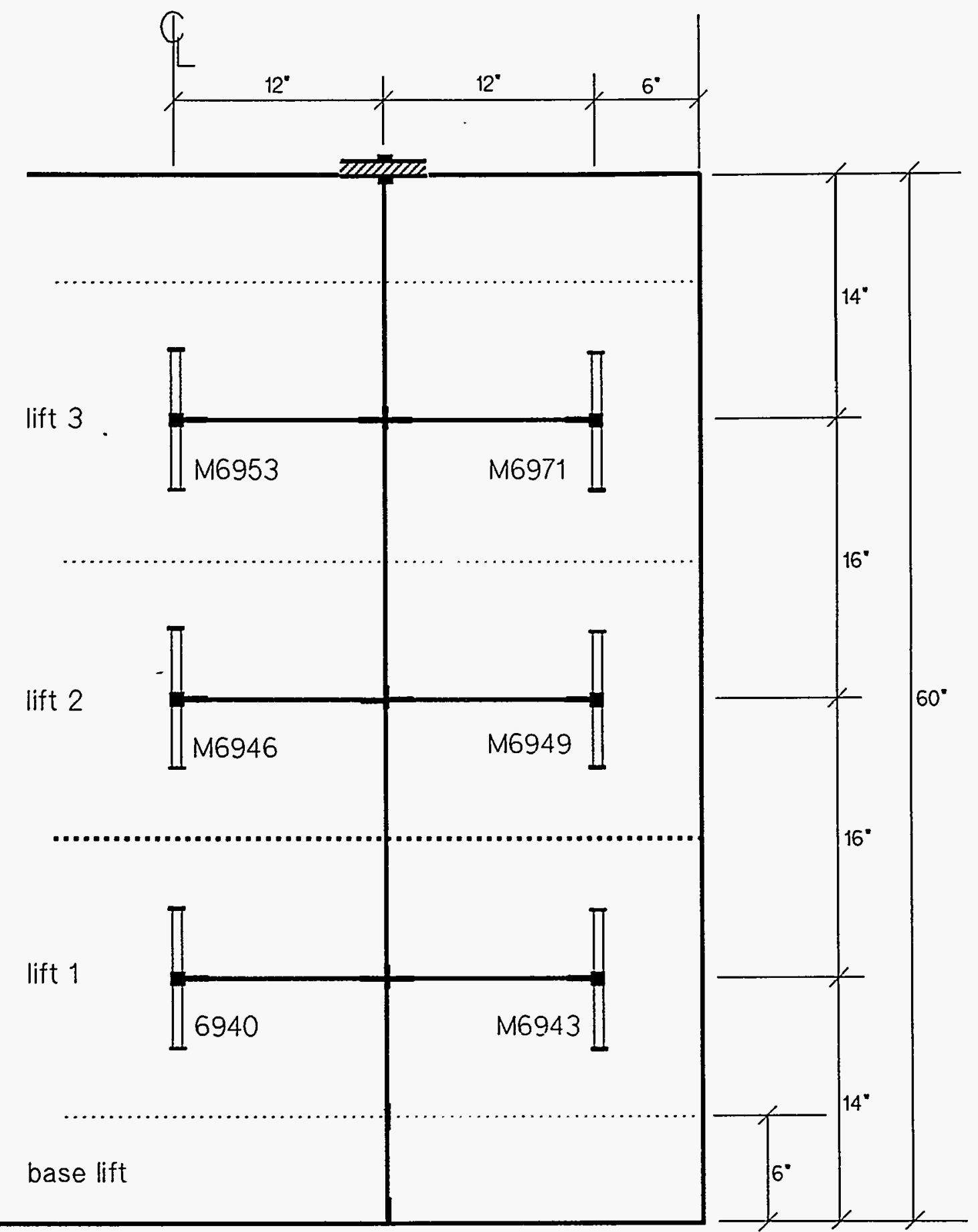

lift 3 .

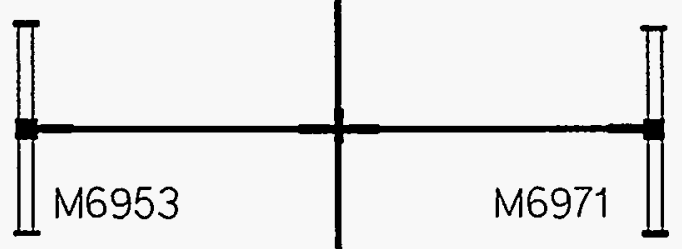

lift 2

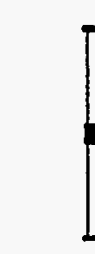

M6953

M6971 I
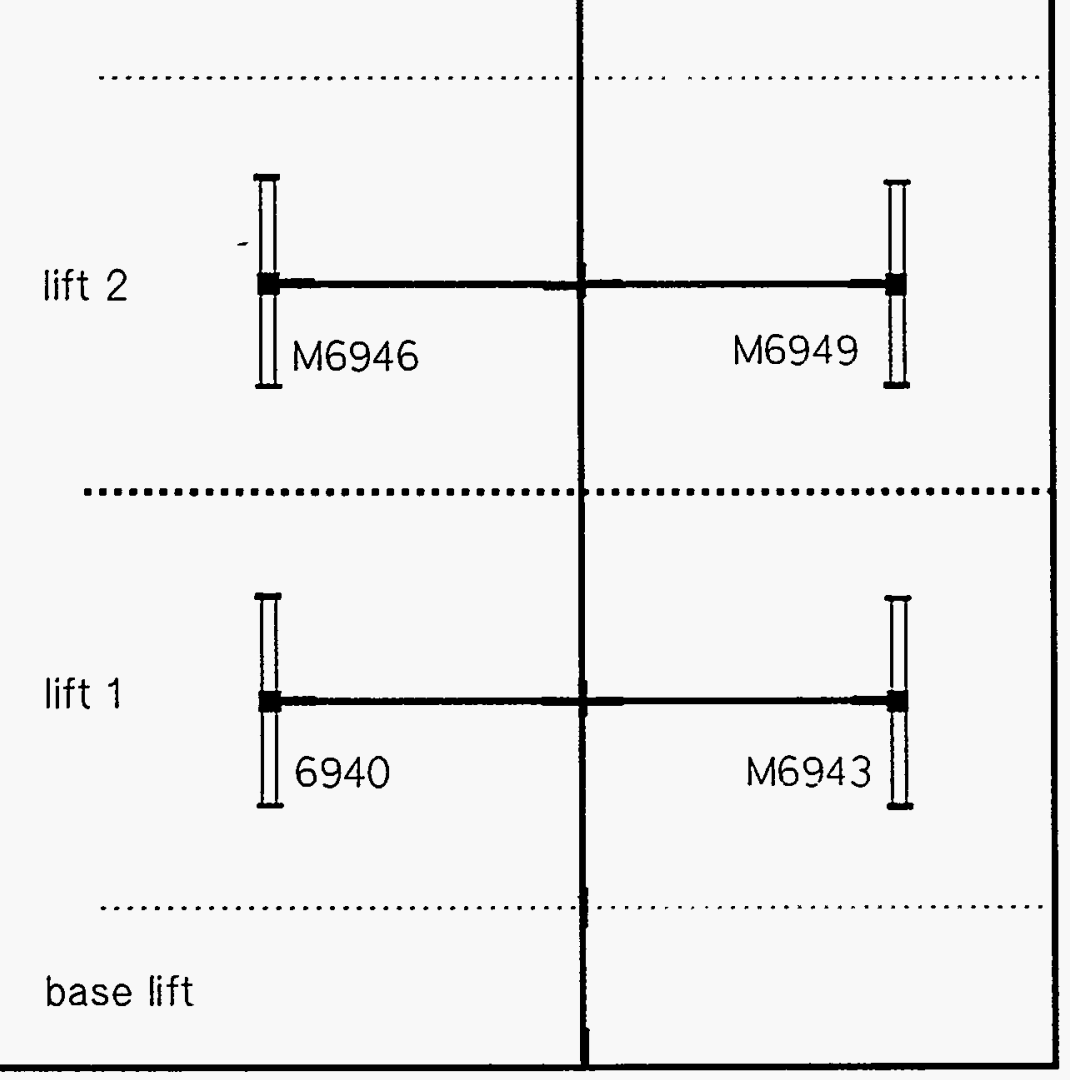

\section{ELEVATION VIEW}

Figure 11. Layout drawing showing location of strain meters 
Carlson gage "TREE" assembly No. 2, Carlson gage layout

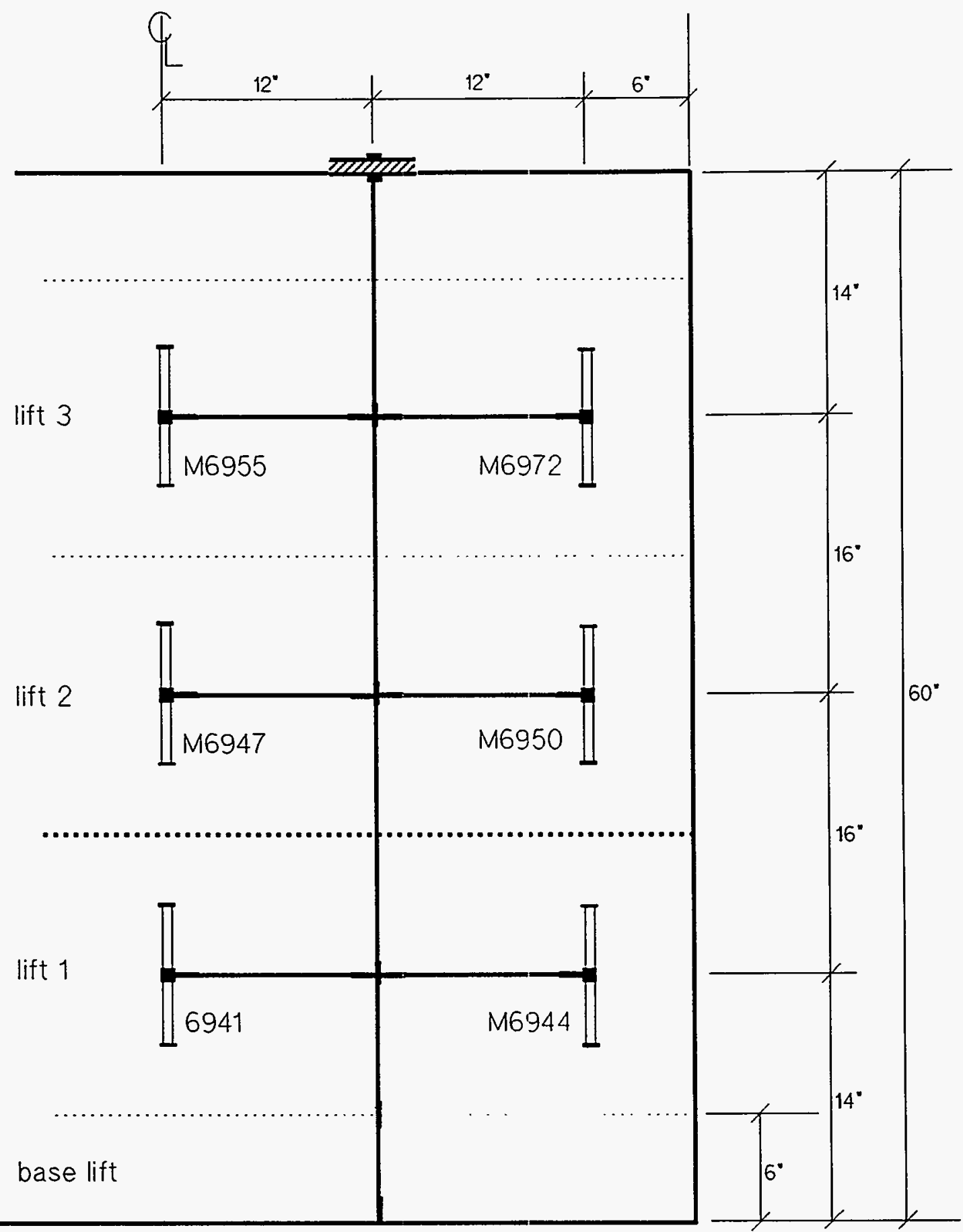

ELEVATION VIEW

Figure 12. Layout drawing showing location of strain meters 
Carlson gage "TREE" assembly No. 3, Carlson gage layout

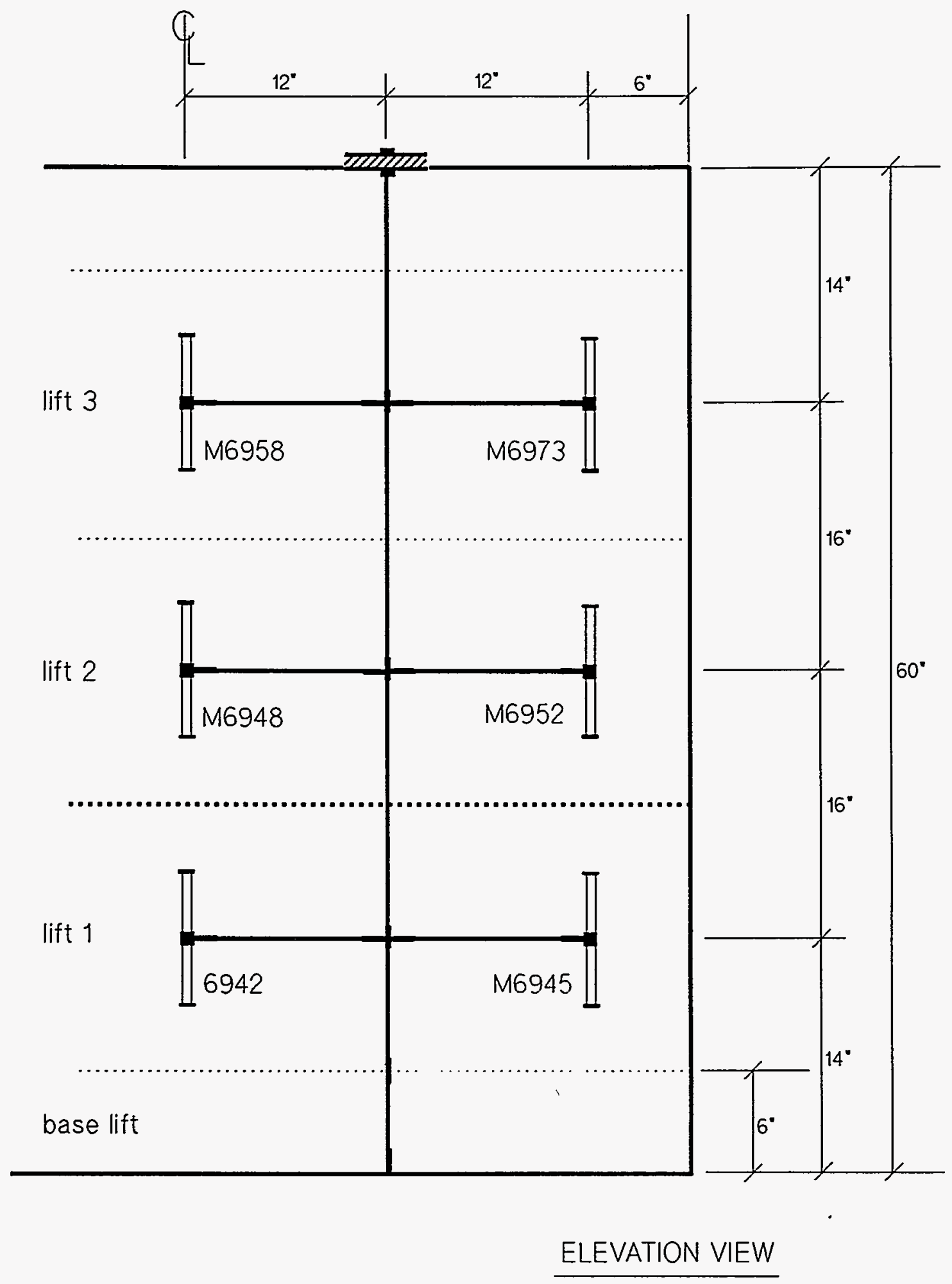

Figure 13. Layout drawing showing location of strain meters 
Carlson gage "TREE" assembly No. 3, Thermocouple layout

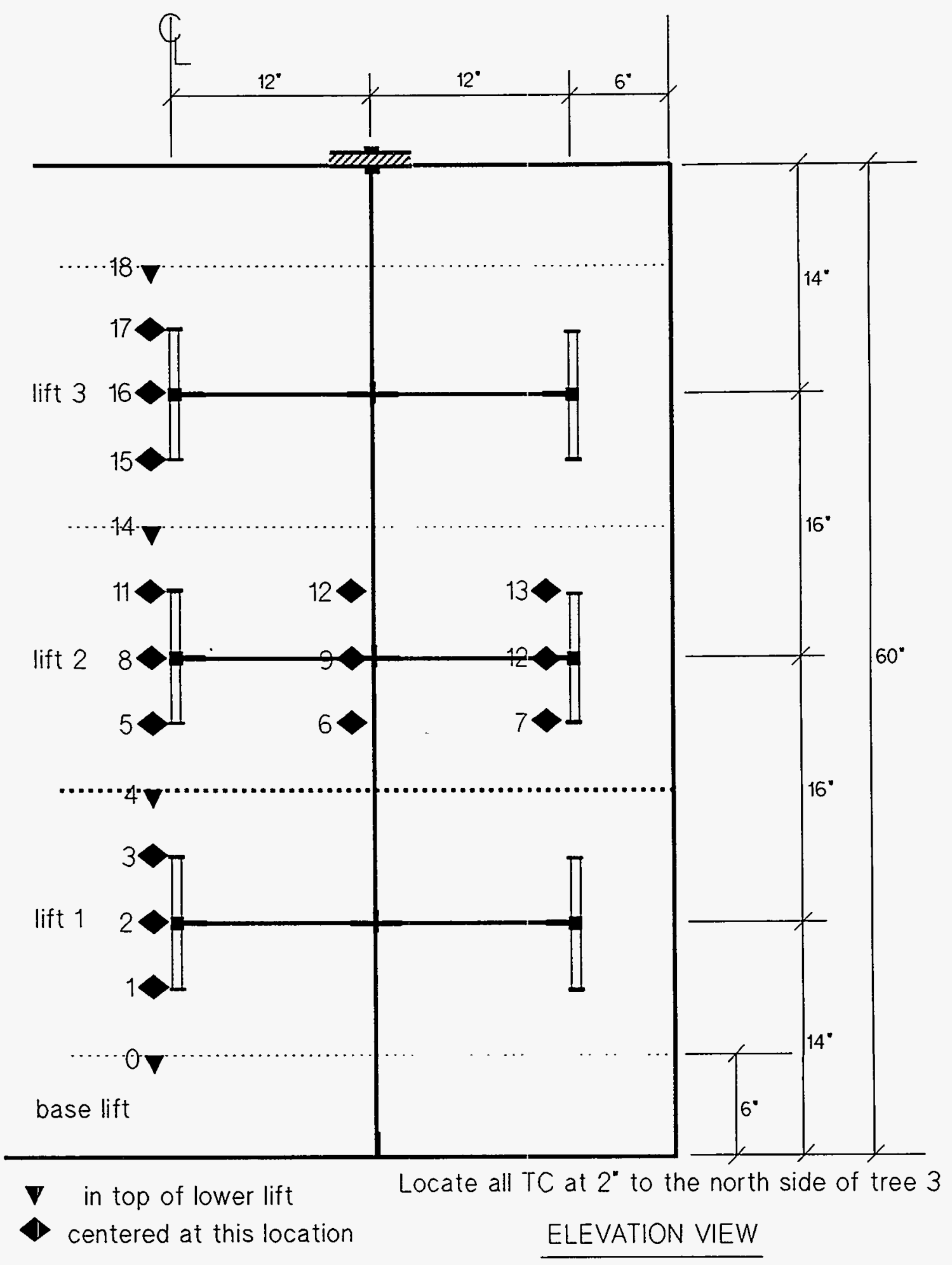

Figure 14. Layout drawing showing location of thermocouples 


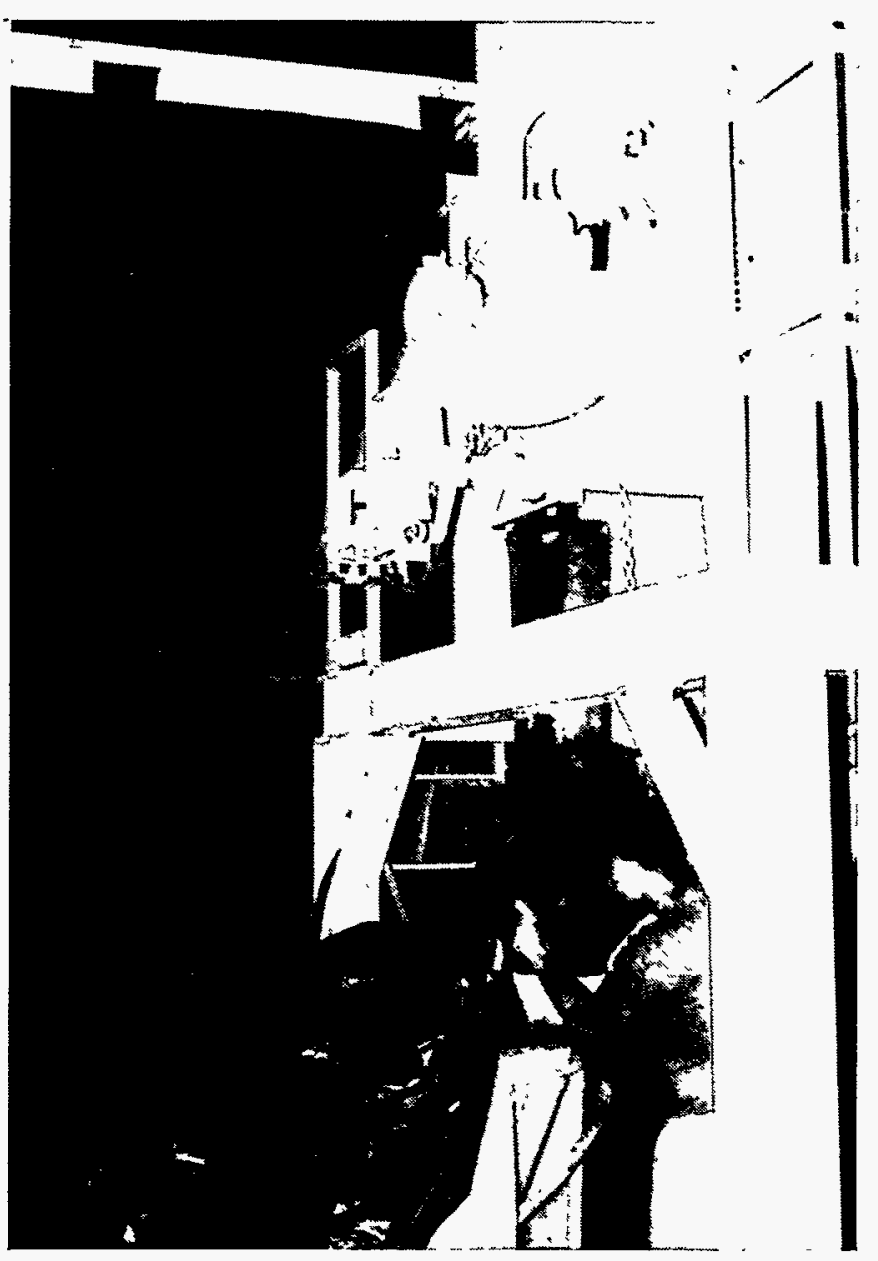

Figure 15. Photograph of discharging grout from the batch plant and pug mill 


\section{PSW Vault Cold Cap Compressive Strength Test Results}

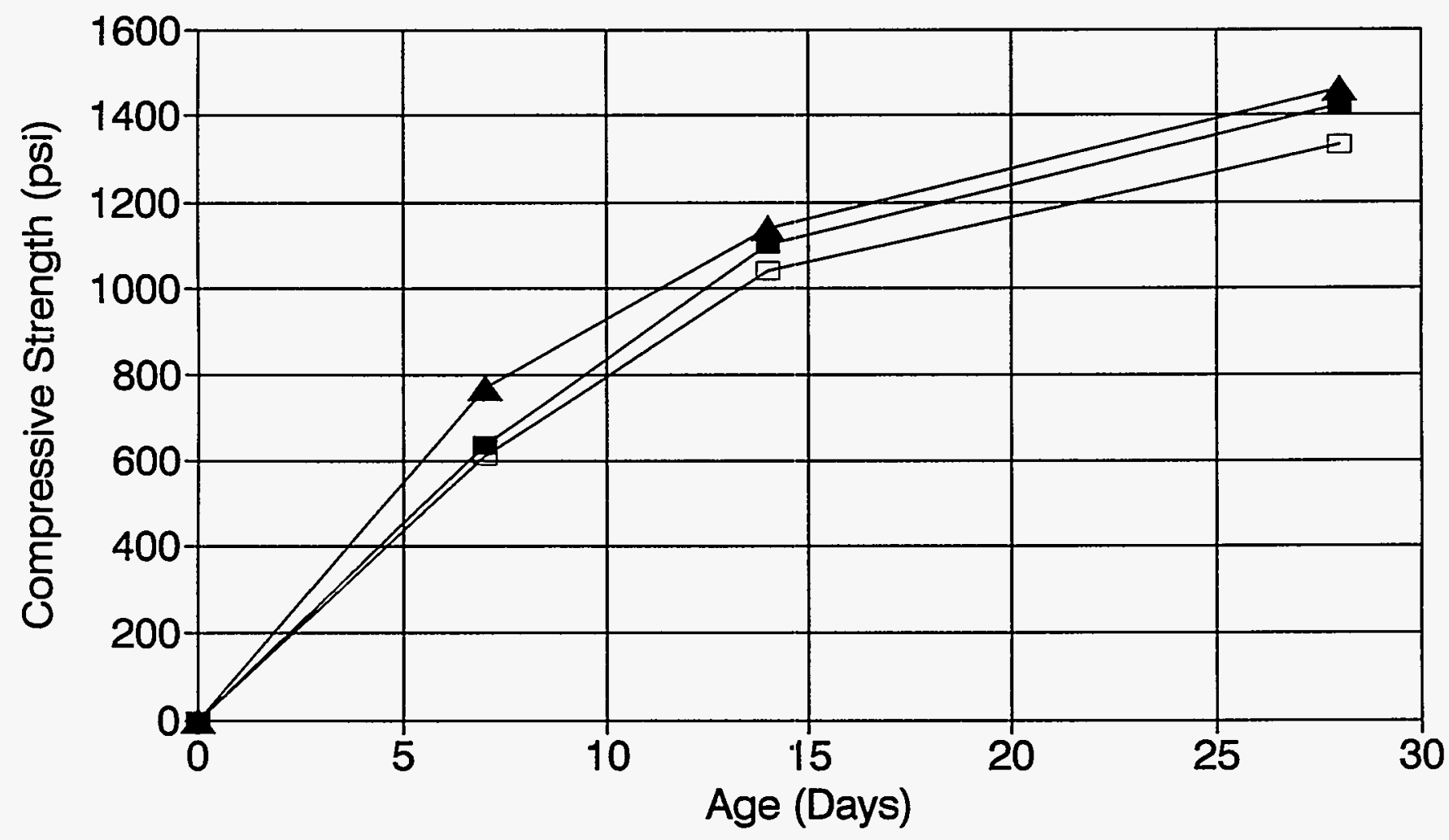

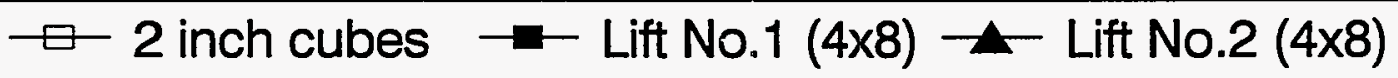

Figure 16. Compressive strength from lifts in physical model 
HANFORD COLD CAP PHYSICAL MODEL CENTERLINE STRAIN MEASUREMENTS

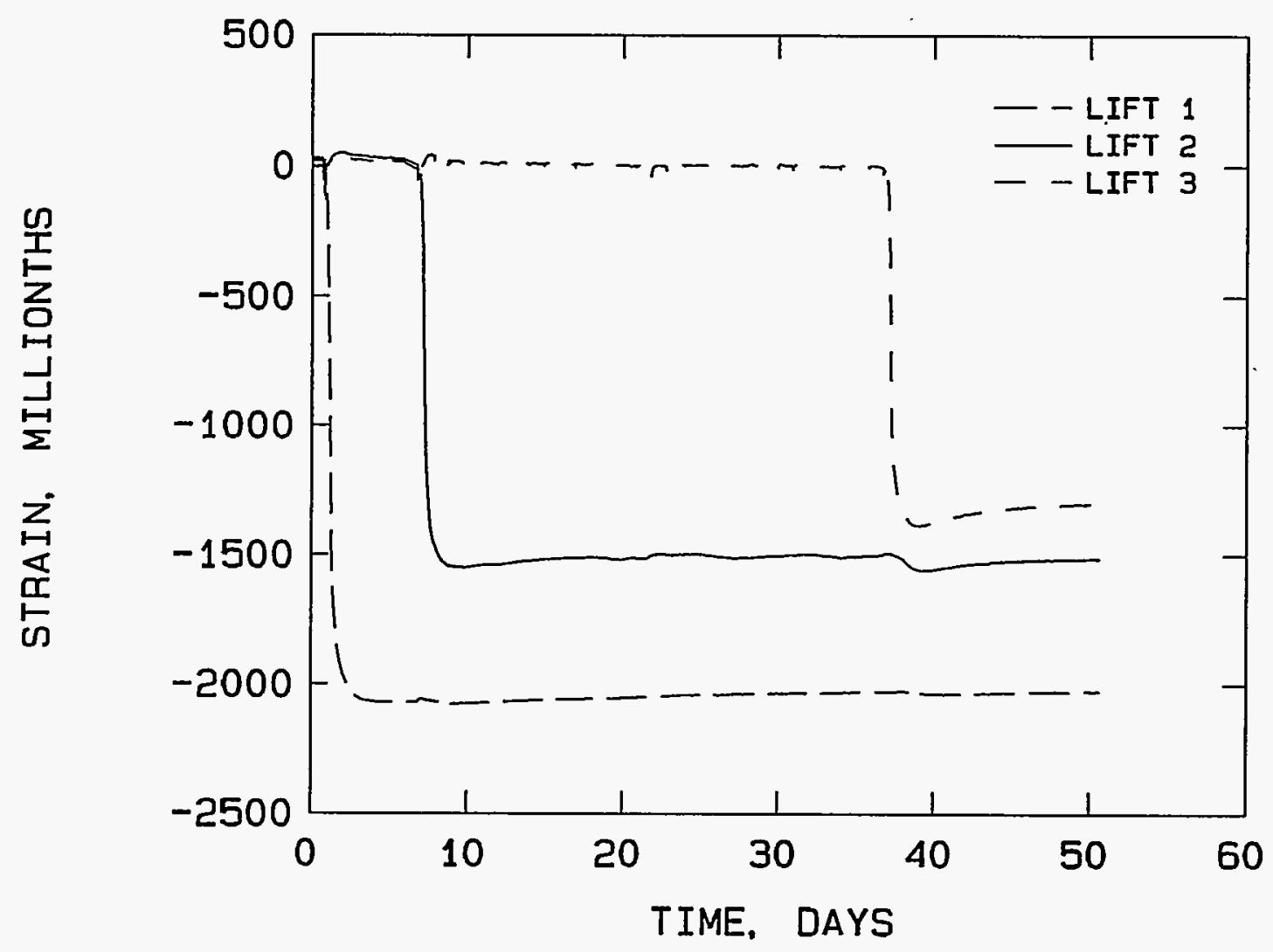

Figure 17. Centerline strain measurements plotted vs time 


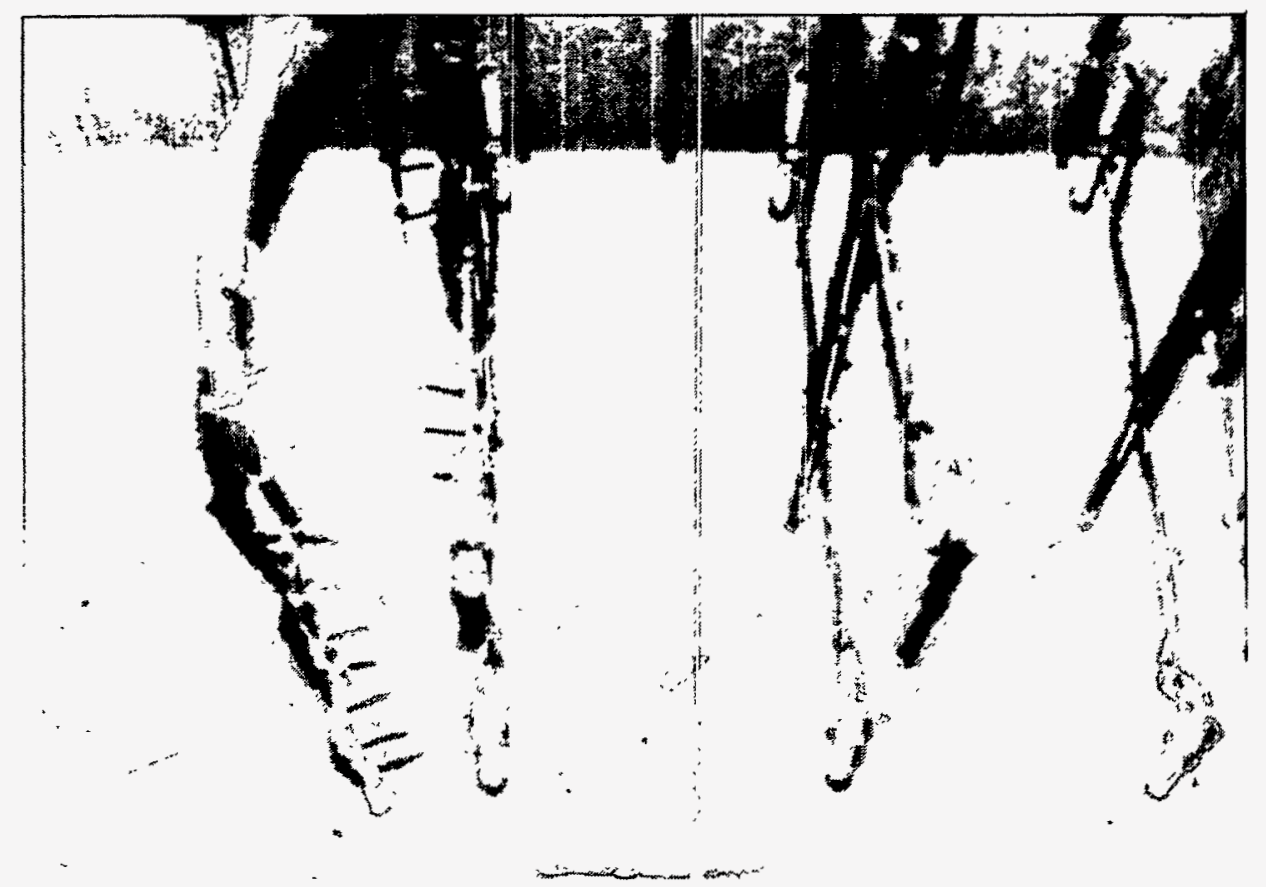

Figure 18. Photograph of the surface of lift 1 at 6 days of age, showing cracks 


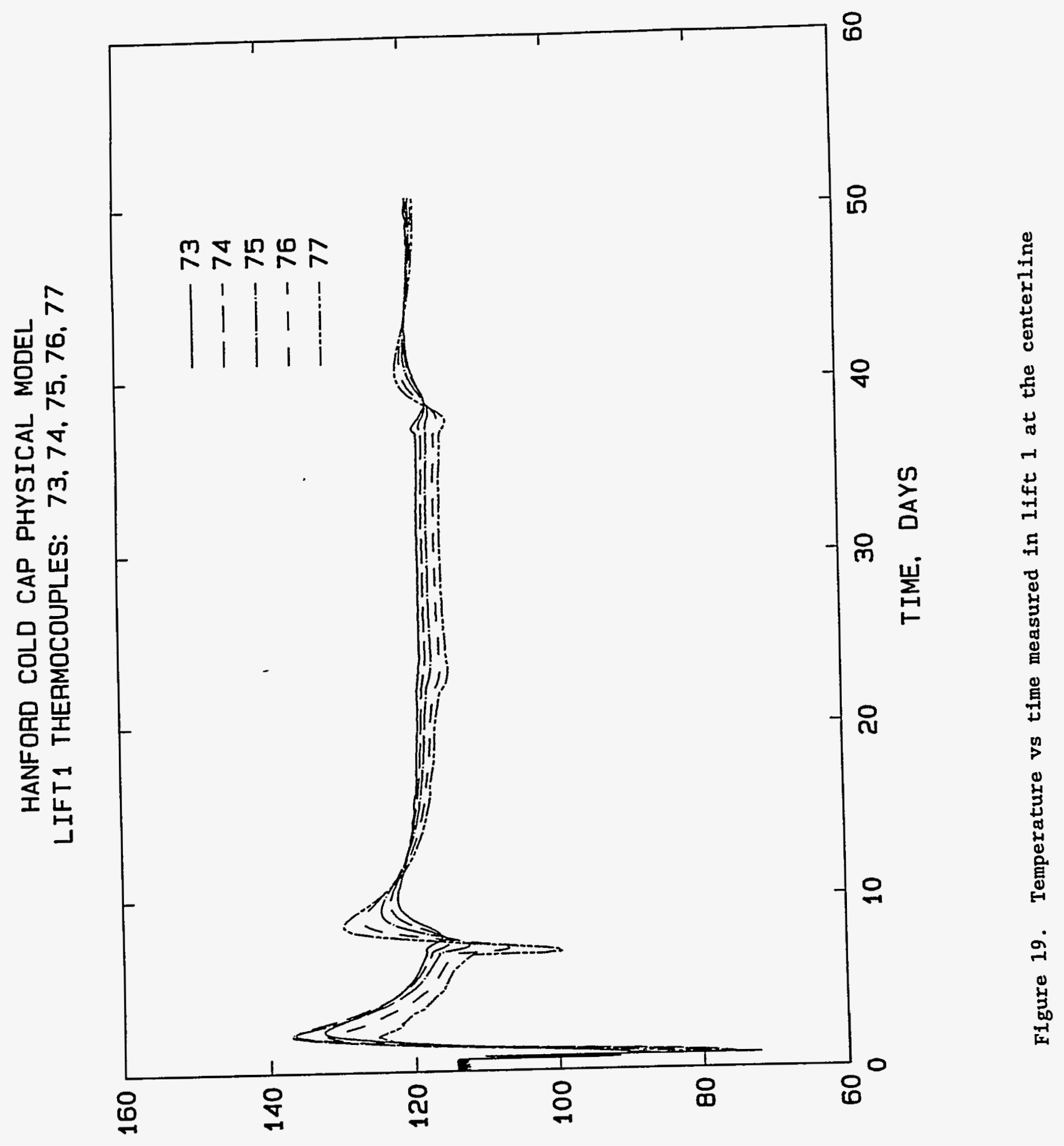

to " $\exists \forall n \perp \forall \forall \exists d W \exists \perp$ 
HANFORD COLD CAP PHYSICAL MODEL

LIFT2 THERMOCOUPLES: $77,78,81,84,87$

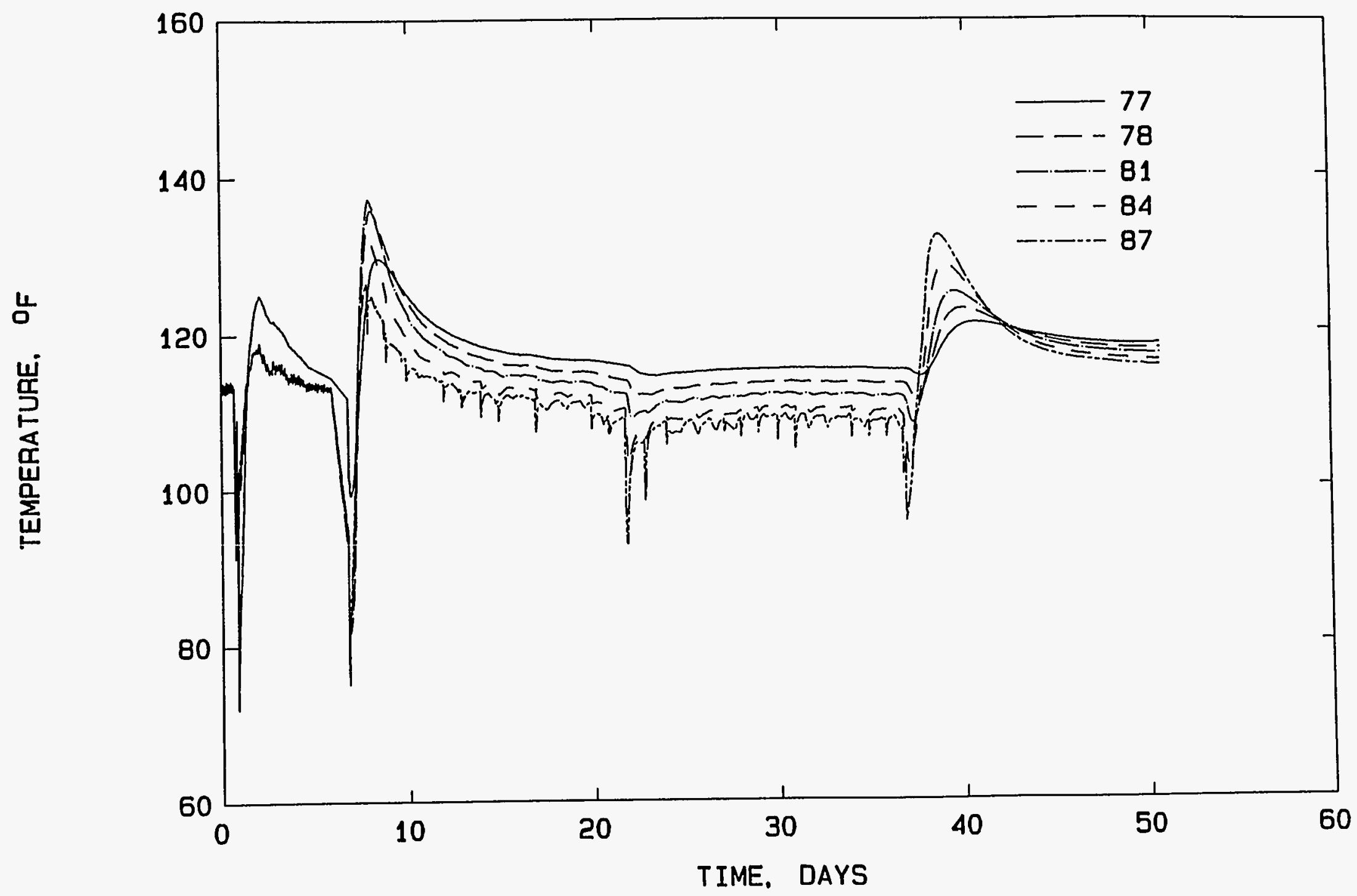

Figure 20. Temperature vs time measured in lift 2 at the centerline 


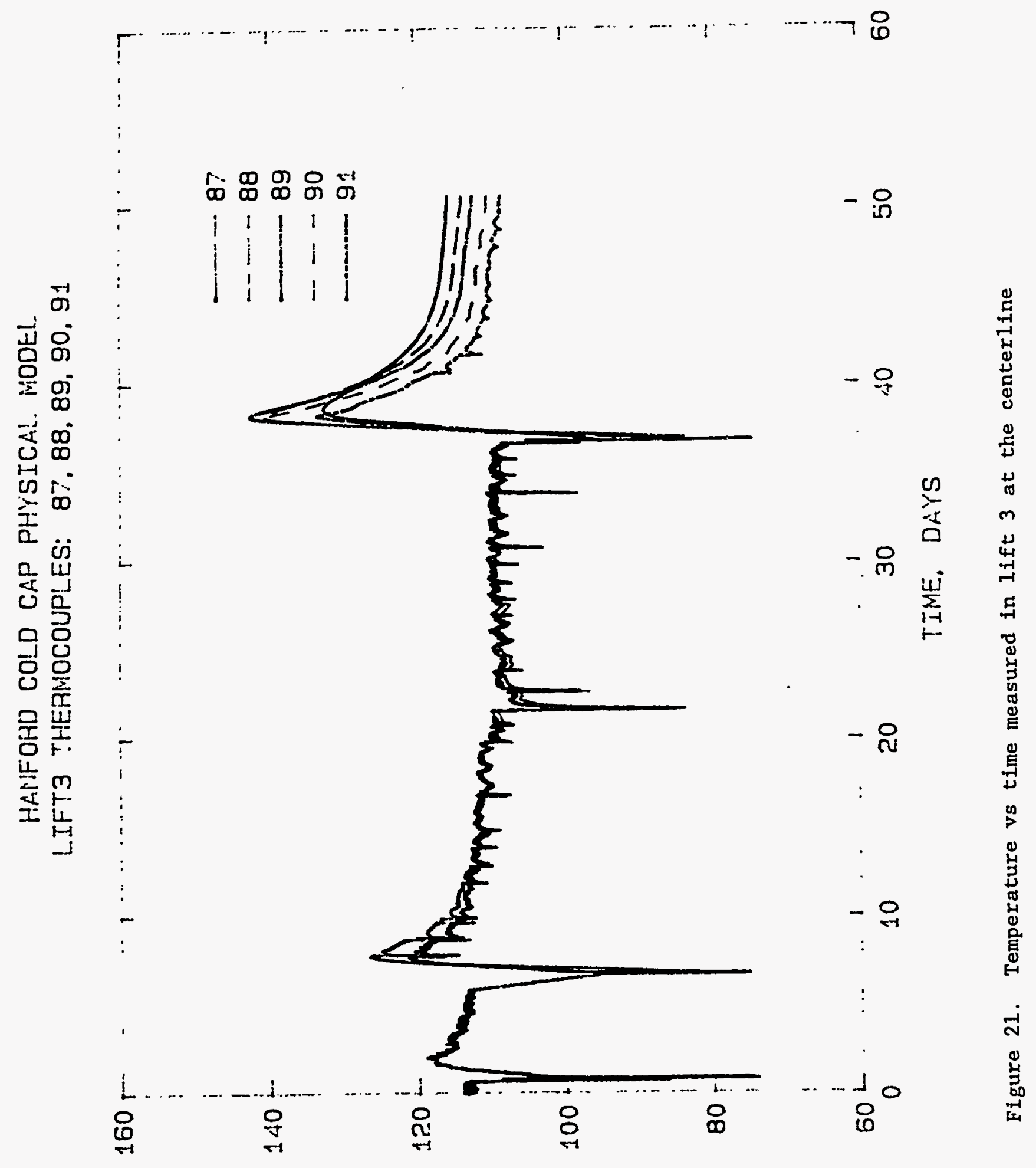

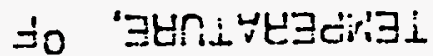


HANFORD COLD CAP PHYSICAL MODEL

LIFT2 THERMOCOUPLES: $79,82,85$

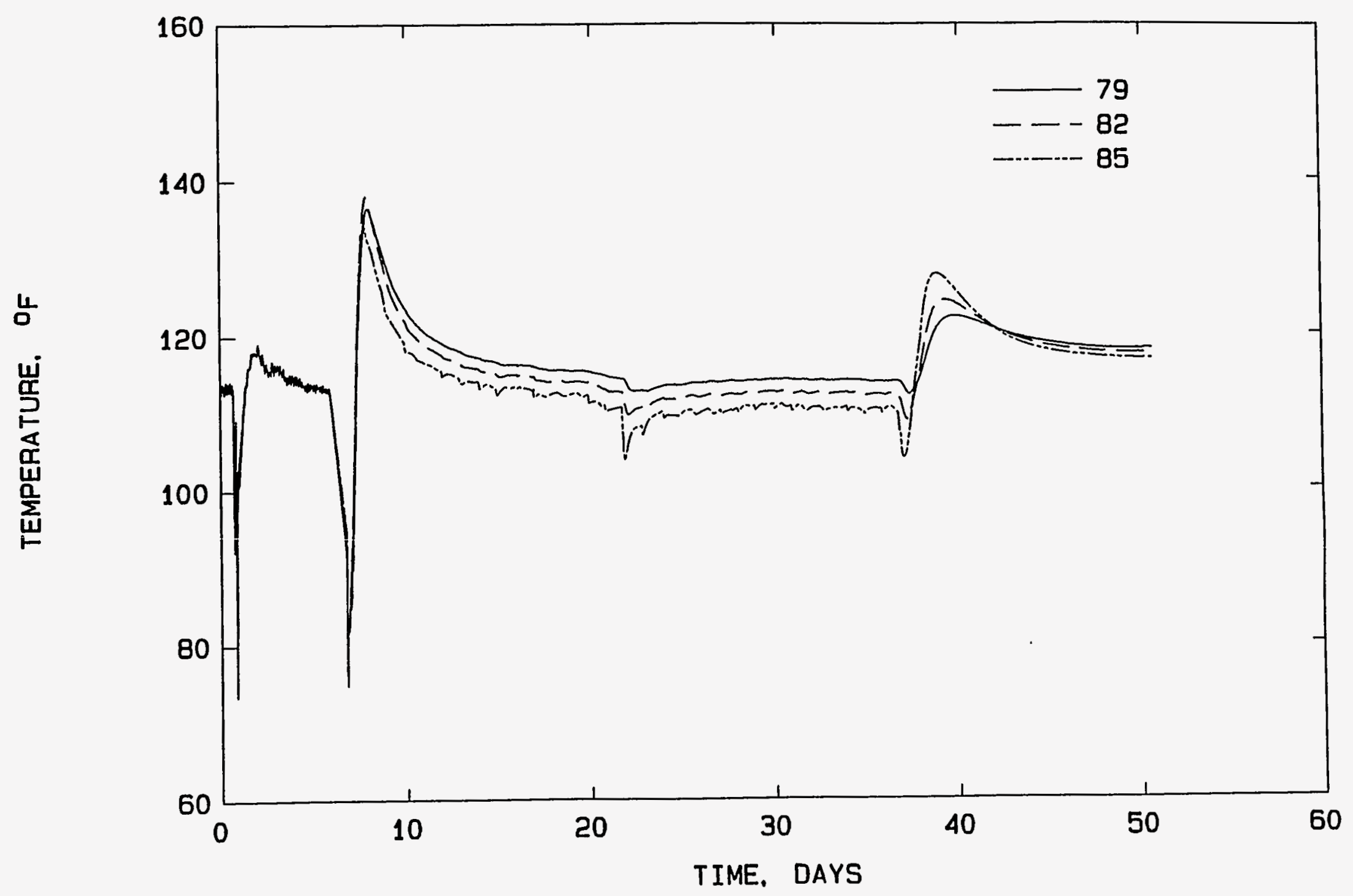

Figure 22. Temperature vs time measured in 1 ift 2 at the 18 inches from outside wall 


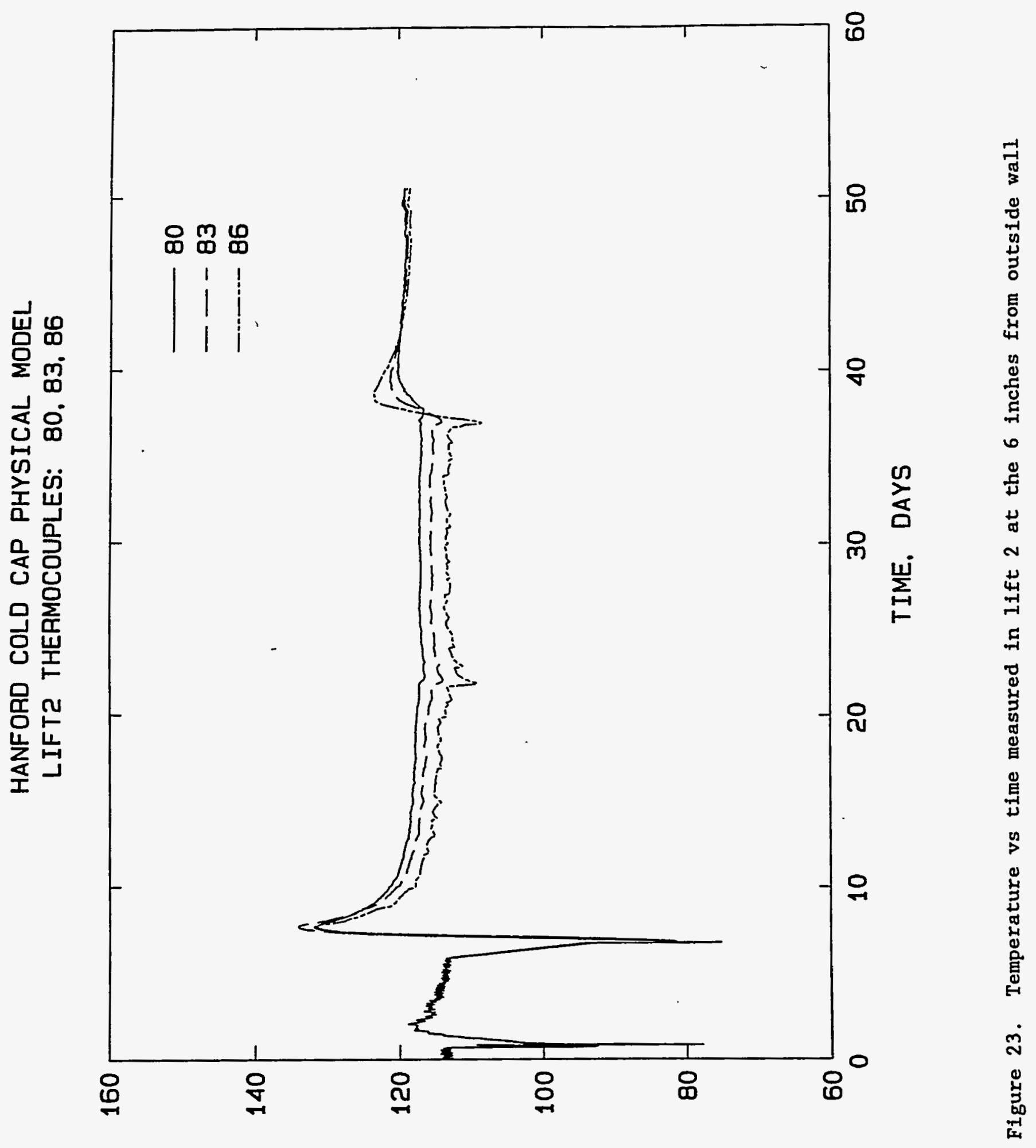

to ' $\exists \forall \cap \perp \forall \forall \exists d W \exists \perp$ 
HANFORD COLD CAP PHYSICAL MODEL

LIFT1 CARLSON GAGES: M6940; M6941; M6942

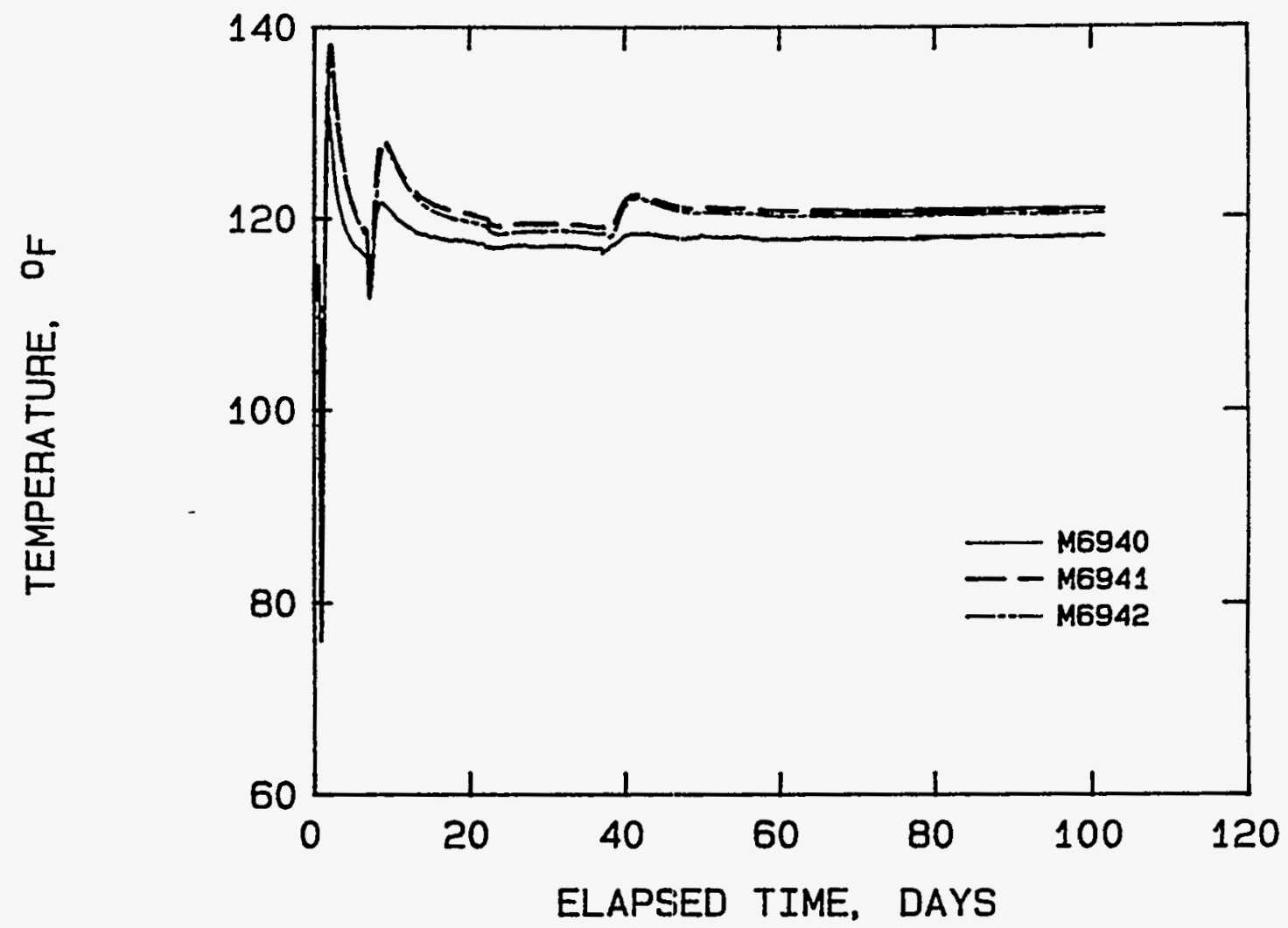

Figure 24. Plot of temperature vs time recorded by strain meters during grouting of lifts in the physical model 
HANFORD COLD CAP PHYSICAL MODEL LIFT1 CARLSON GAGES: M6940; M6941; M6942

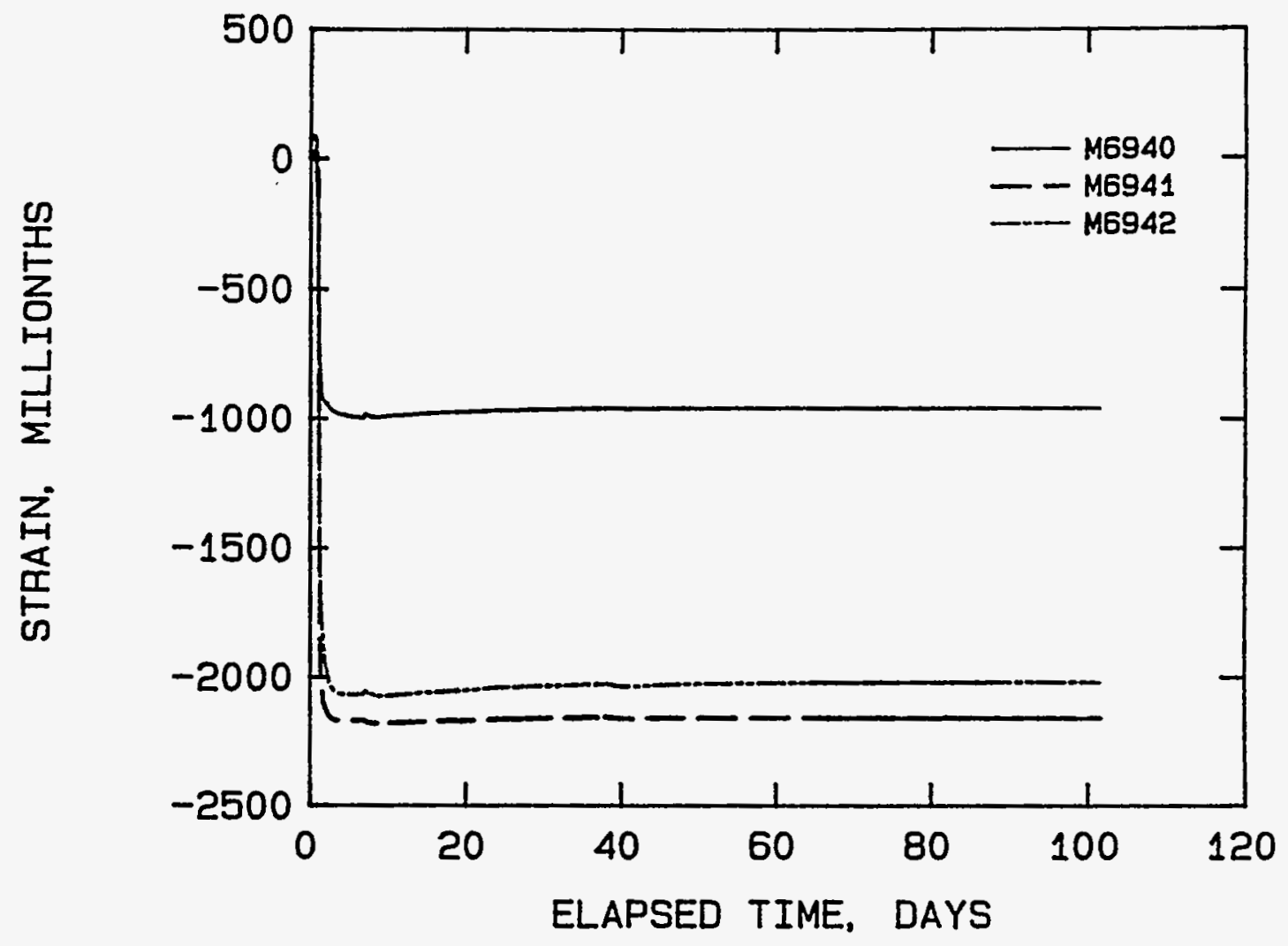

Figure 25. Plot of strain vs time recorded by strain meters during grouting of lifts in the physical model 


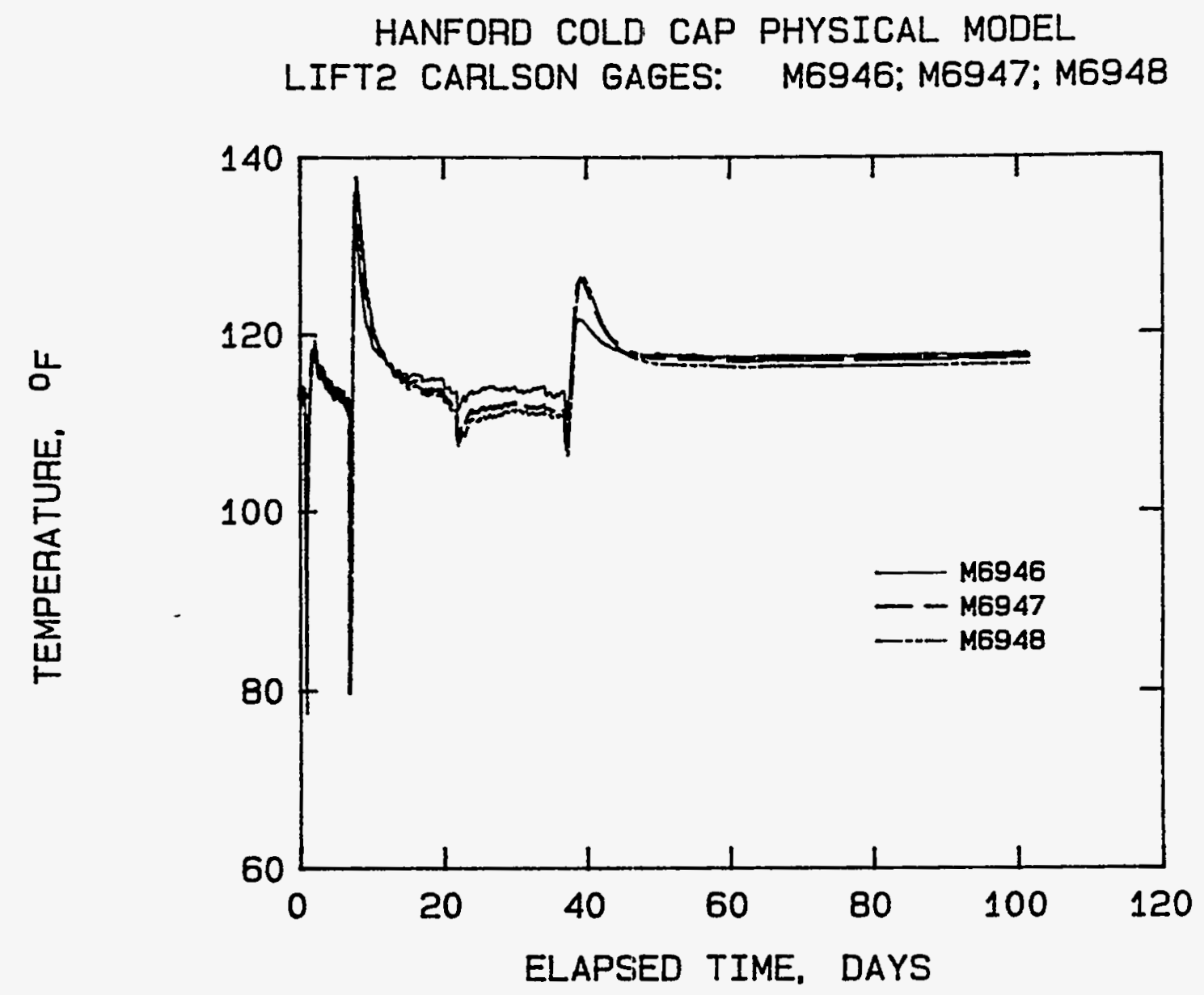

Figure 26. Plot of temperature vs time recorded by strain meters during grouting of lifts in the physical model 
HANFORD COLD CAP PHYSICAL MODEL

LIFT2 CARLSON GAGES: M6946; M6947; M6948

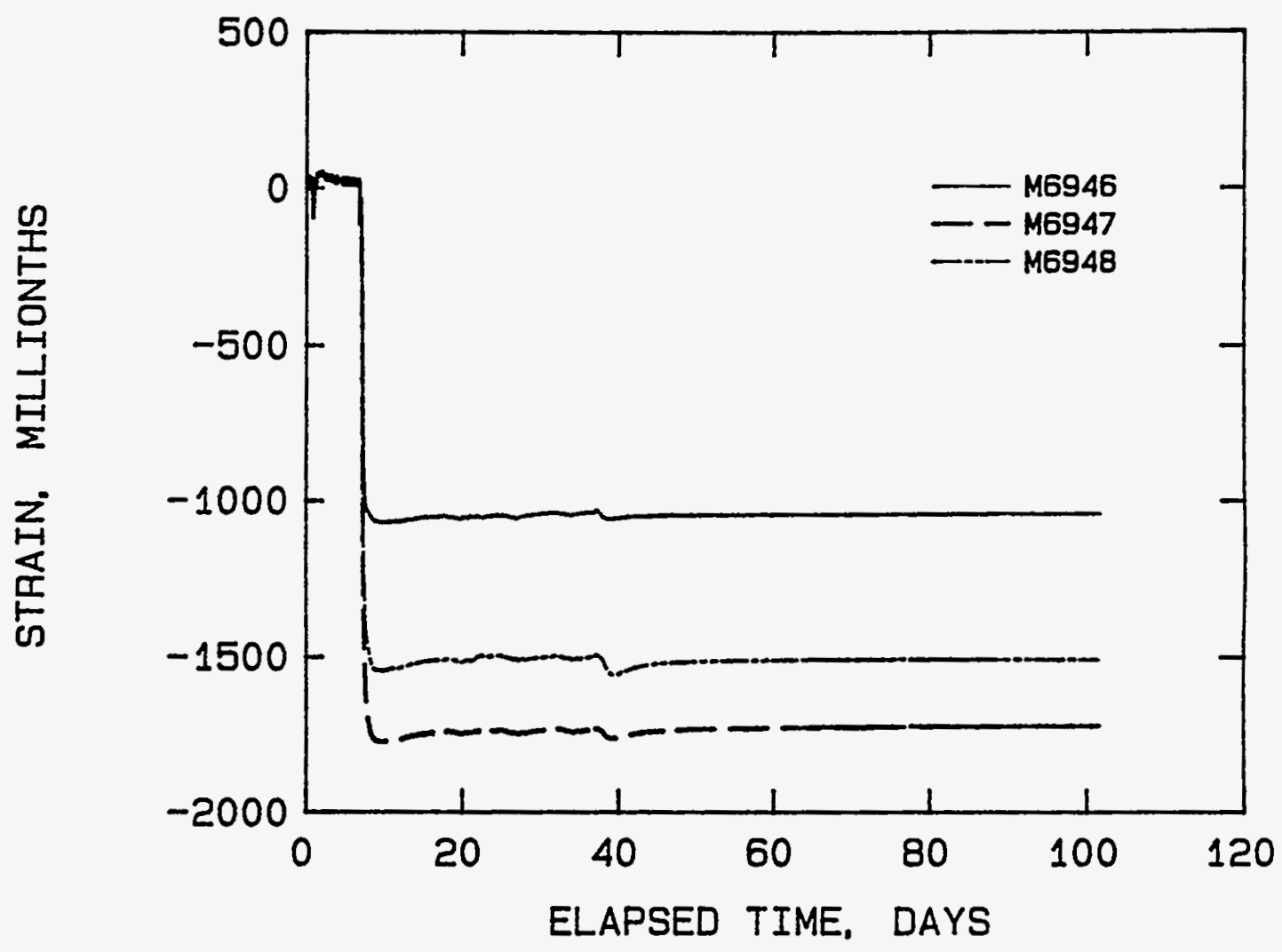

Figure 27. Plot of strain vs time recorded by strain meters during grouting of lifts in the physical model 
HANFORD COLD CAP PHYSICAL MODEL

LIFT3 CARLSON GAGES: M6953; M6955; M6958

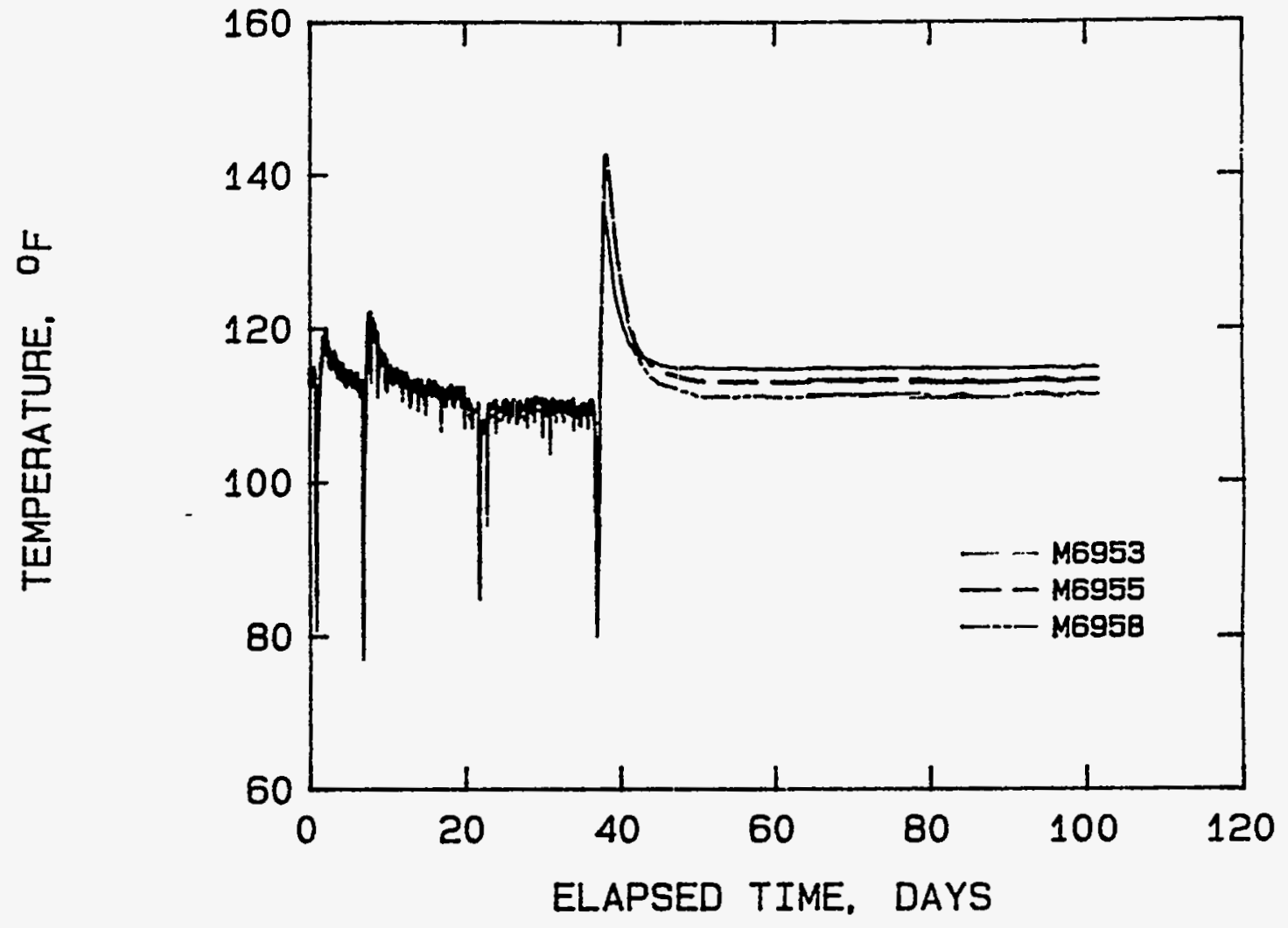

Figure 28. Plot of temperature vs time recorded by strain meters during grouting of lifts in the physical model 
HANFORD COLD CAP PHYSICAL MODEL LIFT3 CARLSON GAGES: M6953; M6955; M6958

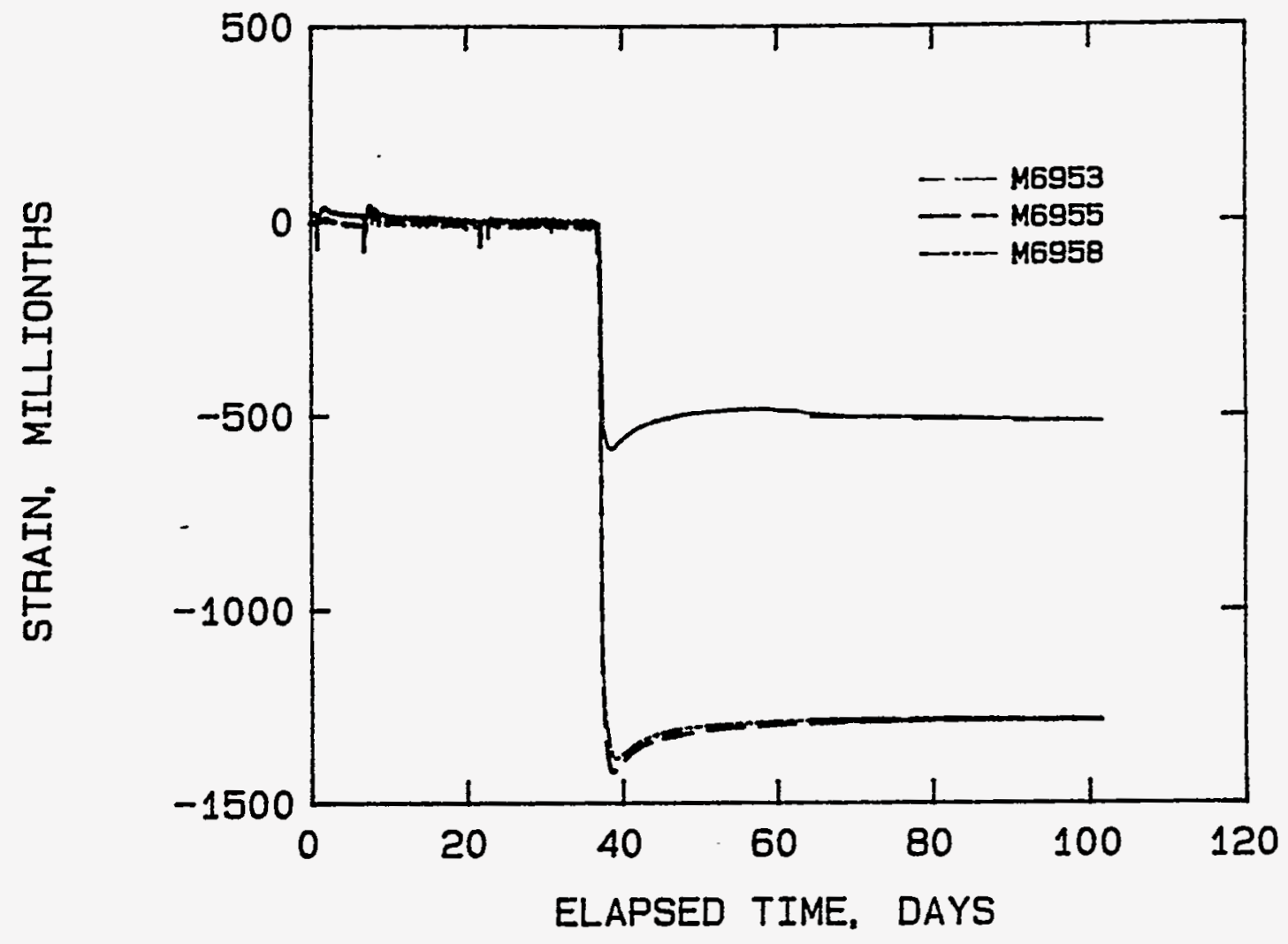

Figure 29. Plot of strain vs time recorded by strain meters during grouting of lifts in the physical model 


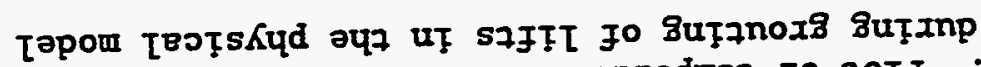

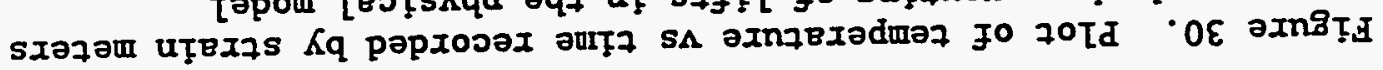

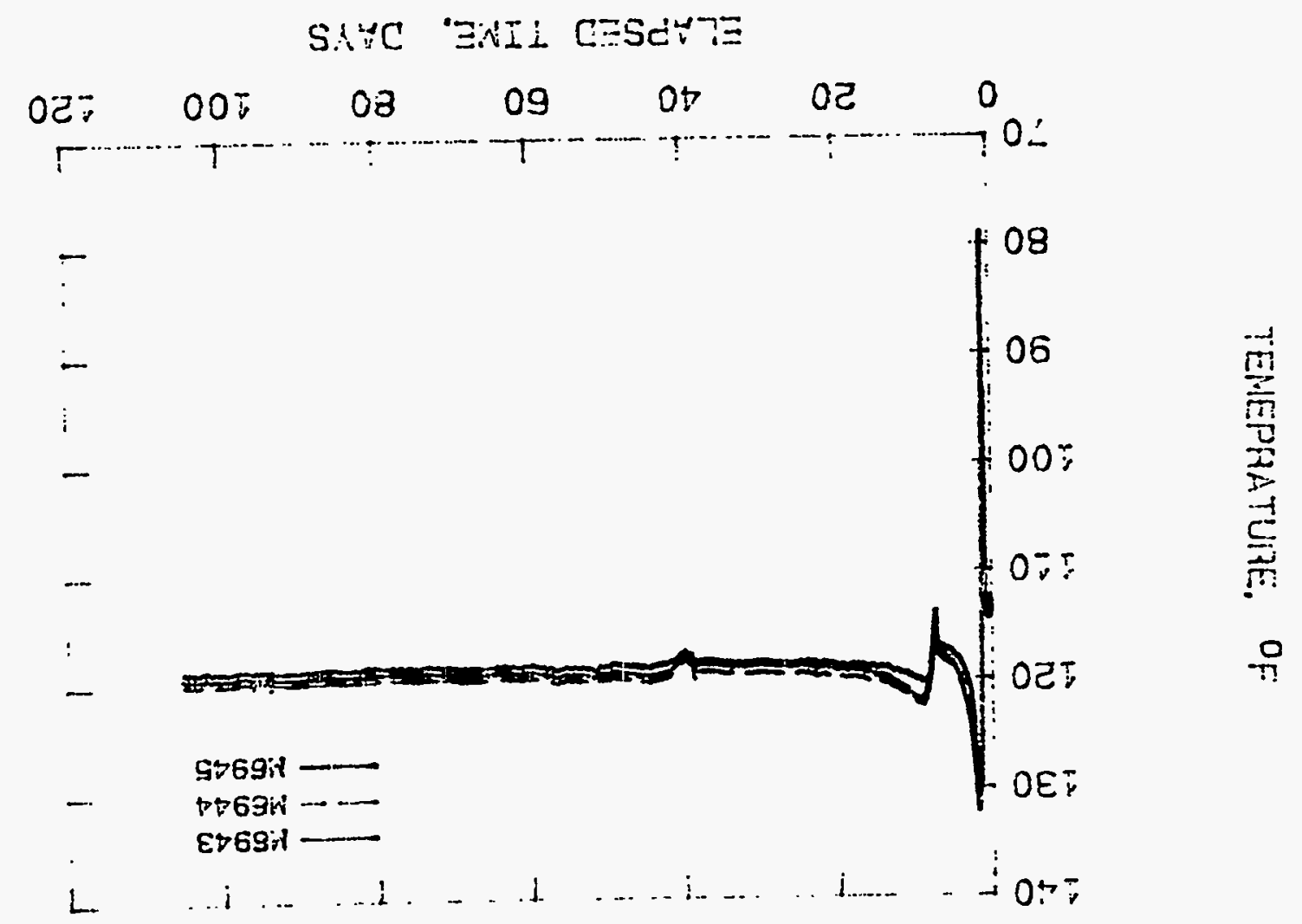

Gt69w:

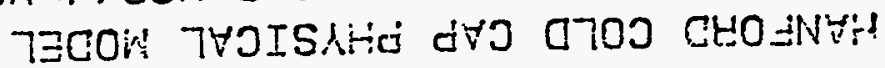


HANFORD CO!D CAP PHYSICAL MODEL

LiFT1 CARL.SOMi GAGES: M6943; M6944; M6945

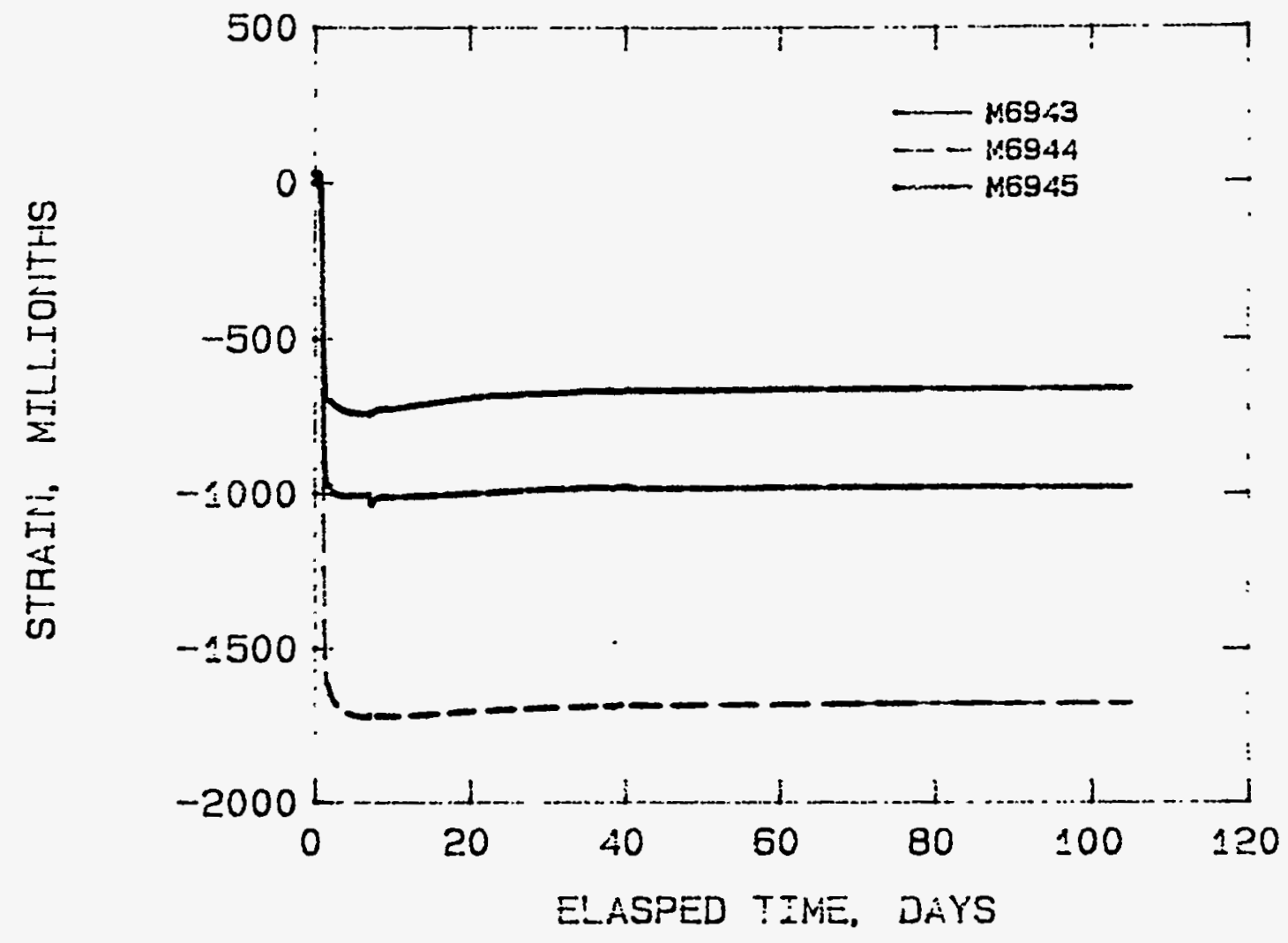

Figure 31. Plot of strain vs time recorded by strain meters during grouting of lifts in the physical model 


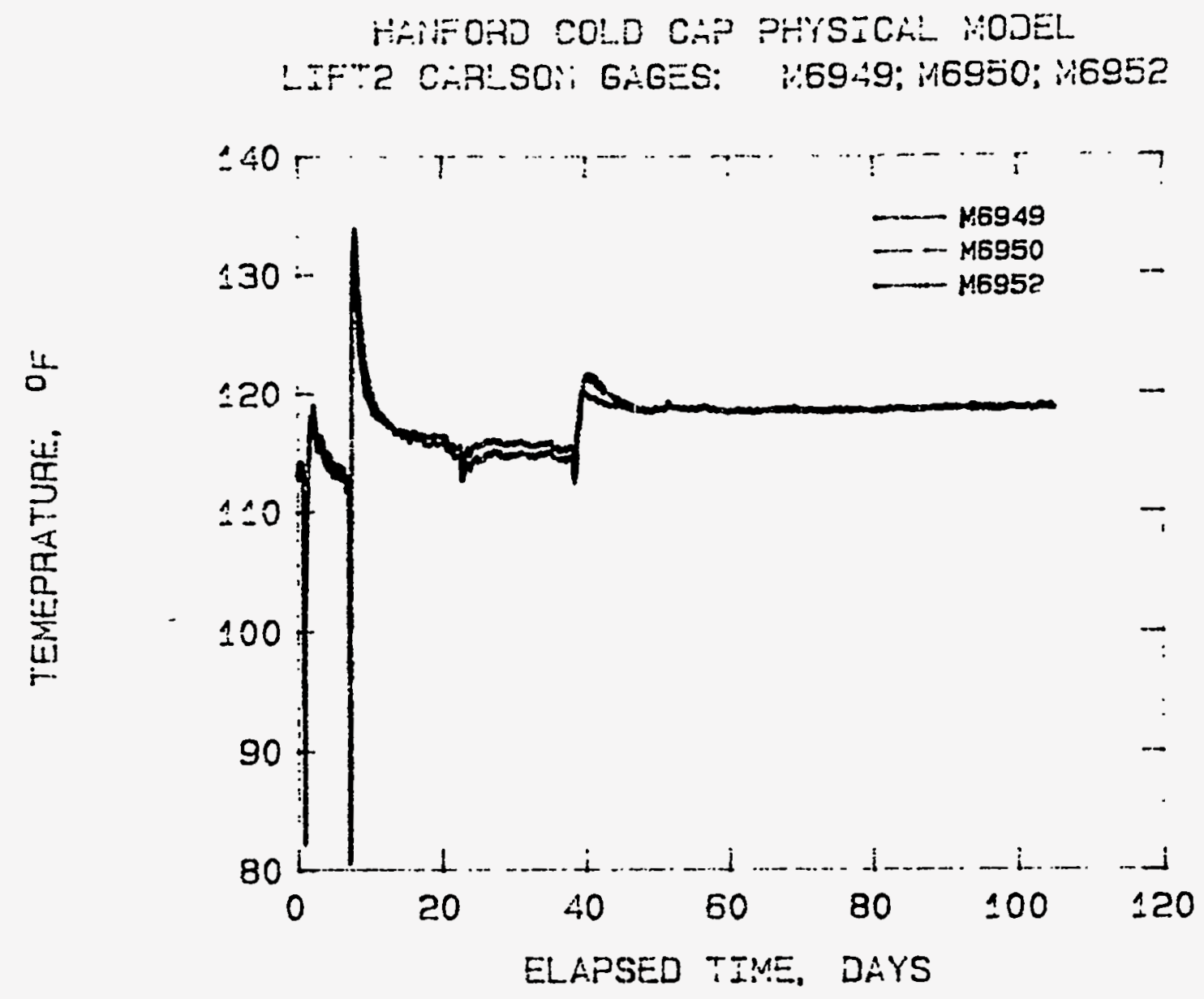

Figure 32. Plot of temperature vs tilme recorded by strain meters during grouting of lifts in the physical model 
HANFORD COLD CAP PHYSICAL MODEL

LIFT2 CAFILSON GAGES: M6949: M6950: M6952

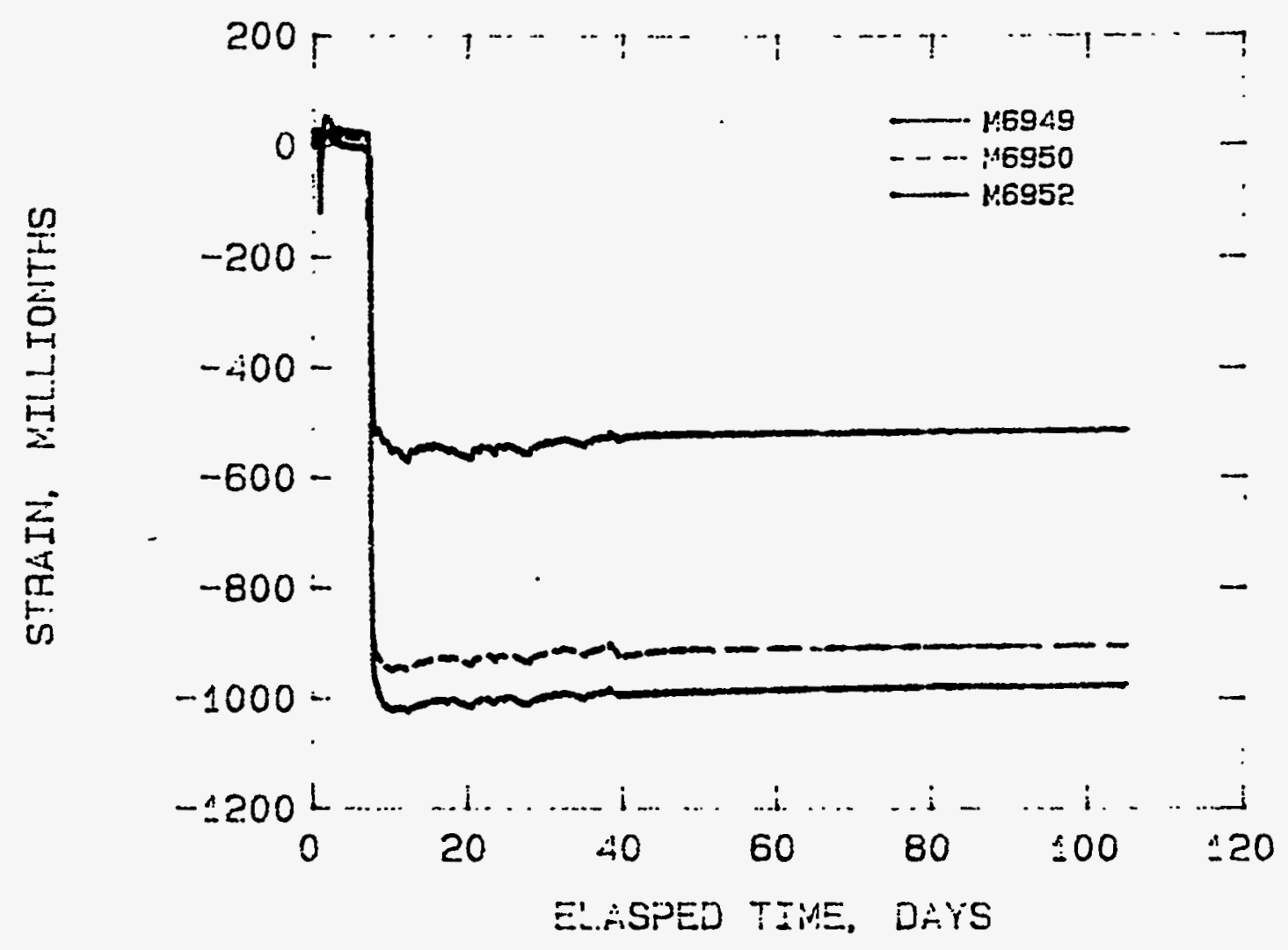

Figure 33. Plot of strain vs time recorded by strain meters during grouting of lifts in the physical model 


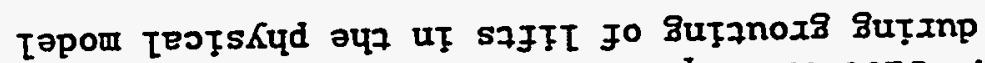

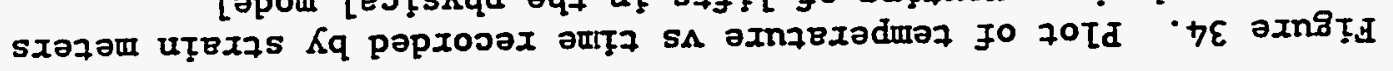

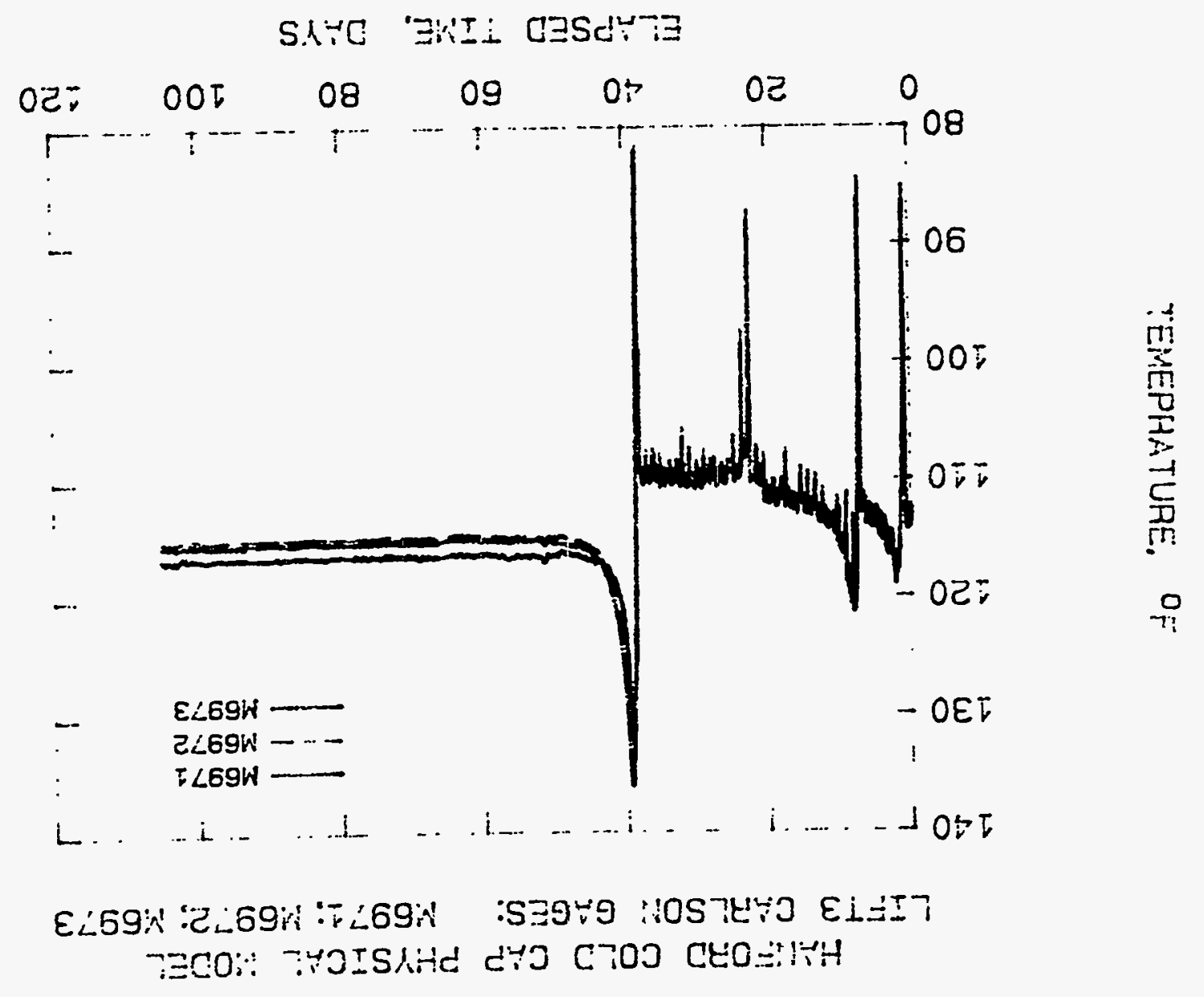


HANFORD COLD CA.J PAYSICAL MODE!

LIFT3 CARI.SON GAGES: M69?:;

是
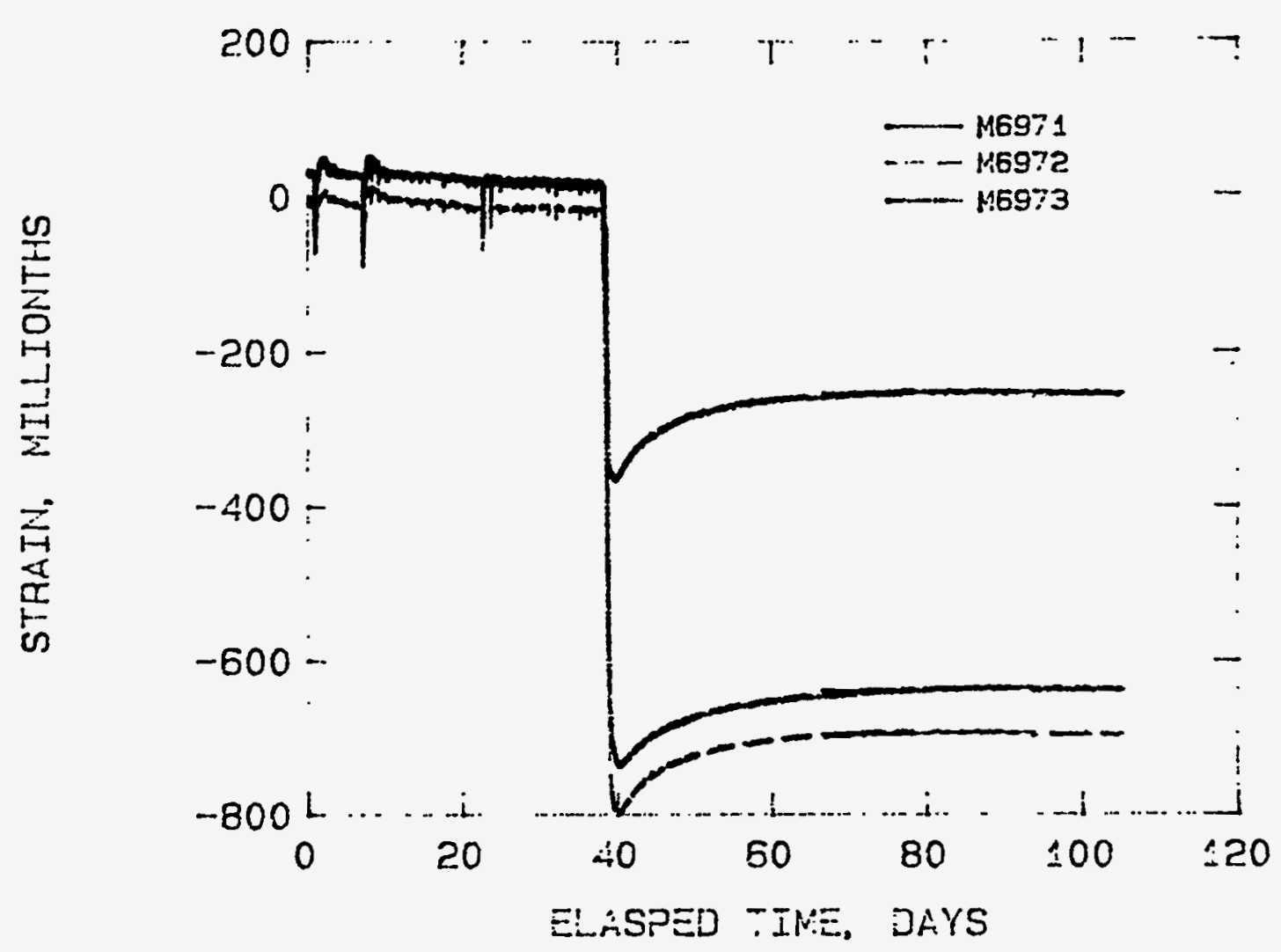

Figure 35. Plot of strain vs time recorded by strain meters during grouting of lifts in the physical model 
FHOORD COLD CAP PHYSICA. MODE.

LFT.3 CARLSO: GAGES: U6958; $469-3$

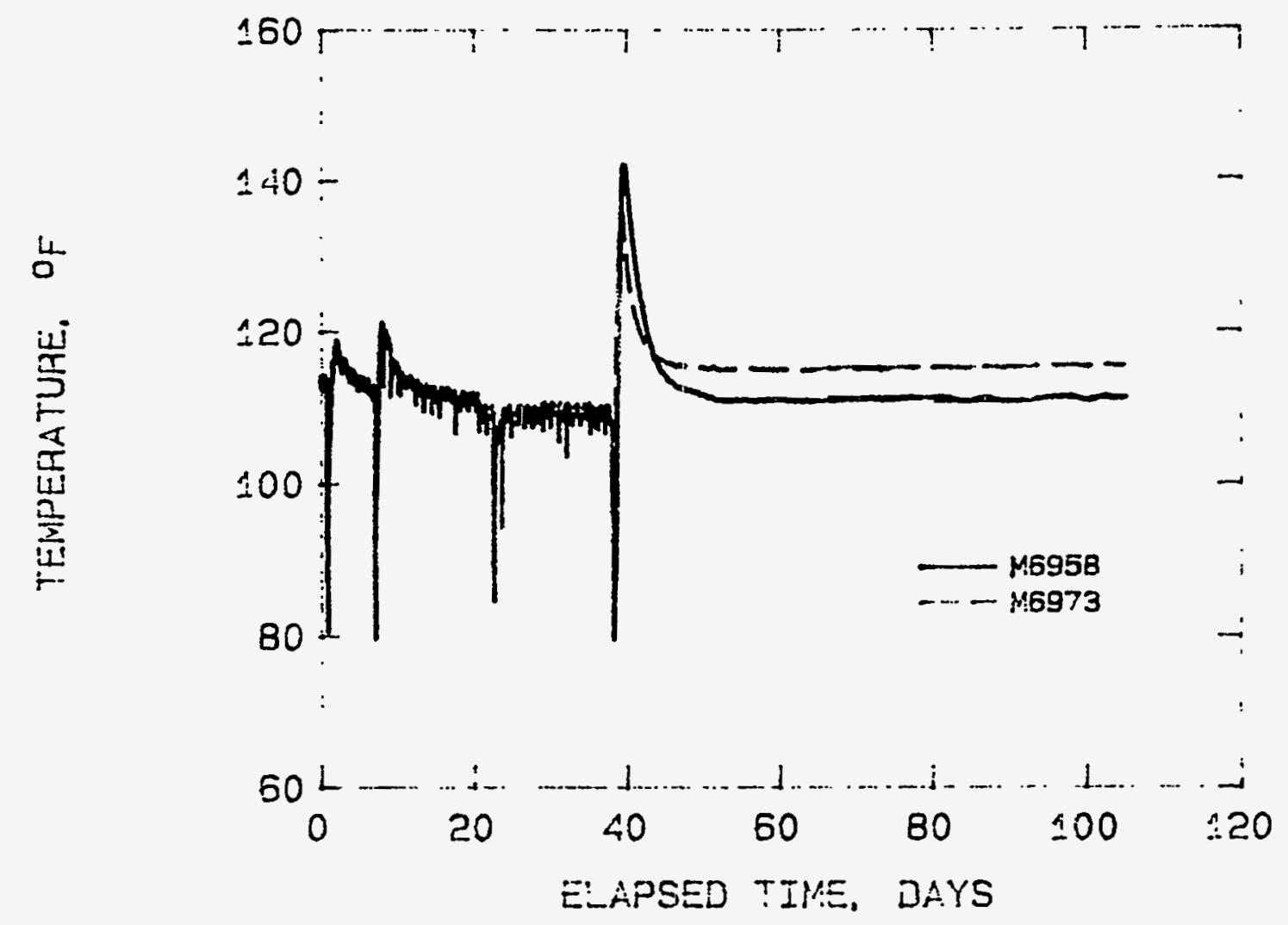

Figure 36. Plot of temperature vs time recorded by strain meters during grouting of lifts in the physical model 
HANFORD COLD CAP PHYSICAL MODEL LIFT3 CARLSON GAGES: M6958; M6973

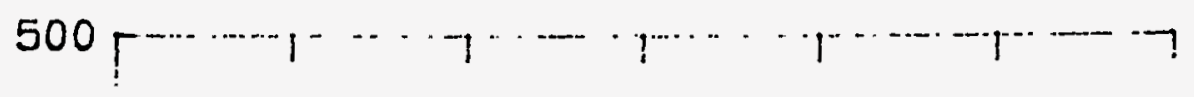

25

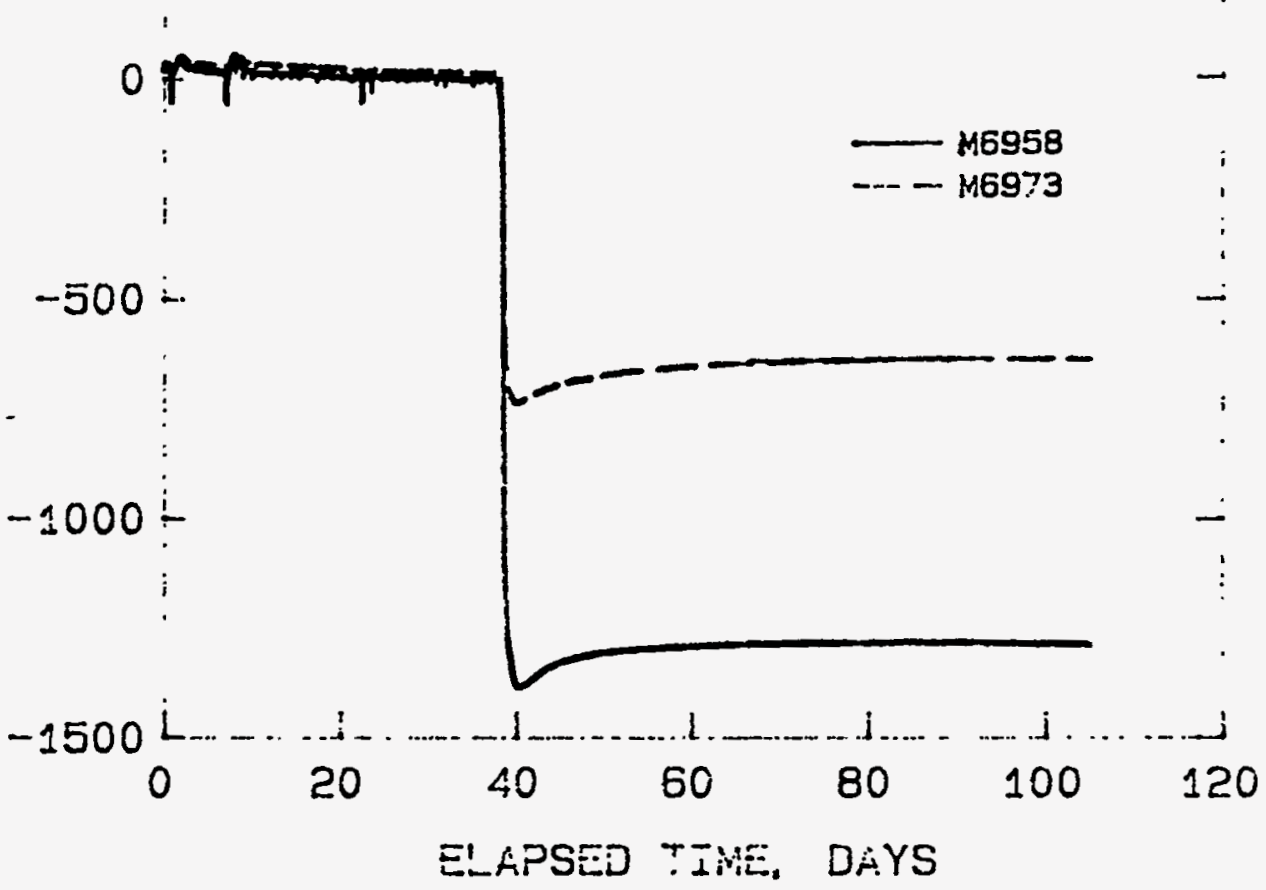

Figure 37. Plot of strain vs time recorded by strain meters during grouting of lifts in the physical model 


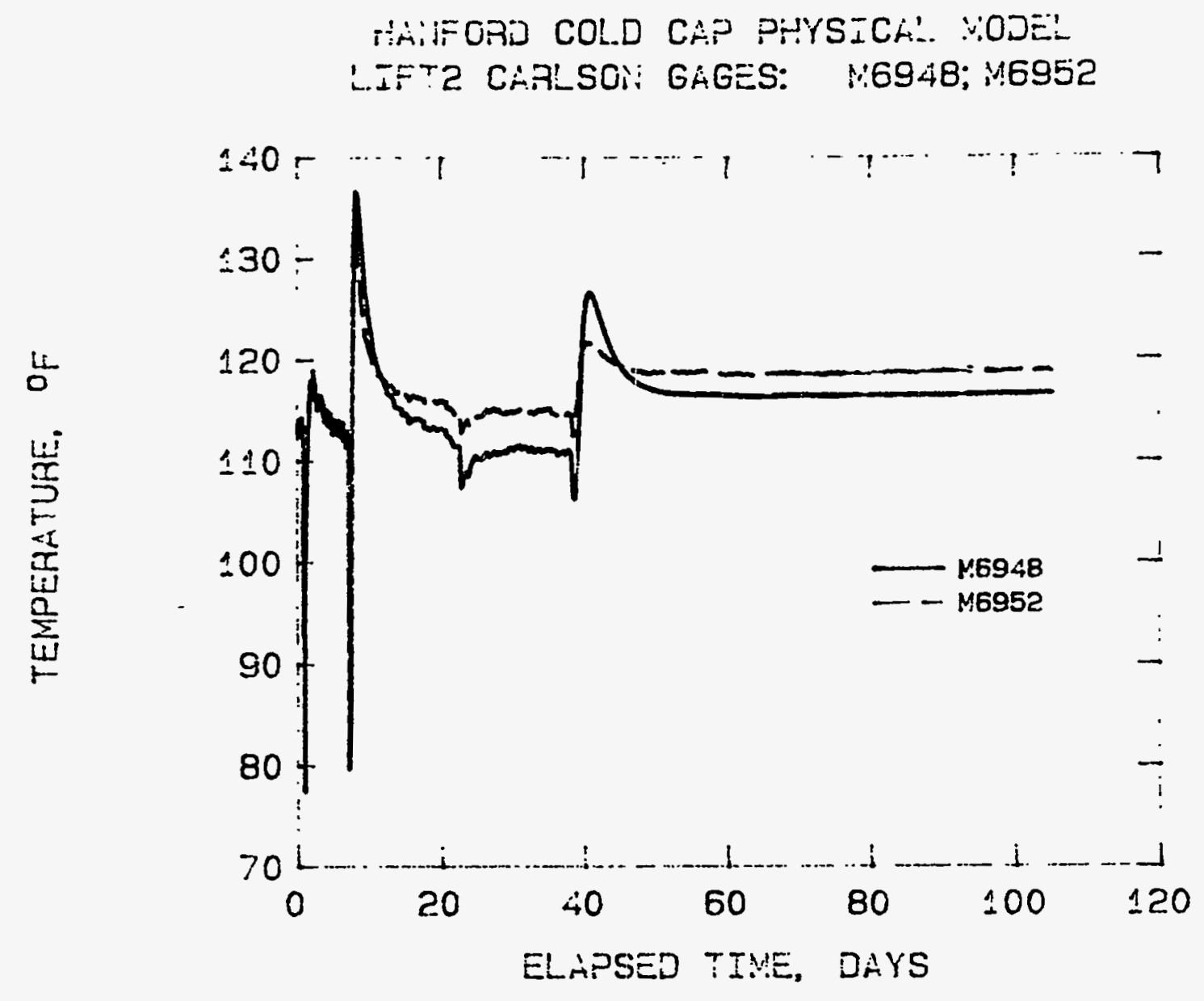

Figure 38. Plot of temperature vs time recorded by strain meters during grouting of lifts in the physical model 


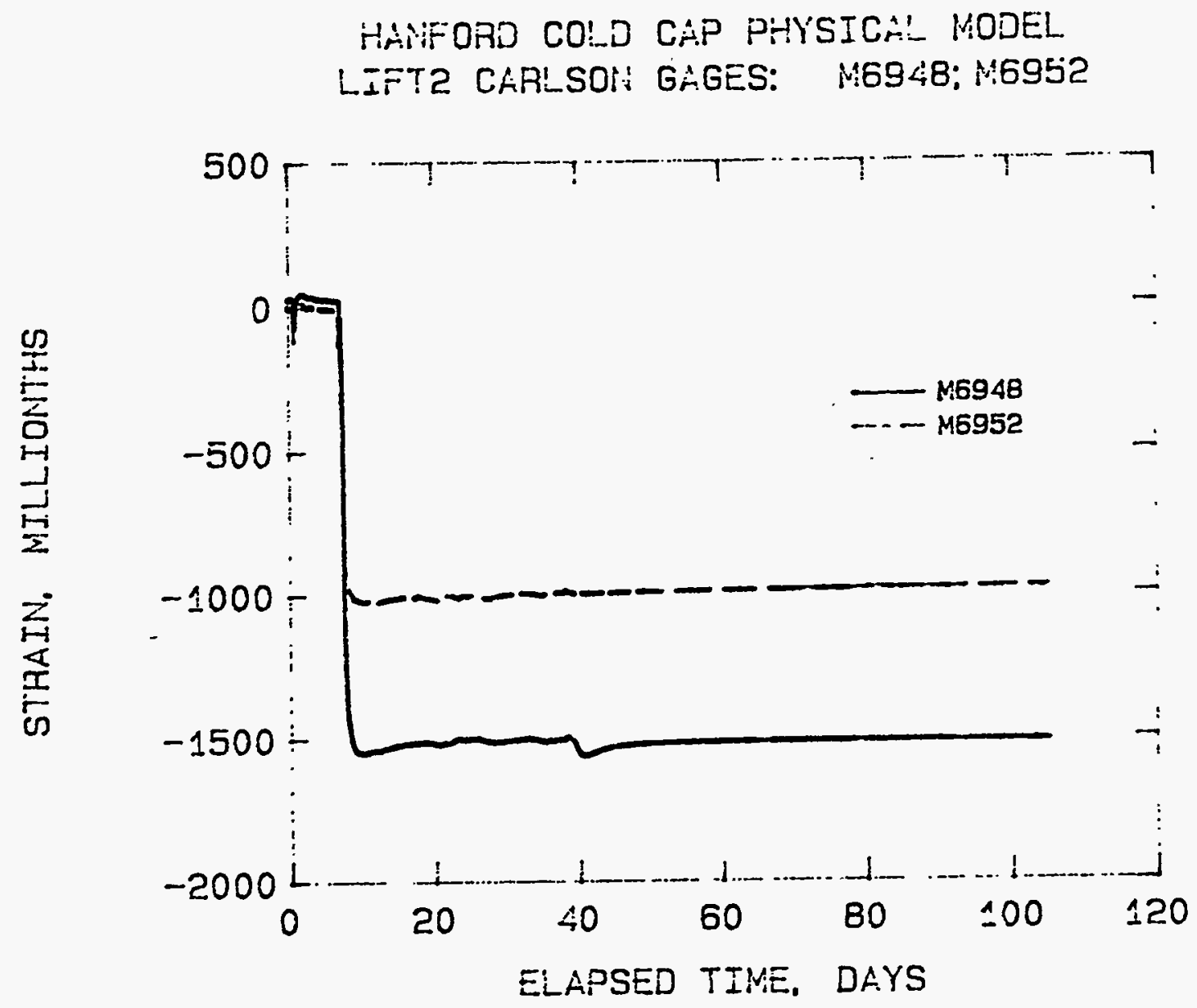

Figure 39. Plot of strain vs time recorded by strain meters during grouting of lifts in the physical model 
HANFORD COLD CAP PHYSICAL MODEL

LIFT1 CARLSON GAGES: M6942: M6945

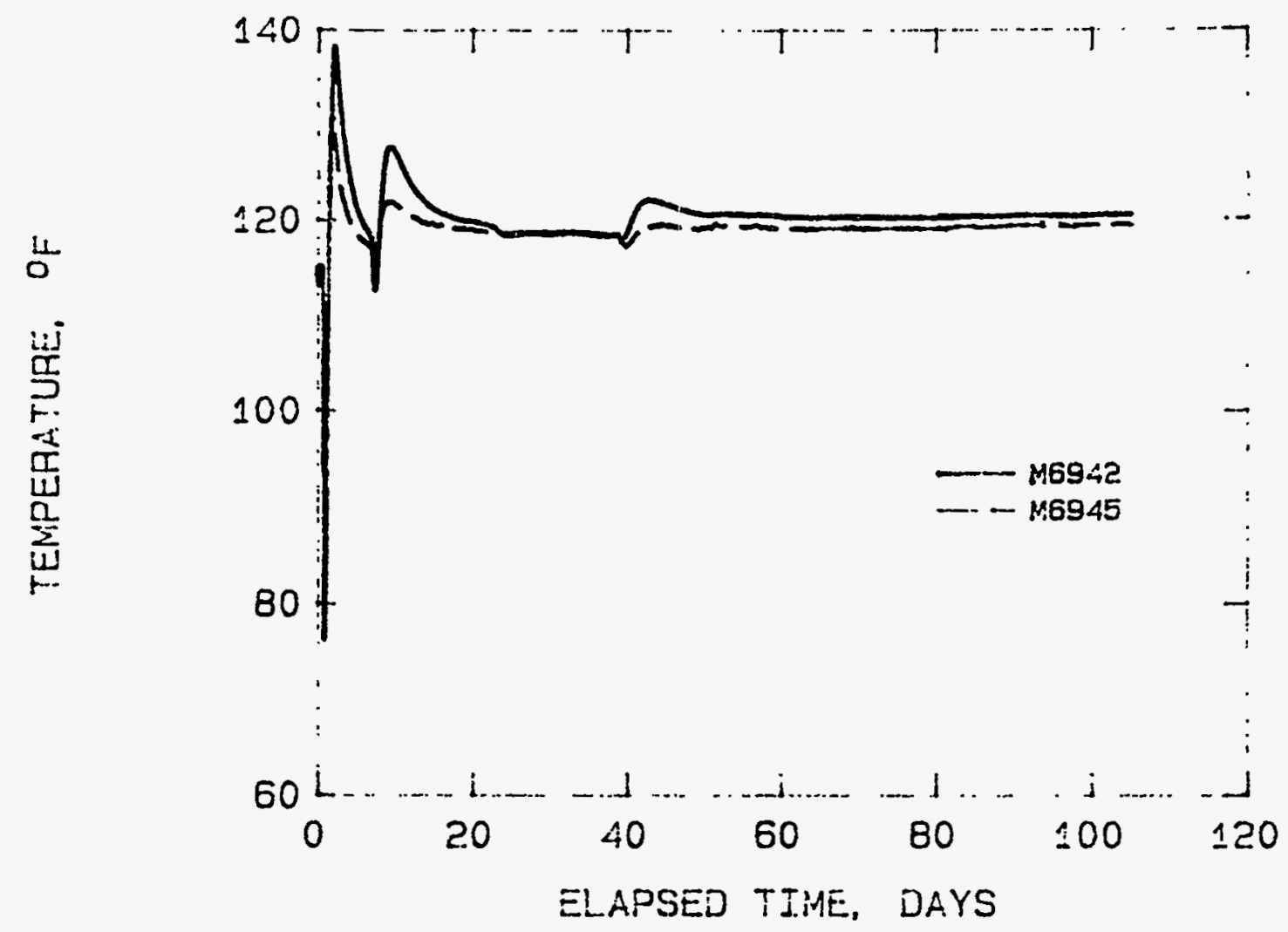

Figure 40. Plot of temperature vs time recorded by strain meters during grouting of lifts in the physical model 


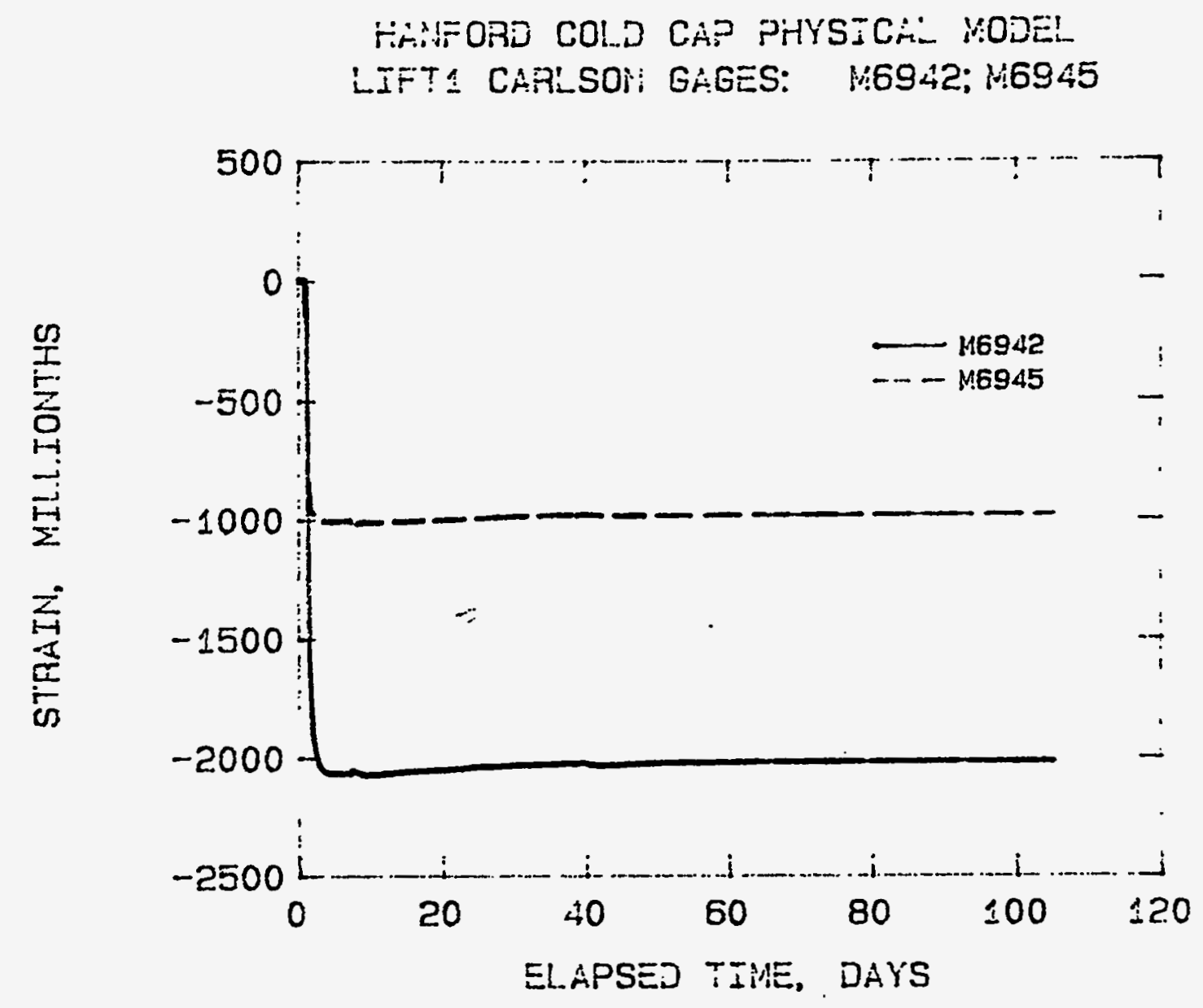

Figure 41. Plot of strain vs time recorded by strain meters during grouting of lifts in the physical model 


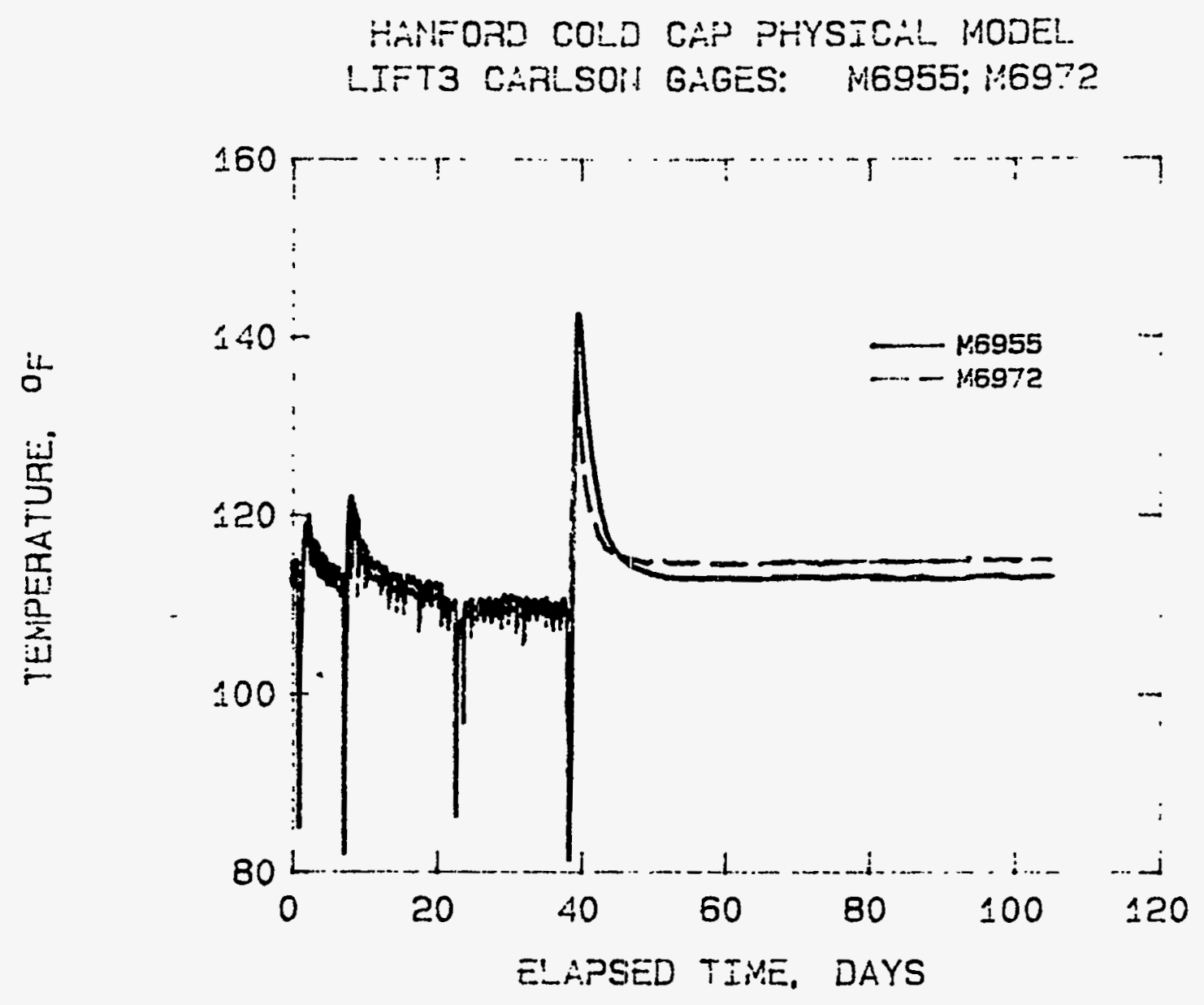

Figure 42. Plot of temperature vs tine recorded by strain meters during grouting of lifts in the physical model 
HANFOAD COLD CAP PHYSICAL MODEL LIFT3 CARLSON GAGES: M6955; M6972

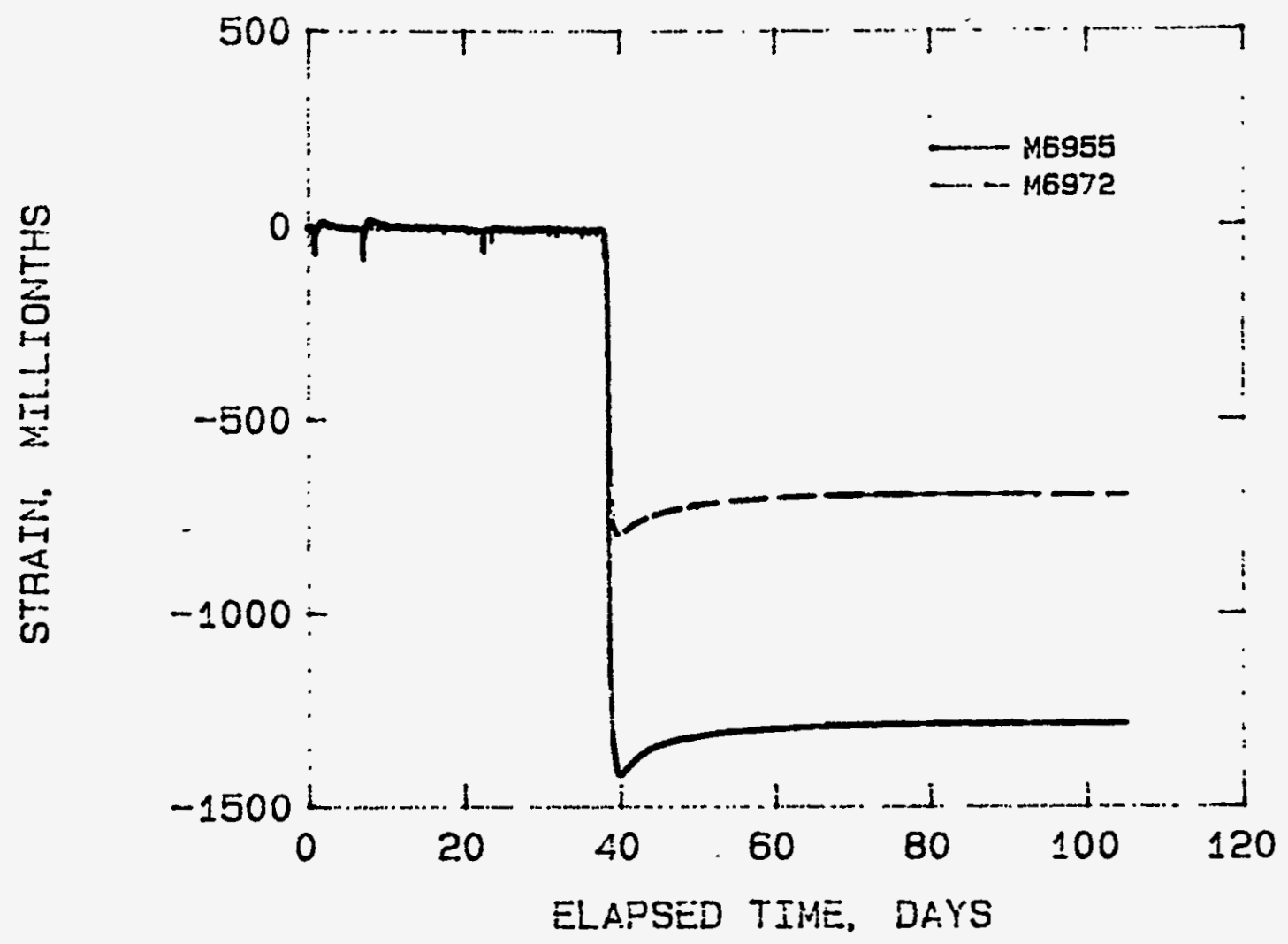

Figure 43. Plot of strain vs time recorded by strain meters during grouting of lifts in the physical model 
FAMFORD COLD CAP PHYSICHL :OODEI

LIFT2 CARLSOIi GAGES: M6947: M6950

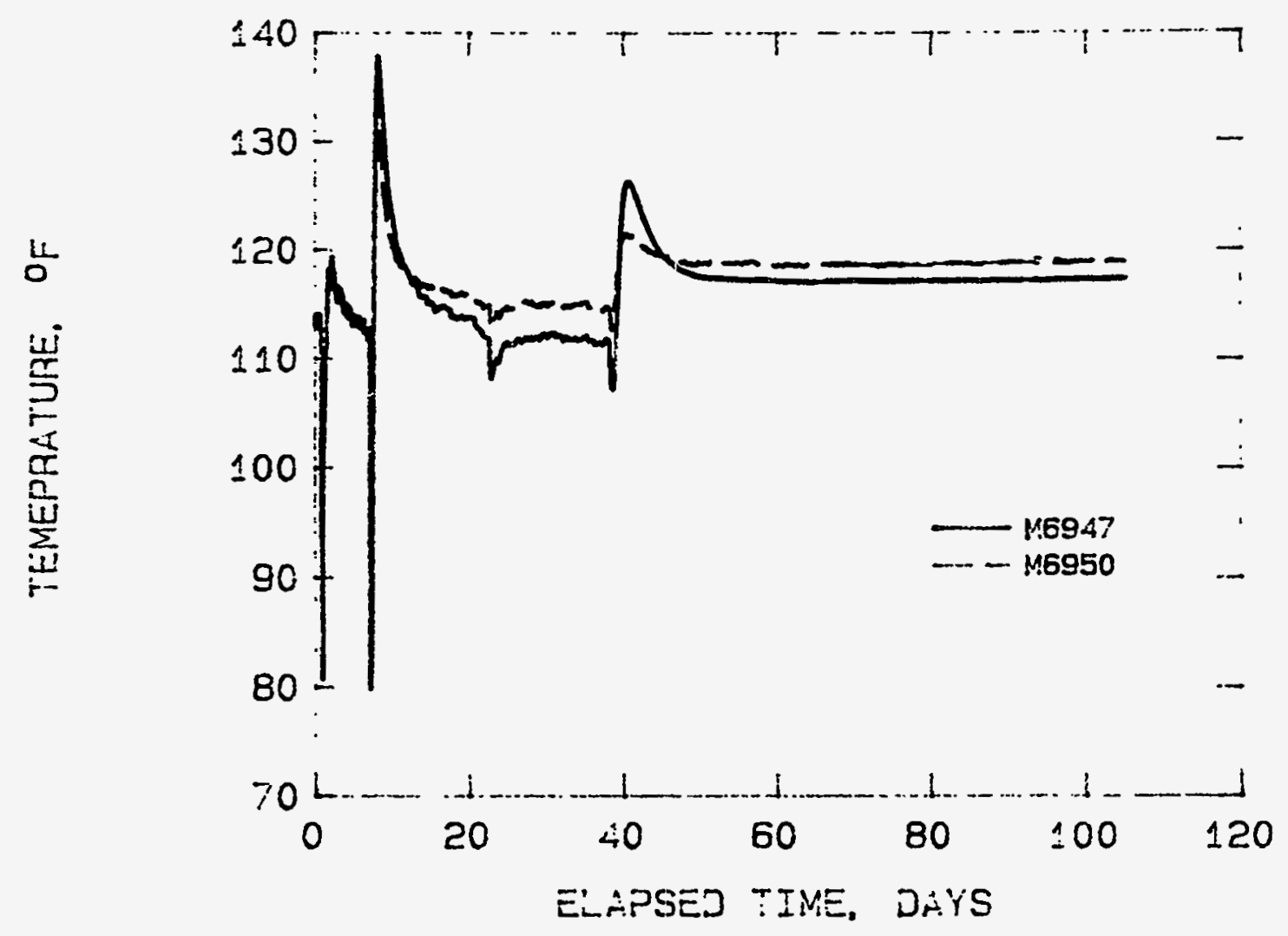

Figure 44. Plot of temperature vs time recorded by strain meters during grouting of lifts in the physical model 
HANFDAD COLD CAP PHYSICAL MODË-

LIFT2 CARI_SON GAGES: H694: $\because 6950$

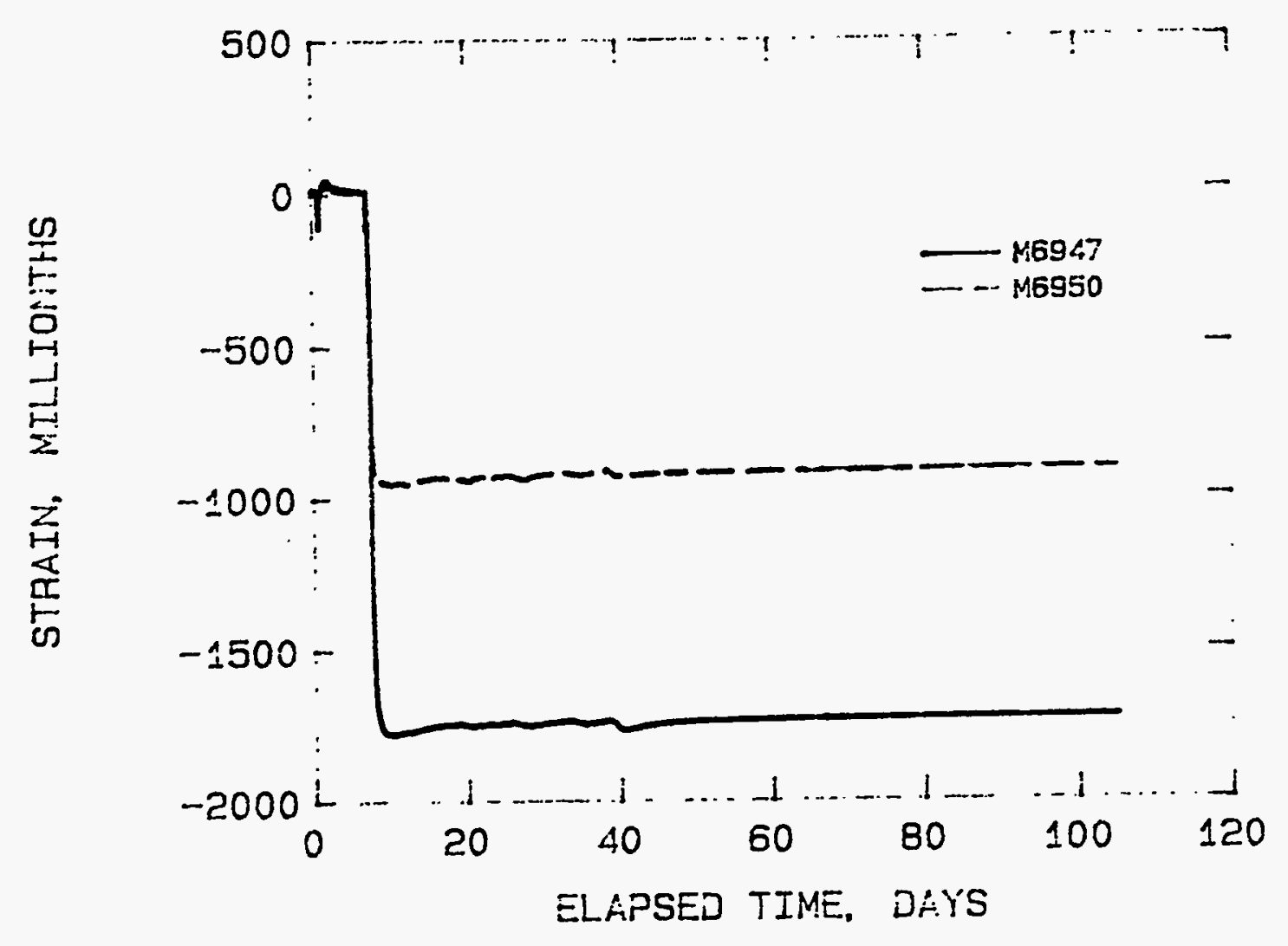

Figure 45. Plot of strain vs time recorded by strain meters during grouting of lifts in the physical model 
HANFORD COLD CAP PHYSICAL MODEL.

LIFT1 CARLSON GAGES: M6941; M6944

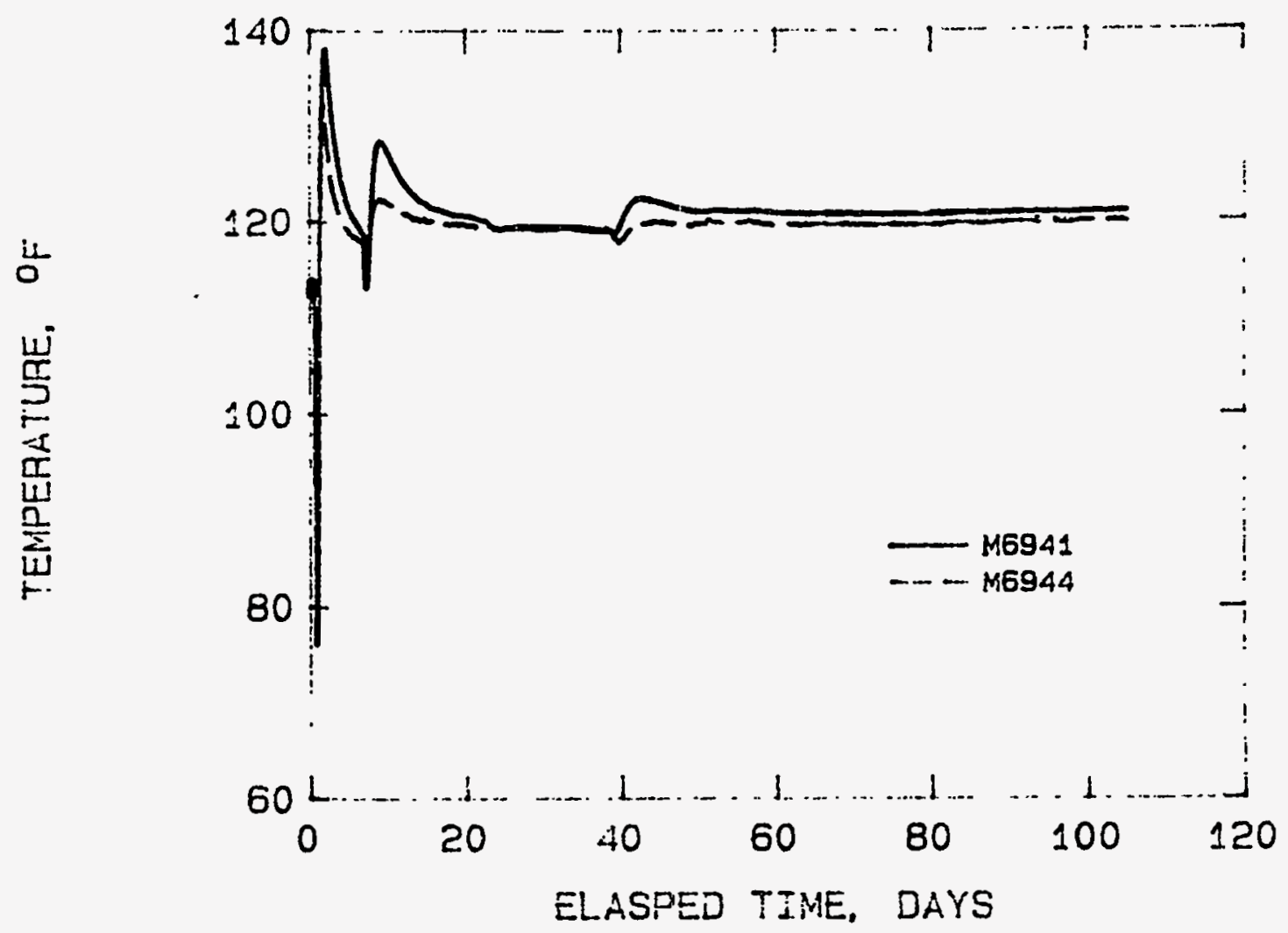

Figure 46. Plot of temperature vs time recorded by strain meters during grouting of lifts in the physical model 


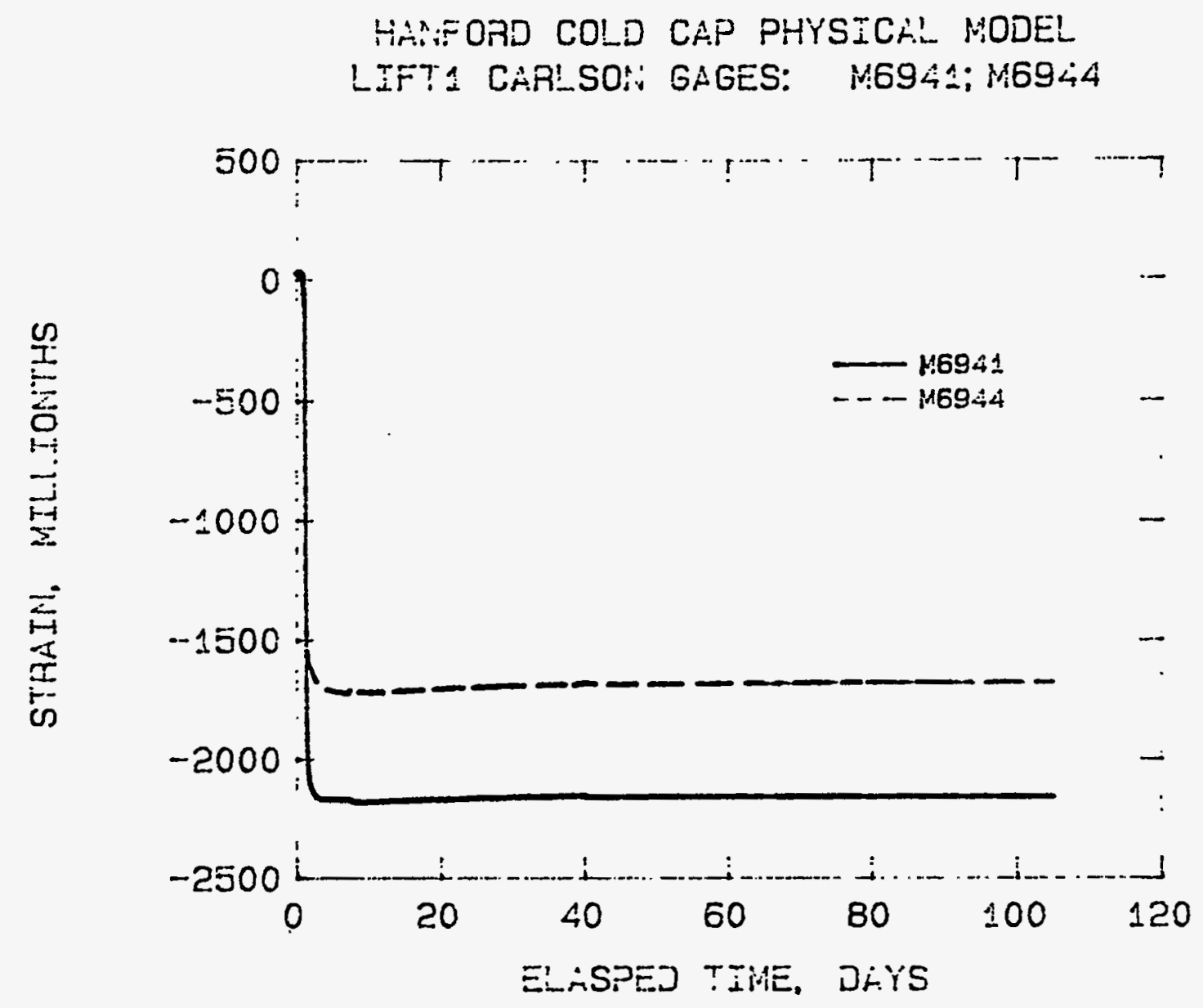

Figure 47. Plot of strain vs time recorded by strain meters during grouting of lifts in the physical model 
HANFORD COLD CAP PHYSICAL MODEL LIFT3 CARLSON GAGES: M6953: M6971

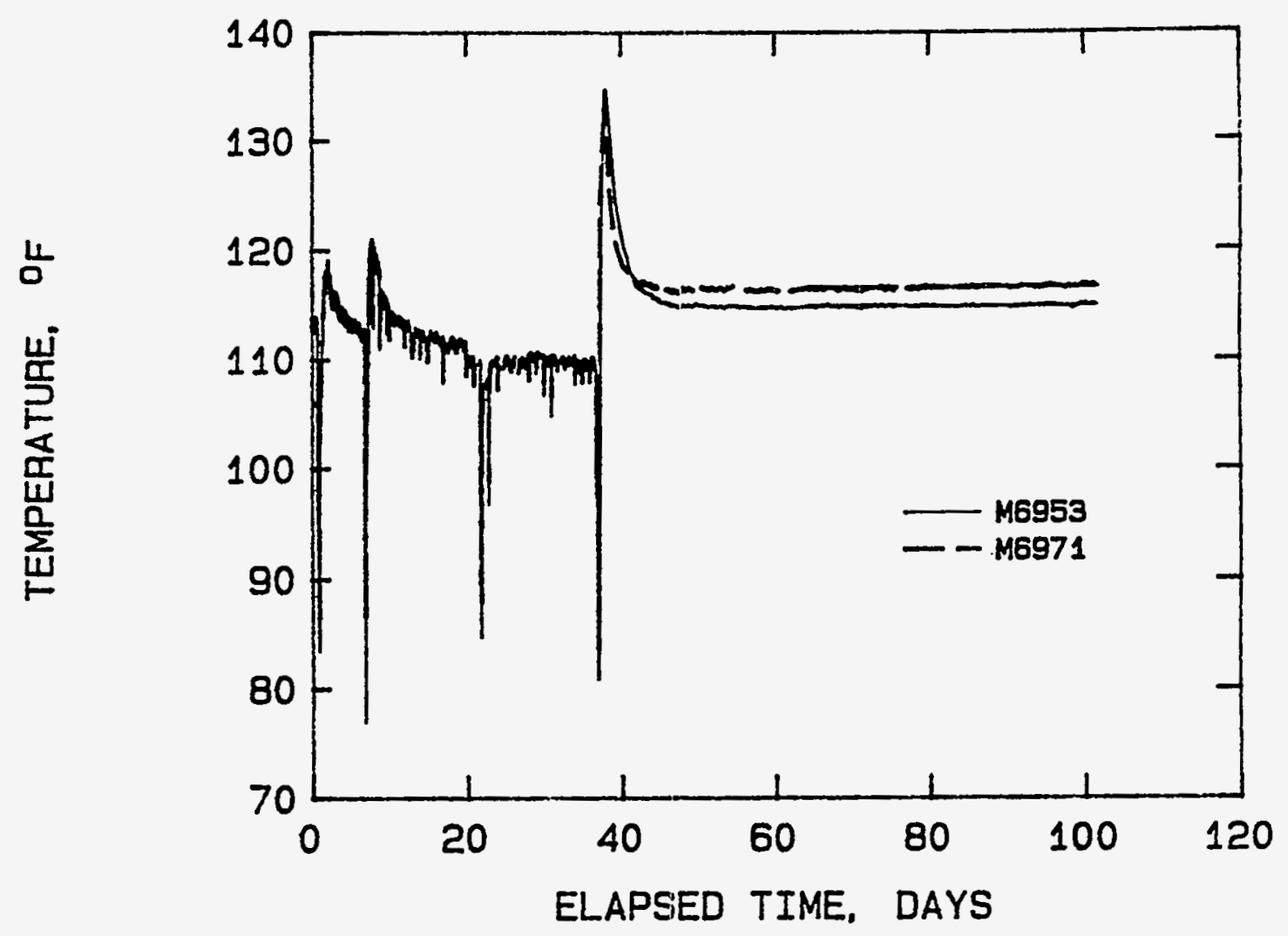

Figure 48. Plot of temperature vs time recorded by strain meters during grouting of lifts in the physical model 
HANFOAD COLD CAP PHYSICAL MODEL LIFT3 CARLSON GAGES: M6953; M6971

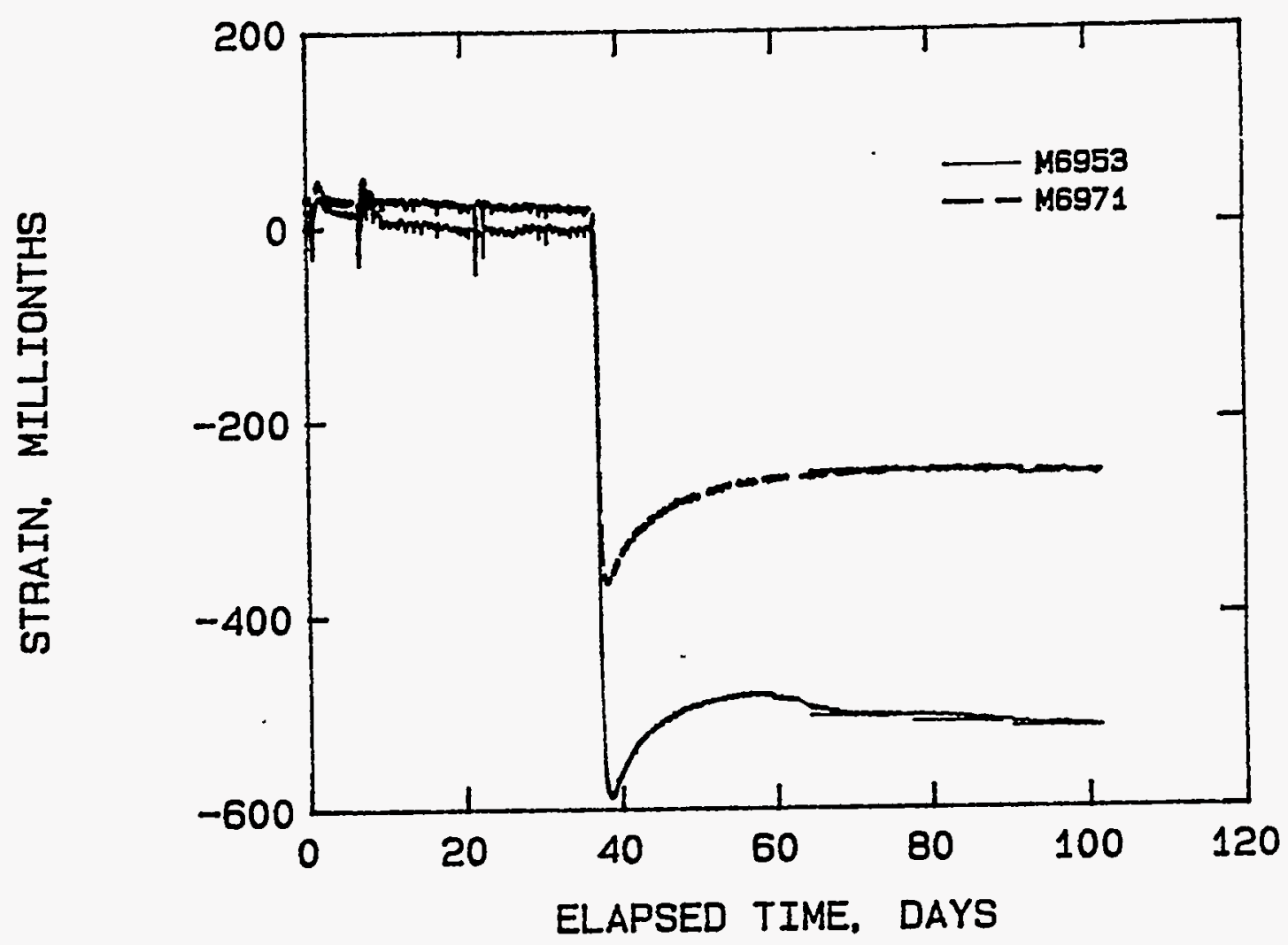

Figure 49. Plot of strain vs time recorded by strain meters during grouting of lifts in the physical model 


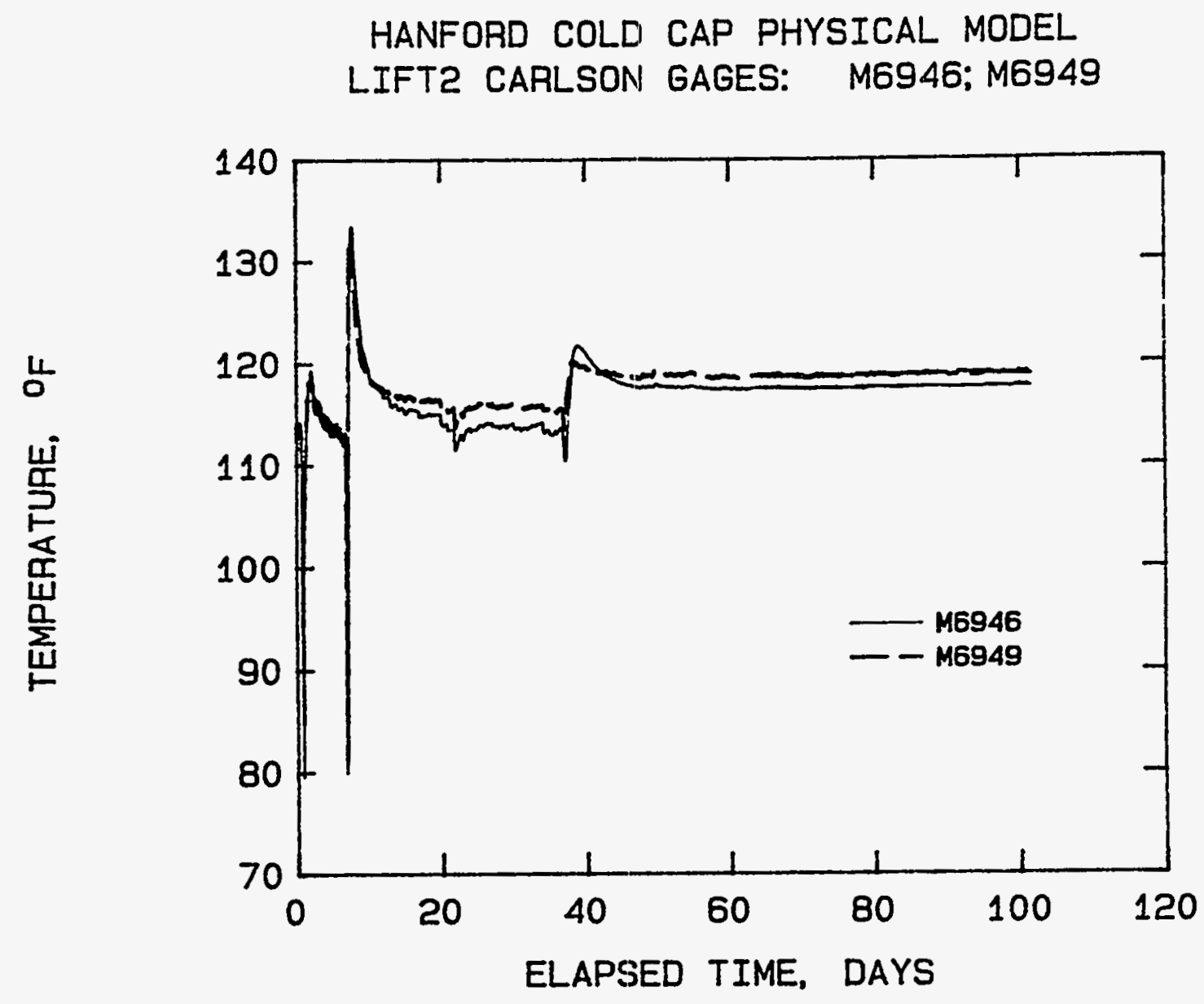

Figure 50. Plot of temperature vs tjme recorded by strain meters during grouting of lifts in the physical model 


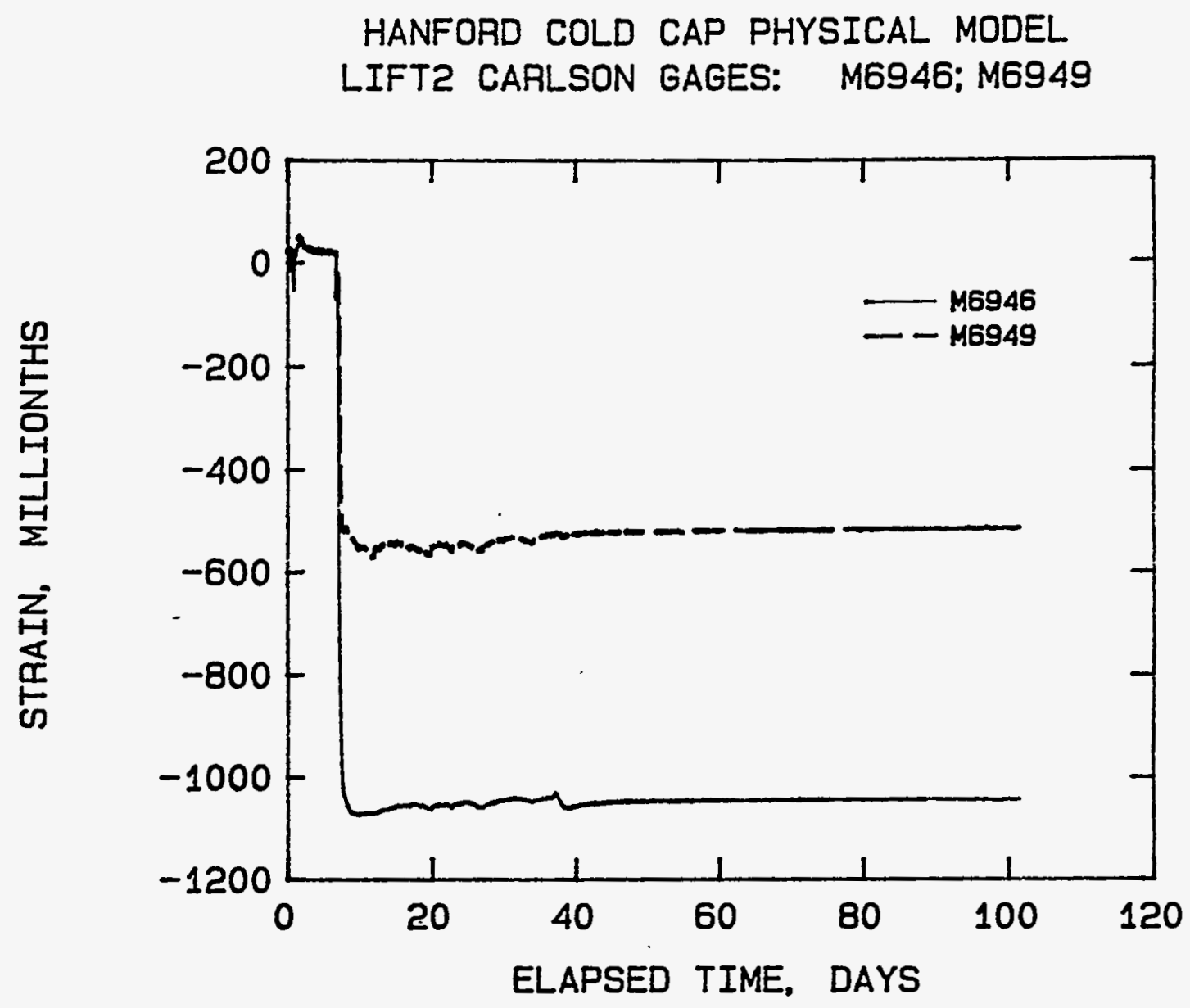

Figure 51. Plot of strain vs time recorded by strain meters during grouting of lifts in the physical model 
HANFORD COLD CAP PHYSICAL MODEL

LIFT1 CARLSON GAGES: M6940; M6943

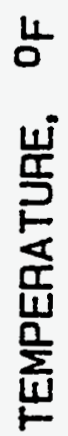

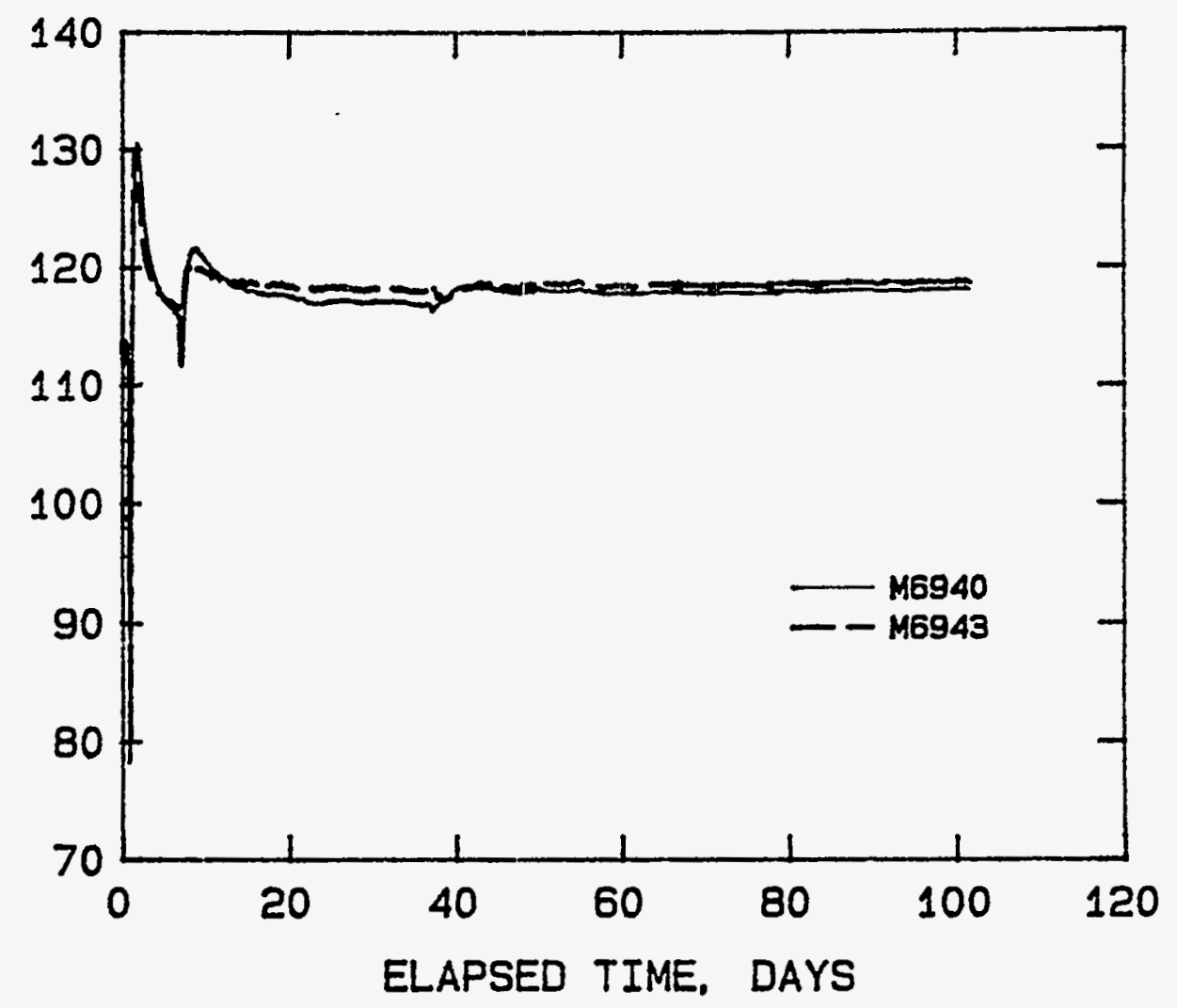

Figure 52. Plot of temperature vs time recorded by strain meters during grouting of lifts in the physical model 
HANFORD COLD CAP PHYSICAL MODEL

LIFT1 CARLSON GAGES: M6940; M6943

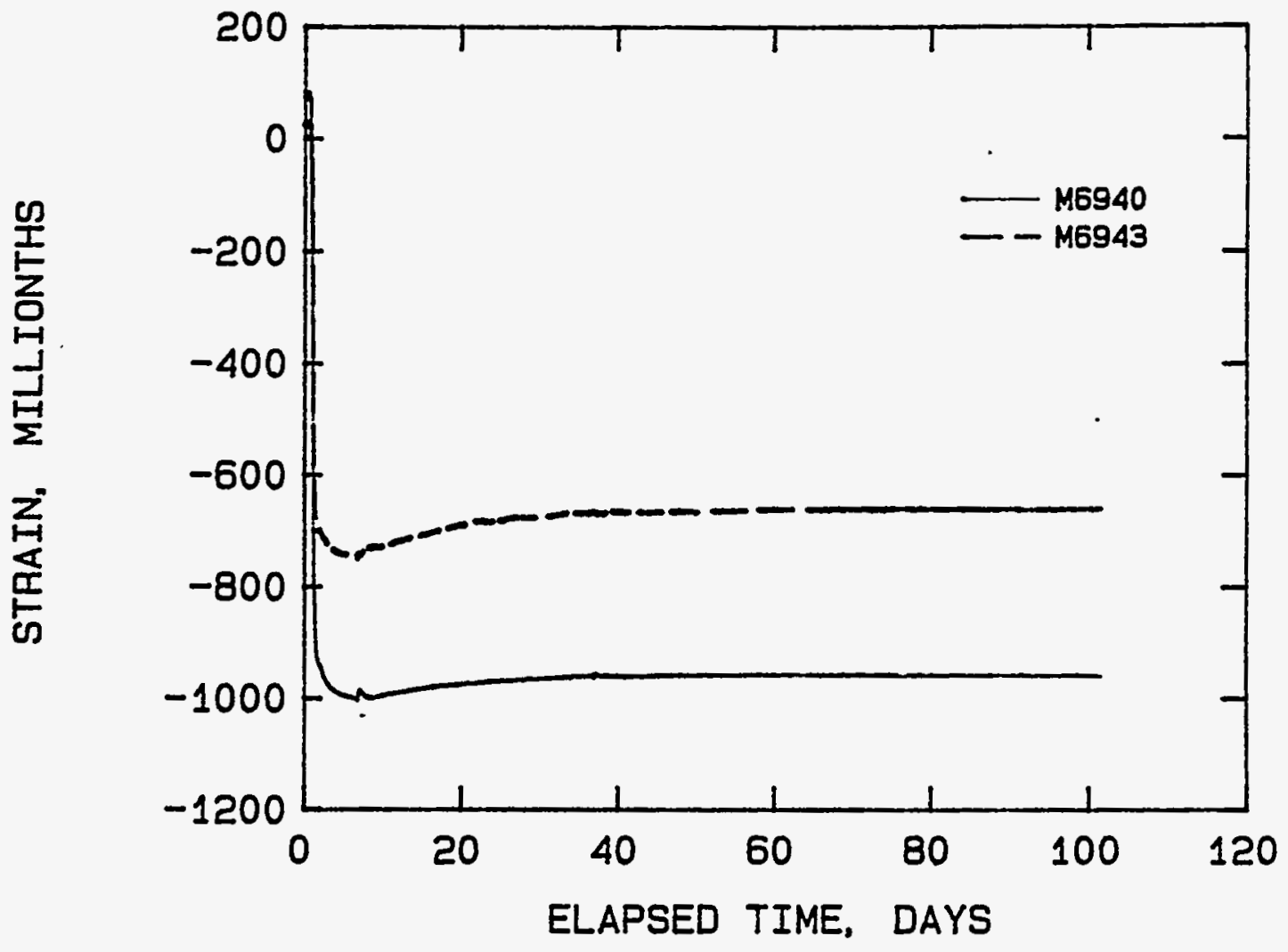

Figure 53. Plot of strain vs time recorded by strain meters during grouting of lifts in the physical model 


\section{HANFORD PSW COLD CAP PHYSICAL MODEL DIAL GAGE LOCATIONS}

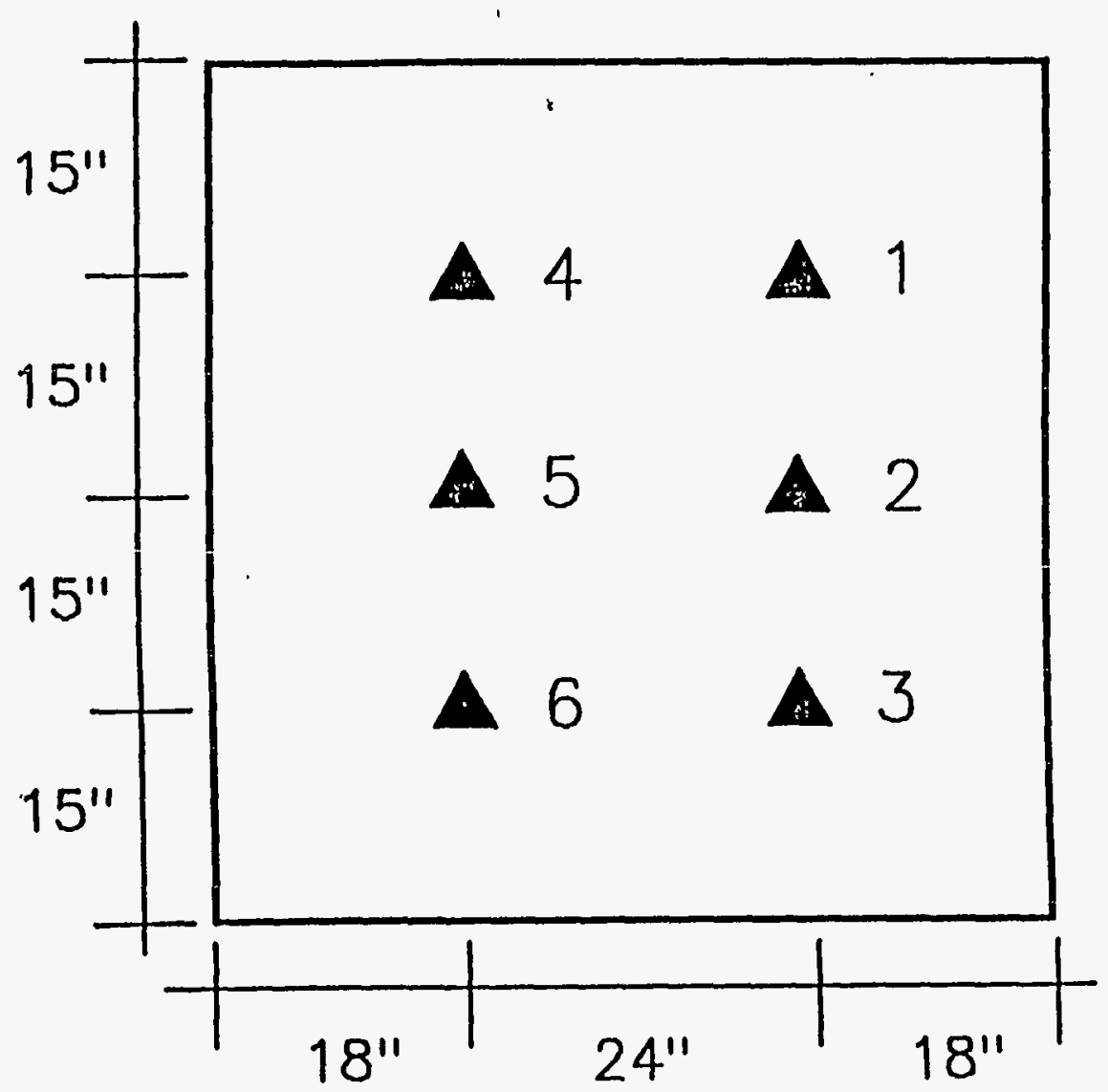

Figure 54. Plan view of physical model showing location of dial gages 


\section{HANFORD PSW COLD CAP VOLUME STABILITY VS TIME}

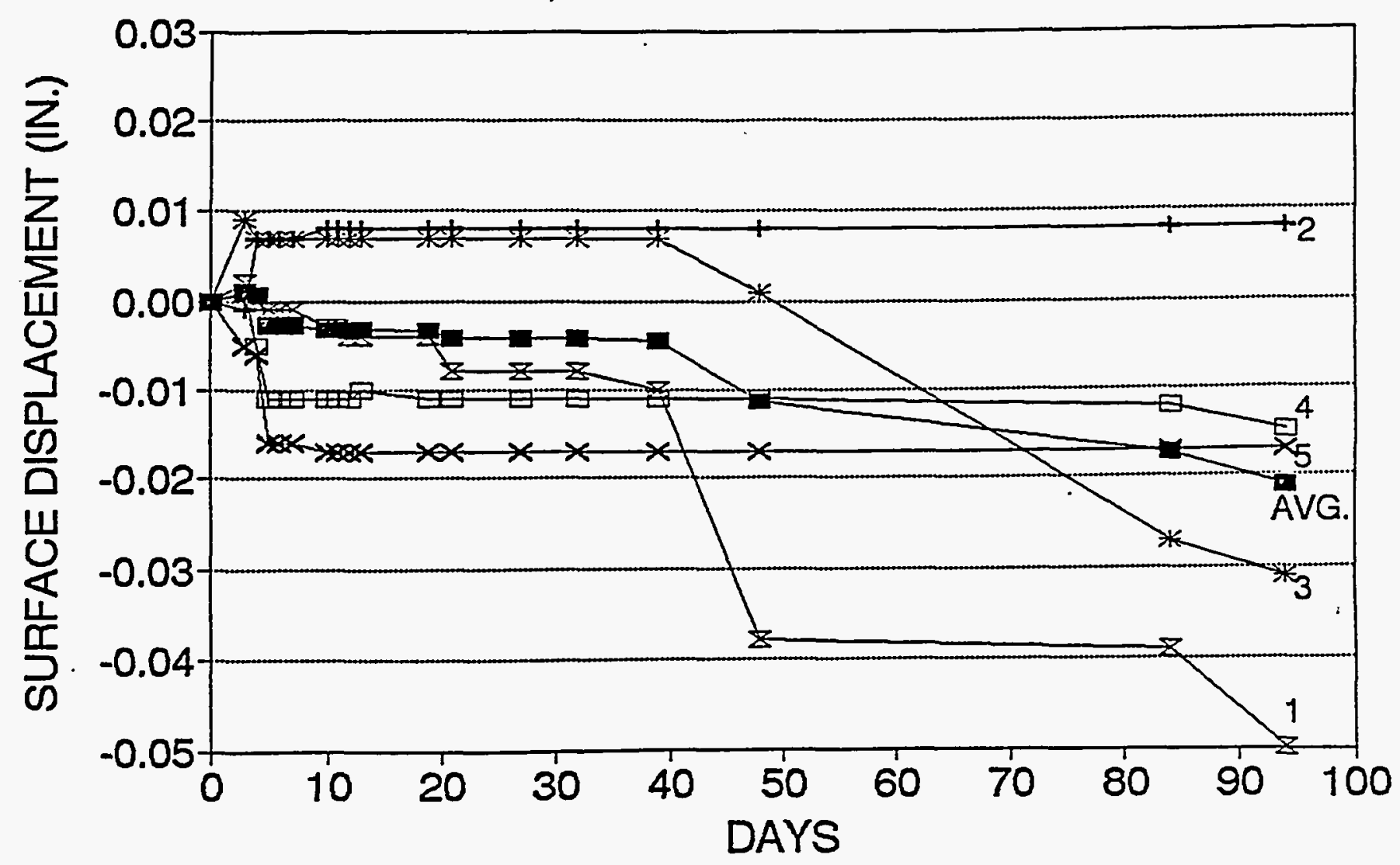

Figure 55. Deflection of the vault surface vs time 
APPENDIX A:

PROPORTIONS OF EXPERIMENTAL GROUT MIXTURES TESTED DURING GROUT DEVELOPMENT 
MIXTURE 2B

\begin{tabular}{|l|c||c|c|c|}
\hline \multicolumn{2}{|c||}{ Mixture Proportions } & \multicolumn{3}{c|}{ Flow Properties } \\
\hline \multicolumn{1}{|c||}{ Material } & Lb/Cy & Time (min) & Flow (sec) & Comments \\
\hline Class H Cement & 432 & 5 & 13.1 & Compressive strength \\
Class F Fly Ash & 980 & 15 & 11.5 & 1,900 psi \\
Masonry Sand & 1,113 & 45 & 12.8 & Estimated volume loss \\
Bentonite & 27 & 75 & 15.0 & to bleed = 1 percent \\
Water & 664 & 105 & 17.6 & \\
HRWRA & 0.78 & & & \\
Retarder & $0 \mathrm{oz}$ & & & \\
& & & & \\
\hline
\end{tabular}

MIXTURE 3B

\begin{tabular}{|l|c||c|c|l|}
\hline \multicolumn{2}{|c||}{ Mixture Proportions } & \multicolumn{3}{c|}{ Flow Properties } \\
\hline \multicolumn{1}{|c|}{ Material } & Lb/Cy & Time (min) & Flow (sec) & \multicolumn{1}{|c|}{ Comments } \\
\hline Class H Cement & 486 & 5 & 11.0 & Compressive strength \\
at 7 days (140 $\mathrm{F}$ ). \\
Class F Fly Ash & 851 & 30 & 11.0 & 3,920 psi \\
Basalt Sand & 1,215 & 60 & 11.0 & Estimated volume loss \\
Bentonite & 27 & 90 & 11.2 & to bleed = 8.7 percent \\
Water & 664 & 120 & 11.3 & \\
HRWRA & 1.1 & & & \\
Retarder & $26 \mathrm{oz}$ & & & \\
& & & & \\
\end{tabular}


MIXTURE 3B-1.

\begin{tabular}{|l|c||c|c|l|}
\hline \multicolumn{2}{|c||}{ Mixture Proportions } & \multicolumn{3}{|c|}{ Flow Properties } \\
\hline \multicolumn{1}{|c|}{ Material } & Lb/Cy & Time (min) & Flow (sec) & \multicolumn{1}{|c|}{ Comments } \\
\hline Class H Cement & 468 & 5 & 14.0 & Cast specimens after \\
Class F Fly Ash & 826 & 30 & 14.5 & 1 hr. Mixture was too \\
thick to use. \\
Basalt Sand & 1,215 & 60 & 16.3 & Estimated volume loss \\
Bentonite & 54 & 90 & & to bleed = 1 percent \\
Water & 664 & 120 & & \\
HRWRA & 1.1 & & & \\
Retarder & $26 \mathrm{oz}$ & & & \\
& & & & \\
\hline
\end{tabular}

MIXTURE 3B-2

\begin{tabular}{|l|c||c|c|c|}
\hline \multicolumn{2}{|c||}{ Mixture Proportions } & \multicolumn{3}{|c|}{ Flow Properties } \\
\hline \multicolumn{1}{|c|}{ Material } & Lb/Cy & Time (min) & Flow (sec) & Comments \\
\hline Class H Cement & 486 & 5 & 11.6 & Estimated volume loss \\
Class F Fly Ash & 845 & 30 & 11.6 & to bleed = 4 percent \\
Basalt Sand & 1,215 & 60 & 11.7 & \\
Bentonite & 34 & 90 & 11.9 & \\
Water & 664 & 120 & 12.0 & \\
HRWRA & 1.1 & & & \\
Retarder & $26 \mathrm{oz}$ & & & \\
& & & & \\
\hline
\end{tabular}


MIXTURE 5B

\begin{tabular}{|c|c|c|c|c|}
\hline \multicolumn{2}{|c|}{ Mixture Proportions } & \multicolumn{3}{|c|}{ Flow Properties } \\
\hline Material & $\mathrm{Lb} / \mathrm{Cy}$ & Time (min) & Flow (sec) & Comments \\
\hline $\begin{array}{l}\text { Class H Cement } \\
\text { Class F Fly Ash } \\
\text { Basalt Sand } \\
\text { Bentonite } \\
\text { Water } \\
\text { HRWRA } \\
\text { Retarder }\end{array}$ & $\begin{array}{r}486 \\
851 \\
1,350 \\
54 \\
599 \\
2.43 \\
26 \text { oz }\end{array}$ & $\begin{array}{r}5 \\
30 \\
60 \\
90 \\
120\end{array}$ & $\begin{array}{l}15.0 \\
15.0 \\
15.6 \\
16.0 \\
17.0\end{array}$ & $\begin{array}{l}\text { Slight fallout of } \\
\text { aggregate. until } \\
30 \text { minutes. } \\
\text { Compressive strength } \\
\text { at } 7 \text { days }\left(140^{\circ} \mathrm{F}\right)= \\
4,055^{2} \text { psi }\end{array}$ \\
\hline
\end{tabular}

MIXTURE 7B

\begin{tabular}{|c|c|c|c|c|}
\hline \multicolumn{2}{|c|}{ Mixture Proportions } & \multicolumn{3}{|c|}{ Flow Properties } \\
\hline Material & $\mathrm{Lb} / \mathrm{Cy}$ & Time (min) & Flow (sec) & Comments \\
\hline Class H Cement & 486 & 5 & $\approx 30 \mathrm{sec}$ & Aggregate fellout \\
\hline Class F Fly Ash & 1,586 & 30 & & excessively. \\
\hline Basalt Sand & 540 & 60 & & Estimated volume loss \\
\hline Bentonite & 27 & 90 & & \\
\hline Water & 621 & 120 & & \\
\hline HRWRA & 1.1 & & & \\
\hline Retarder & $26 \circ z$ & & & \\
\hline
\end{tabular}


MIXTURE 8B

\begin{tabular}{|c|c|c|c|c|}
\hline \multicolumn{2}{|c|}{ Mixture Proportions } & \multicolumn{3}{|c|}{ Flow Properties } \\
\hline Material & $\mathrm{Lb} / \mathrm{Cy}$ & Time (min) & Flow (sec) & Comments \\
\hline $\begin{array}{l}\text { Class H Cement } \\
\text { Class F Fly Ash } \\
\text { Basalt Sand } \\
\text { Bentonite } \\
\text { Water } \\
\text { HRWRA } \\
\text { Retarder }\end{array}$ & $\begin{array}{r}486 \\
1,207 \\
810 \\
0 \\
675 \\
1.35 \\
16 \mathrm{oz}\end{array}$ & $\begin{array}{r}5 \\
30 \\
60 \\
90 \\
120\end{array}$ & & $\begin{array}{l}\text { Did not test flow - } \\
\text { mixtures experienced } \\
\text { excessive fallout and } \\
\text { bleed. }\end{array}$ \\
\hline
\end{tabular}

MIXTURE 9B

\begin{tabular}{|l|c||c|c|c|}
\hline \multicolumn{2}{|c||}{ Mixture Proportions } & \multicolumn{3}{|c|}{ Flow Properties } \\
\hline \multicolumn{1}{|c|}{ Material } & Lb/Cy & Time (min) & Flow (sec) & \multicolumn{1}{|c|}{ Comments } \\
\hline Class H Cement & 486 & 5 & 13.0 & Cast specimens after \\
Class F Fly Ash & 1,156 & 30 & 14.7 & 30 minutes. \\
Basalt Sand & 810 & 60 & & \\
Bentonite & 54 & 90 & & \\
Water & 675 & 120 & & \\
HRWRA & 3.0 & & & \\
Retarder & $0 \mathrm{oz}$ & & & \\
& & & & \\
\hline
\end{tabular}


MIXTURE 1OB

\begin{tabular}{|l|c||c|c|c|}
\hline \multicolumn{2}{|c||}{ Mixture Proportions } & \multicolumn{3}{c|}{ Flow Properties } \\
\hline \multicolumn{1}{|c|}{ Material } & Lb/Cy & Time (min) & Flow (sec) & Comments \\
\hline Class H Cement & 486 & 5 & 13.8 & Slight fallout of \\
Class F Fly Ash & 1,182 & 30 & 11.8 & aggregate at 30 minutes. \\
Basalt Sand & 810 & 60 & 11.9 & No fallout after \\
Bentonite & 27 & 90 & 11.9 & 60 minutes of mixing. \\
Water & 675 & 120 & 12.0 & \\
HRWRA & 2.67 & & & \\
Retarder & 15.4 oz & & & \\
& & & & \\
\hline
\end{tabular}

MIXTURE 12B

\begin{tabular}{|l|c||c|c|c|}
\hline \multicolumn{2}{|c||}{ Mixture Proportions } & \multicolumn{3}{c|}{ Flow Properties } \\
\hline \multicolumn{1}{|c|}{ Material } & Lb/Cy & Time (min) & Flow (sec) & Comments \\
\hline Class H Cement & 486 & 5 & 12.5 & Slight fallout of \\
Class F Fly Ash & 1,000 & 30 & 13.2 & aggregate at 60 minutes. \\
Basalt Sand & 1,280 & 60 & 14.0 & \\
Bentonite & 13 & & & \\
Water. & 594 & & & \\
HRWRA & 2.43 & & & \\
Retarder & $13.5 \mathrm{oz}$ & & & \\
& & & & \\
\hline
\end{tabular}


MIXTURE IL

\begin{tabular}{|l|c||c|c|l|}
\hline \multicolumn{2}{|c||}{ Mixture Proportions } & \multicolumn{3}{|c|}{ Flow Properties } \\
\hline \multicolumn{1}{|c|}{ Material } & Lb/Cy & Time (min) & Flow (sec) & \multicolumn{1}{|c|}{ Comments } \\
\hline Class H Cement & 432 & 5 & 12.0 & Slight fallout of \\
Class F Fly Ash & 967 & 30 & 12.0 & aggregate at 30 minutes. \\
Limestone Sand & 1,160 & 60 & 12.5 & Compressive strength at \\
Bentonite & 54 & 90 & 13 & days (140 ${ }^{\circ}$ F) - \\
Water & 664 & 120 & 13.6 & Estimated volume loss to \\
HRWRA & 1.1 & & & bleed = 2 percent \\
Retarder & $23 \mathrm{oz}$ & & & \\
& & & & \\
\hline
\end{tabular}

MIXTURE 4L

\begin{tabular}{|l|c||c|c|l|}
\hline \multicolumn{2}{|c||}{ Mixture Proportions } & \multicolumn{3}{c|}{ Flow Properties } \\
\hline \multicolumn{1}{|c|}{ Material } & Lb/Cy & Time (min) & Flow (sec) & \multicolumn{1}{|c|}{ Comments } \\
\hline Class H Cement & 468 & 5 & 13.0 & Compressive strength \\
Class F Fly Ash & 869 & 30 & 12.7 & at days (140 ${ }^{\circ} \mathrm{F}$ ) \\
Limestone Sand & 1,215 & 60 & 13.0 & Estimated volume loss \\
Bentonite & 67.5 & 90 & 13.0 & to bleed = 3 percent \\
Water & 664 & 120 & 13.8 & \\
HRWRA & 2.43 & & & \\
Retarder & 31 oz & & & \\
& & & \\
\hline
\end{tabular}


MIXTURE 6L

\begin{tabular}{|l|c||c|c|c|}
\hline \multicolumn{2}{|c||}{ Mixture Proportions } & \multicolumn{3}{|c|}{ Flow Properties } \\
\hline \multicolumn{1}{|c|}{ Material } & Lb/Cy & Time (min) & Flow (sec) & Comments \\
\hline Class H Cement & 468 & 5 & 13.8 & Compressive strength \\
Class F Fly Ash & 869 & 30 & 13.8 & 3,480 psi \\
Limestone Sand & 1,350 & 60 & 14.5 & \\
Bentonite & 54 & 90 & 15.5 & \\
Water & 619 & 120 & 17.3 & \\
HRWRA & 2.43 & & & \\
Retarder & $26 \mathrm{oz}$ & & & \\
& & & & \\
\hline
\end{tabular}

MIXTURE 10L

\begin{tabular}{|l|c||c|c|c|}
\hline \multicolumn{2}{|c||}{ Mixture Proportions } & \multicolumn{3}{c|}{ Flow Properties } \\
\hline \multicolumn{1}{|c|}{ Material } & Lb/Cy & Time (min) & Flow (sec) & Comments \\
\hline Class H Cement & 468 & 5 & 13.2 & \\
Class F Fly Ash & 1,182 & 30 & 13.0 & \\
Limestone Sand & 854 & 60 & 13.0 & \\
Bentonite & 27 & 90 & 13.2 & \\
Water & 675 & 120 & 13.4 & \\
HRWRA & 0.9 & & & \\
Retarder & 15 oz & & & \\
& & & & \\
\hline
\end{tabular}


MIXTURE IIL

\begin{tabular}{|l|c||c|c|c|}
\hline \multicolumn{2}{|c||}{ Mixture Proportions } & \multicolumn{3}{c|}{ Flow Properties } \\
\hline \multicolumn{1}{|c|}{ Material } & Lb/Cy & Time (min) & Flow (sec) & Comments \\
\hline Class H Cement & 468 & 5 & 14.5 & Specimens cast after \\
Class F Fly Ash & 999 & 30 & 13.4 & 60 minutes of mixing. \\
Limestone Sand & 1,350 & 60 & 13.0 & \\
Bentonite & 13 & 90 & & \\
Water & 594 & 120 & & \\
HRWRA & 2.43 & & & \\
Retarder & 13.5 oz & & & \\
& & & & \\
\hline
\end{tabular}

MIXTURE 17

\begin{tabular}{|l|c||c|c|c|}
\hline \multicolumn{2}{|c||}{ Mixture Proportions } & \multicolumn{3}{c|}{ Flow Properties } \\
\hline \multicolumn{1}{|c|}{ Material } & Lb/Cy & Time (min) & Flow (sec) & \multicolumn{1}{|c|}{ Comments } \\
\hline Class K Cement & 500 & 5 & 11.2 & Compressive strength \\
Class F Fly Ash & 1,000 & 30 & 13.0 & 810 days (73 ${ }^{\circ}$ ) $=$ \\
Basalt Sand & 1,233 & 60 & 12.5 & Specimens cast after \\
Bentonite & 0 & 90 & & 60 minutes of mixing. \\
Water & 600 & 120 & & \\
HRWRA & 0 & & & \\
Retarder & 0 & & & \\
\end{tabular}


MIXTURE 18

\begin{tabular}{|l|c||c|c|l|}
\hline \multicolumn{2}{|c||}{ Mixture Proportions } & \multicolumn{3}{c|}{ Flow Properties } \\
\hline \multicolumn{1}{|c|}{ Material } & Lb/Cy & Time (min) & Flow (sec) & \multicolumn{1}{|c|}{ Comments } \\
\hline Class K Cement & 500 & 5 & 13.6 & Compressive strength \\
Class F Fly Ash & 1,000 & 30 & 13.8 & at 7 days (73 ${ }^{\circ}$ F) - \\
Basalt Sand & 850 & 60 & 14.0 & \\
Bentonite & 0 & 90 & & \\
Water & 750 & 120 & & \\
HRWRA & 2.6 & & & \\
Retarder & $15 \mathrm{oz}$ & & & \\
& & & & \\
\hline
\end{tabular}

MIXTURE 19

\begin{tabular}{|l|c||c|c|l|}
\hline \multicolumn{2}{|c||}{ Mixture Proportions } & \multicolumn{3}{c|}{ Flow Properties } \\
\hline \multicolumn{1}{|c|}{ Material } & Lb/Cy & Time (min) & Flow (sec) & \multicolumn{1}{|c|}{ Comments } \\
\hline Class K Cement & 400 & 5 & 12.2 & Slight aggregate fallout \\
Class F Fly Ash & 1,072 & 30 & 13.0 & at 5 minutes. \\
Basalt Sand & 1,233 & 60 & 13.0 & No fallout at 60 minutes. \\
Bentonite & 0 & 90 & & Compressive strength at \\
Water & 600 & 120 & & 7 days (73 ${ }^{\circ}$ F) $=700$ psi \\
HRWRA & 0 & & & \\
Retarder & 12 oz & & & \\
& & & & \\
\hline
\end{tabular}


MIXTURE 20

\begin{tabular}{|l|c||c|c|c|}
\hline \multicolumn{2}{|c|}{ Mixture Proportions } & \multicolumn{3}{|c|}{ Flow Properties } \\
\hline Material & Lb/Cy & Time (min) & Flow (sec) & Comments \\
\hline Class H Cement & 300 & 5 & 19 & \\
Class F Fly Ash & 1,112 & 30 & 17.4 &, \\
Basalt Sand & 1,314 & 60 & 17.9 & \\
Bentonite & 38 & 90 & 17.8 & \\
Water & 564 & 120 & 18.6 & \\
HRWRA & 4.86 & & & \\
Retarder & 4.6 oz & & & \\
& & & \\
\hline
\end{tabular}

MIXTURE 21

\begin{tabular}{|l|c||c|c|c|}
\hline \multicolumn{2}{|c||}{ Mixture Proportions } & \multicolumn{3}{c|}{ Flow Properties } \\
\hline \multicolumn{1}{|c|}{ Material } & Lb/Cy & Time (min) & Flow (sec) & Comments \\
\hline Class K Cement & 607 & 5 & 27 & Mixture not fluid \\
Class F Fly Ash & 1,087 & 30 & 22 & enough. \\
Basalt Sand & 835 & 60 & 17.8 & \\
Bentonite & 48 & 90 & 20.0 & \\
Water & 677 & 120 & 16.8 & \\
HRWRA & 10.3 & & & \\
Retarder & $8.3 \mathrm{oz}$ & & & \\
& & & & \\
\end{tabular}


MIXTURE 22

\begin{tabular}{|l|c||c|c|c|}
\hline \multicolumn{2}{|c||}{ Mixture Proportions } & \multicolumn{3}{c|}{ Flow Properties } \\
\hline \multicolumn{1}{|c|}{ Material } & Lb/Cy & Time (min) & Flow (sec) & Comments \\
\hline Class H Cement & 350 & 5 & 16.8 & \\
Class F Fly Ash & 1,077 & 30 & 17.1 & \\
Basalt Sand & 1,296 & 60 & 17.3 & 17.9 \\
Bentonite & 42 & 90 & 19.3 & \\
Water & 571 & 120 & & \\
HRWRA & 5.4 & & & \\
Retarder & 5.4 oz & & & \\
& & & & \\
\hline
\end{tabular}


APPENDIX B:

REPORTS FROM EXAMINATION OF CEMENT, AGGREGATES, AND INTERFACE BETWEEN COLD-CAP GROUT AND SIMULATED WASTE 
US Army Engineer

Waterways Experiment Station 3909 Halls Ferry Road

Vicksburg, Mississippi 39180-6199
SUBJECT: Petrographic Examination of a Class $H$ Oil Well Cement (HAN-I C-1)

DATE: 22 March 1991

1. In March 1991, you requested a petrographic examination of a Class H Oil Well cement received from the Lone Star Industries, Inc., Mary Neal, Texas. The cement was assigned the Structures Laboratory serial No. HAN-1 C-1.

2. A composite of the as-received cement was examined by $X$-ray diffraction (XRD).

3. Approximately $5 \mathrm{-g}$ was treated for $30 \mathrm{~min}$ in a 20 percent solution of maleic acid in methanol. This test was done to remove the silicates, alite $\left(\mathrm{C}_{3} \mathrm{~S}\right)$ and belite $\left(\mathrm{C}_{2} \mathrm{~S}\right)$, from the sample. The insoluble material was collected on filter paper, dried and weighed. The percent of silicates in the sample were calculated. A composite of the residue was examined by XRD.

4. The residue left after the maleic acid treatment was next treated for one hour with a 10 percent solution of ammonium chloride $\left(\mathrm{NH}_{4} \mathrm{Cl}\right)$ in deionized water. This test will remove sulfates. The insoluble material was collected on filter paper, dried and weighed. The percent of material lost was calculated. A composite of the residue was examined by XRD.

5. The tests by selective dissolution to determine the percent of silicates and sulfates in the sample showed that 81.7 percent were $C_{3} S$ and $C_{2} S$. Of the 18.3 percent insoluble, 4.9 percent was lost during the $\mathrm{NH}_{4} \mathrm{Cl}$ treatment. However, some $\mathrm{MgO}$ was lost during the $\mathrm{NH}_{4} \mathrm{Cl}$ test, as evidenced by the loss in intensity of $\mathrm{MgO}$ XRD lines after treatment with $\mathrm{NH}_{4} \mathrm{Cl}$. A good estimate of total sulfates in the sample would be approximately three percent.

6. The crystalline phases present, as determined by XRD are:

Alite $\left(\mathrm{C}_{3} \mathrm{~S}\right)$

Belite $\left(\mathrm{C}_{2} \mathrm{~S}\right)$

Calcium aluminoferrite $\left(\mathrm{C}_{4} \mathrm{AF}\right)$

MgO

Gypsum $(C \bar{S} \cdot 2 \mathrm{H})$

Anhydxite $(C \bar{S})$

Calcium sulfate hemihydrate $(C \bar{S} \cdot 1 / 2 \mathrm{H})$

Quartz (tr)

A trace of potassium sulfate, and a trace of the substituted $\left(\mathrm{NC}_{8} \mathrm{~A}_{3}\right)$ calcium aluminate was tentatively identified. Alite was the major phase. 
US Army Engineer

Waterways Experiment Station

3909 Halls Ferry Road

Vicksburg, Mississippi 39180-6199
SUBJECT: Examination of $\mathrm{HAN}-1$ S-3 Sand

DATE: 8 March 1991

1. A small plastic bag containing several pounds of basaltic sand from Acme Materials, Richland, WA, was received for tests. A composite of the sand was separated into six sieve sizes. The percent by weight of each size was determined (Table Bl).

2. X-ray diffraction was used to determine the mineralogy of sand collected on sieve sizes No. $4(4.75 \mathrm{~mm})$, No. $100(150 \mu \mathrm{m})$, and Pan (Table B2).

3. A stereomicroscope was used to examine the sand. Particle shapes were determined.

4. Selected particles from each sample were picked to be examined as immersion mounts prepared using an oil with a refractive index of $n=1.544$. The mounts were examined with a polarizing microscope.

5. Chert was found. Some has an index of refraction lower than $n=1.544$.

6. The examination showed that this sand, and sand HAN-1 S-2 which was a previous batch from Acme Materials, are similar. The color, mineralogical composition, and shapes of particles are alike. The finer sieve fractions of both HAN-1 S-2 and S-3 contain considerable quartz.

7. The characteristics of this natural sand make it suitable for use as a fine aggregate for grout or concrete.

Table B1

Size Fractions by Weight of HAN -1 S -3

\begin{tabular}{lc}
\hline Sieve Size & Percent Contained \\
\hline No. $4(4.75 \mathrm{~mm})$ & 2.7 \\
No. $8(2.36 \mathrm{~mm})$ & 19.3 \\
No. $16(1.18 \mathrm{~mm})$ & 13.0 \\
No. $100(150 \mu \mathrm{m})$ & 59.0 \\
No. $200(75 \mu \mathrm{m})$ & 4.4 \\
Pan & 1.1 \\
Total & 100
\end{tabular}


Table B2

Mineralogical Composition by X-ray Diffraction of HAN-1 S-3

\begin{tabular}{lc}
\hline Constituents & HAN $-1 \mathrm{~S}-3$ \\
\hline Clay & Prob. \\
Smectite & $\mathrm{X}$ \\
Clay mica & $\mathrm{X}$ \\
Chlorite & Poss. \\
Kaolinite group & \\
Nonclays & $\mathrm{X}$ \\
Quartz & $\mathrm{X}$ \\
Plagioclase Feldspar & $\mathrm{X}$ \\
Potassium Feldspar & $\mathrm{X}$ \\
Calcite & $\mathrm{X}$ \\
Pyroxene* & $\mathrm{X}$ \\
Amphibole* & $\mathrm{X}$ \\
Magnetite & $\mathrm{X}$ \\
Hematite & $\mathrm{X}$ \\
Glass & \\
\hline Monoclinic crystal structure & \\
\hline
\end{tabular}


US Army Engineer

Waterways Experiment Station

3909 Halls Ferry Road

Vicksburg, Mississippi 39180-6199
SUBJECT: Petrographic Examination of Specimen CC-9, Hanford Cold-Gap Grout

DATE: 3 April 1991

1. Background. Samples of interfaces between candidate cold-cap grouts CC-9 through CC-16 and simulated wasteform grout were examinated to determine characteristics of the interface. Samples were laboratory-cast 2- by 4-in. cylinders, the lower half of each being simulated wasteform grout. Interfaces were studied for phase composition (X-ray diffraction (XRD)), chemical composition (energy-dispersive X-ray (EDX)), and physical appearance (microscopy and scanning electronic microscopy (SEM)). These studies revealed no notable differences among all candidate grouts. Results of the studies of CC-9 and CC-II interfaces are reported here as examples.

2. The interface between cold-cap grout and wasteform had a thin layer of frothy material for both specimens. The frothy material was filled with air voids. No bond was formed. Grout and wasteform fell apart when the two specimens were demolded. No evidence of fluid movement was found by visual examination.

3. Examination of the froth by EDX showed sodium (Na) was a little high. Tables B3 and B4 gives a semiquantitative listing of chemical elements found in froth from the cold-cap and wasteform, respectively.

4. Eleven EDX spectrum were made from a specimen of the cold-cap grout. Ten of the spectrum were collected within $5-\mathrm{mm}$ of the interface with wasteform. One spectrum was collected near the top of the cold-cap, on opposite end from the wasteform. Figure BI shows the two spectrum that were collected at opposite ends, superimposed to show that a phosphorus (P) peak is probably present in the cold-cap grout at the interface, but not present at the other (top) end of the grout. Table B5 gives a semiquantitative listing of chemical elements in one of the spectrum collected near the interface.

5. SEM examination of pieces of cold-cap and wasteform material showed $\mathrm{C}-\mathrm{S}-\mathrm{H}$ gel was common to both materials. Small thin platelets of calcium hydroxide (CH) were also present in both materials. Figures $\mathrm{B} 2$ and $\mathrm{B} 3$ shows some $\mathrm{C}-\mathrm{S}-\mathrm{H}$ gel that was typical to both the cold-cap and wasteform, respectively. Figure B2 shows thin platelets of what is probably $\mathrm{CH}$ in the top portion of the photomicrograph. Figure B3 shows thin CH platelets in the lower right corner of the bottom portion of the photomicrograph. The C-S-H gel in both have the Type II reticular network morphology.

6. X-ray diffraction examination of the two froth samples examined showed several crystalline phases present. Ettringite, $\mathrm{CH}$, and $\mathrm{C}-\mathrm{S}-\mathrm{H}$ gel were identified by $\mathrm{XRD}$. Tetracalcium aluminate carbonate-11-hydrate $\left(C_{4} A \mathrm{CH}_{11}\right)$ was present in the froth from the cold-cap, but not in froth from the wasteform. Unhydrated portland cement and fly ash were present in both froth samples; however, more was present in the cold-cap froth than the froth from wasteform.

7. Examination by XRD of a piece of wasteform, and a piece of the cold-cap both from near the contact zone, showed broad, but well defined peaks of $\mathrm{C}-\mathrm{S}-\mathrm{H}$ 
ge1. Calcium hydroxide was also identified in both samples. No ettringite or $\mathrm{C}_{4} \mathrm{ACH}_{11}$ were identified. Calcite and dolomite probably from the palygorskite, were present in the wasteform material. The cold-cap material showed peaks of plagioclase feldspar from the basalt aggregate. No crystalline clay remains in the wasteform. 
Table B3

FILE NAME: SPT DIG01B

LABEL: FROTH CC-9 COLD CAP GROUT STORED ELEMENTS

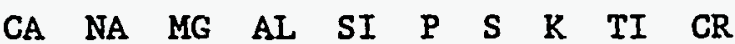
MN FE

$X$-AXIS IABEL: ENERGY (KEV)

SPECTRUM STATUS:

LINEAR BACKGROUND SUBTRACTION

NOT FILTERED

SPECTRUM HAS BEEN PROCESSED BY QUANT

SPECTRUM HAS NOT BEEN SMOOTHED

LIVE TIME (SEC):

ACCELER. VOLT. (KEV):

100.00

COLLECTION DATE:

START OF SPECTRUM:

END OF SPECTRUM:

21

$3 / 28 / 91$

0.000

BEGINNING OF QUANT DATA

TAKE OFF ANGLE [DEG]:

TIIT ANGLE [DEG]:

PROBE CURRENT [AMPS] :

ELEMENT METHOD VALENCE K-RATIO

\begin{tabular}{lcccr} 
EMENT & METHOD & VALENCE & K-RATIO & \multicolumn{1}{c}{ WT \% } \\
CA & $\mathrm{K}$ & 2.00 & 0.23717 & 27.0491 \\
NA & $\mathrm{K}$ & 1.00 & 0.02617 & 6.3045 \\
MG & $\mathrm{K}$ & 2.00 & 0.01577 & 2.9587 \\
AI & $\mathrm{K}$ & 3.00 & 0.11234 & 17.6140 \\
SI & $\mathrm{K}$ & 4.00 & 0.20761 & 34.9049 \\
P & $\mathrm{K}$ & 5.00 & 0.00181 & 0.3858 \\
S & $\mathrm{K}$ & 6.00 & 0.00911 & 1.5108 \\
K & $\mathrm{K}$ & 1.00 & 0.01075 & 1.2684 \\
TI & $\mathrm{K}$ & 4.00 & 0.02036 & 2.6176 \\
CR & $\mathrm{K}$ & 3.00 & 0.00199 & 0.2384 \\
MN & $\mathrm{K}$ & 2.00 & 0.00000 & 0.0005 \\
FE & $\mathrm{K}$ & 2.00 & 0.04447 & 5.1472
\end{tabular}

\# OF ELEMENTS ANALYZED BY QUANT: 12 
Table B4

-FILE NAME: SPT DIGO2B

LABEL: FROTH CC-9 WASTE GROUT

STORED ELEMENTS

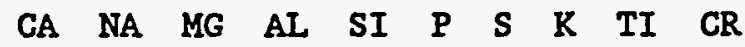

MN FE

X-AXIS LABEL: ENERGY (KEV)

SPECTRUM STATUS:

LINEAR BACKGROUND SUBTRACTION

NOT FILTERED

SPECTRUM HAS BEEN PROCESSED BY QUANT

SPECTRUM HAS NOT BEEN SMOOTHED

LIVE TIME (SEC):

ACCELER. VOLT. (KEV):

100.00

COLLECTION DATE:

21

START OF SPECTRUM:

$3 / 28 / 91$

END OF SPECTRUM:

0.000

NUMBER OF CHANNELS IN SPECTRUM: 2000

BEGINNING OF QUANT DATA

TAKE OFF ANGLE [DEG]:

TILT ANGLE [DEG]:

PROBE CURRENT [AMPS]:

ELEMENT METHOD VALENCE

K-RATIO

CA

NA

$\mathrm{K}$

2.00

0.25001

MG

$\mathrm{K}$

1.00

0.03047

35

AL

K $\quad 2.00$

0.01351

SI

$\mathrm{K}$

3.00

0.11262

0.18823

$P \quad K \quad 5.00$

0.00131

S $\quad K \quad 6.00$

0.01661

$\mathrm{K}$

$\mathrm{K} \quad 1.00$

0.00963

TI

$\mathrm{K} \quad 4.00$

0.01936

$\begin{array}{ll}\mathrm{K} & 3.00 \\ \mathrm{~K} & 2.00\end{array}$

0.00091

0

CR

0.00000

FE

$\mathrm{K}$

2.00

0.04328

非 OF ELEMENTS ANALYZED BY QUANT:

$0.54 E-09$

WT $x$

28.4356

7.3835

2.6007

17.8884

31.9687

0.2720

2.6992

1.1313

2.4985

0.1091

0.0000

5.0130

12 
Table B5

FILE NAME: SPT DIGO9B

IABEL: HANFORD CC-9 COLD CAP GROUT STORED ELEMENTS

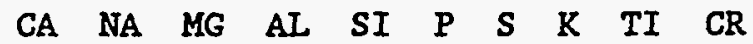

MN FE

X-AXIS LABEL: ENERGY (KEV)

SPECTRUM STATUS :

LINEAR BACKGROUND SUBTRACTION

NOT FILTERED

SPECTRUM HAS BEEN PROCESSED BY QUANT

SPECTRUM HAS NOT BEEN SMOOTHED

LIVE TIME (SEC) :

ACCELER. VOLT. (KEV):

88.84

COLLECTION DATE:

START OF SPECTRUM:

21

END OF SPECTRUM:

$3 / 29 / 91$

NUMBER OF CHANNELS IN SPECTRUM: 2000

0.000

BEGINNING OF QUANT DATA

TAKE OFF ANGLE [DEG]:

TIIT ANGLE [DEG] :

PROBE CURRENT [AMPS] :

ELEMENT METHOD VALENCE K-RATIO

0

$0.54 \mathrm{E}-09$

$\begin{array}{llllr}\text { CA } & \mathrm{K} & 2.00 & 0.30845 & 34.5640 \\ \text { NA } & \mathrm{K} & 1.00 & 0.01341 & 3.6046 \\ \text { MG } & \mathrm{K} & 2.00 & 0.01369 & 2.6290 \\ \text { AL } & \mathrm{K} & 3.00 & 0.10644 & 16.8832 \\ \text { SI } & \mathrm{K} & 4.00 & 0.18631 & 31.1610 \\ \text { P } & \mathrm{K} & 5.00 & 0.00180 & 0.3663 \\ \text { S } & \mathrm{K} & 6.00 & 0.00476 & 0.7607 \\ \text { K } & \mathrm{K} & 1.00 & 0.00803 & 0.9168 \\ \text { TI } & \mathrm{K} & 4.00 & 0.02097 & 2.7407 \\ \text { CR } & \mathrm{K} & 3.00 & 0.00245 & 0.2959 \\ \text { MN } & \mathrm{K} & 2.00 & 0.00031 & 0.0373 \\ \text { FE } & \mathrm{K} & 2.00 & 0.05192 & 6.0406\end{array}$

非 OF ELEMENTS ANALYZED BY QUANT: 12 


\begin{tabular}{|c|c|c|c|c|c|c|c|}
\hline 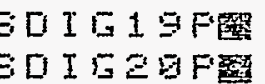 & $\begin{array}{l}\text { HAH } \\
\text { HAH }\end{array}$ & $\begin{array}{l}B E-9 \\
E-9\end{array}$ & $\begin{array}{l}\text { COLO } \\
\text { EOLO }\end{array}$ & $\begin{array}{l}E A F \\
C A F\end{array}$ & $\begin{array}{l}\text { EOHTACT } \\
\text { TOP }\end{array}$ & & AUS \\
\hline & & & & & $F$ & $K \Sigma$ & \\
\hline $5005:$ & $\begin{array}{l}\text { II } \\
\text { Cuf }\end{array}$ & & 2090 & 8 & 17 201 & $4 T E$ & $\begin{array}{l}100 \\
100\end{array}$ \\
\hline
\end{tabular}

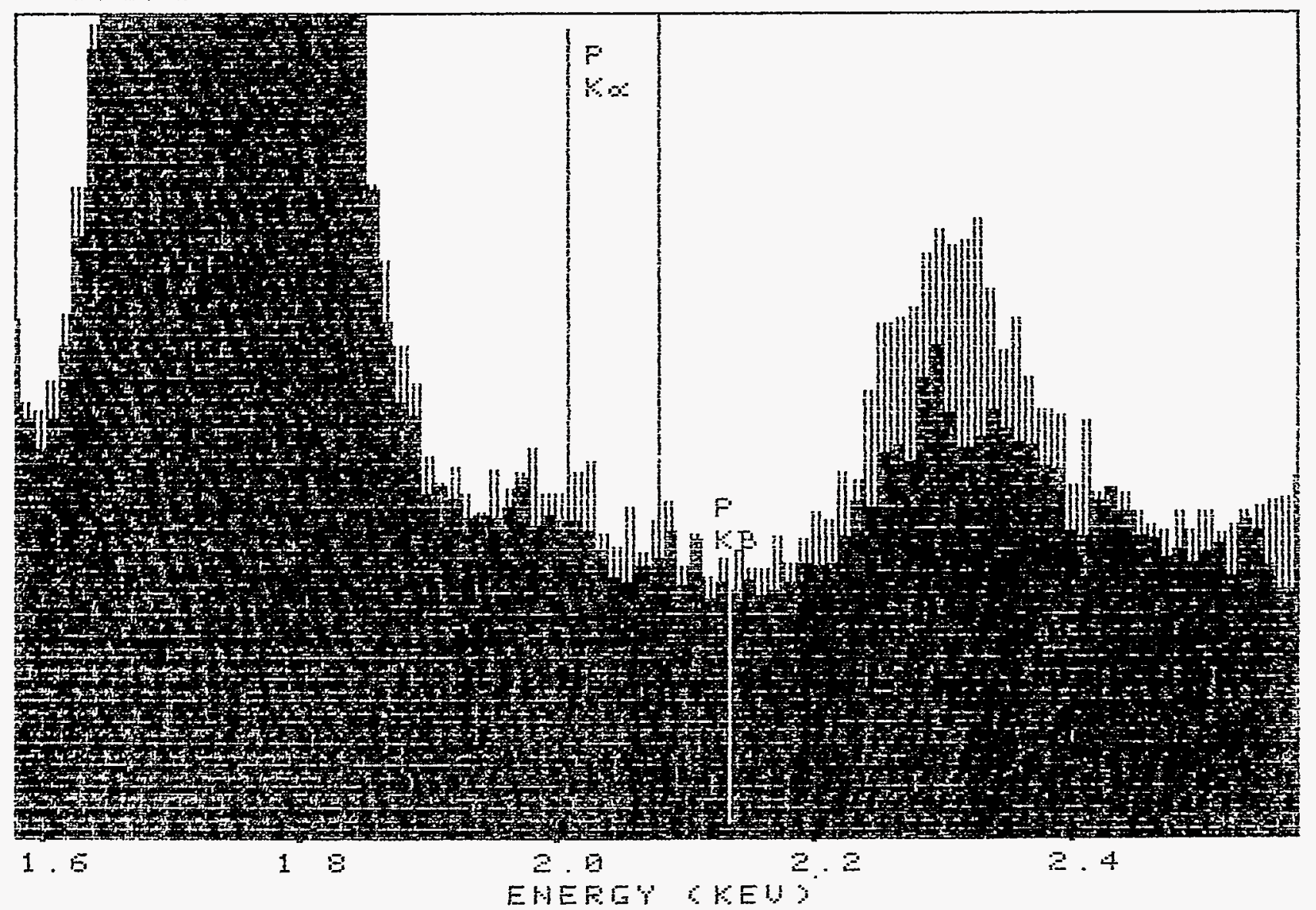

Figure B1. The dark portion is the spectrum collected at the top of cold-cap grout. The light portion is the spectrum collected near the interface of cold-cap and wasteform. A slight peak at $2.013 \mathrm{kev}$ is probably $P$. Sulfur is probably higher near the interface, also. 


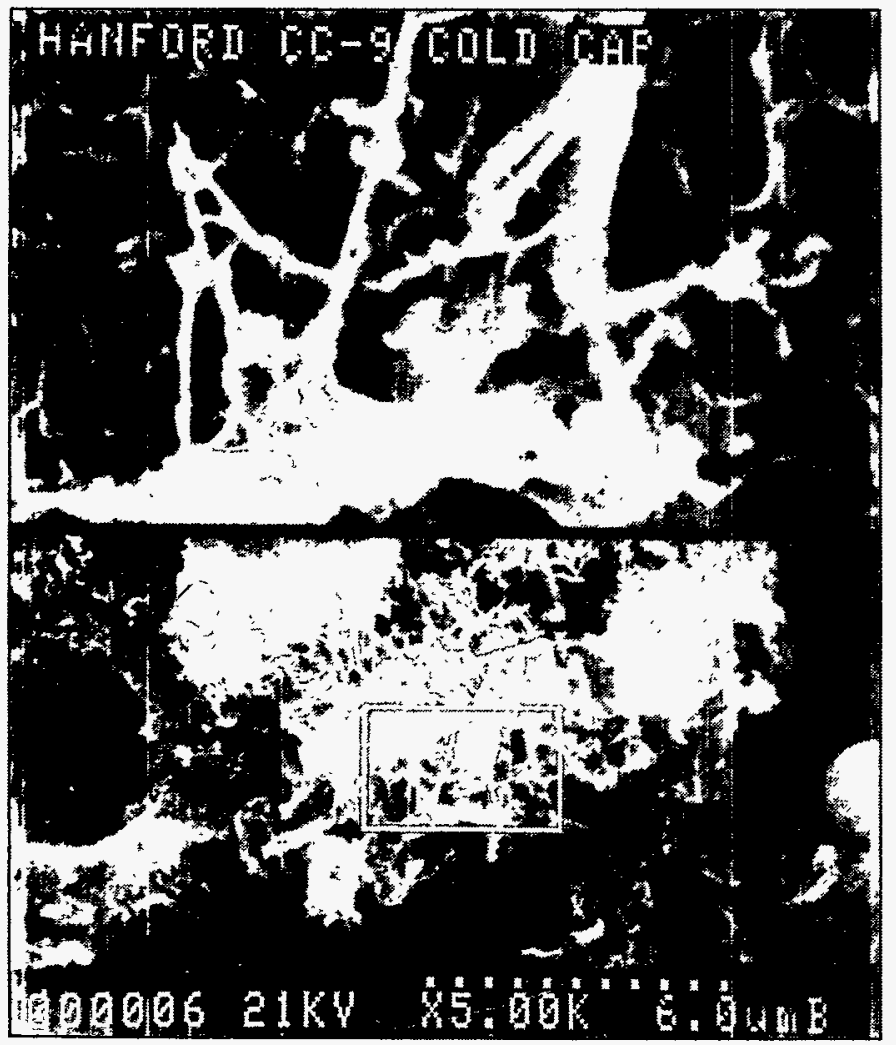

Figure B2

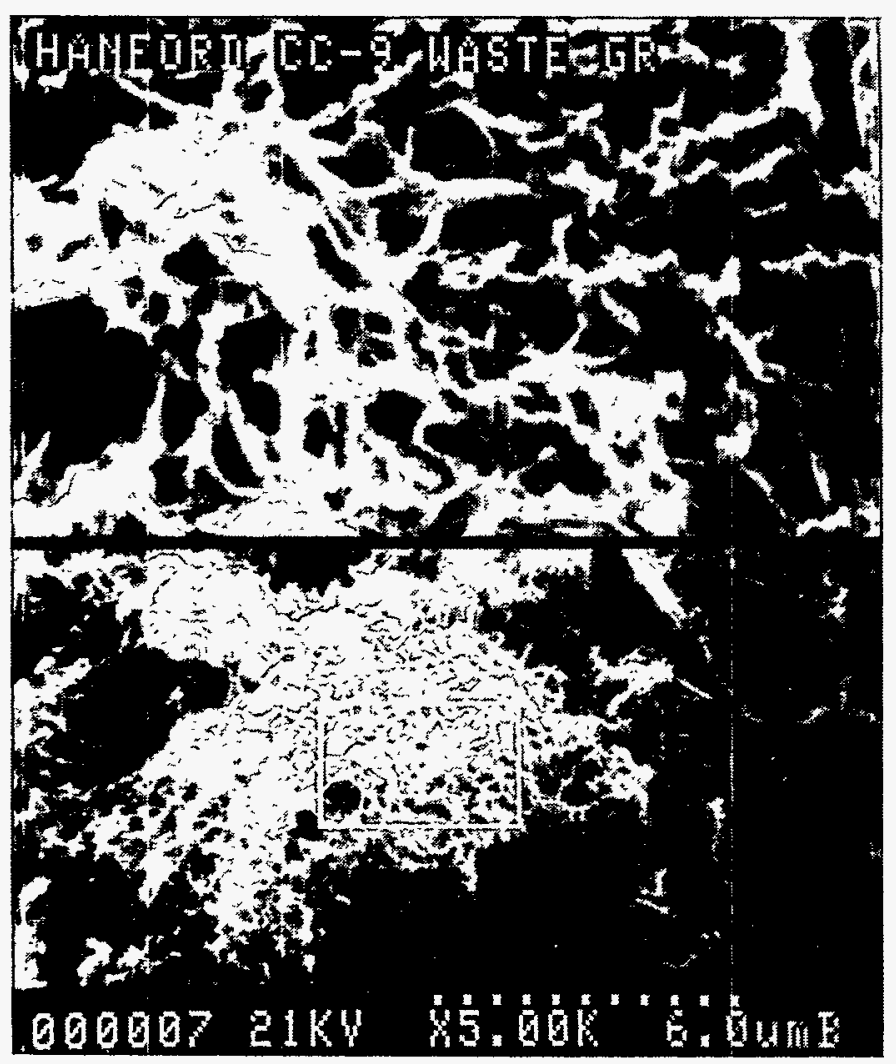

Figure B3
Figure B2

Photomicrograph 1 . Hanford CC-9 cold-cap. The lower half is magnified X 5,000. The upper half consists of the area in the rectangle magnified X 25,000. C-S-H gel with type II reticular network morphology is present. Thin platelets of $\mathrm{CH}$ appear to be present in the upper portion.

\section{Figure B3}

Photomicrograph 2. Hanford CC-9 wasteform. The lower half is magnified $X 5,000$. The upper half consists of the area in the rectangle magnified X 25,000. Type II reticular network morphology $\mathrm{C}-\mathrm{S}-\mathrm{H}$ gel is present. Thin platelets of $\mathrm{CH}$ are present in the lower right corner of the micrograph. 
April 20, 1992

From: Dr. Charles A. Weiss, Jr./J. Pete Burkes

To: Dr. Lillian Wakeley

Subject: Mineralogy and Chemistry of Longitudinal Core Samples Taken from Interface between simulated Waste and Cold-Cap Grout in Physical Model

\section{X-ray Analysis}

$\mathrm{X}$-ray diffraction analysis of bulk samples revealed the presence of the following minerals from most to least abundant.

\section{(A) Cold Cap Distal from Interface}

Quartz

Na, Ca-Feldspar

Diopside $\left[\mathrm{CaMg}\left(\mathrm{SiO}_{3}\right)_{2}\right]$ - minor

$\mathrm{Ca}_{2} \mathrm{SiO}_{4}\left(\mathrm{C}_{2} \mathrm{~S}\right)$ - minor

(C) Material on Contact - Waste Side

Quartz

Albite

Calcite

Hematite

Iron

(E) Waste Side Distal from Interface

Calcite

Quartz

Dolomite
(B) Interface - Cold Cap Side

Quartz

$\mathrm{Na}, \mathrm{Ca}-\mathrm{Feldspar}$

Diopside $\left[\mathrm{CaMg}\left(\mathrm{SiO}_{3}\right)_{2}\right]$ - minor

$\mathrm{Ca}_{2} \mathrm{SiO}_{4}\left(\mathrm{C}_{2} \mathrm{~S}\right)$ - minor

Dolomite - minor

(D) Interface - Waste Side

Calcite

Quartz

Aragonite

Vaterite

In addition there is an amorphous component present in all the samples.

\section{Elemental Analysis}

(E) Waste vs. (A) Cold Cap

$20 \%$ less $\mathrm{SiO}_{2}$

$4 \%$ less $\mathrm{Al}_{2} \mathrm{O}_{3}$

$1 \%$ more $\mathrm{P}_{2} \mathrm{O}_{5}$

$22 \%$ more $\mathrm{CaO}$
(C) Material on Waste Side vs. (B) Cold Cap Interf.

6.5\% less $\mathrm{SiO}_{2}$

$2 \%$ more $\mathrm{Al}_{2} \mathrm{O}_{3}$

$1.5 \%$ more $\mathrm{CaO}$

2.5\% more $\mathrm{Fe}_{2} \mathrm{O}_{3}$ 
(C) Material on Waste Side vs. (A) Distal from Cold Cap

$3 \%$ less $\mathrm{SiO}_{2}$

2.5\% more $\mathrm{Al}_{2} \mathrm{O}_{3}$

$1 \%$ less $\mathrm{CaO}$

(C) Material on Waste Side vs. (D) Waste Interf.

$15.5 \%$ more $\mathrm{SiO}_{2}$

$6 \%$ more $\mathrm{Al}_{2} \mathrm{O}_{3}$

$1 \%$ less $\mathrm{P}_{2} \mathrm{O}_{5}$

$24 \%$ less $\mathrm{CaO}$

On the waste side of the interface the 3 polymorphs of $\mathrm{CaCO}_{3}$, Calcite, Aragonite, and Vaterite are observed. Since neither Vaterite, nor Aragonite are observed in any of the other samples, this indicates that they were formed in situ and not transported from either the waste or cold cap. As with the cold cap-9 samples, the carbonate minerals probably formed prior to the emplacement of the cold cap. The source for the $\mathrm{Ca}^{2+}$ is the waste grout which has $37 \% \mathrm{CaO}$ far from the interface and $40 \%$ $\mathrm{CaO}$ at the interface. The source of $\mathrm{CO}_{2}$ is most likely to be the air over the waste.

The other elements in the waste grout are minor compared to water $\mathrm{Ca}(37 \%), \mathrm{Al}(13 \%), \mathrm{Si}(35 \%)$, and $\mathrm{Fe}(4 \%)$ which are presumably derived from the solid components added to the waste, i.e., the Type I/II Portland Cement, the Class F Fly Ash, and the clays.

The material found adhered to the waste side of the interface was derived from the cold cap due to the presence of $\mathrm{Na}$, Ca-Feldspar which is only found in the cold cap. The elemental analyses supports this hypothesis, because the chemistry more closely resembles that of the bulk chemistry for the cold cap.

Dr. Charles A. Weiss, Jr. Geochemist
J. Pete Burkes

Geologist 
APPENDIX C:

PLOTS OF THE DATA FROM INDIVIDUAL STRAIN METERS 

HANFORD COLD CAP PHYSICAL MODEL

LIFT1 CARLSON GAGE: M6940

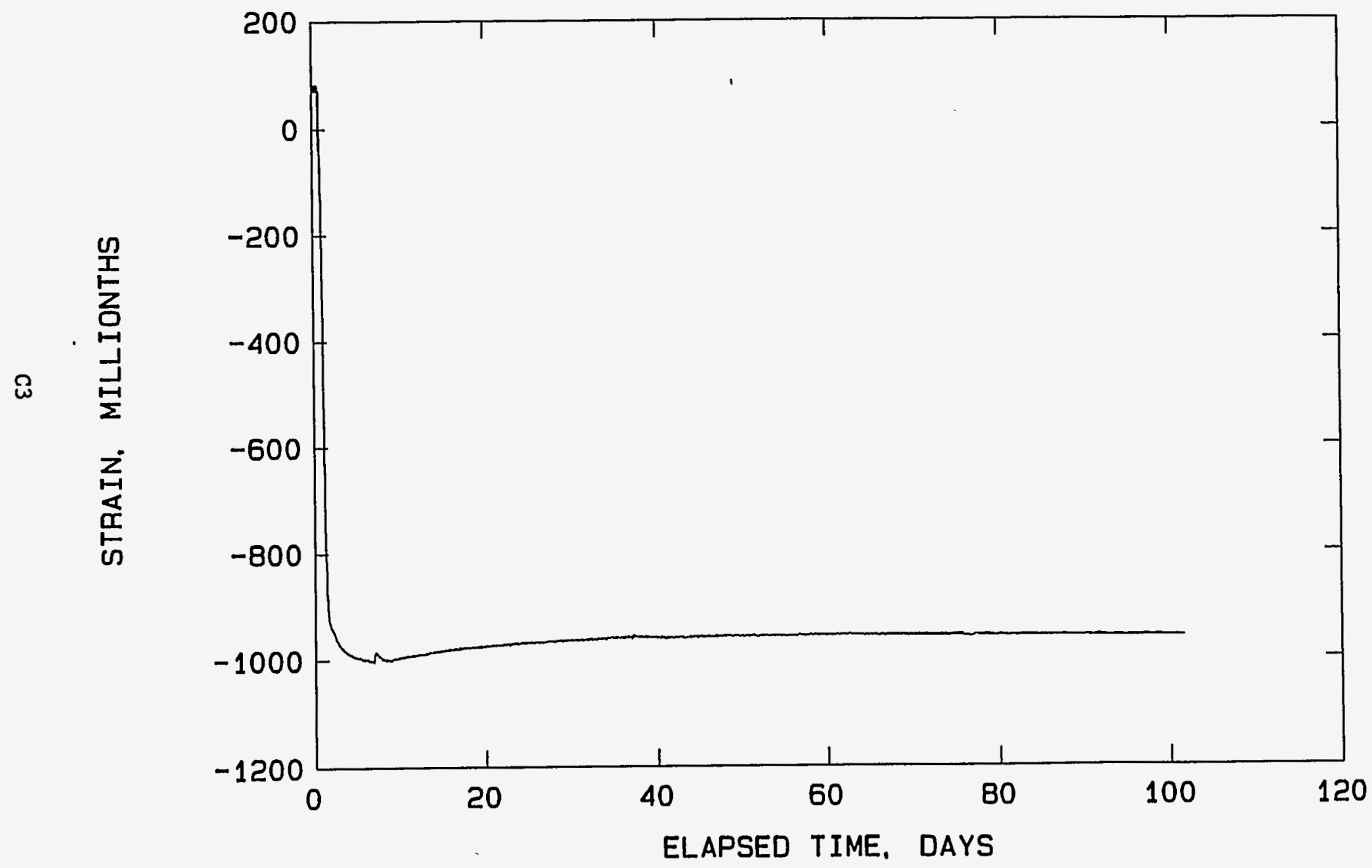


HANFORD COLD CAP PHYSICAL MODEL

LIFT1 CARLSON GAGE: M6940

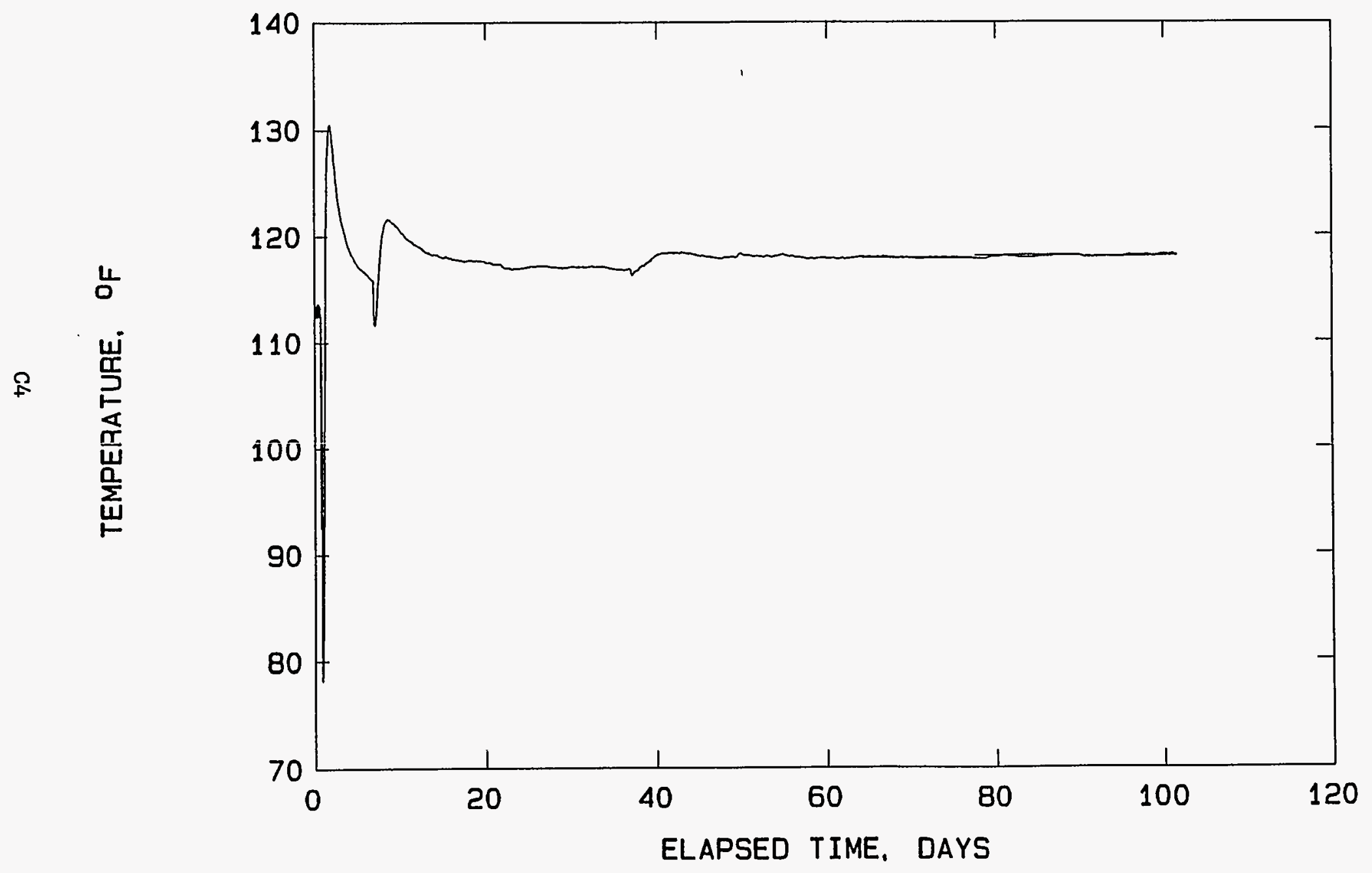


HANFORD COLD CAP PHYSICAL MODEL

LIFT 1 CARLSON GAGE: M6941

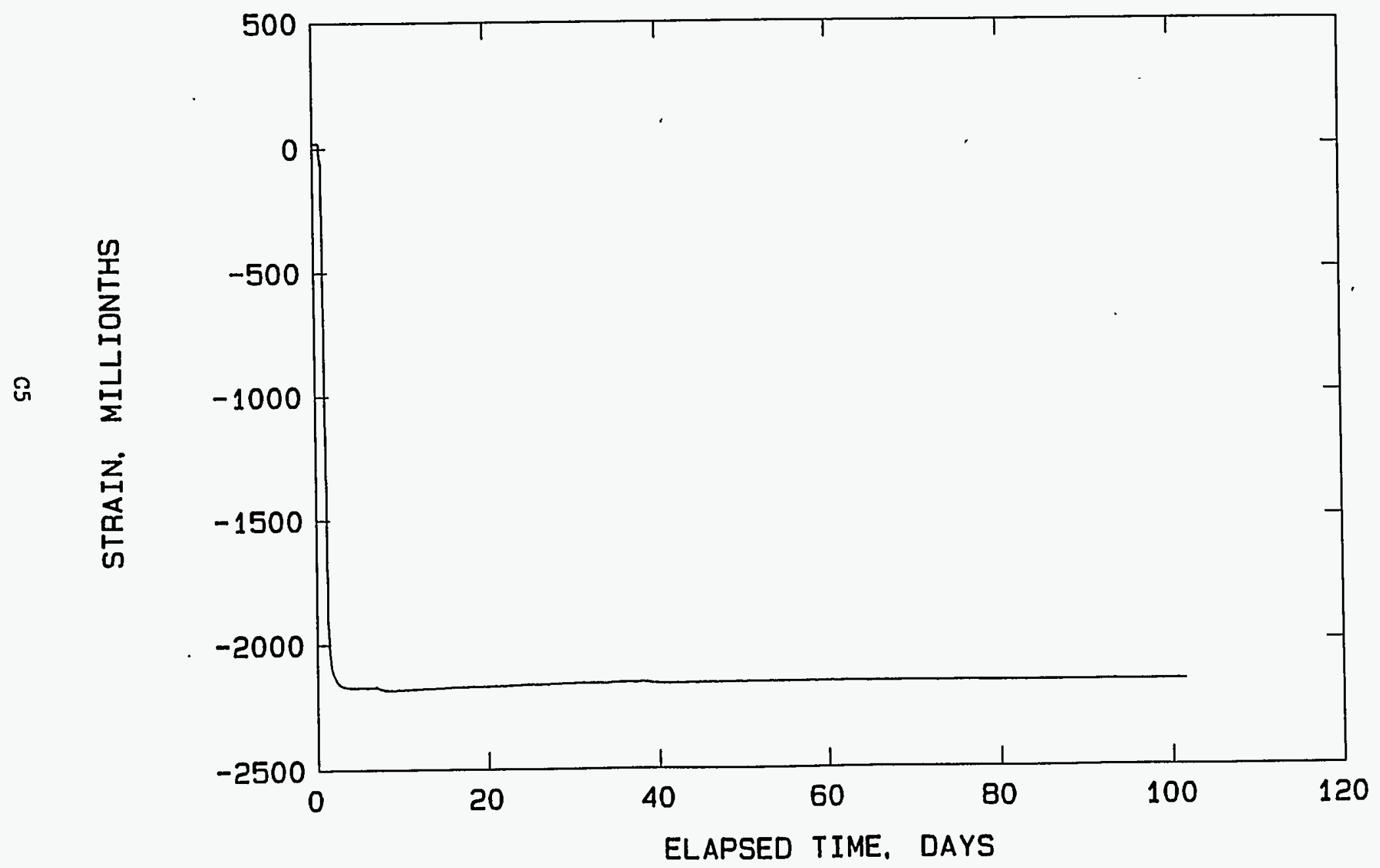


HANFORD COLD CAP PHYSICAL MODEL

LIFT1 CARLSON GAGE: M6941

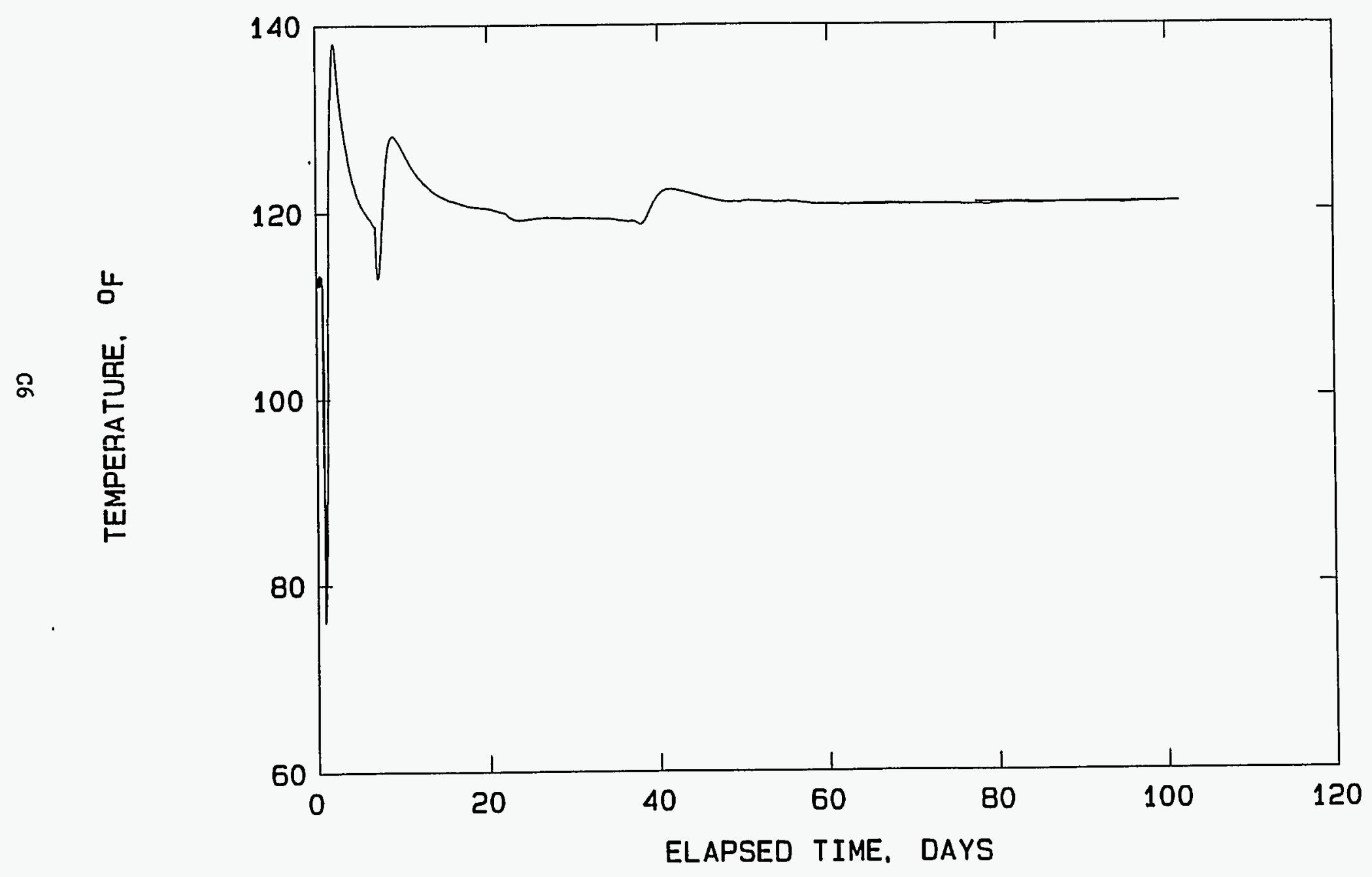




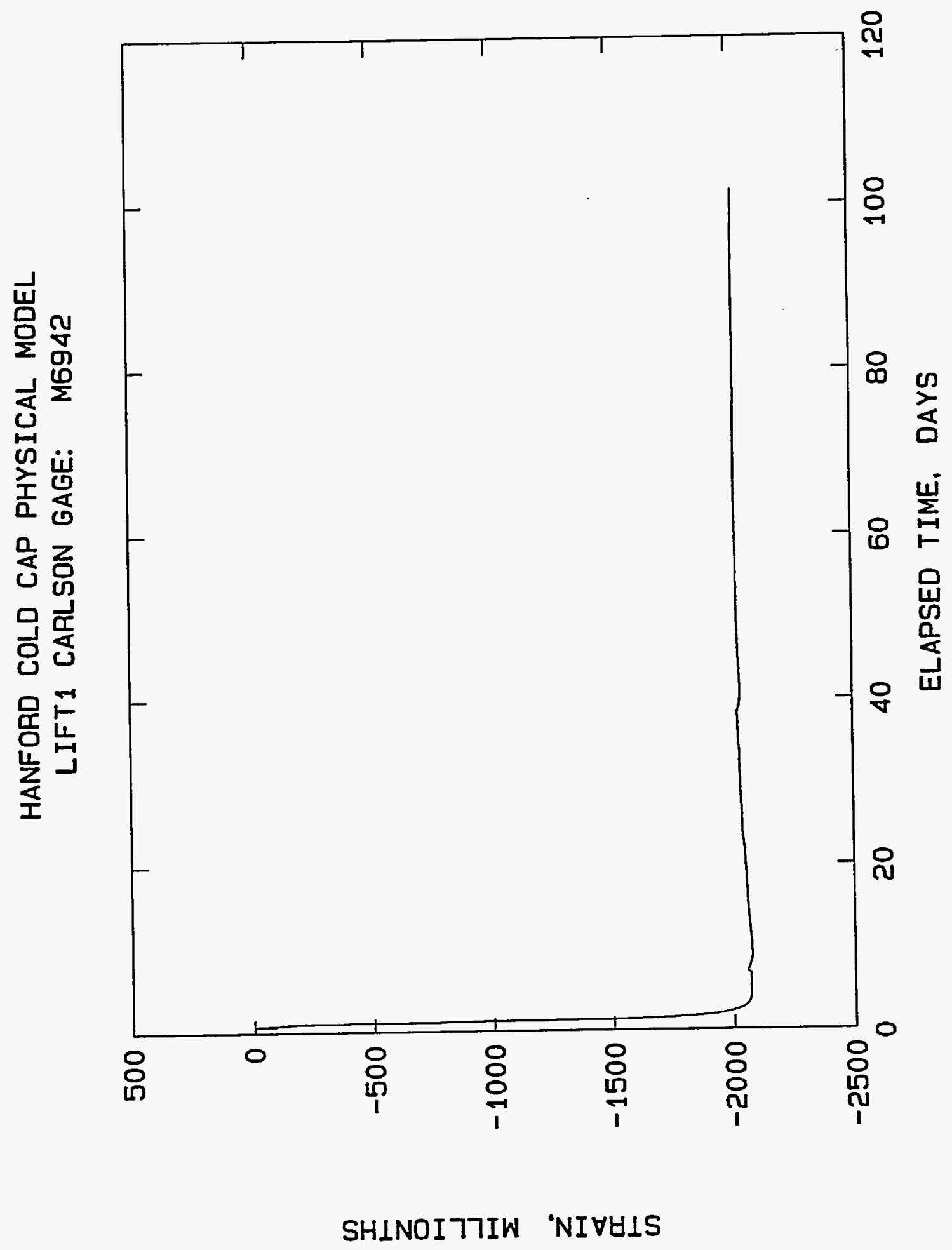


HANFORD COLD CAP PHYSICAL MODEL

LIFT1 CARLSON GAGE: M6942

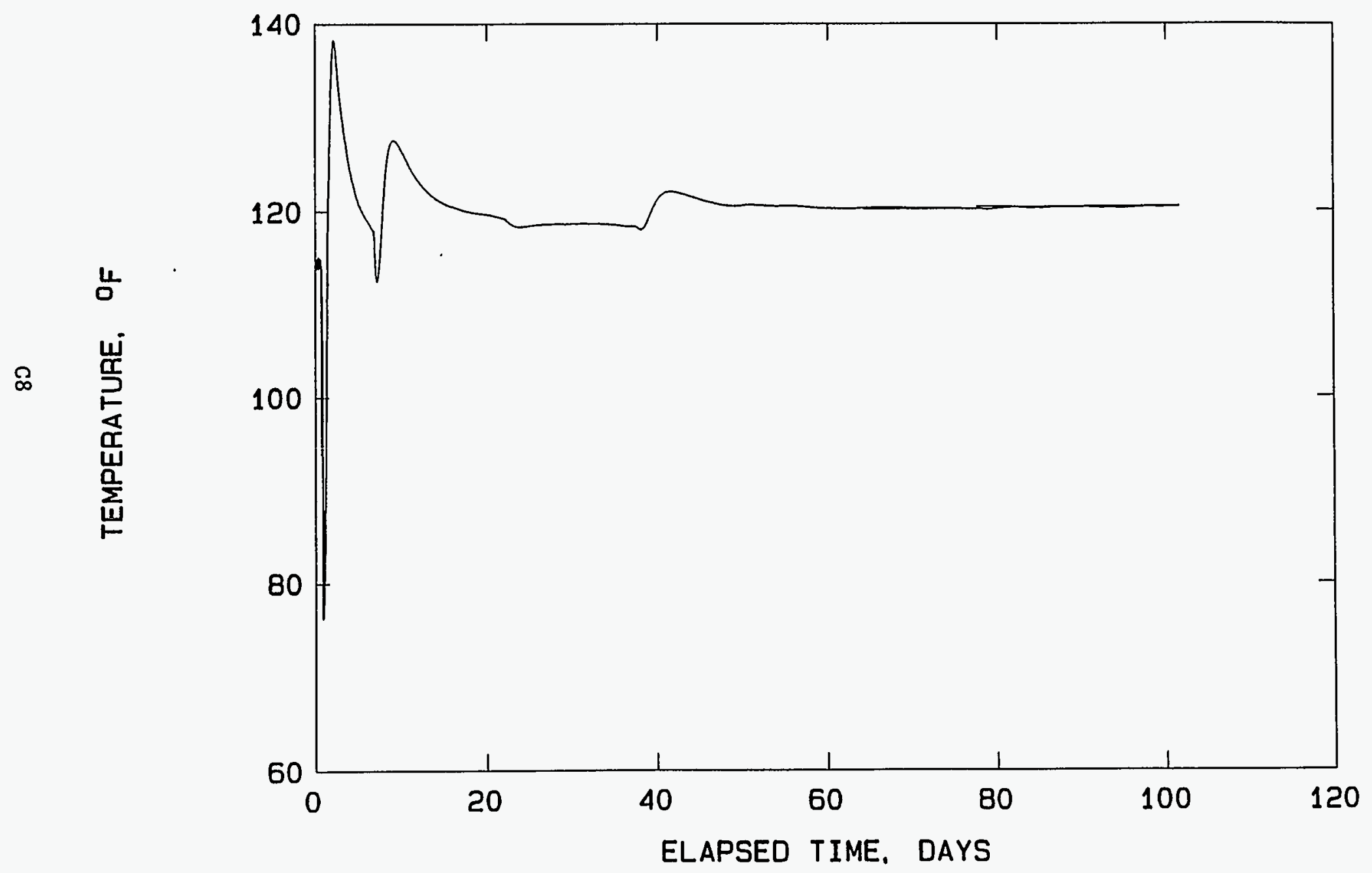




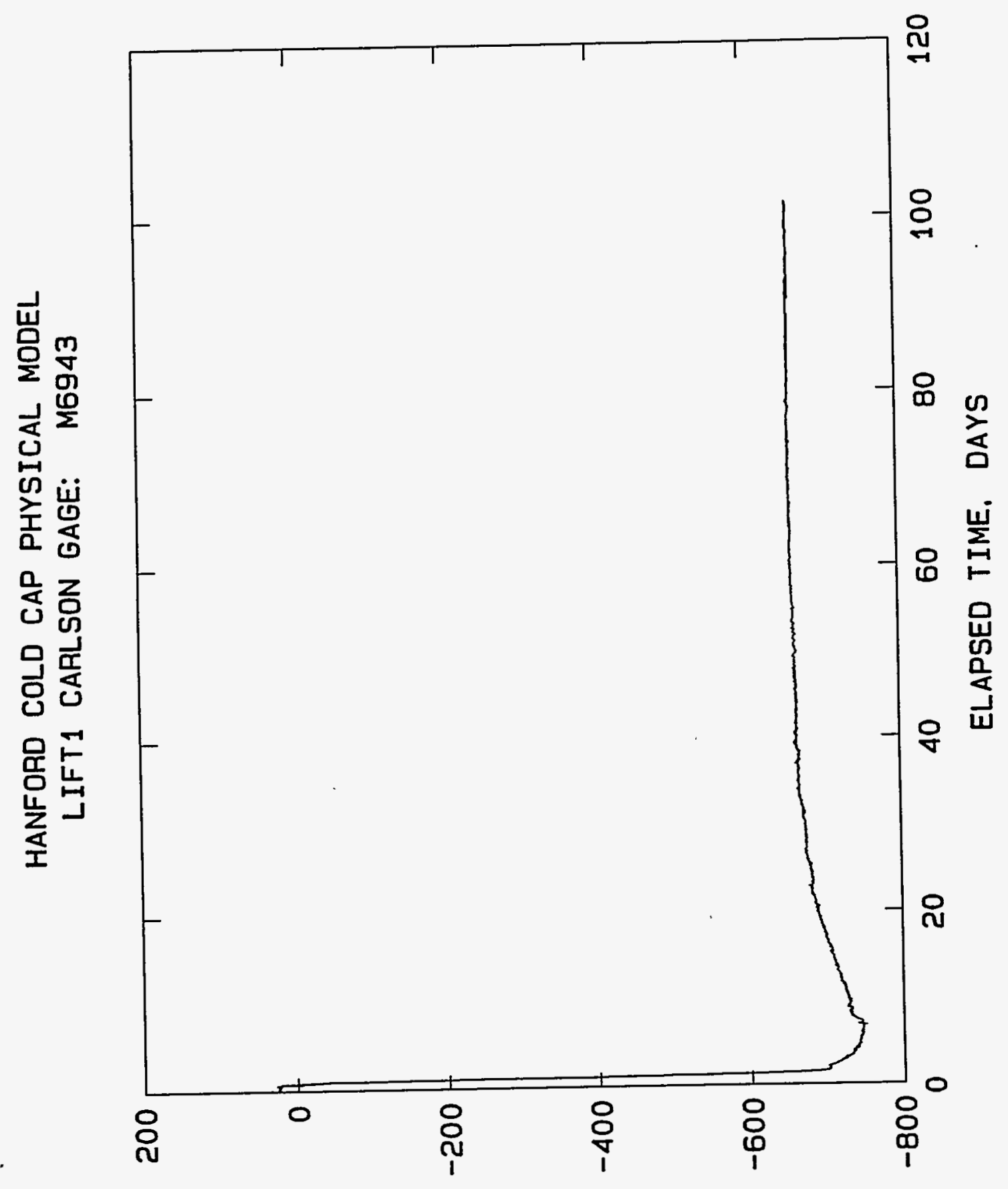

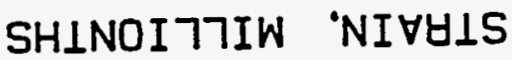


HANFORD COLD CAP PHYSICAL MODEL

LIFT 1 CARLSON GAGE: M6943

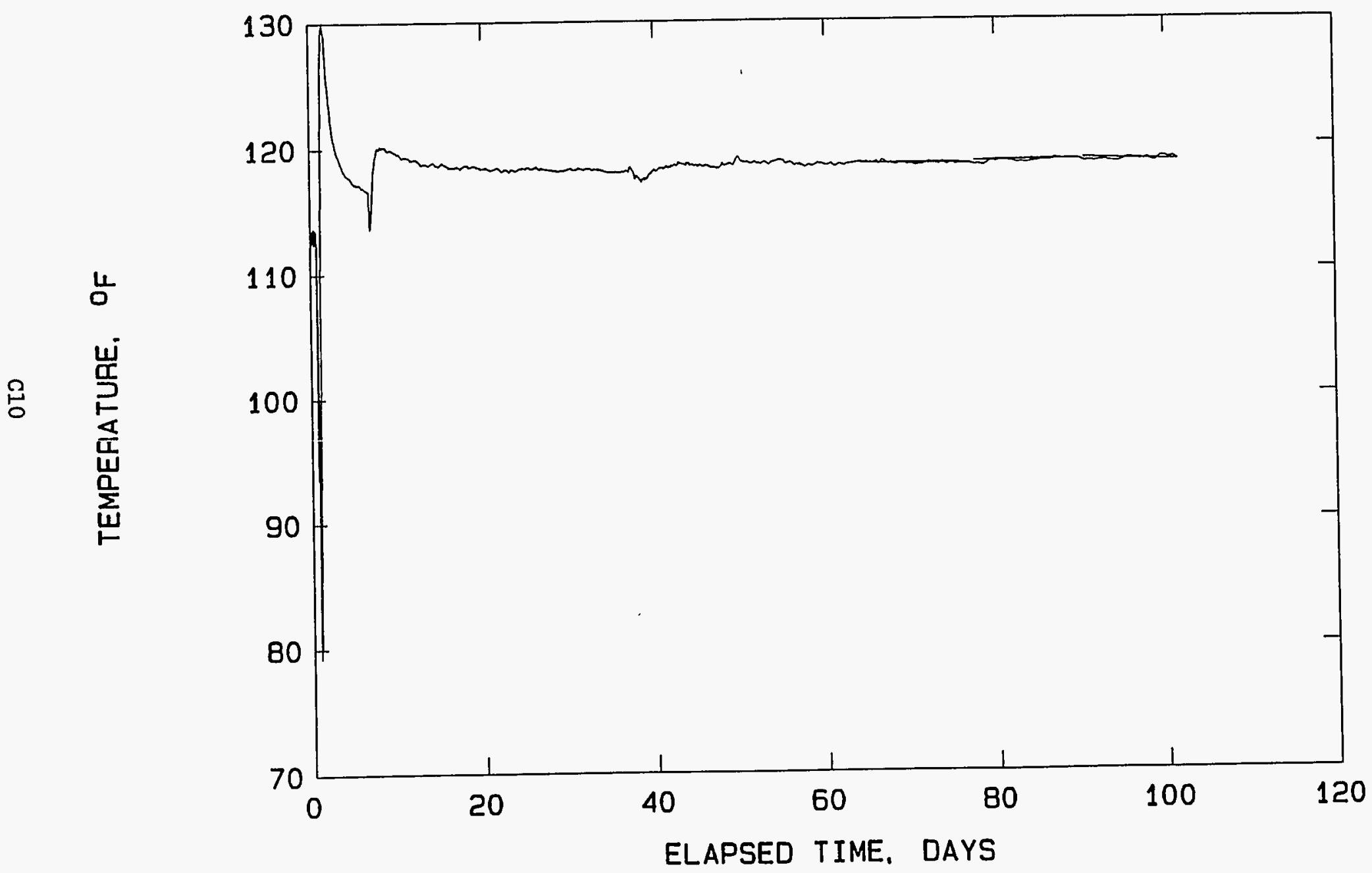


HANFORD COLD CAP PHYSICAL MODEL

LIFT1 CARLSON GAGE: M6944

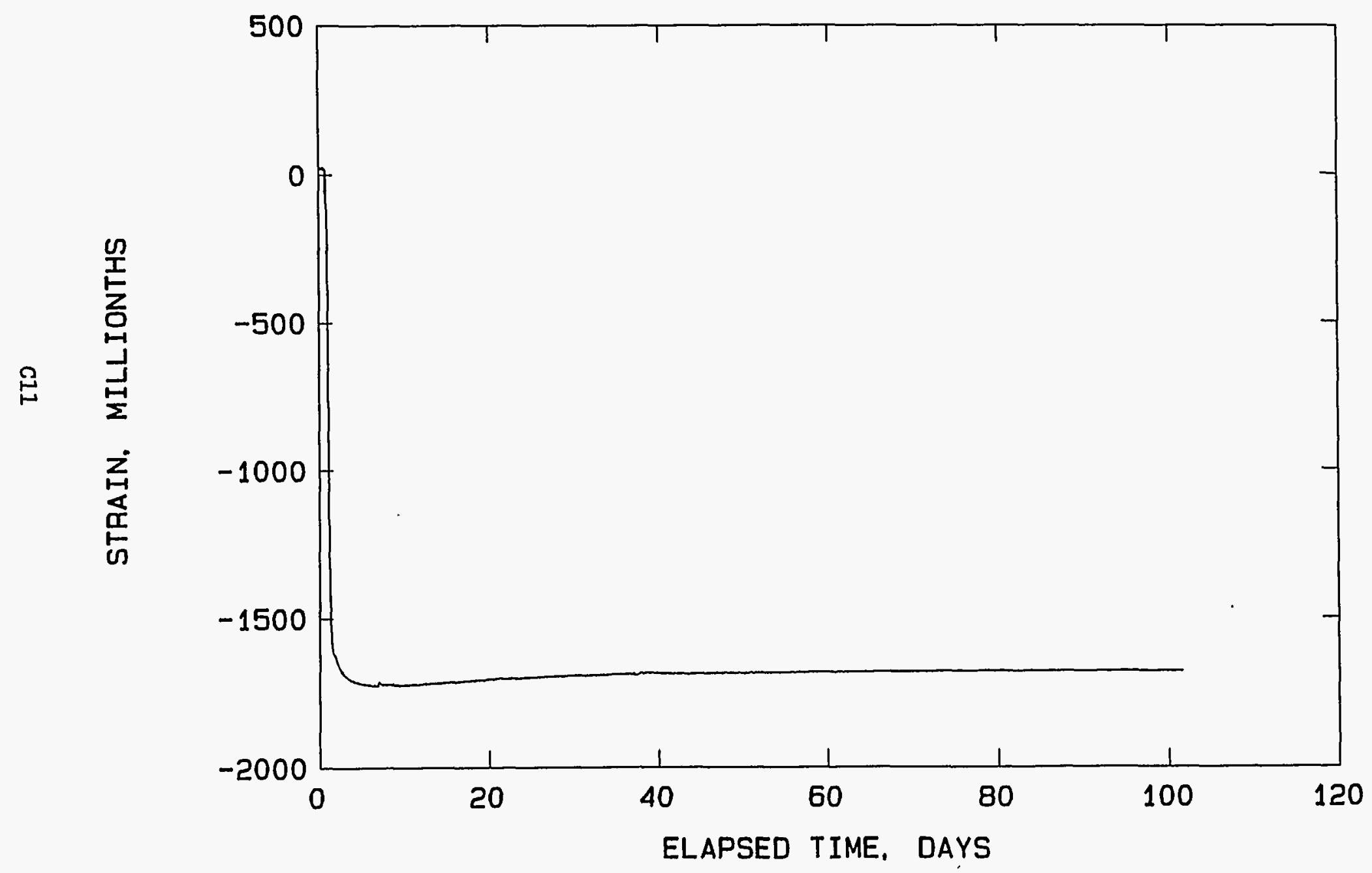


HANFORD COLD CAP PHYSICAL MODEL

LIFT1 CARLSON GAGE: M6944

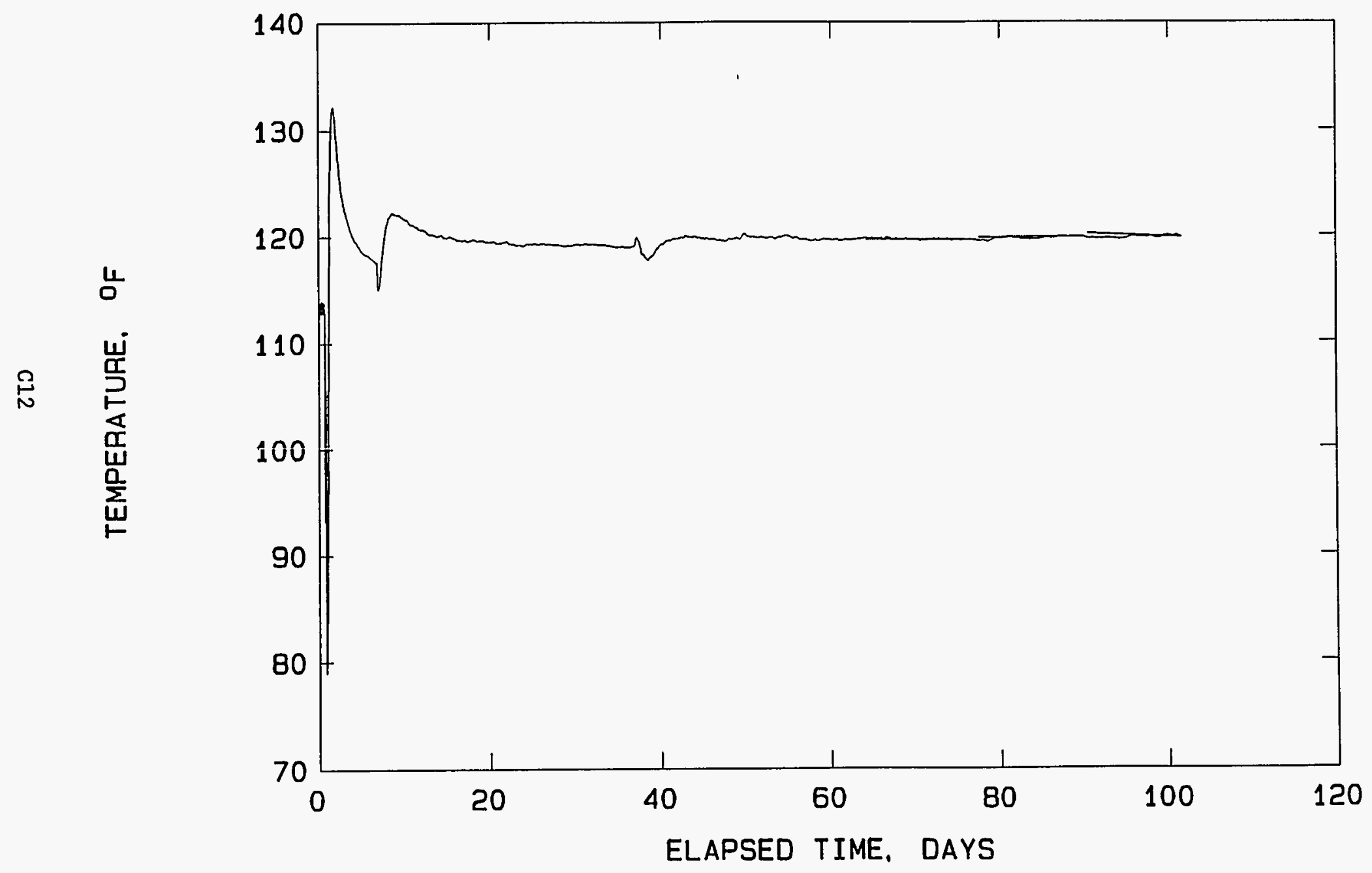


HANFORD COLD CAP PHYSICAL MODEL

LIFT1 CARLSON GAGE: $\quad$ M6945

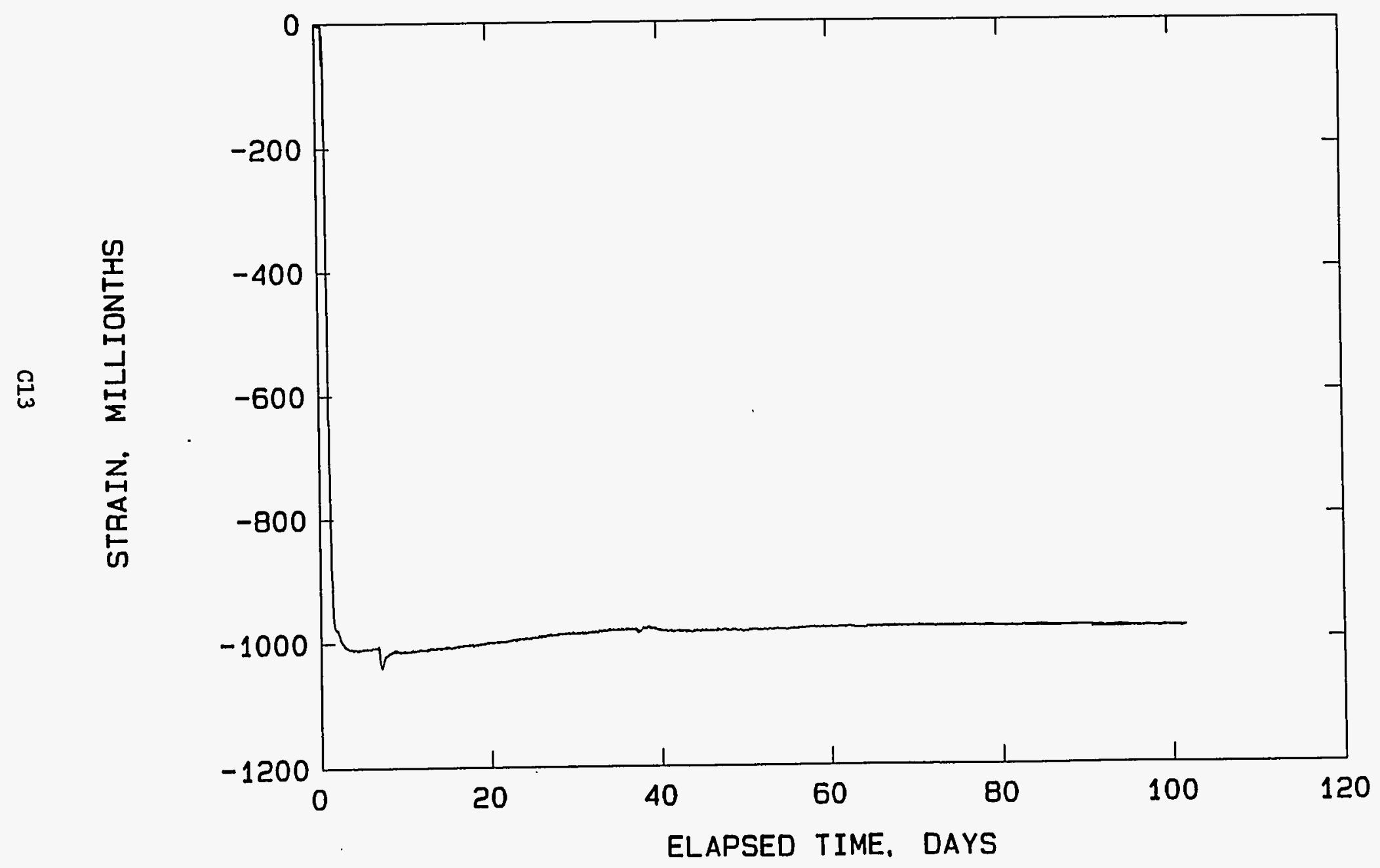


HANFORD COLD CAP PHYSICAL MODEL

LIFT1 CARLSON GAGE: M6945

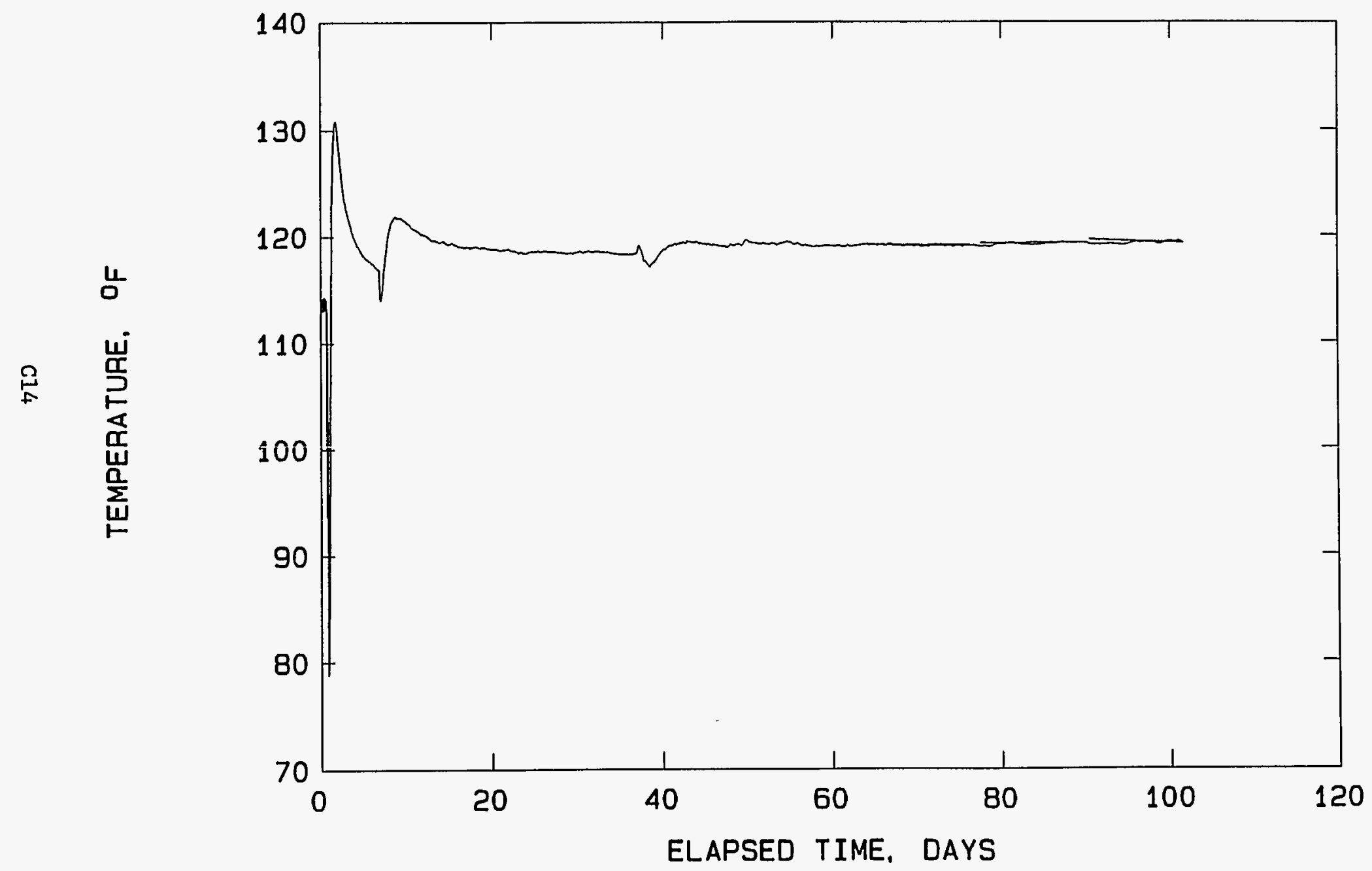




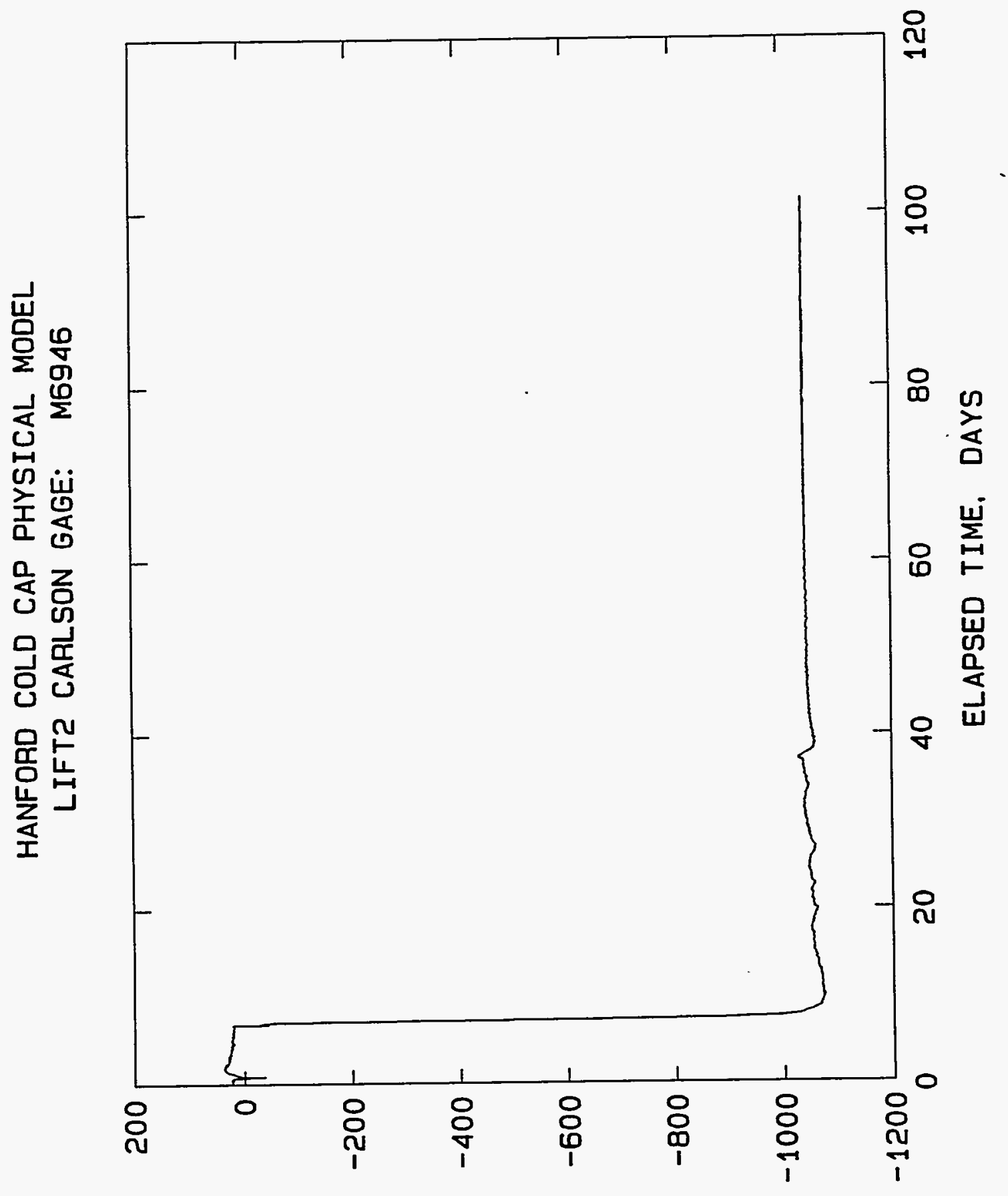

SHINOI רIIW 'NI $\forall \forall \perp S$ 
HANFORD COLD CAP PHYSICAL MODEL

LIFT2 CARLSON GAGE: M6946

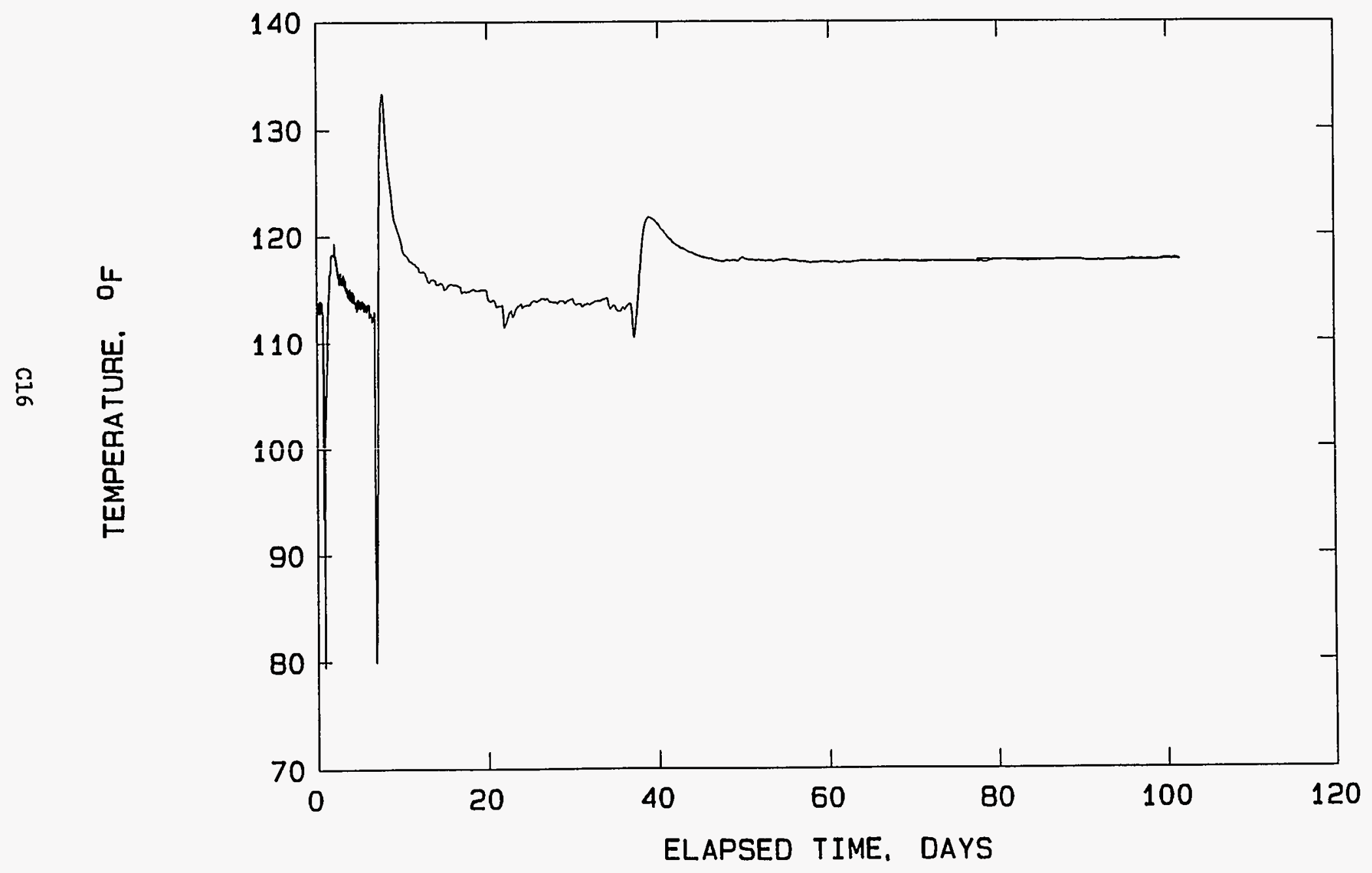




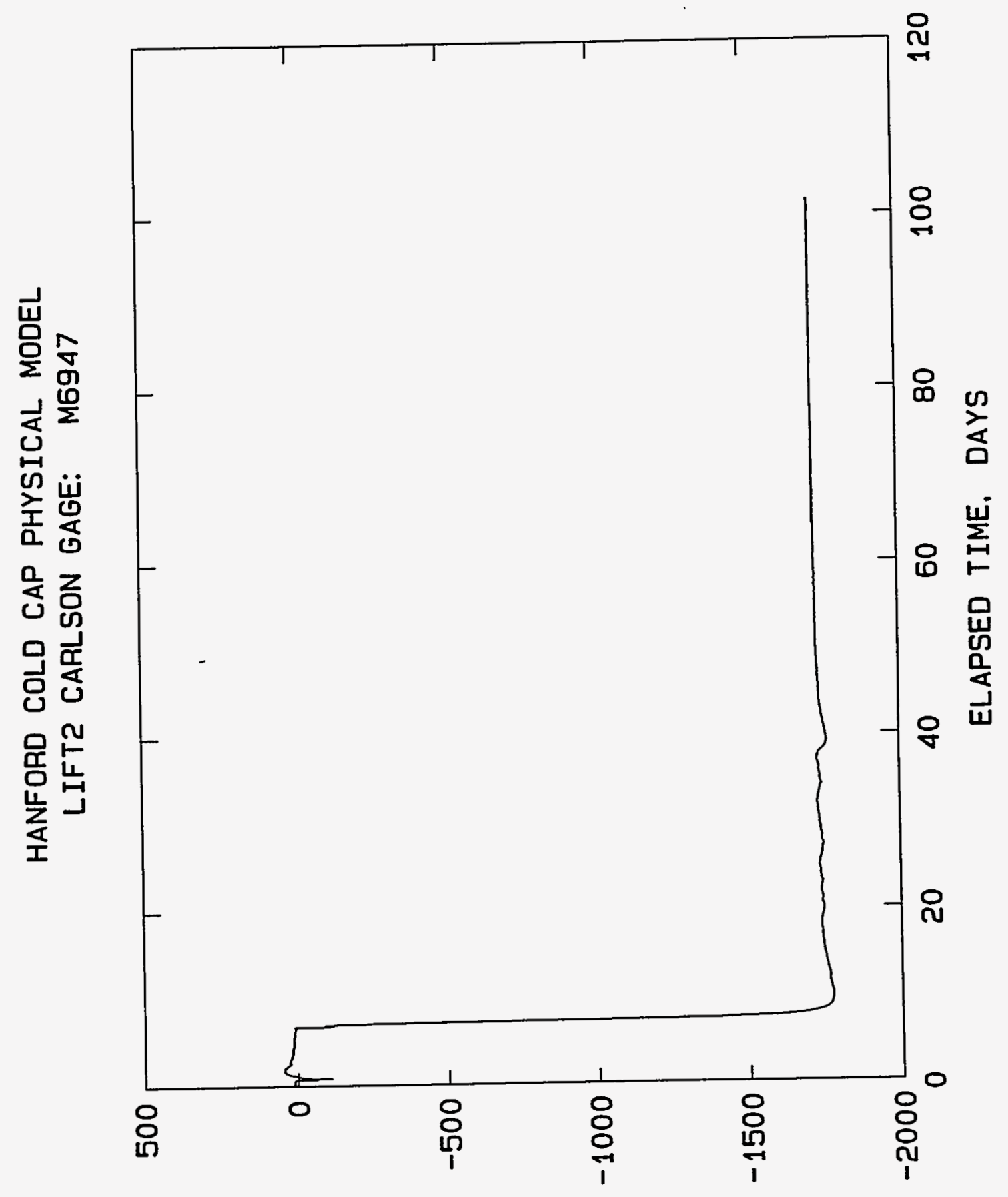

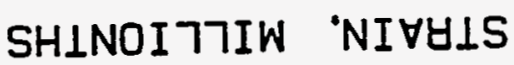


HANFORD COLD CAP PHYSICAL MODEL

LIFT2 CARLSON GAGE: M6947

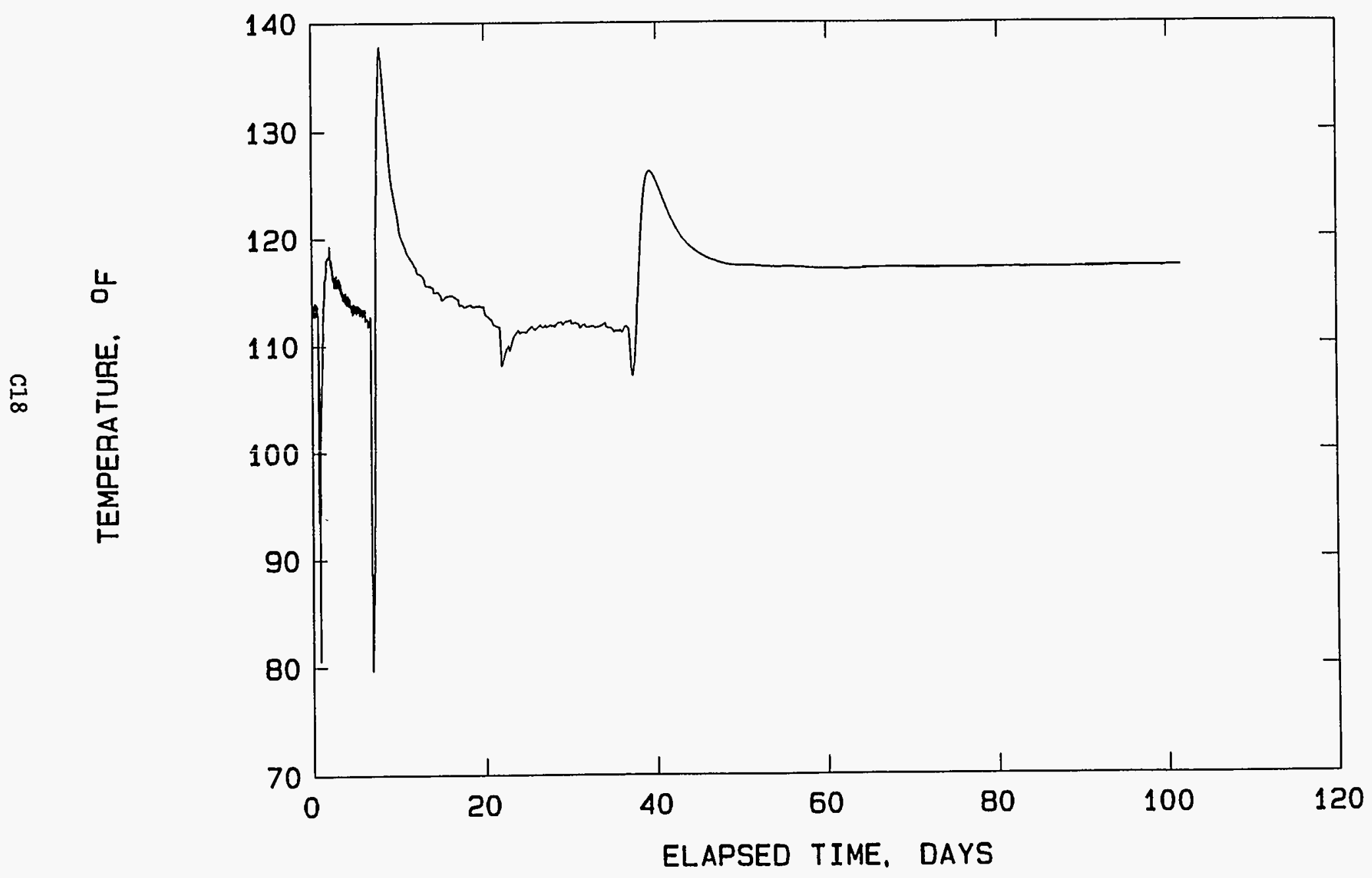


HANFORD COLD CAP PHYSICAL MODEL

LIFT2 CARLSON GAGE: M694B

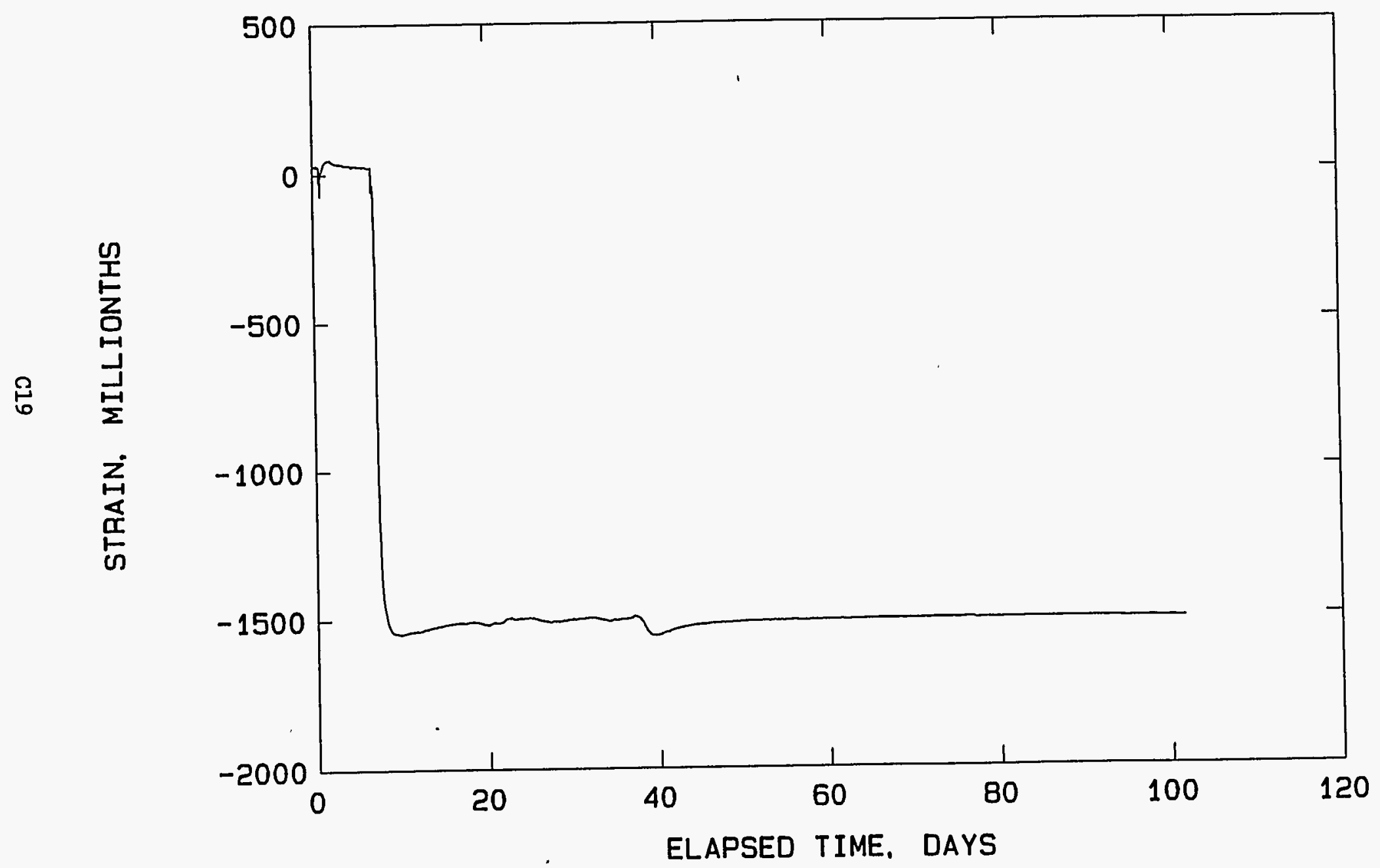


HANFORD COLD CAP PHYSICAL MODEL

LIFT2 CARLSON GAGE: M6948

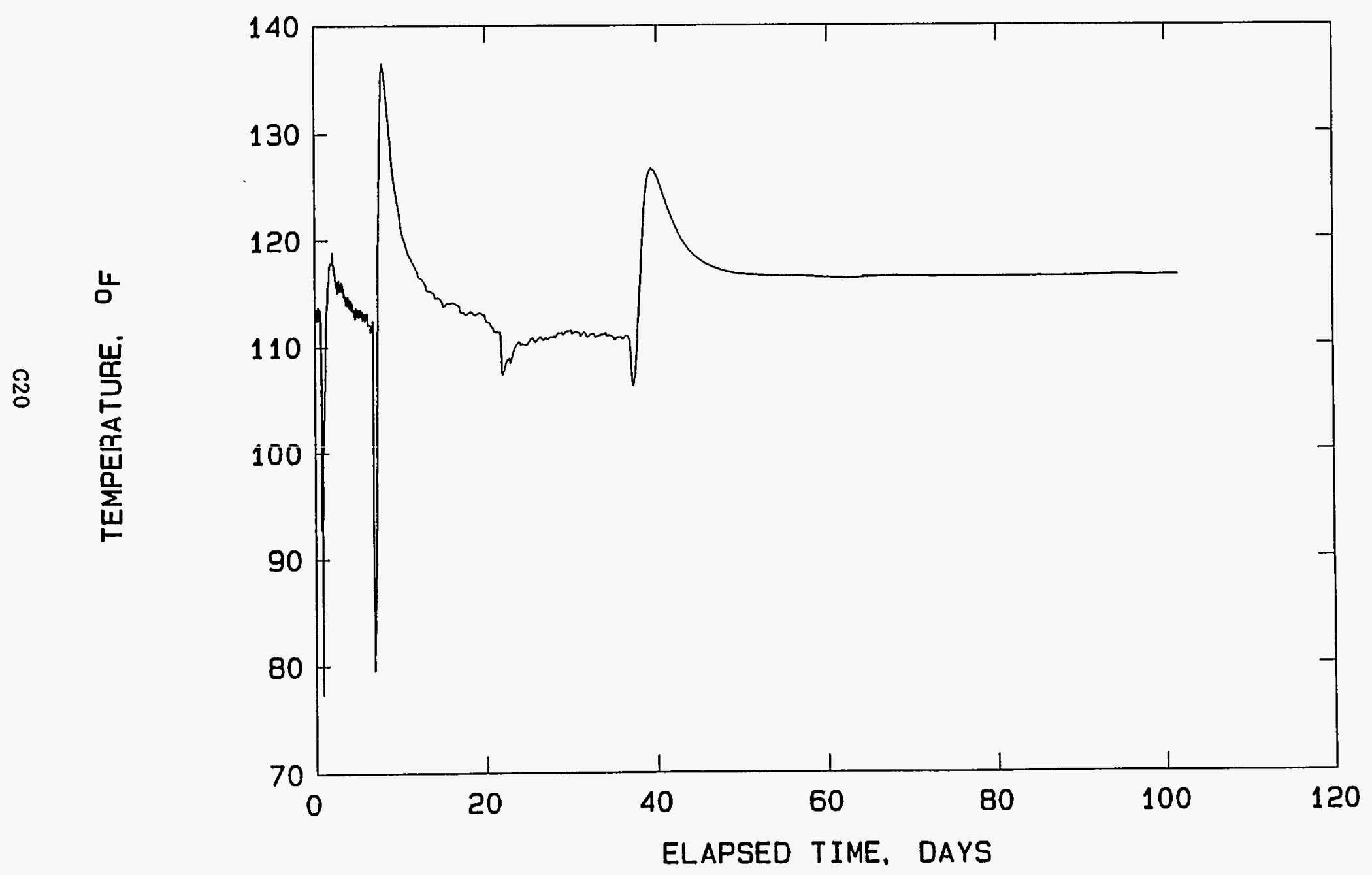


HANFORD COLD CAP PHYSICAL MODEL

LIFT2 CARLSON GAGE: M6949

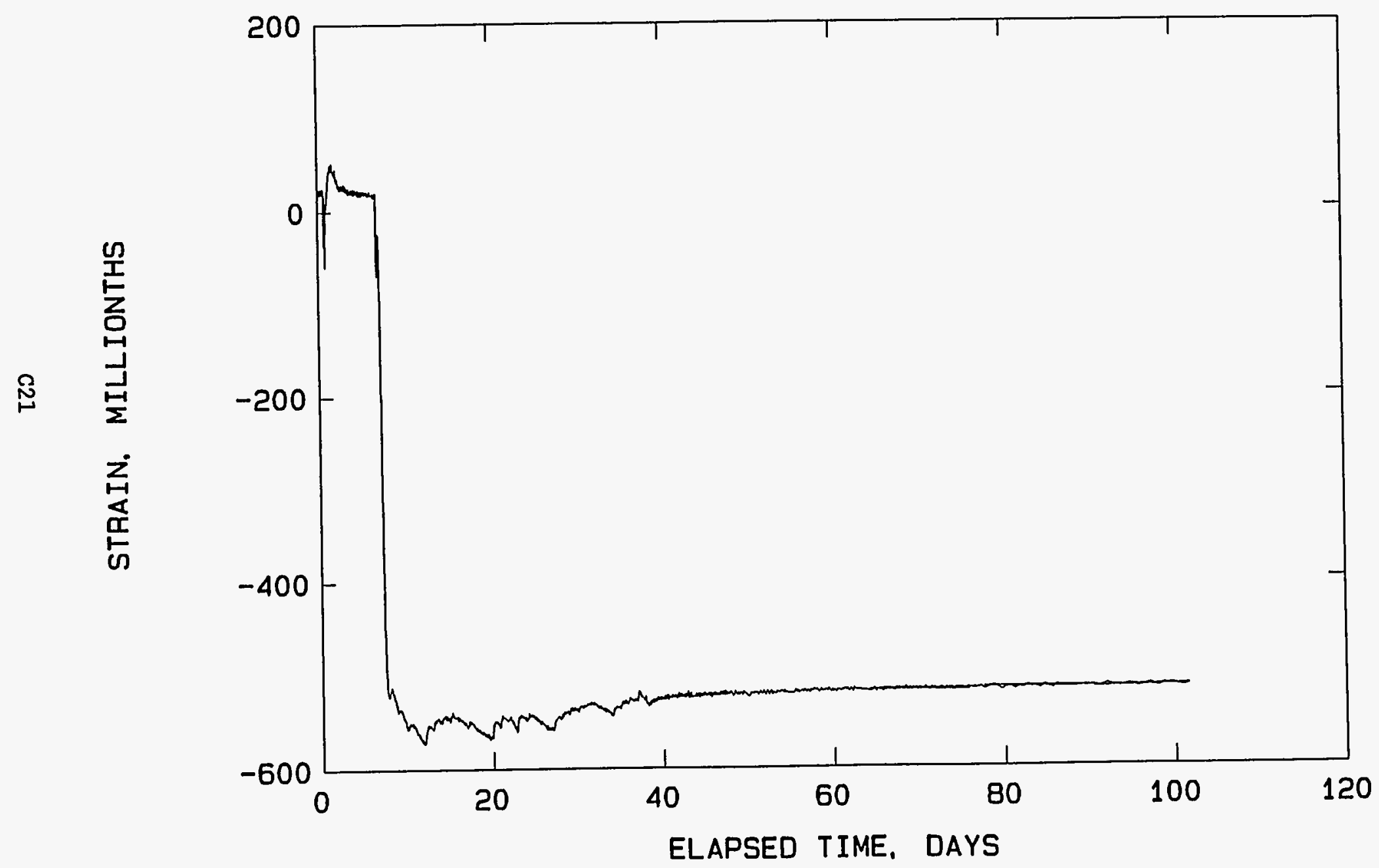


HANFORD COLD CAP PHYSICAL MODEL

LIFT2 CARLSON GAGE: M6949

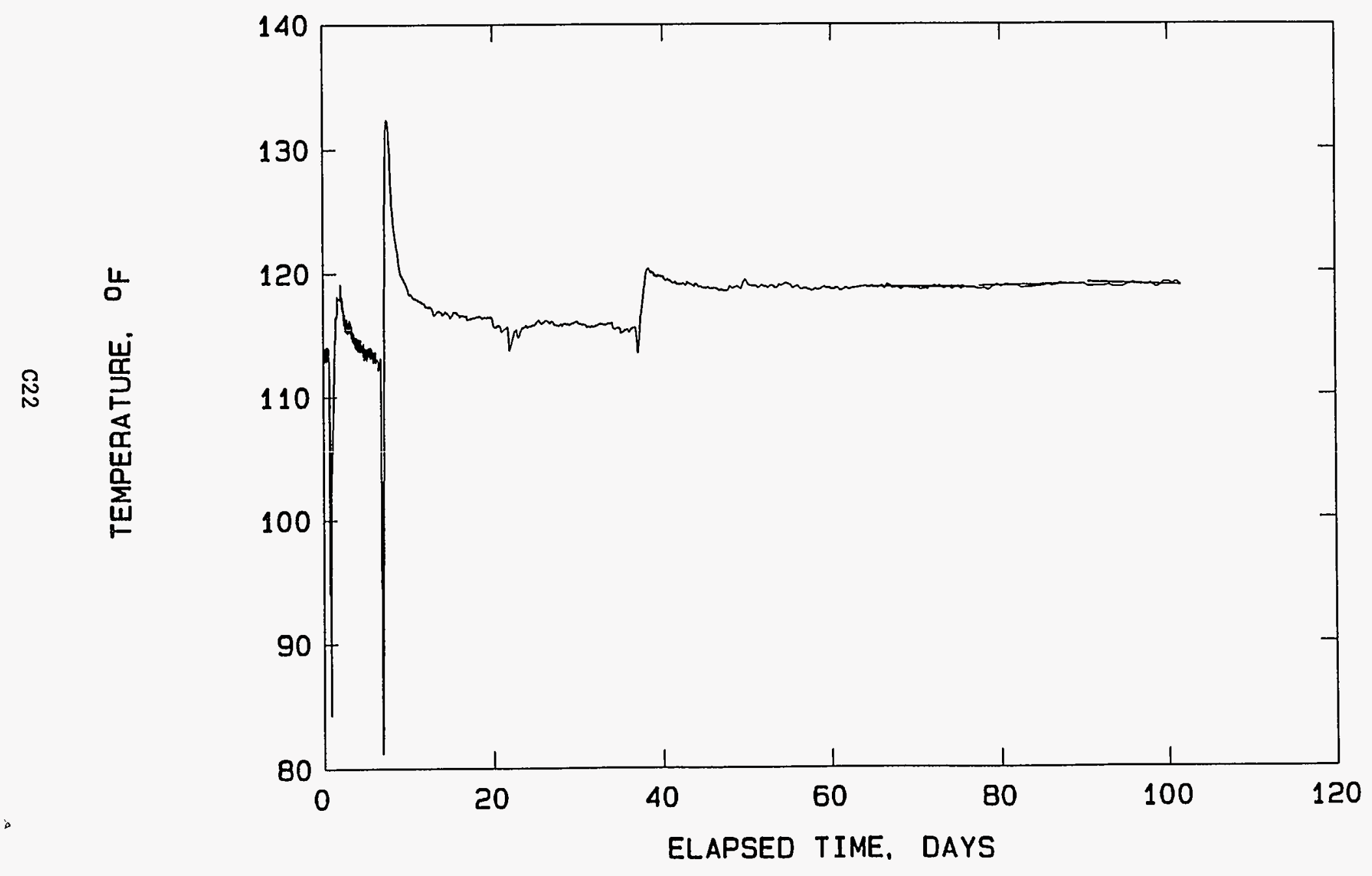


HANFORD COLD CAP PHYSICAL MODEL

LIFT2 CARLSON GAGE: M6950

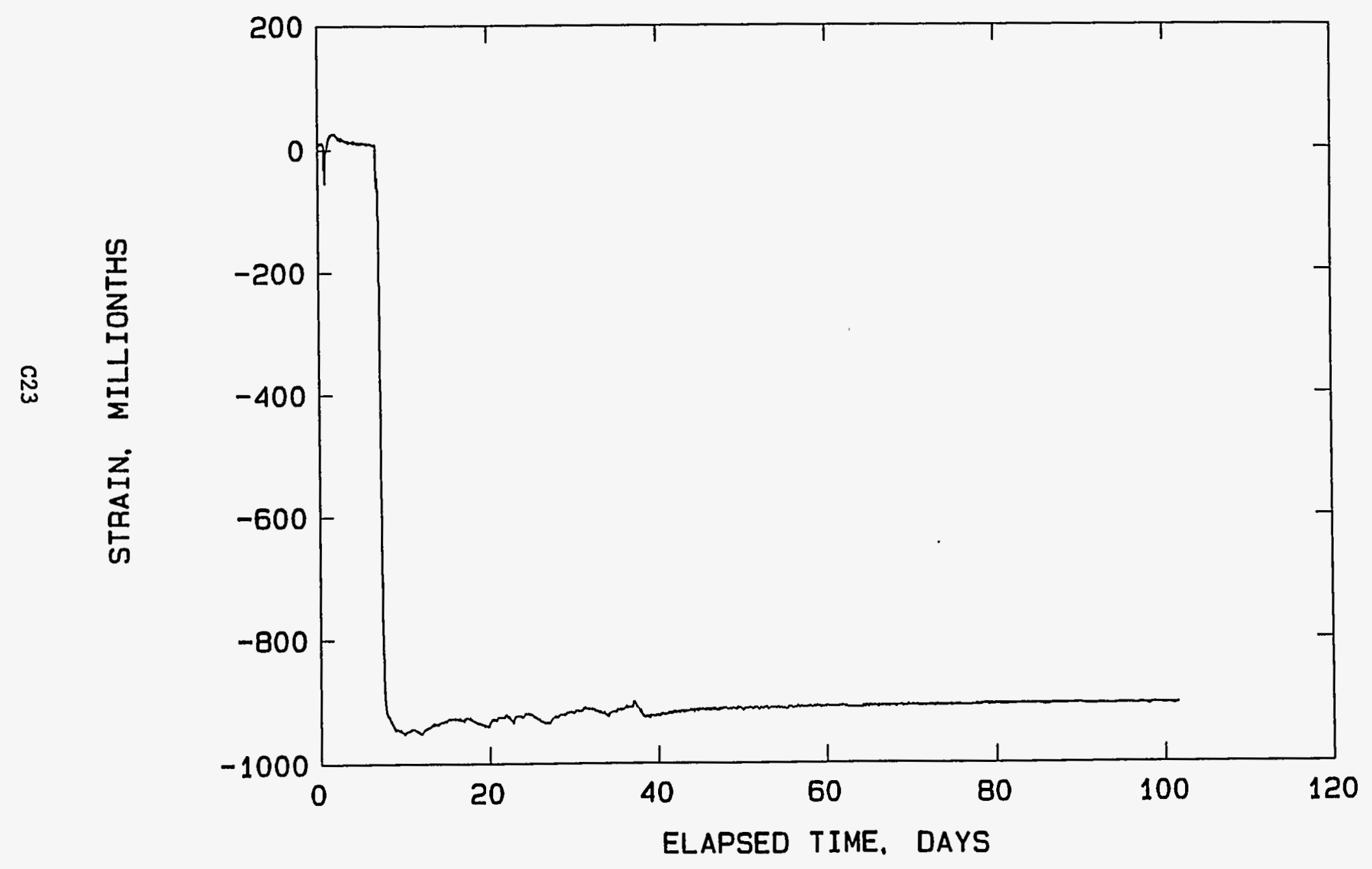


HANFORD COLD CAP PHYSICAL MODEL

LIFT2 CARLSON GAGE: M6950

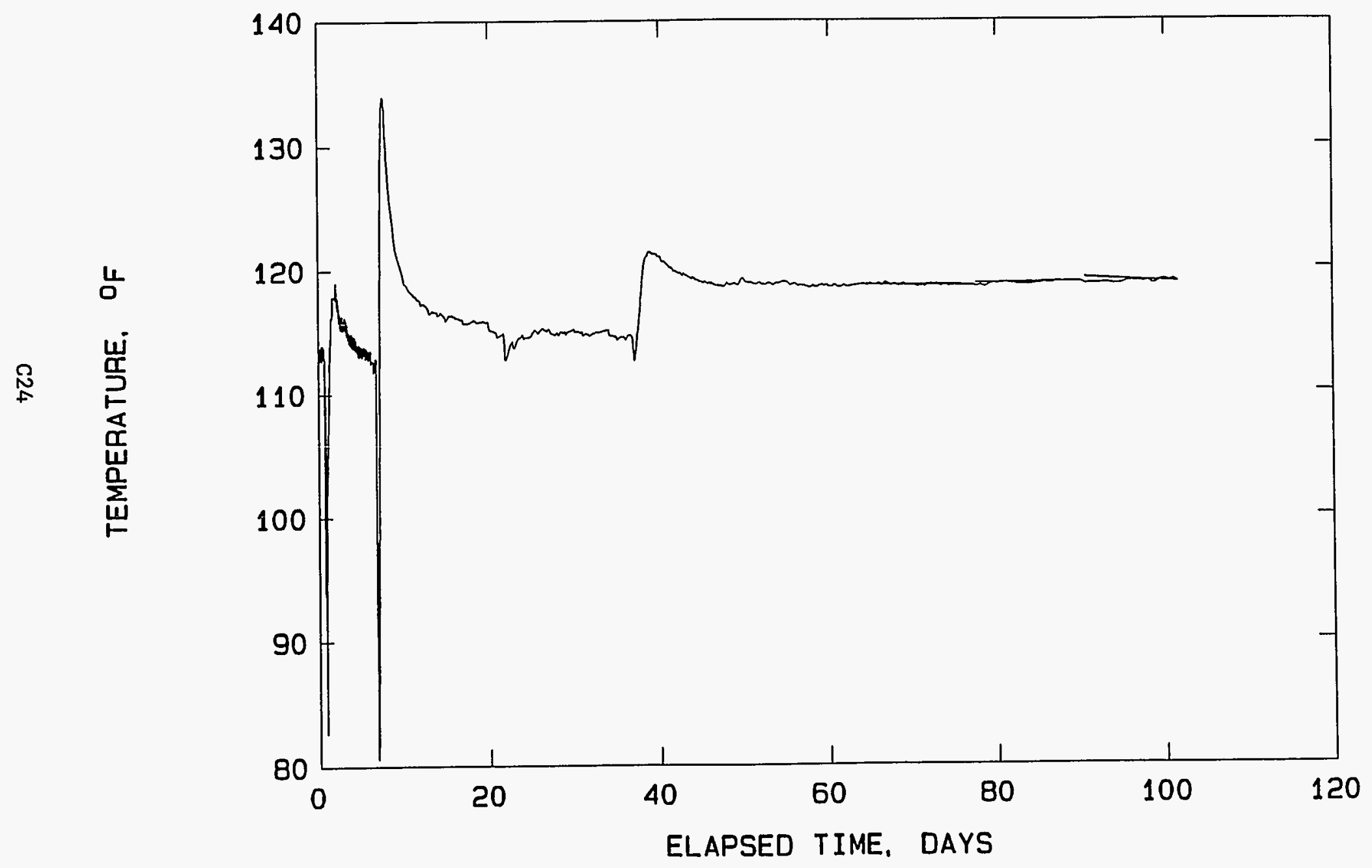




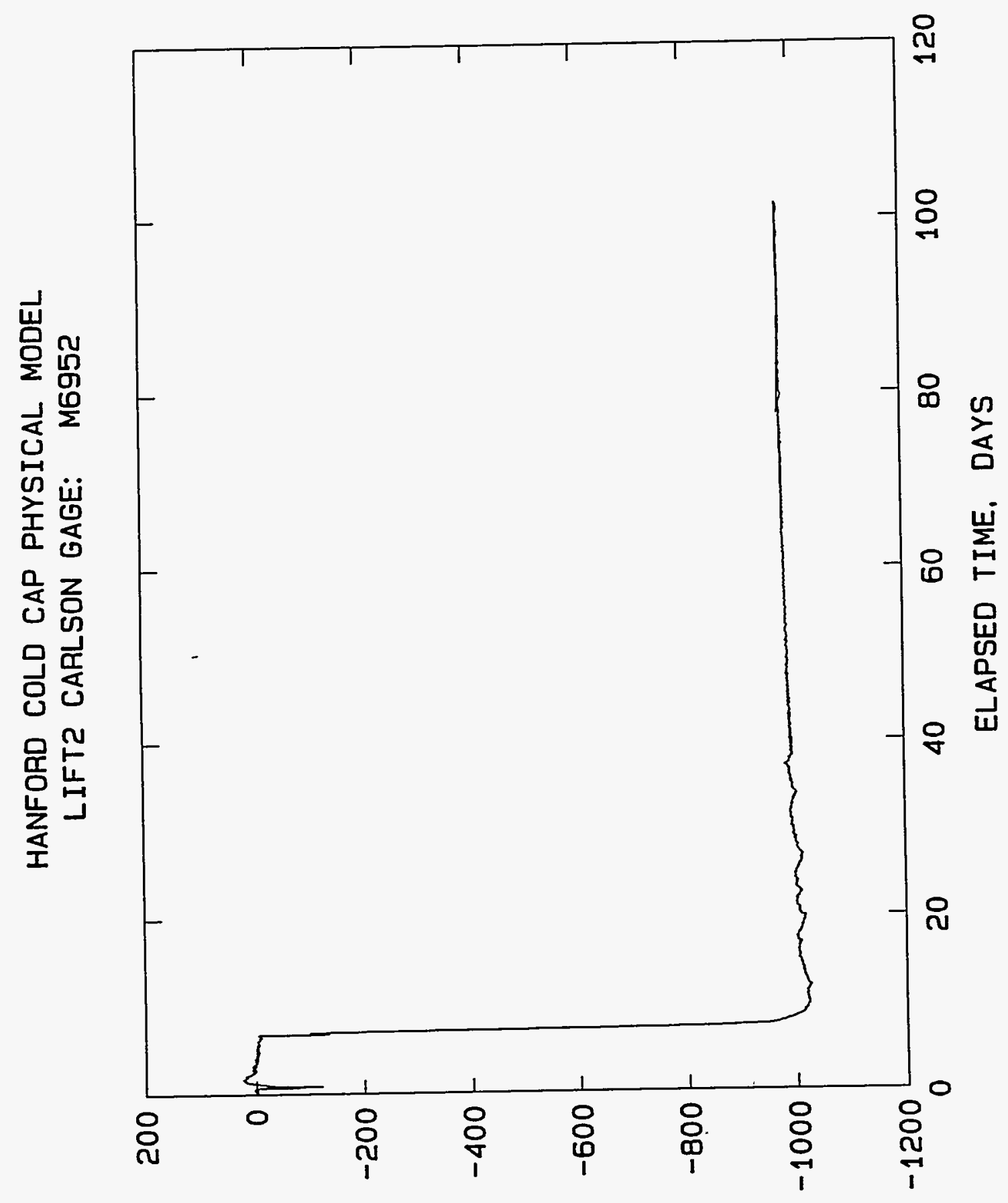

SHINOI רIIW 'NIVULS 
HANFORD COLD CAP PHYSICAL MODEL

LIFT2 CARLSON GAGE: M6952

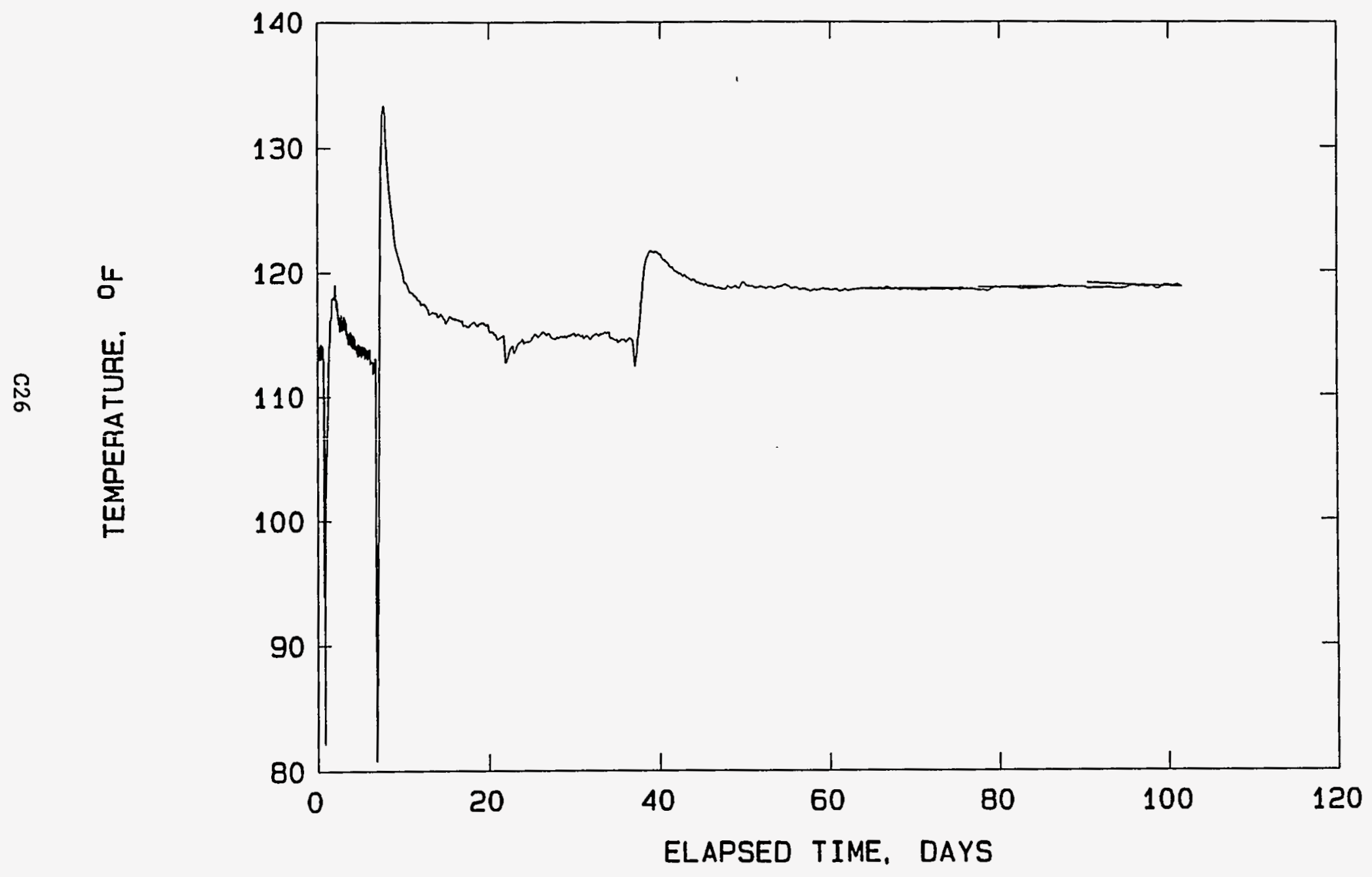




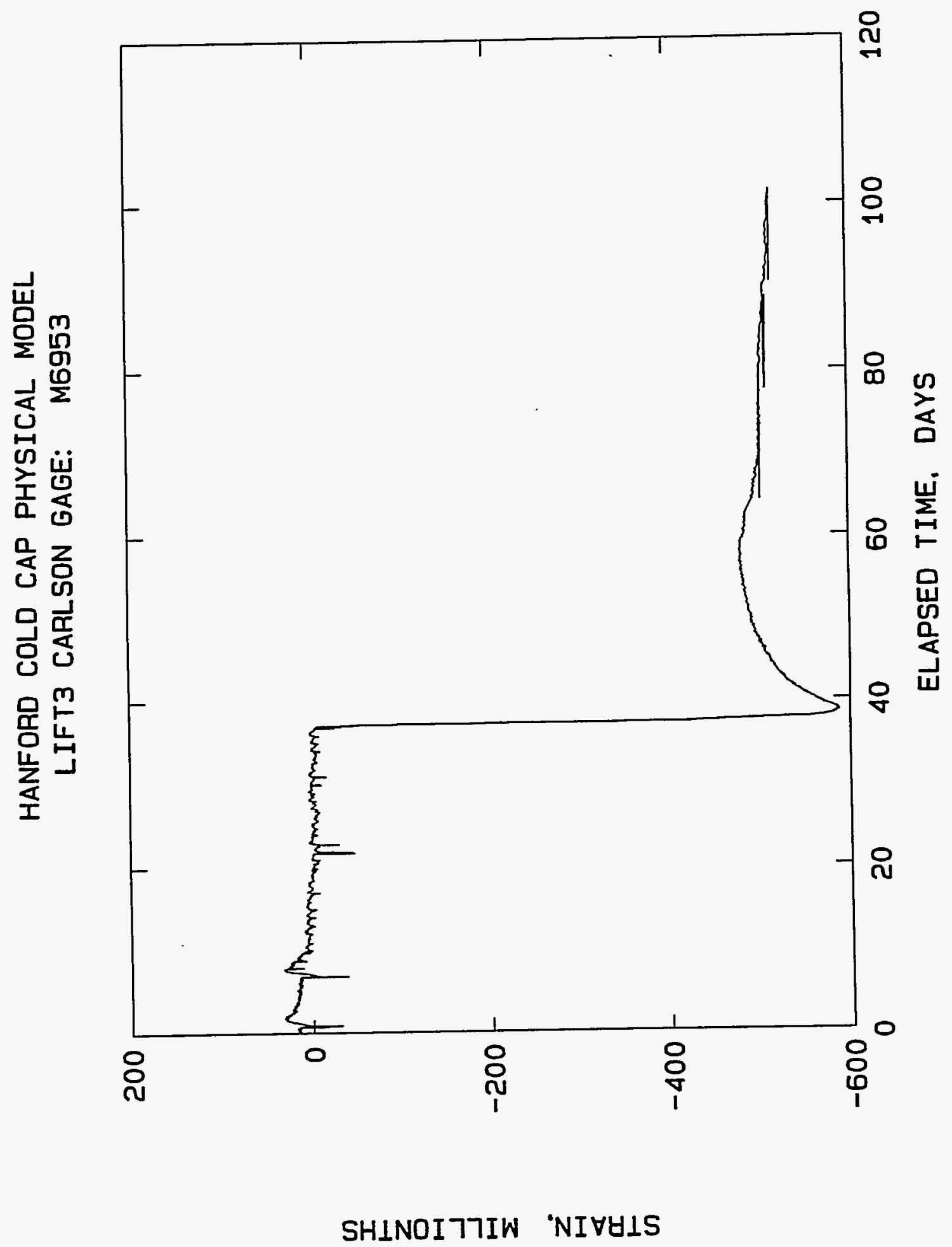


HANFORD COLD CAP PHYSICAL MODEL

LIFT3 CARLSON GAGE: M6953

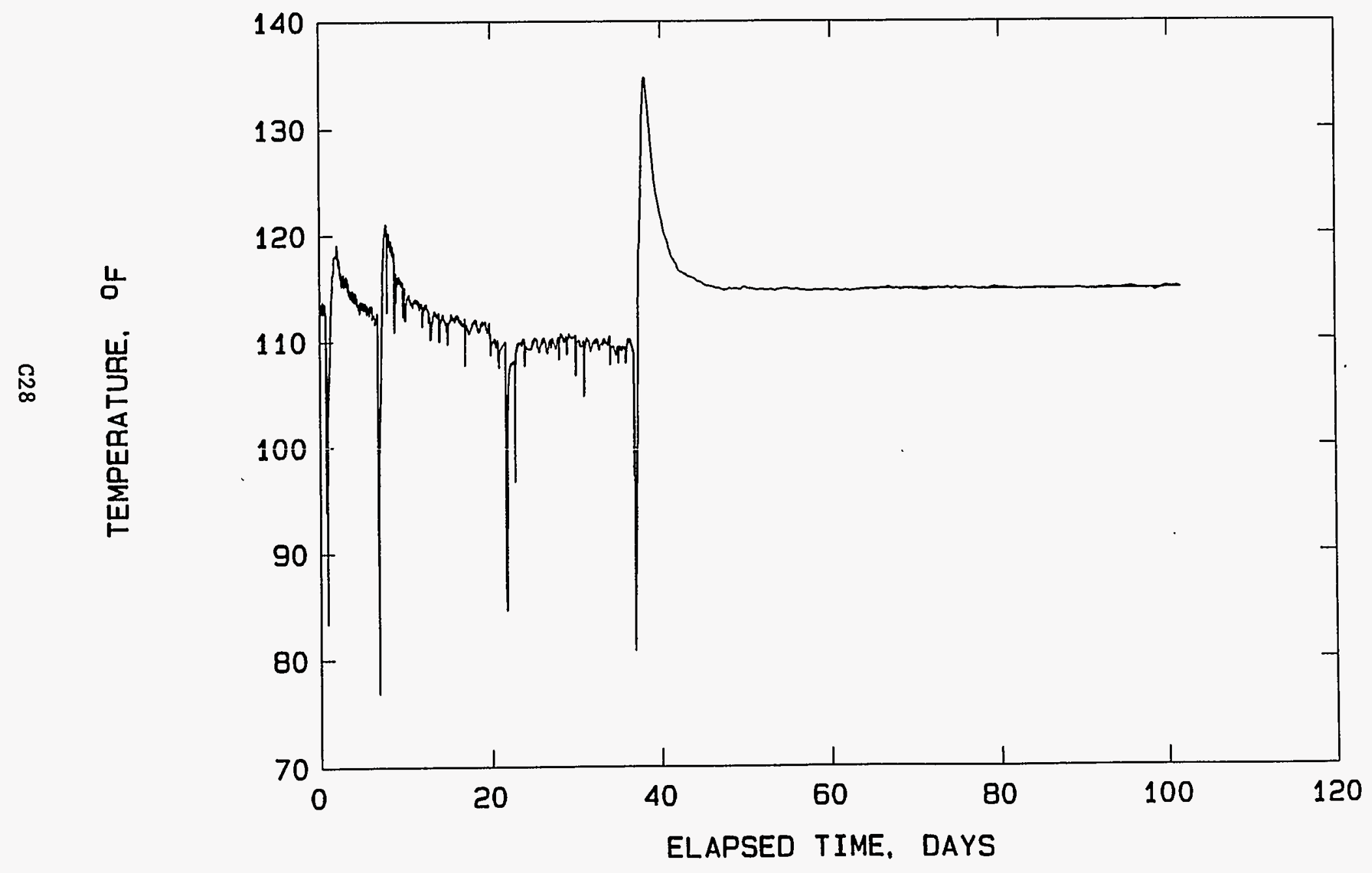




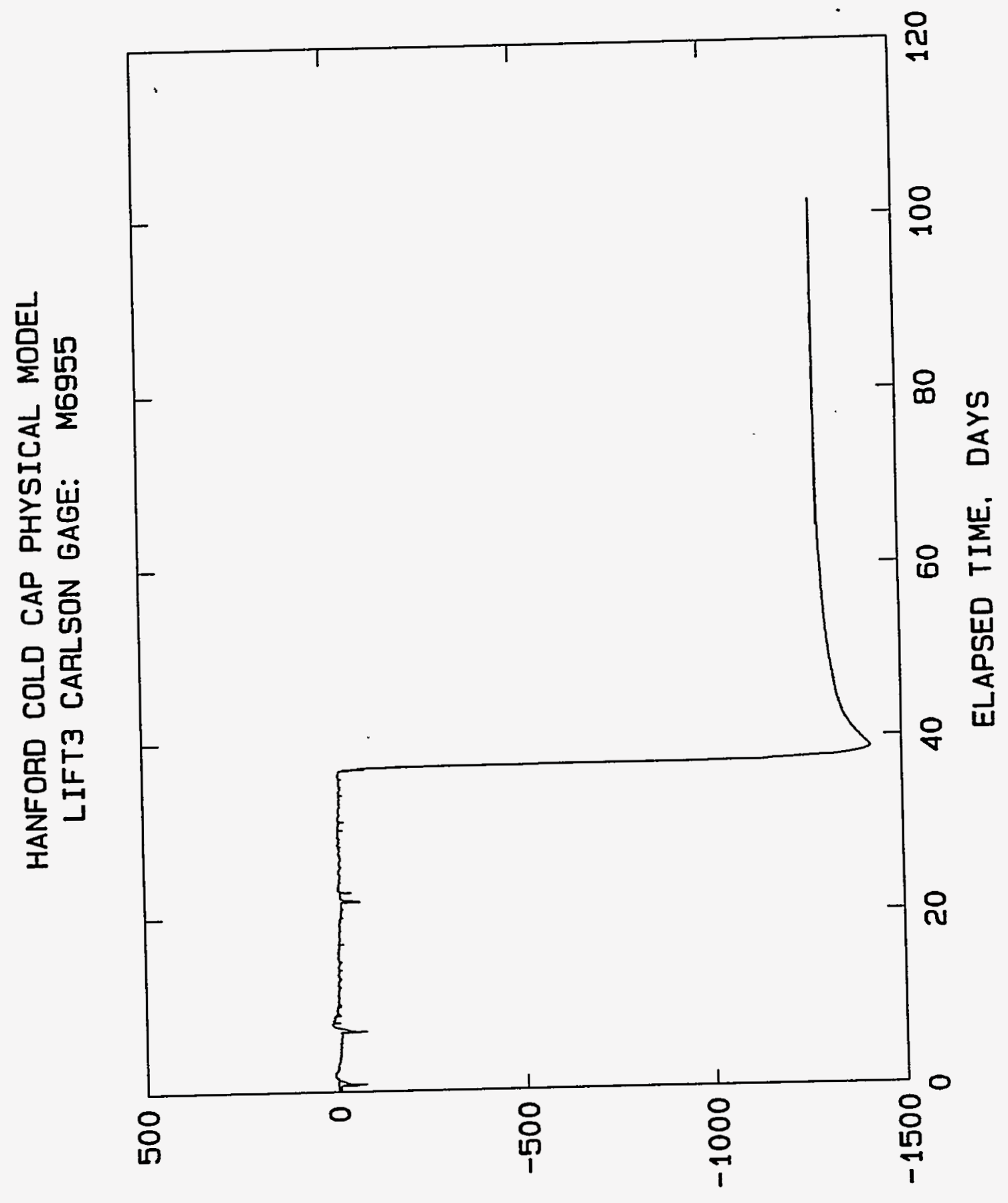

SHINOI 7רIW 'NIVUIS 
HANFORD COLD CAP PHYSICAL MODEL

LIFT3 CARLSON GAGE: M6955

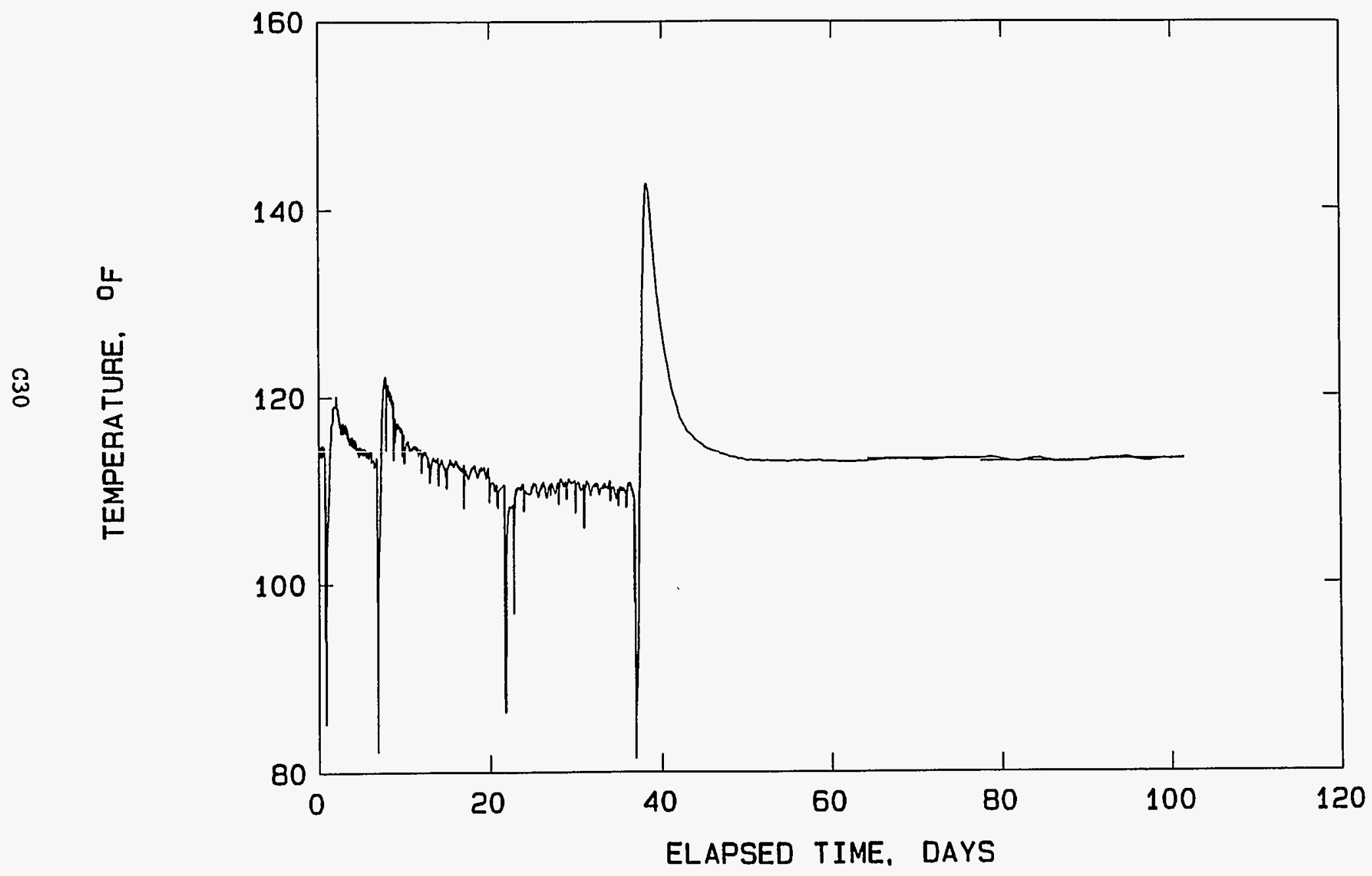


HANFORD COLD CAP PHYSICAL MODEL

LIFT3 CARLSON GAGE: M6958

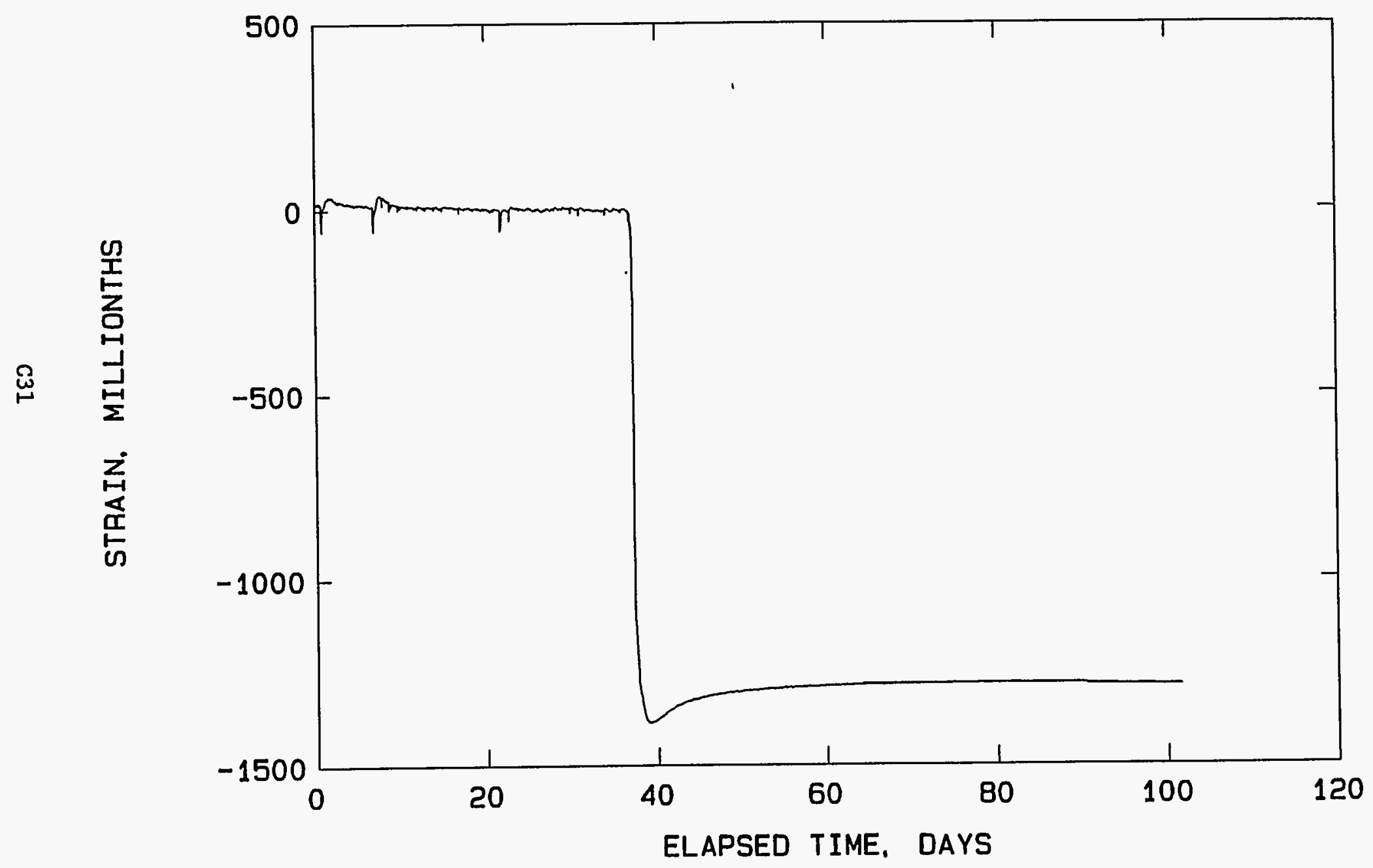


HANFORD COLD CAP PHYSICAL MODEL

LIFT3 CARLSON GAGE: M6958

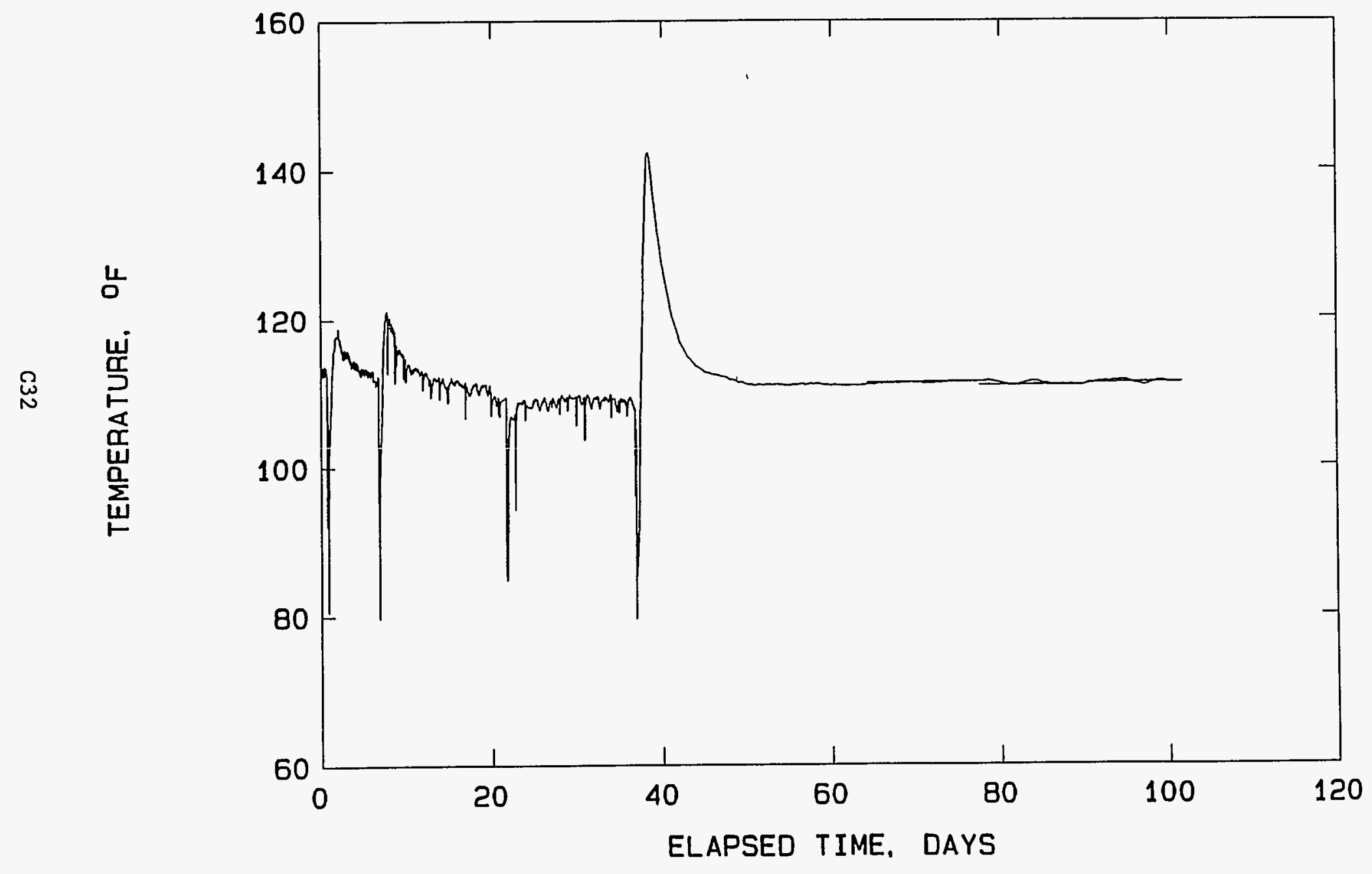


HANFORD COLD CAP PHYSICAL MODEL

LIFT3 CARLSON GAGE: M6971

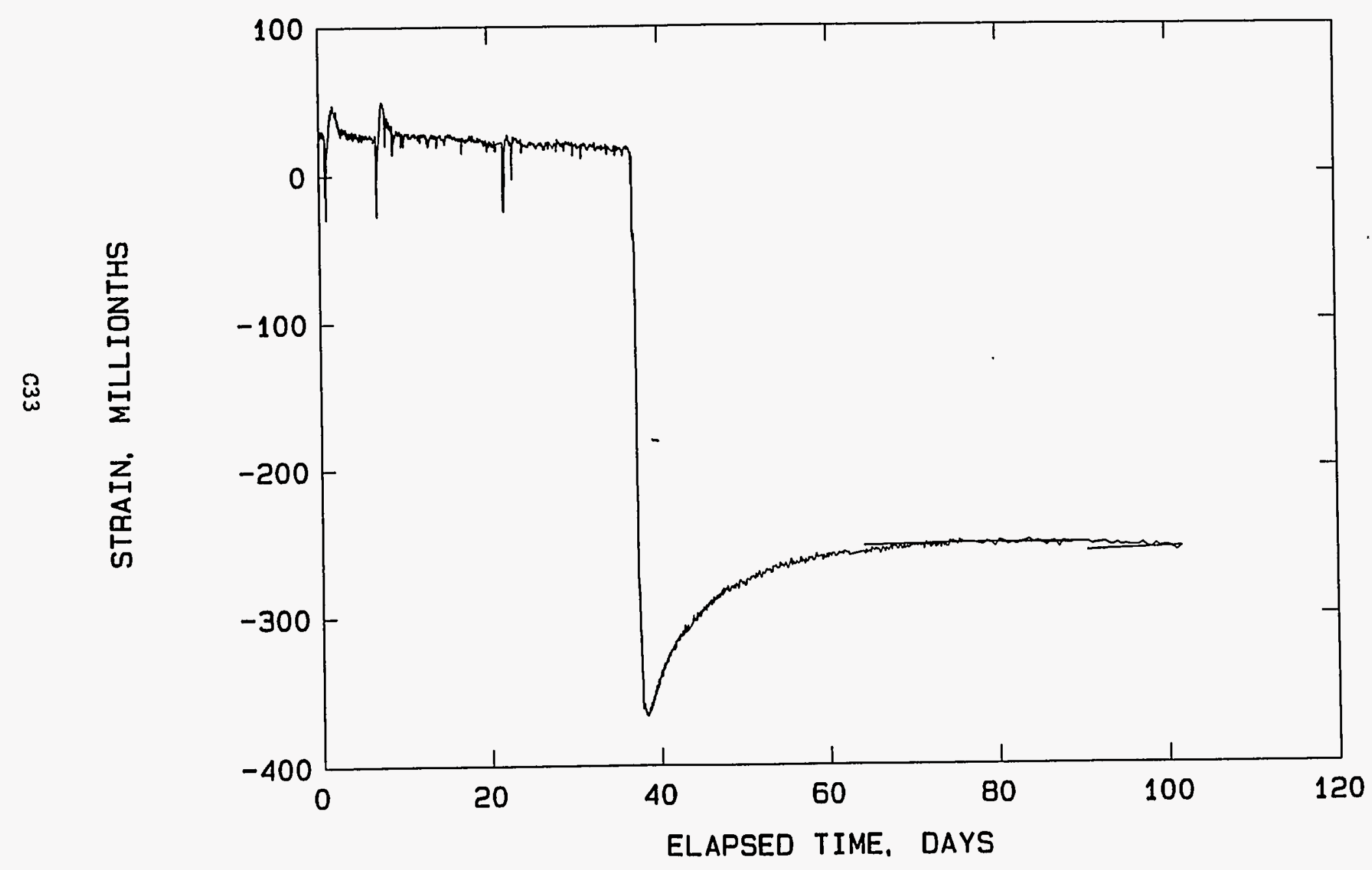


HANFORD COLD CAP PHYSICAL MODEL

LIFT3 CARLSON GAGE: M6971

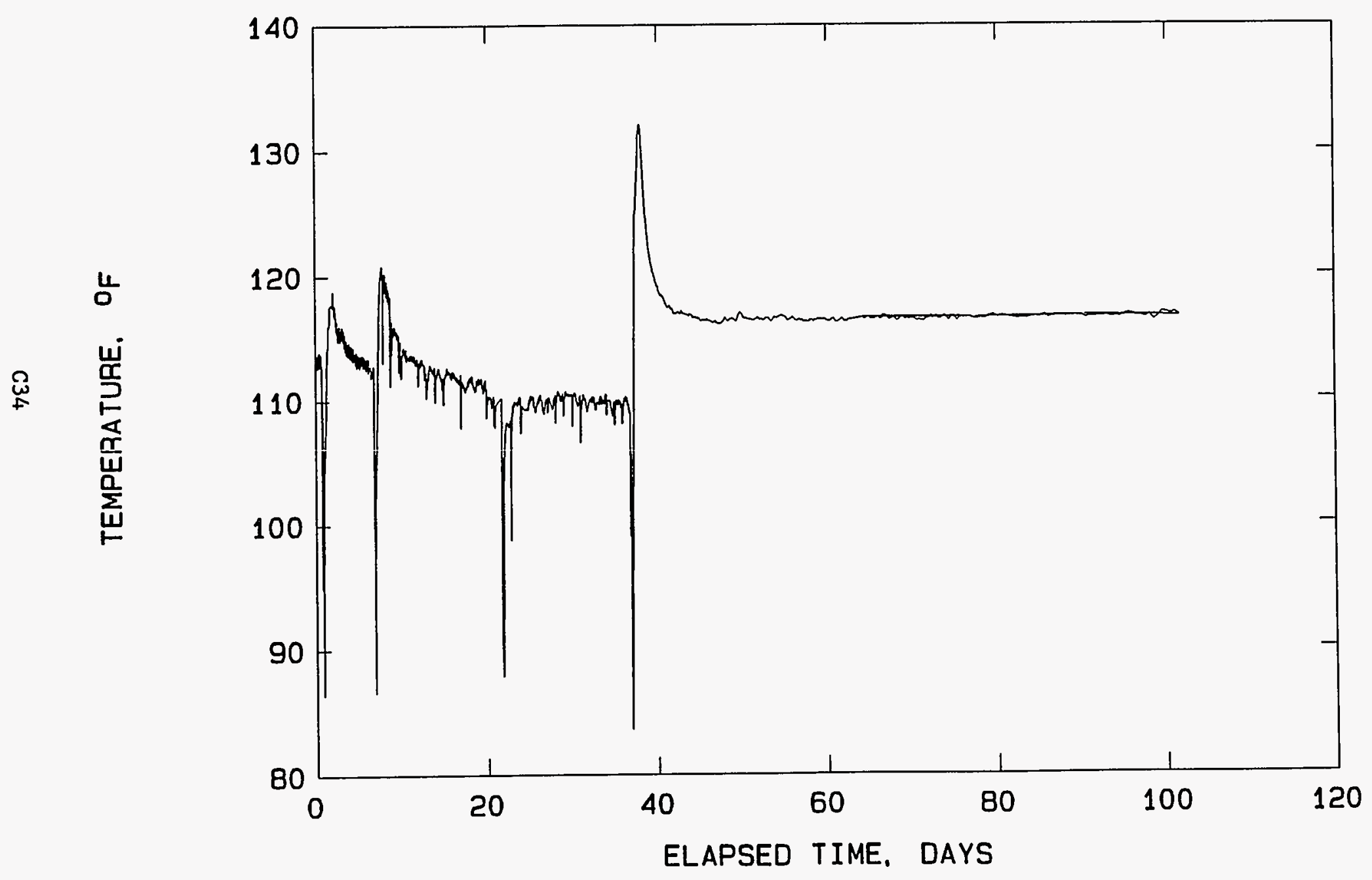




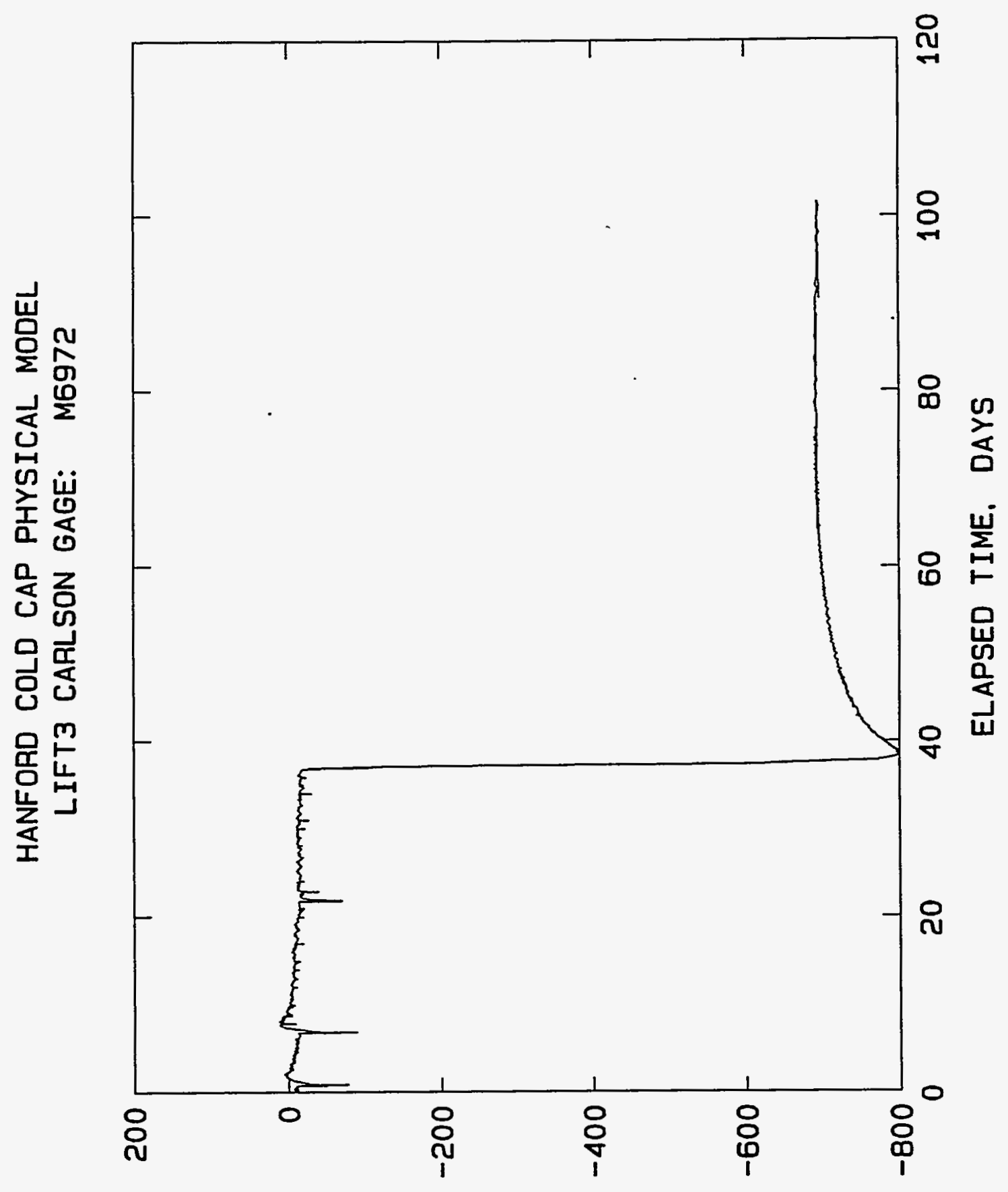

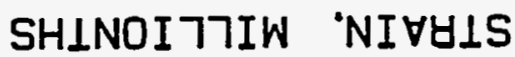


HANFORD COLD CAP PHYSICAL MODEL LIFT3 CARLSON GAGE: M6972

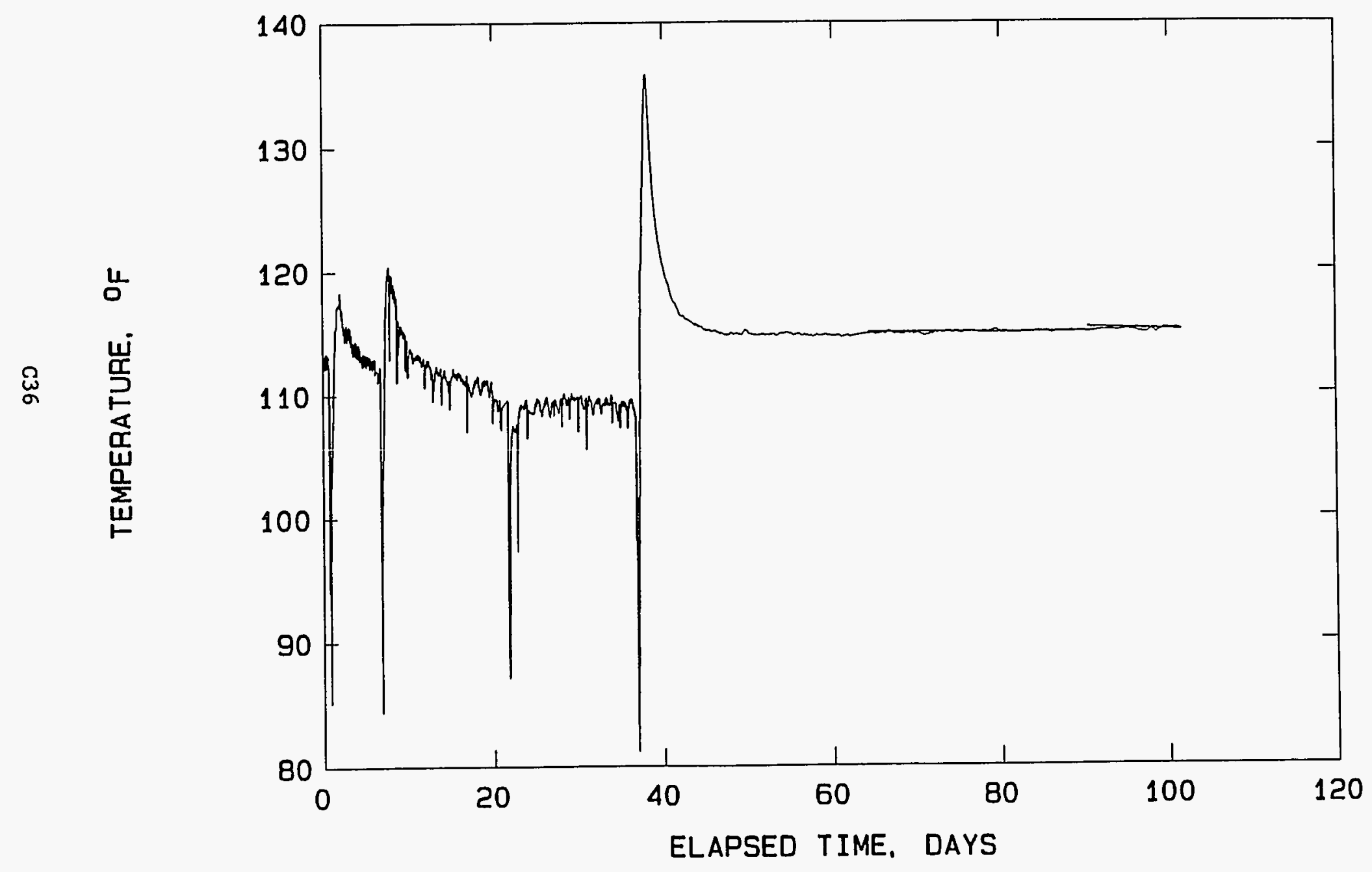


HANFORD COLD CAP PHYSICAL MODEL

LIFT3 CARLSON GAGE: M6973

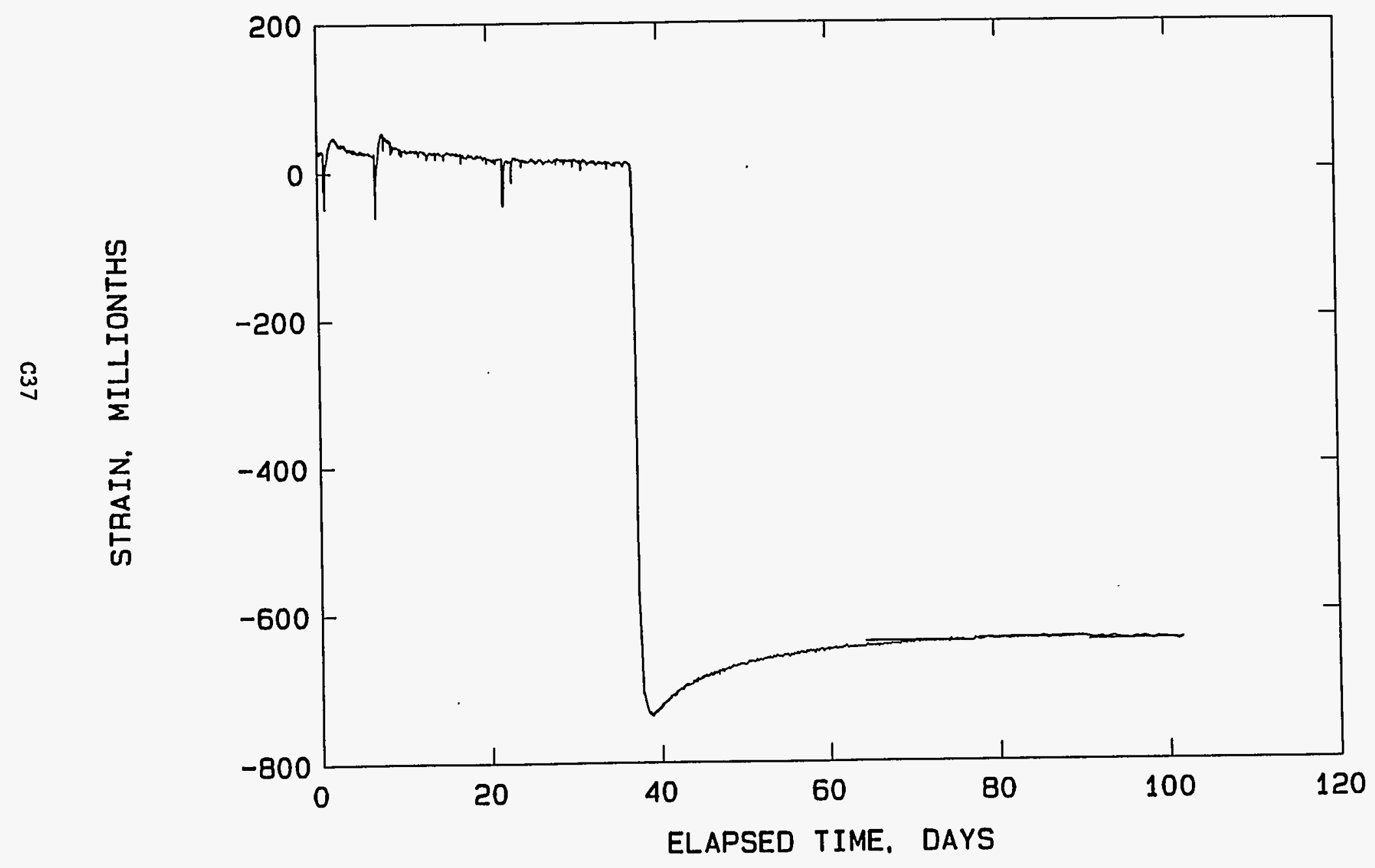


HANFORD COLD CAP PHYSICAL MODEL

LIFT3 CARLSON GAGE: M6973

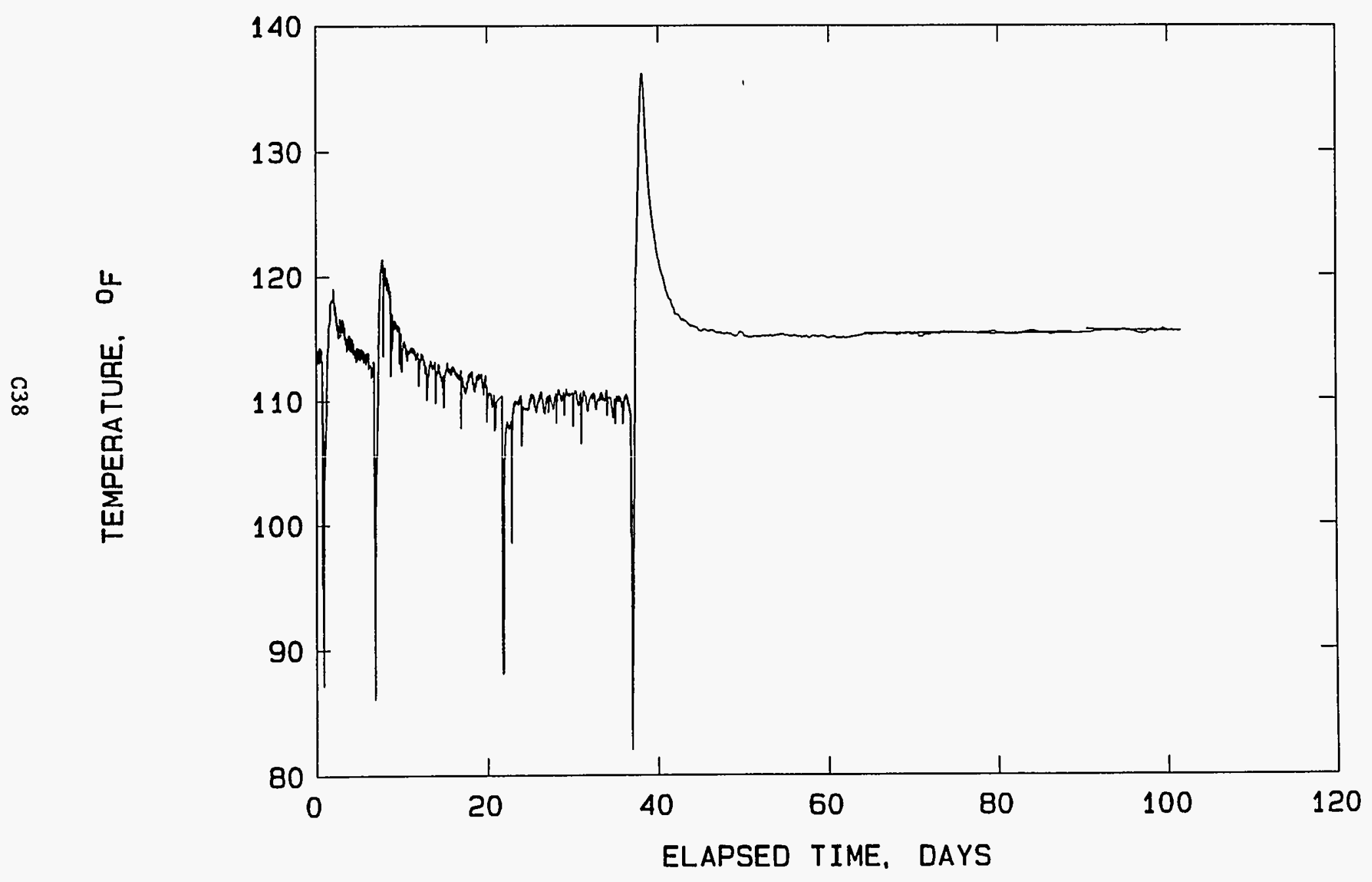

